\title{
LAMPF \\ Proposal Status and Summaries
}

\author{
Compiled by \\ Lois Rayburn \\ Beverly Talley
}

Revision 1 issued October 1979

Revision 2 issued November 1980

Revision 3 issued March 1982

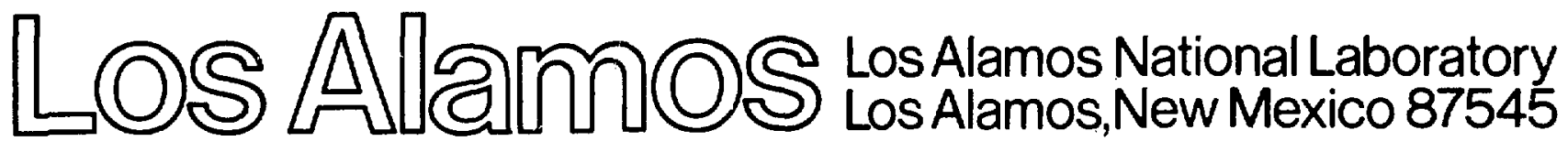




\section{LAMPF \\ PROPOSAL STATUS}

STATUS OF PROPOSALS AS OF $82 / 01 / 11$.

THIS REPORT REFLECTS THE ACTIONS OF THE AUGUST 1981 PAC.

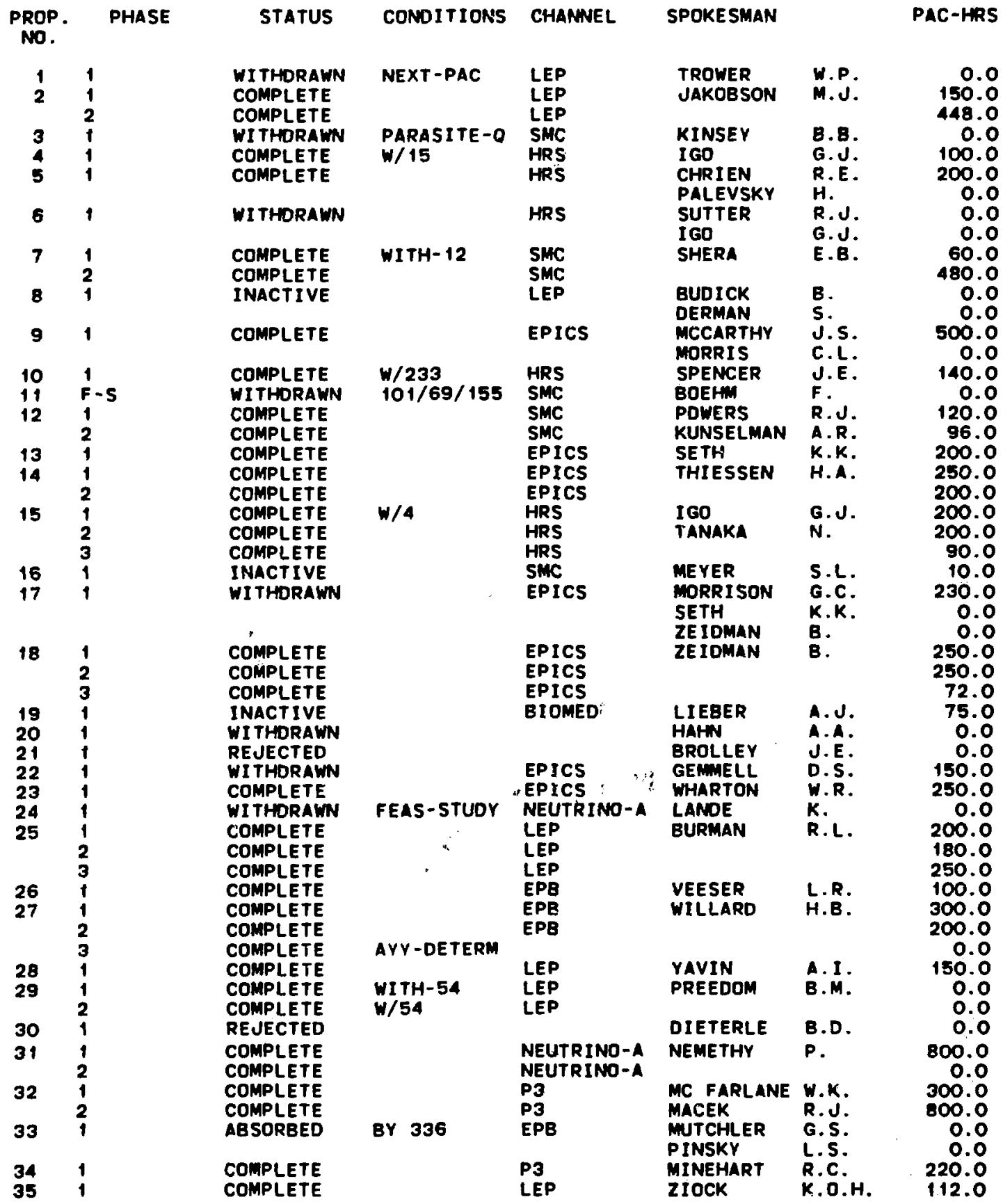




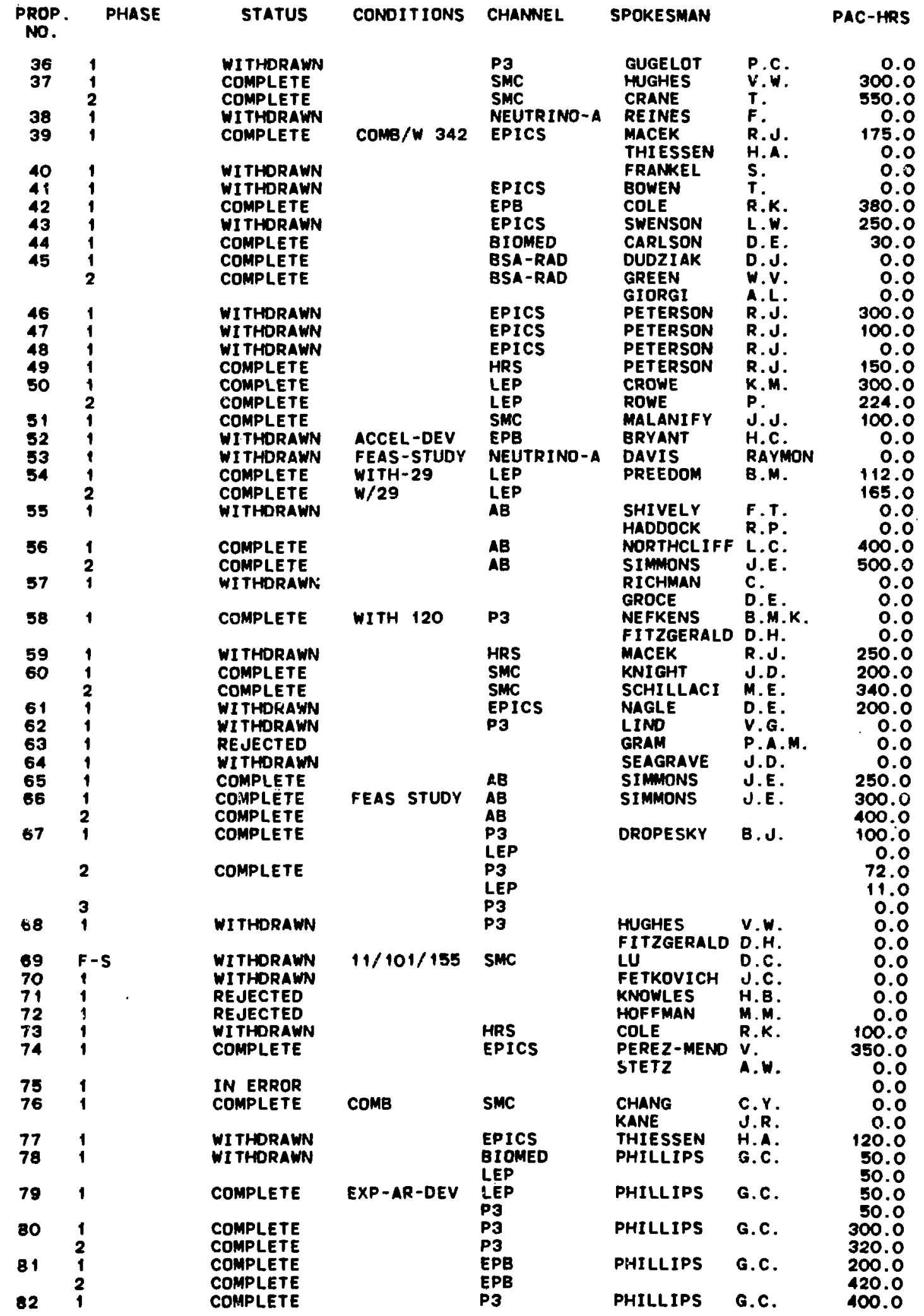




\begin{tabular}{|c|c|c|}
\hline $\begin{array}{l}\text { PROP. } \\
\text { NO. }\end{array}$ & PHASE & STATUS \\
\hline $\begin{array}{l}83 \\
84 \\
85 \\
86 \\
\\
87 \\
88 \\
89 \\
90\end{array}$ & $\begin{array}{l}1 \\
1 \\
1 \\
1 \\
2 \\
3 \\
1 \\
1 \\
1 \\
1 \\
2\end{array}$ & $\begin{array}{l}\text { INACTIVE } \\
\text { COMPLETE } \\
\text { COMPLETE } \\
\text { COMPLETE } \\
\text { COMPLETE } \\
\text { COMPLETE } \\
\text { COMPLETE } \\
\text { REJECTED } \\
\text { REJECTED } \\
\text { COMPLETE } \\
\text { COMPLETE }\end{array}$ \\
\hline
\end{tabular}

$\begin{array}{ll}91 & 1 \\ 92 & 1 \\ 93 & 1 \\ 94 & 1 \\ 95 & 1 \\ 96 & 1 \\ 97 & 2\end{array}$

$\begin{array}{ll}98 & 1 \\ 99 & 1 \\ & 2 \\ 100 & 1 \\ 101 & 2 \\ 10-5 \\ 102 & 1 \\ 103 & 1 \\ & 2\end{array}$

104
2

$\begin{array}{ccl}105 & 1 & \text { COMPLETE } \\ 106 & 2 & \begin{array}{l}\text { COMPLETE } \\ \text { COMPLETE }\end{array} \\ & 1 & \text { APPROVED } \\ 107 & 1 & \text { REPLACED } \\ 108 & 1 & \text { WITHDRAWN } \\ 109 & 1 & \text { WITHDRAWN } \\ 110 & 1 & \text { WITHDRAWN }\end{array}$

1111 COMPLETE

$\begin{array}{lll}112 & 2 & \text { COMPLETE } \\ 113 & 1 & \text { WITHDRAWN }\end{array}$

1131 RESUBMIT

1141 WITHDRAWN

1151 WITHDRAWN

1161 WITHDRAWN

1171 COMPLETE

1181 COMPLETE

$\begin{array}{lll} & 2 & \text { COMPLETE } \\ 119 & 2 & \text { COMPLETE } \\ & 1 & \text { COMPLETE }\end{array}$

$\begin{array}{ll}\text { CONDITIONS } & \text { CHANEL } \\ \text { FOR PION } & \text { BIOMED } \\ \text { BIOMED } \\ \text { SMC } \\ \text { TTA } \\ \text { TTA } \\ \text { TTA } \\ \text { EPICS } \\ \text { EPICS } \\ \text { P3 } \\ \text { P3 }\end{array}$

BY 139

$\begin{array}{ll}\text { PAKASITE-O } & \\ \text { BY } 139 & \text { LEP } \\ & \text { LEP } \\ & \text { SMC }\end{array}$

$\begin{array}{ll} & P 3 \\ & P 3 \\ & \text { SHC } \\ & \text { SMC } \\ 11 / 69 / 155 & \text { SMC } \\ & \text { P3 } \\ & \text { LEP } \\ & \text { P3 } \\ & \text { AB-NUCCHEM } \\ & \text { P3 } \\ & \text { P3 } \\ & \text { AB-NUCCHEM } \\ & \text { AB-NUCCHEM } \\ \text { PH-P_GHPI } & \\ & \text { AB-NUCCHEM } \\ & \text { SWY-LABS } \\ & \text { AB-NUCCHEM } \\ & \text { AB-NUCCHEM } \\ & \text { AB-NUCCHEM }\end{array}$

BY 134

AB-NUCCHEM

HRS
P3
BSA-RAD
BSA-RAD
BSA-RAD
SMC
HRS
AB-NUCCHEM
P3
SWY-LABS
P3
AB-NUCCHEM
P3
P3
AB-NUCCHEM

PAC-HRS

PHILLIPS
PHILLIPS
WELSH
POSKANZER

MCCARTHY
SHIVELY
BARNES
SHERHAN
SHIVELY
GLOOIS
SPENCER
WADLINGER
NEFKENS
HADDOCK
MAGLIC
PLENDL

G.C.

G.C.

R.E.

A.M.

J.S.

F.T.

P.D.

R.H.

F.T.

P.F.

J.E.

A.

B.M.K.

R.P.

B.C.

H.S.

GREENF I LLO M.B.

LEE

NAGLE

D.E.

wit

HUGHES

DUGAN

EGAN

LU

SPENCER

REBKA

GRAM

HUTSON

BOEHM

L.U

MARKowITZ

HUDIS

C. 5 .

v.w.

G.

P.D.

D.C.

J.E.

G.A.

P.A.M

R.L.

F.

D.C.

100.0
50.0
150.0
300.0
0.0
1500.0
300.0
0.0
300.0
300.0
100.0
0.0
0.0
0.0
0.0
0.0
0.0
150.0
0.0
0.0
0.0

0.0
150.0

300.0

32.0

0.0

0.0

0.0

0.0

0.0

250.0

275.0

100.0

170.0

0.0

30.0

0.0

J.

50.0

10.0

70.0

pate

B.D.

6.0

6.0

10.0

BUNKER

M.E.

10.0

50.0

OBRIEN H.A. $\quad 75.0$

RYAN 20.0

$\begin{array}{lll}\text { RYAN } & \text { V.A. } & 0.0\end{array}$

$\begin{array}{llr}\text { PLENDL } & \text { H.S. } & 0.0 \\ \text { FLYNN } & \text { E.R. } & 250.0\end{array}$

SIMON W.G. 50.0

HILL J.C. 150.0

PETERSON R.J. 0.0

$\begin{array}{lll}\text { KNAPP } & \text { D.J. } & 0.0 \\ \text { E.A. } & 0.0\end{array}$

WOLFSBERG $K$. 70.0

$\begin{array}{lll}\text { CoCK } & \text { B.C. } & 0.0\end{array}$

IGO G.J. 120.0

PORILE N.T.

20.0

0.0

5o.0

KAUFMAN S.B. $\quad 67.0$

32.0
0.0 


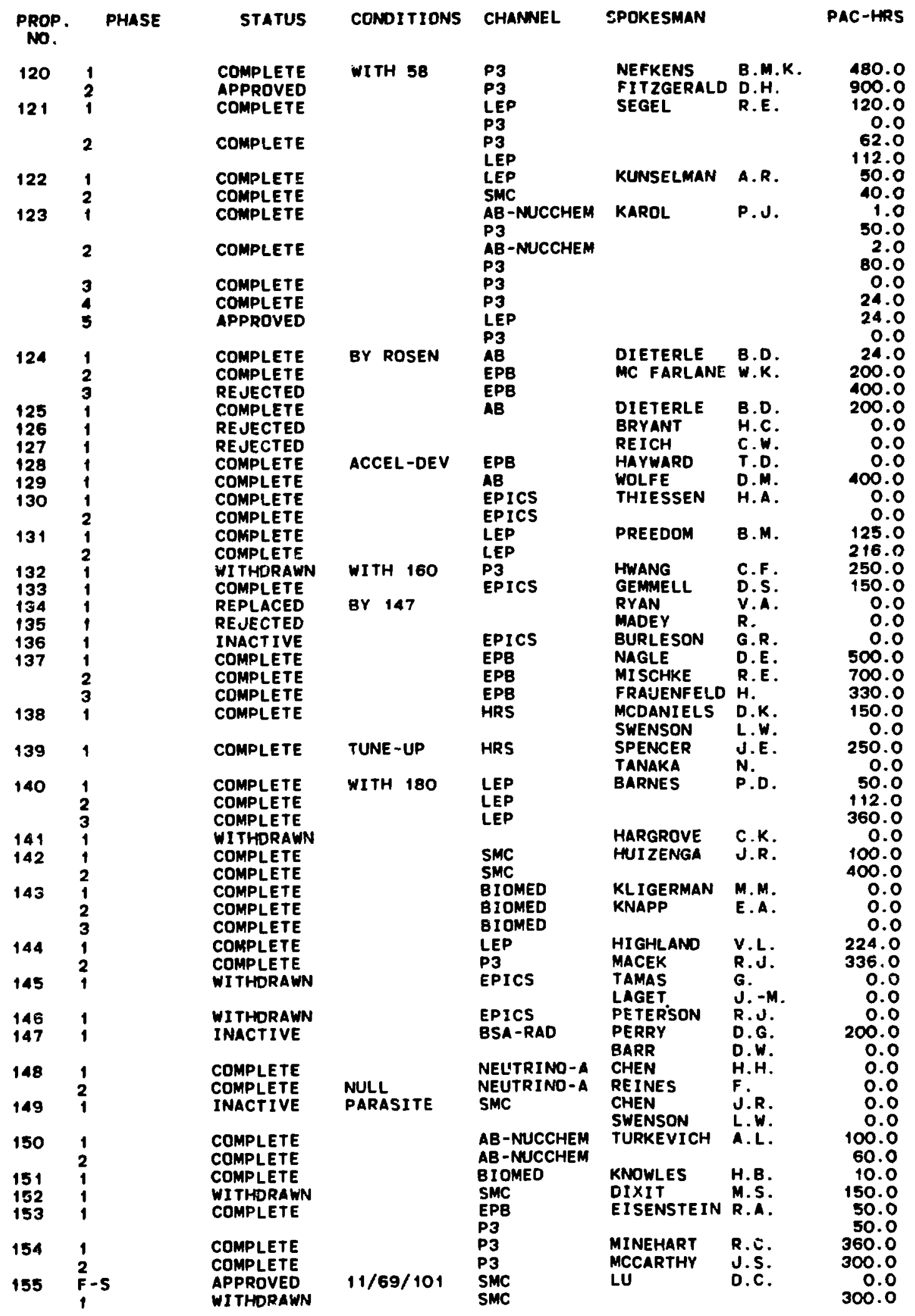


statUs of PROPOSALS AS OF $82 / 01 / 11$.

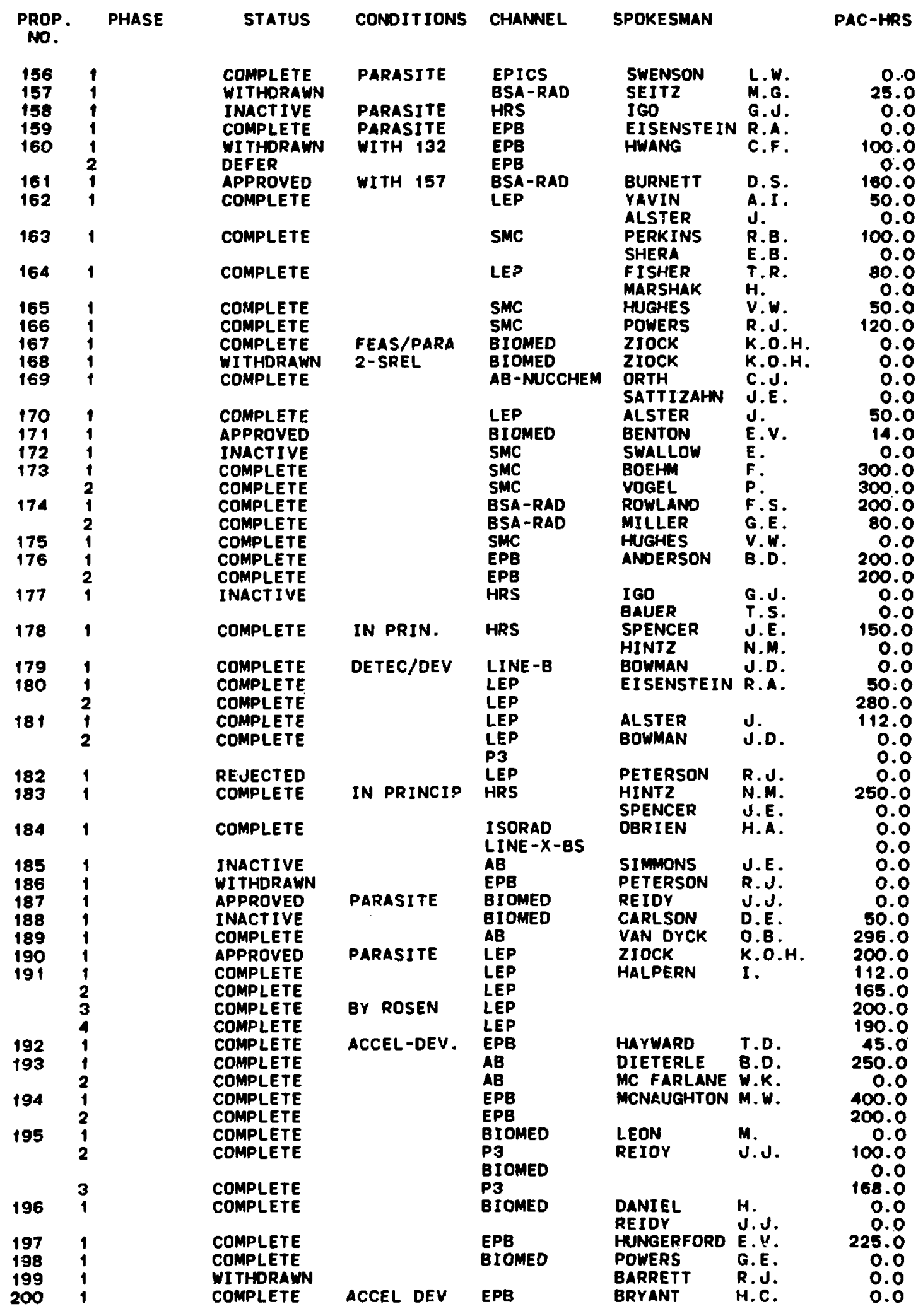




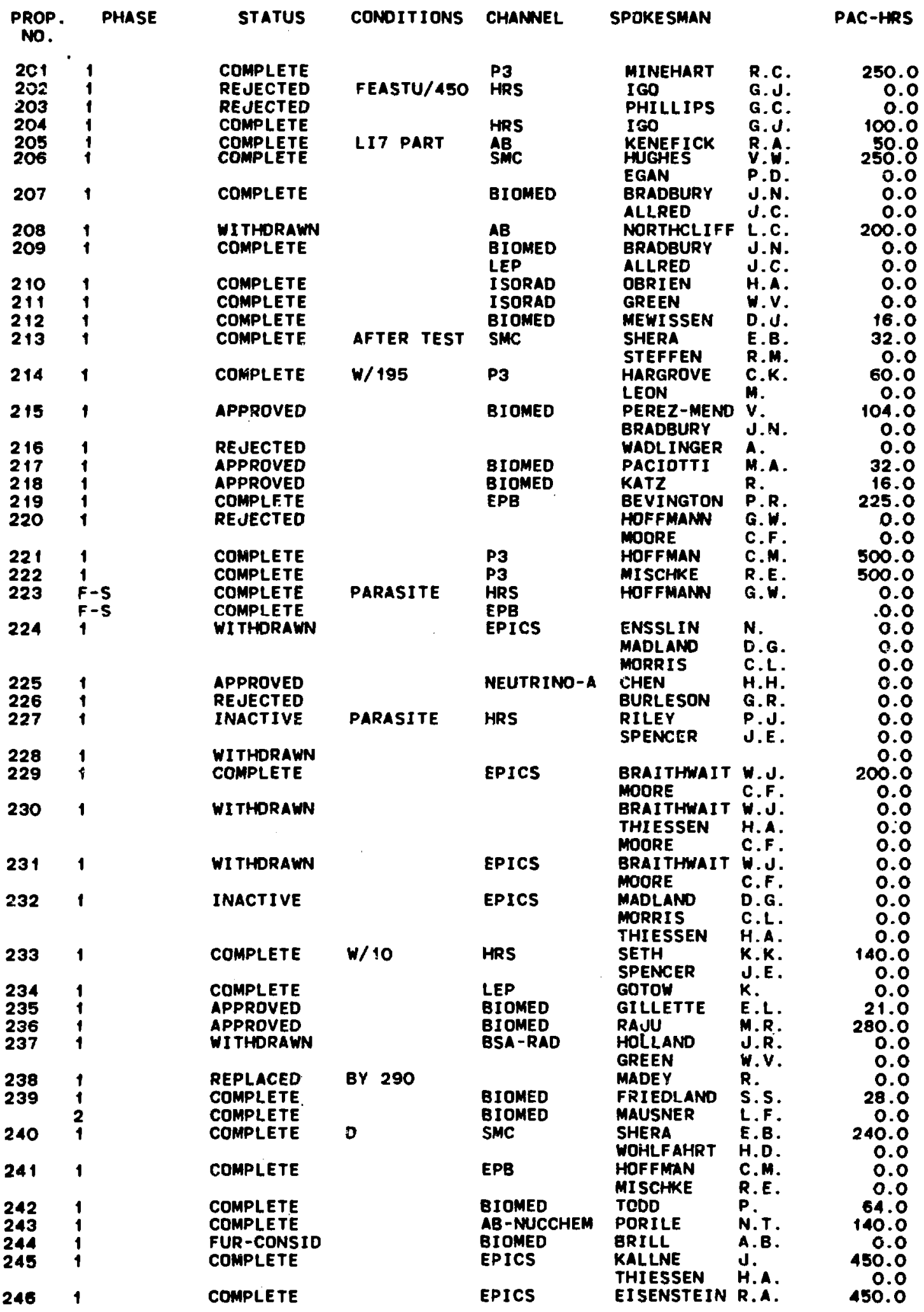




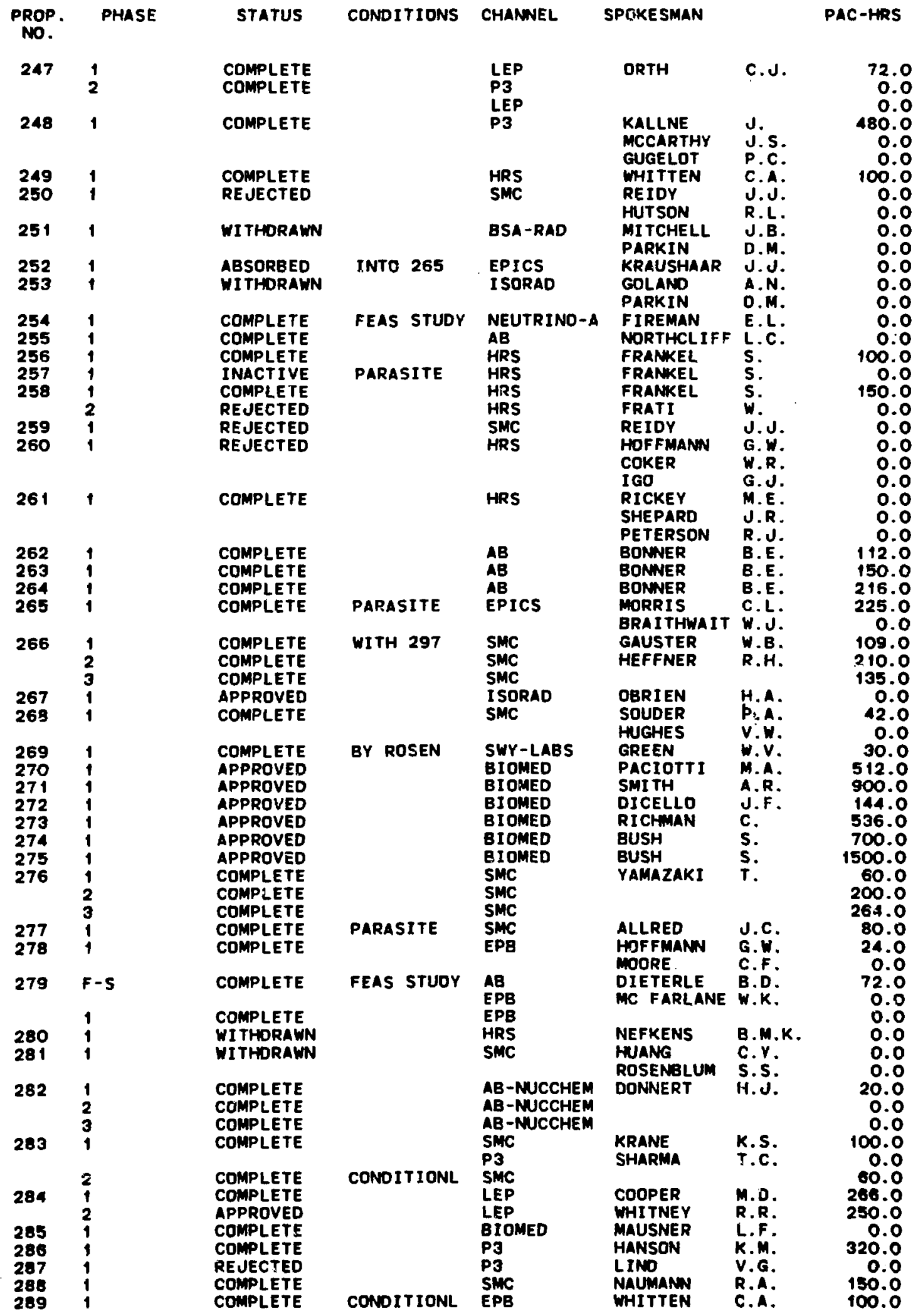


STATUS OF PROPOSALS AS OF $02 / 01 / 11$.

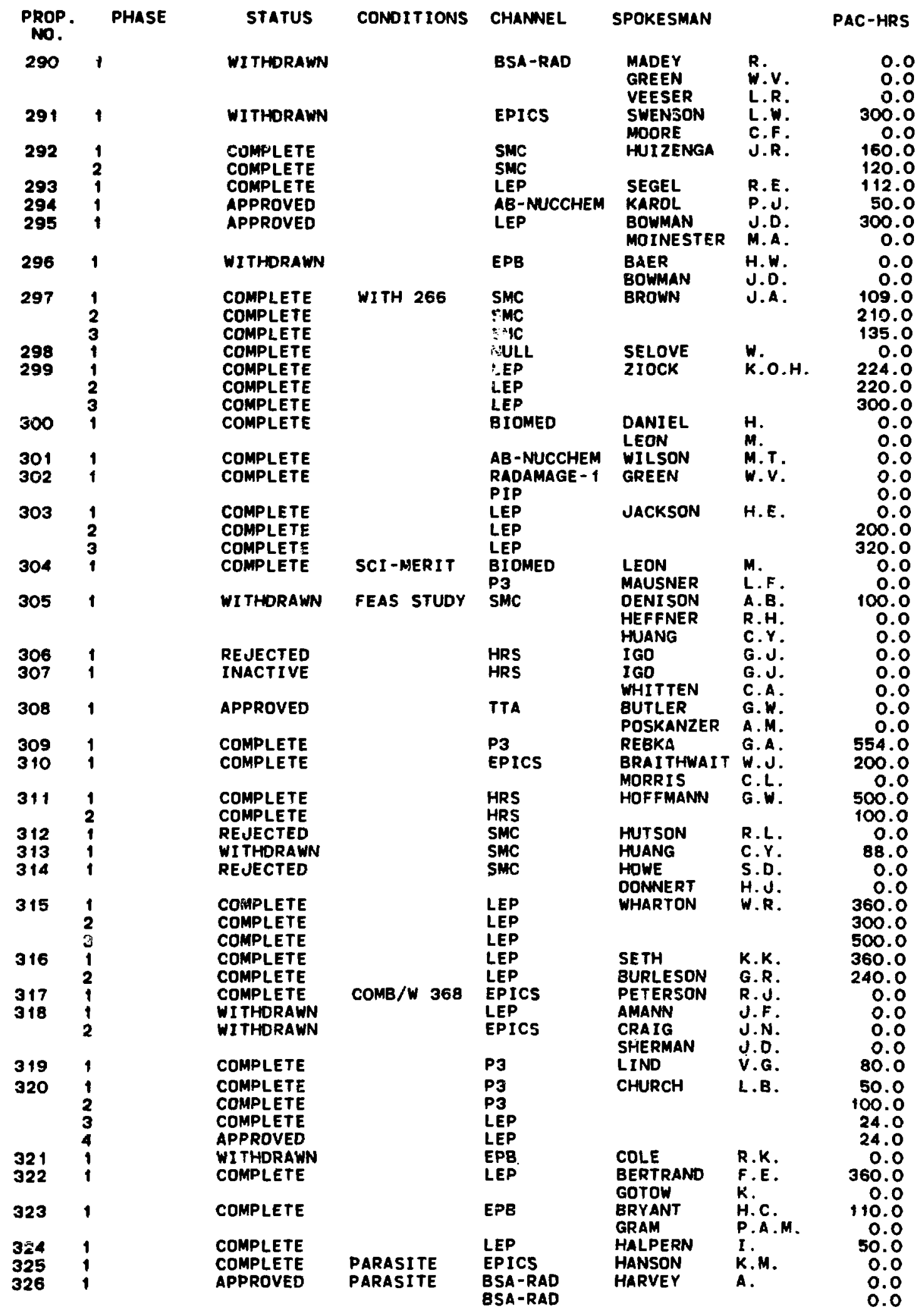


STATUS DF PROPOSALS AS OF $82 / 01 / 11$.

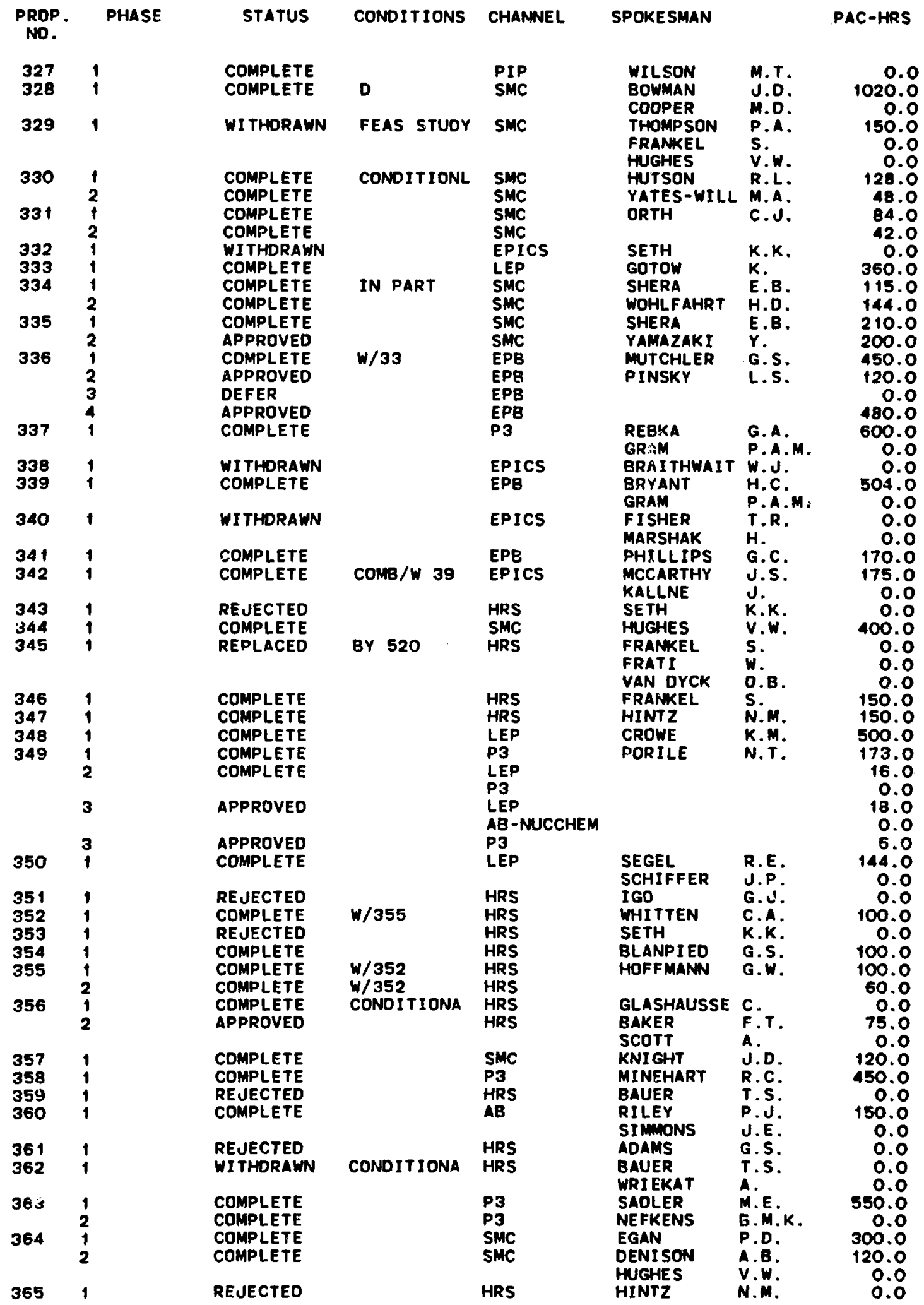




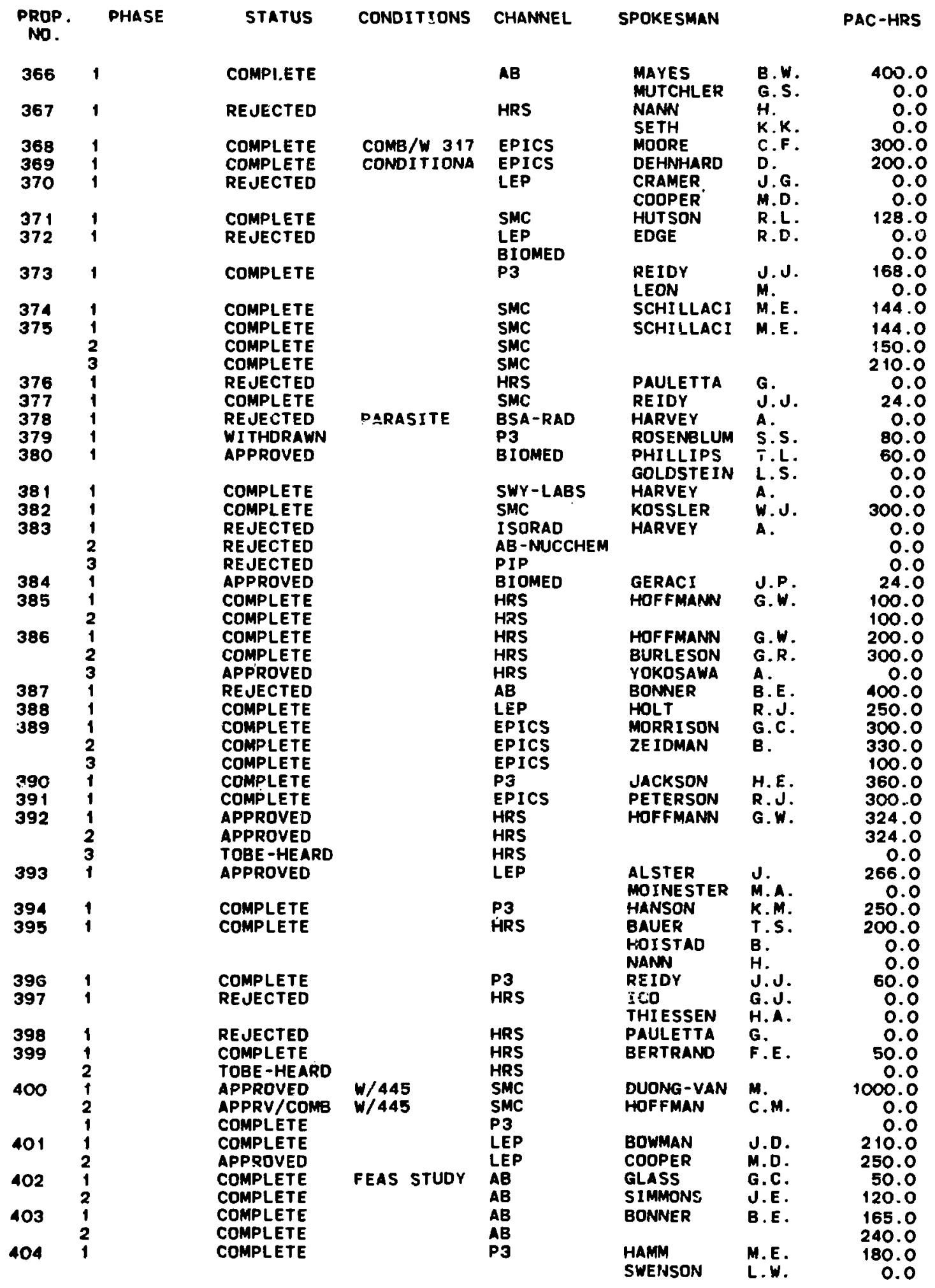




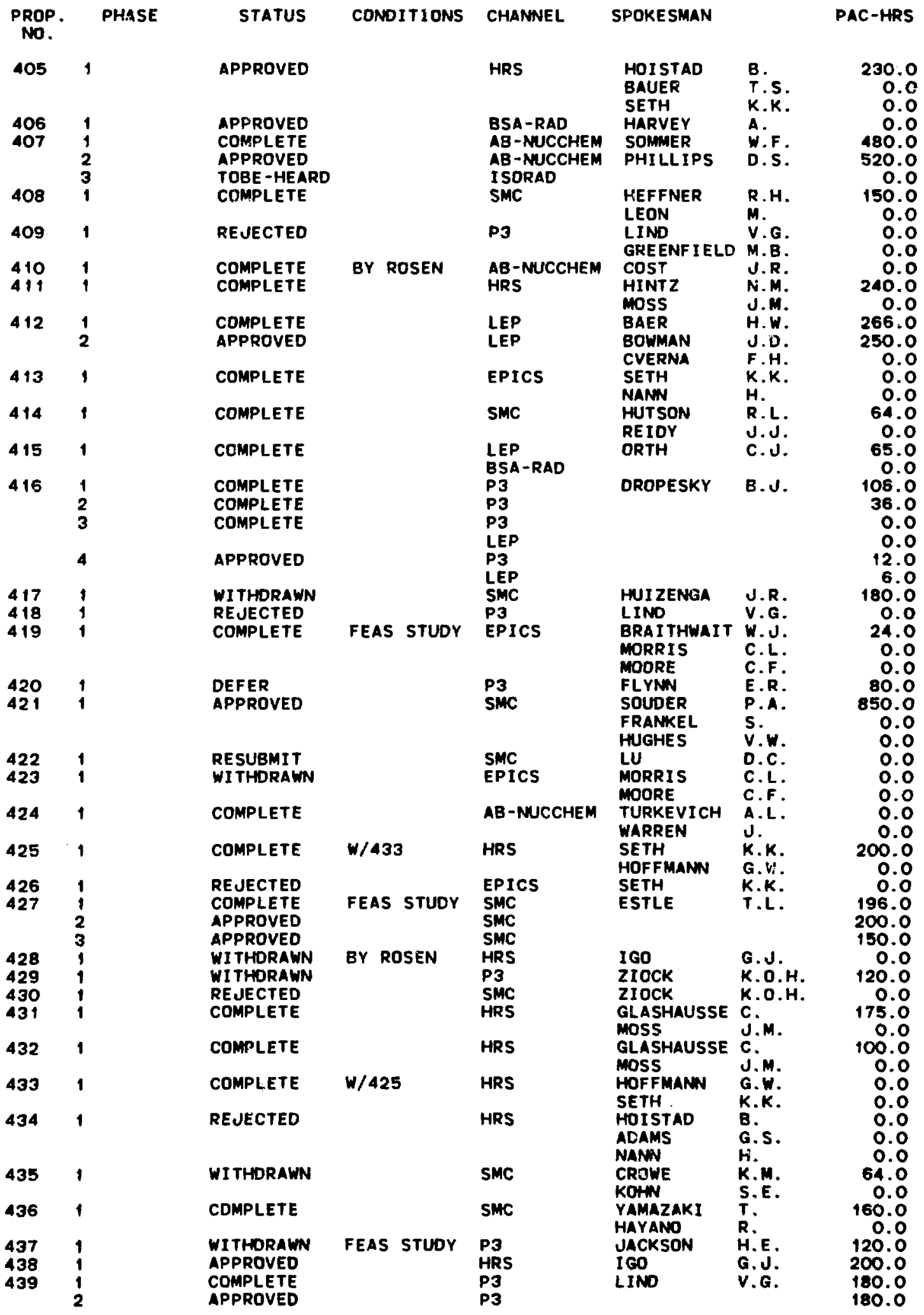




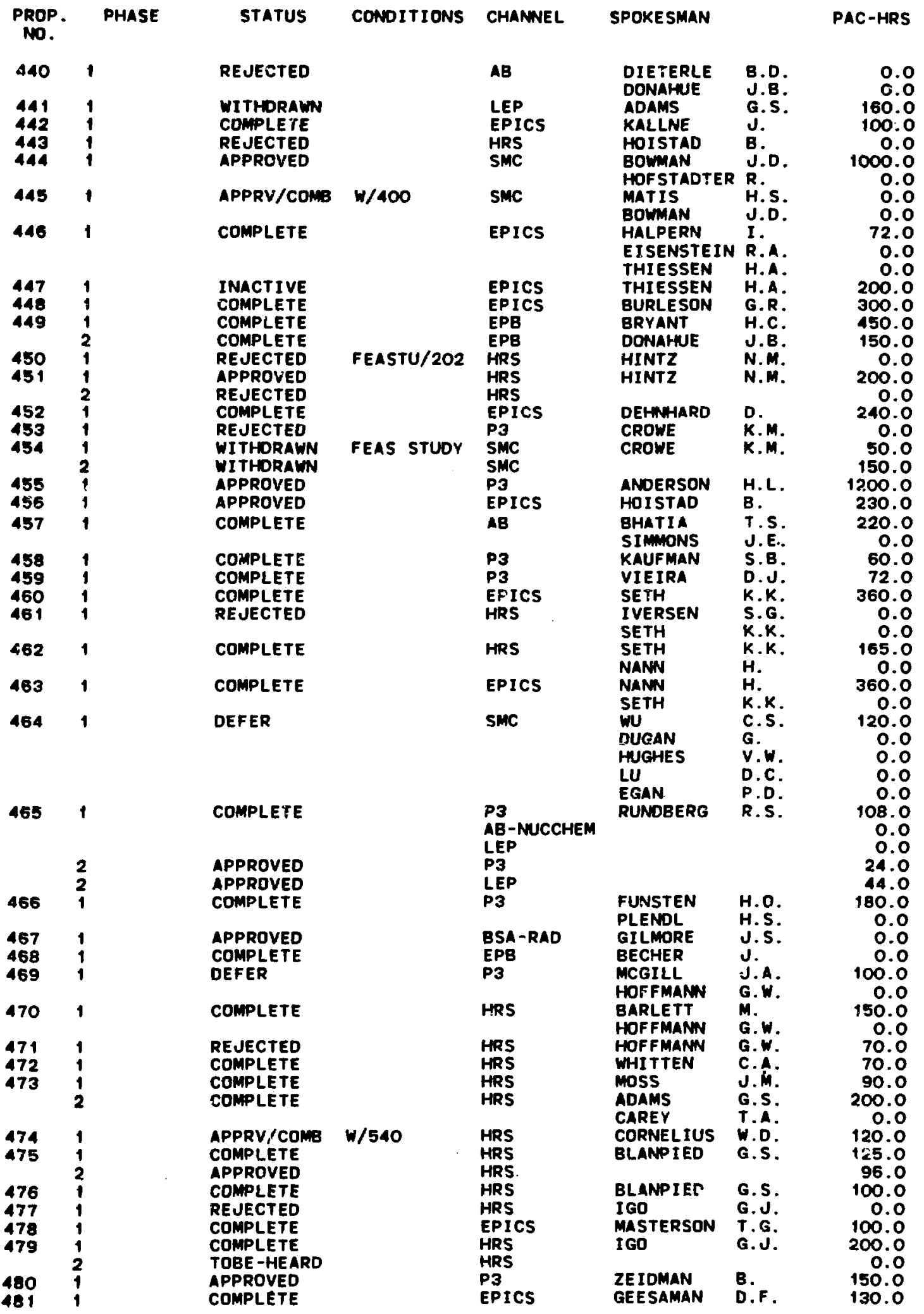




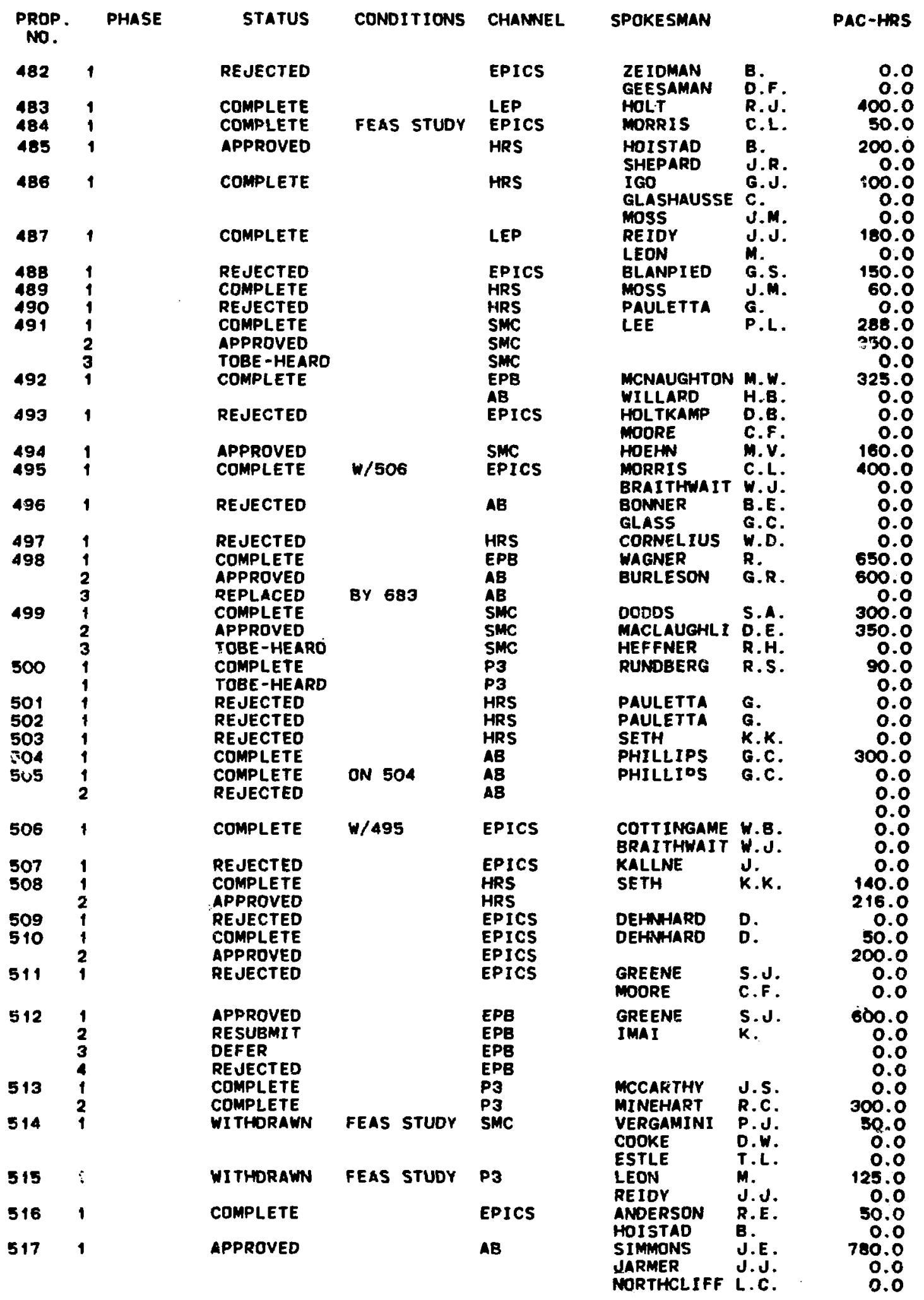


STATUS OF PROPOSALS AS OF 82/01/11.

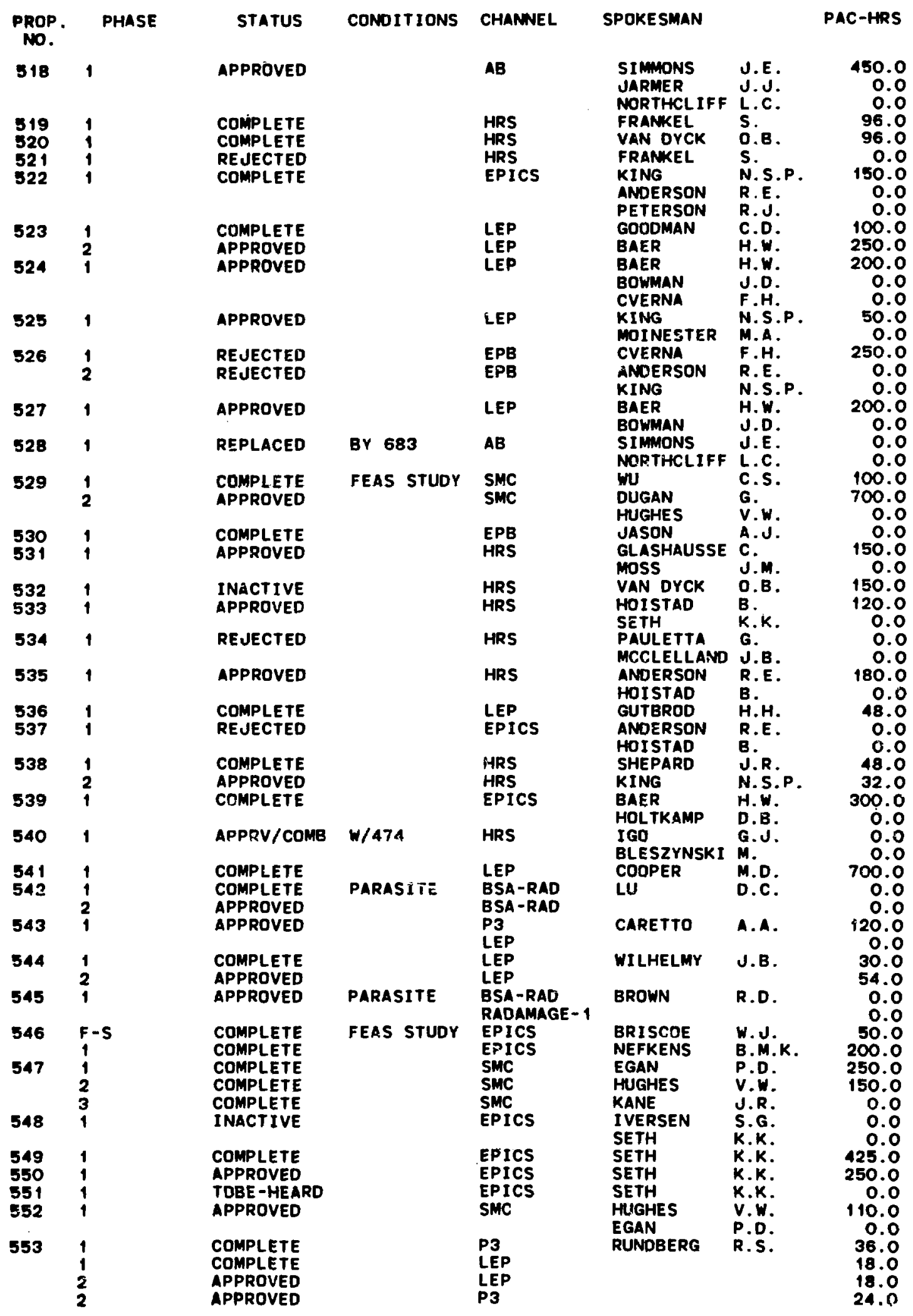


STATUS OF PROPOSALS AS OF B2/01/11.

\begin{tabular}{|c|c|c|c|c|c|c|c|}
\hline $\begin{array}{l}\text { PRDP. } \\
\text { NO. }\end{array}$ & PHASE & Status & CONDITIONS & CHANWEL & SPOKESMAN & & PAC-HRS \\
\hline 554 & 1 & APPROVED & & $\begin{array}{l}\text { BSA-RAD } \\
\text { BSA-RAD }\end{array}$ & $\begin{array}{l}\text { BROWN } \\
\text { COST }\end{array}$ & $\begin{array}{l}\text { R.O. } \\
\text { U.R. }\end{array}$ & $\begin{array}{l}0.0 \\
0.0\end{array}$ \\
\hline 555 & $\begin{array}{l}2 \\
1\end{array}$ & $\begin{array}{l}\text { TOBE - HEARD } \\
\text { COMPLETE }\end{array}$ & & $\begin{array}{l}\text { BSA-RAD } \\
\text { P3 }\end{array}$ & $\underset{\text { IMANISHI }}{\operatorname{IMIRA}}$ & $\begin{array}{l}\text { N. } \\
\text { D.J. }\end{array}$ & $\begin{array}{r}0.0 \\
100.0 \\
0.0\end{array}$ \\
\hline $\begin{array}{l}556 \\
557 \\
558\end{array}$ & $\begin{array}{l}1 \\
1 \\
1\end{array}$ & $\begin{array}{l}\text { COMPLETE } \\
\text { APPROVED } \\
\text { APPROVED }\end{array}$ & $\begin{array}{l}\text { FEASTUDY } \\
\text { PARASITE }\end{array}$ & $\begin{array}{l}\text { HRS } \\
\text { LEP } \\
\text { EPICS }\end{array}$ & $\begin{array}{l}\text { BERTOZZI } \\
\text { COWSIK } \\
\text { BAER } \\
\text { BURLESDN }\end{array}$ & $\begin{array}{l}\text { R. } \\
\text { R.w. } \\
\text { G.R. }\end{array}$ & $\begin{array}{r}48.0 \\
0.0 \\
382.0 \\
0.0\end{array}$ \\
\hline 559 & 1 & APPROVED & PARASITE & NEUTRIND-A & $\begin{array}{l}\text { DUONG-VAN } \\
\text { PHILLIPS }\end{array}$ & G.C. & $\begin{array}{l}0.0 \\
0.0\end{array}$ \\
\hline $\begin{array}{l}560 \\
551\end{array}$ & $\begin{array}{l}1 \\
1\end{array}$ & $\begin{array}{l}\text { APPROVED } \\
\text { APPROVED }\end{array}$ & & $\begin{array}{l}\text { BSA-RAD } \\
\text { LEP }\end{array}$ & $\begin{array}{l}\text { HARVEY } \\
\text { BLECHER } \\
\text { OBENSHAIN } \\
\text { HYNES }\end{array}$ & $\begin{array}{l}\text { A. } \\
\text { M. } \\
\text { F.E. } \\
\text { M.V. }\end{array}$ & $\begin{array}{r}0.0 \\
500.0 \\
0.0 \\
0.0\end{array}$ \\
\hline 562 & 1 & COMPLETE & & P3 & $\begin{array}{l}\text { JACKSON } \\
\text { SCHIFFER }\end{array}$ & $\begin{array}{l}\text { H.E. } \\
\text { J.P. }\end{array}$ & $\begin{array}{r}320.0 \\
0.0\end{array}$ \\
\hline $\begin{array}{l}563 \\
564 \\
565\end{array}$ & $\begin{array}{l}1 \\
1 \\
1\end{array}$ & $\begin{array}{l}\text { APPROVED } \\
\text { COMPLETE } \\
\text { APPROVED }\end{array}$ & & $\begin{array}{l}\text { HRS } \\
\text { P3 } \\
\text { EPICS }\end{array}$ & $\begin{array}{l}\text { HOFFMANN } \\
\text { MCKEOWN } \\
\text { ZEIDMAN } \\
\text { GEESAMAN }\end{array}$ & $\begin{array}{l}\text { G.W. } \\
\text { R.D. } \\
\text { B. } \\
\text { D.F. }\end{array}$ & $\begin{array}{r}150.0 \\
340.0 \\
200.0 \\
0.0\end{array}$ \\
\hline 565 & 1 & REJECTED & & HRS & $\begin{array}{l}\text { GARELICK } \\
\text { HURST }\end{array}$ & D.A. & $\begin{array}{l}0.0 \\
0.0\end{array}$ \\
\hline 567 & 1 & APPRDVED & & LEP & $\begin{array}{l}\text { GOTOW } \\
\text { MINEHART } \\
\text { RITCHIE }\end{array}$ & $\begin{array}{l}\text { K. } \\
\text { R.C. } \\
\text { B.G. }\end{array}$ & $\begin{array}{r}400.0 \\
0.0 \\
0.0\end{array}$ \\
\hline 568 & 1 & REJECTED & & EPICS & $\begin{array}{l}\text { BURLESON } \\
\text { MORRIS }\end{array}$ & $\begin{array}{l}\text { G.R. } \\
\text { C.L. }\end{array}$ & $\begin{array}{l}0.0 \\
0.0\end{array}$ \\
\hline 569 & 1 & REJECTED & & EPICS & $\begin{array}{l}\text { DEHNHARD } \\
\text { HOLTKAMP }\end{array}$ & D. & $\begin{array}{l}0.0 \\
0.0\end{array}$ \\
\hline 570 & 1 & COMPLETE & & EPICS & $\begin{array}{l}\text { HOLTKANAP } \\
\text { FORTUNE }\end{array}$ & D.B. & $\begin{array}{r}255.0 \\
0.0\end{array}$ \\
\hline 571 & 1 & APPRDVF.D & & SMC & $\begin{array}{l}\text { DDDDS } \\
\text { HEFFNER } \\
\text { SCHILLACI }\end{array}$ & $\begin{array}{l}\text { S.A. } \\
\text { R.H. } \\
\text { M.E. }\end{array}$ & $\begin{array}{r}350.0 \\
0.0 \\
0.0\end{array}$ \\
\hline 572 & 1 & APPROVED & & EPICS & $\begin{array}{l}\text { GREENE } \\
\text { MOORE }\end{array}$ & $\begin{array}{l}\text { S.J. } \\
\text { C.F. }\end{array}$ & $\begin{array}{r}200.0 \\
0.0\end{array}$ \\
\hline $\begin{array}{l}573 \\
578 \\
575\end{array}$ & $\begin{array}{l}1 \\
1 \\
1\end{array}$ & $\begin{array}{l}\text { APPROVED } \\
\text { REJECTED } \\
\text { REJECTED }\end{array}$ & & $\begin{array}{l}\text { EPICS } \\
\text { HRS } \\
\text { HRS }\end{array}$ & $\begin{array}{l}\text { BLANPIED } \\
\text { BLANPIED } \\
\text { BLANPIED } \\
\text { HOFFMANW }\end{array}$ & $\begin{array}{l}\text { G.S. } \\
\text { G.S. } \\
\text { G.S. } \\
\text { G.W. }\end{array}$ & $\begin{array}{r}279.0 \\
0.0 \\
0.0 \\
0.0\end{array}$ \\
\hline 576 & 1 & APPROVED & & LEP & $\begin{array}{l}\text { ROOS } \\
\text { PREEDOM } \\
\text { CHANT }\end{array}$ & $\begin{array}{l}\text { P.G. } \\
\text { S.M. } \\
\text { N.S. }\end{array}$ & $\begin{array}{r}200.0 \\
0.0 \\
0.0\end{array}$ \\
\hline 577 & 1 & COMPLETE & & EPICS & $\begin{array}{l}\text { GREENE } \\
\text { FORTUNE }\end{array}$ & $\begin{array}{l}\text { S.U. } \\
\text { H.T. }\end{array}$ & $\begin{array}{r}250.0 \\
0.0\end{array}$ \\
\hline 578 & 1 & REJECTED & & EPICS & $\begin{array}{l}\text { MORRIS } \\
\text { FORTUNE }\end{array}$ & $\begin{array}{l}\text { C.I. } \\
\text { H.T. }\end{array}$ & $\begin{array}{l}0 . c \\
0.0\end{array}$ \\
\hline $\begin{array}{l}579 \\
580\end{array}$ & $\begin{array}{l}1 \\
1\end{array}$ & $\begin{array}{l}\text { APPROVED } \\
\text { APPROVED }\end{array}$ & & $\begin{array}{l}\text { AB-NUCCHEM } \\
\text { HRS }\end{array}$ & $\begin{array}{l}\text { FAUBEL } \\
\text { SEESTROM-M } \\
\text { DEHNHARD }\end{array}$ & $\begin{array}{l}\text { W. } \\
\text { S.J. } \\
\text { D. }\end{array}$ & $\begin{array}{r}1.0 \\
80.0 \\
0.0\end{array}$ \\
\hline 581 & 1 & COMPLETE & & EPICS & $\begin{array}{l}\text { MASTERSON } \\
\text { BOUDRIE }\end{array}$ & $\begin{array}{l}\text { T.G. } \\
\text { R.L. }\end{array}$ & $\begin{array}{r}180.0 \\
0.0\end{array}$ \\
\hline 582 & 1 & REJECTEO & & EPICS & $\begin{array}{l}\text { COTTINGAME } \\
\text { BURLESON }\end{array}$ & $\begin{array}{l}\text { W.B. } \\
\text { G.R. }\end{array}$ & $\begin{array}{l}0.0 \\
0.0\end{array}$ \\
\hline 583 & 1 & APPROVED & & HRS & $\begin{array}{l}\text { AULETTA } \\
\text { GAZZALY }\end{array}$ & G.M. & $\begin{array}{r}240.0 \\
0.0\end{array}$ \\
\hline 584 & 1 & REJECTED & & EPICS & $\begin{array}{l}\text { DEHAHARD } \\
\text { FORTUNE }\end{array}$ & D. & $\begin{array}{l}0.0 \\
0.0\end{array}$ \\
\hline 585 & 1 & COMPLETE & & HRS & PAULETTA & G. & 80.0 \\
\hline 586 & 1 & APEROVED & & EPB & $\begin{array}{l}\text { BRYANT } \\
\text { GRAM }\end{array}$ & $\begin{array}{l}\text { H.C. } \\
\text { P.A.M. }\end{array}$ & $\begin{array}{r}350.0 \\
0.0\end{array}$ \\
\hline 587 & 1 & APPROVED & & EPE & $\begin{array}{l}\text { SMITH } \\
\text { DONAHUE }\end{array}$ & $\begin{array}{l}\text { W.W. } \\
\text { J.B. }\end{array}$ & $\begin{array}{r}400.0 \\
0.0\end{array}$ \\
\hline 588 & 1 & APPROVED & & EPB & $\begin{array}{l}\text { CL.ARK } \\
\text { BRYANT }\end{array}$ & D.A. & $\begin{array}{r}350.0 \\
0.0\end{array}$ \\
\hline 589 & 1 & APPROVED & & $A B$ & $\begin{array}{l}\text { GLASS } \\
\text { NORTHCLIFF }\end{array}$ & $\begin{array}{l}\text { G.C. } \\
\text { L.C. }\end{array}$ & $\begin{array}{r}350.0 \\
0.0\end{array}$ \\
\hline
\end{tabular}




\begin{tabular}{|c|c|c|c|c|c|c|c|}
\hline $\begin{array}{l}\text { PROP. } \\
\text { NO. }\end{array}$ & PHASE & STATUS & CONDITIONS & CHANNEL & SPOKESMAN & & PAC-HRS \\
\hline 590 & $\begin{array}{l}14 \\
2 \\
18\end{array}$ & $\begin{array}{l}\text { APPRQVED } \\
\text { APPROVED } \\
\text { RESUBMIT }\end{array}$ & & $\begin{array}{l}A B \\
A B \\
A B\end{array}$ & $\begin{array}{l}\text { SIMMONS } \\
\text { NORTHCLIFF }\end{array}$ & $\begin{array}{l}\text { J.E. } \\
\text { L.C. }\end{array}$ & $\begin{array}{r}330.0 \\
0.0 \\
0.0\end{array}$ \\
\hline 591 & 1 & APPROVED & & EPB & $\begin{array}{l}\text { DEVRIES } \\
\text { DIGI ACOMO }\end{array}$ & $\begin{array}{l}\text { R.M. } \\
\text { N. }\end{array}$ & $\begin{array}{r}270.0 \\
0.0\end{array}$ \\
\hline $\mathbf{5 9 2}$ & 1 & APPROVED & & EPB & $\begin{array}{l}\text { DEVRIES } \\
\text { DIGIACOMO }\end{array}$ & $\begin{array}{l}\text { R.M. } \\
\text { N. }\end{array}$ & $\begin{array}{r}140.0 \\
0.0\end{array}$ \\
\hline $\mathbf{5 9 3}$ & 1 & REJECTED & & HRS & $\begin{array}{l}\text { BLESZYNSKI } \\
\text { MCCLELLAND } \\
\text { WHITTEN }\end{array}$ & $\begin{array}{l}\text { M. } \\
\text { J.B. } \\
\text { C.A. }\end{array}$ & $\begin{array}{l}0.0 \\
0.0 \\
0.0\end{array}$ \\
\hline $\begin{array}{l}594 \\
595\end{array}$ & $\begin{array}{l}1 \\
1\end{array}$ & $\begin{array}{l}\text { APPROVED } \\
\text { APPROVED }\end{array}$ & & $\begin{array}{l}\text { SMC } \\
\text { P3 }\end{array}$ & $\begin{array}{l}\text { REIDY } \\
\text { ORTH } \\
\text { VIEIRA }\end{array}$ & $\begin{array}{l}\text { J.J. } \\
\text { C.J. } \\
\text { D.J. }\end{array}$ & $\begin{array}{r}84.0 \\
264.0 \\
0.0\end{array}$ \\
\hline 596. & 1 & REJECTED & . & LEP & $\begin{array}{l}\text { CRAMER } \\
\text { MORRIS } \\
\text { BRAITHWAIT } \\
\text { MOORE }\end{array}$ & $\begin{array}{l}\text { J.G. } \\
\text { C.L. } \\
\text { W.J. } \\
\text { C.F. }\end{array}$ & $\begin{array}{l}0.0 \\
0.0 \\
0.0 \\
0.0\end{array}$ \\
\hline 597 & 1 & COMPLETE & & EPICS & $\begin{array}{l}\text { HALPERN } \\
\text { EISENSTEIN }\end{array}$ & & \\
\hline 598 & 1 & APPROVED & & EPICS & $\begin{array}{l}\text { COTTINGAME } \\
\text { KIZIAH }\end{array}$ & $\begin{array}{l}\text { W.B. } \\
\text { R.R. }\end{array}$ & $\begin{array}{r}224.0 \\
0.0\end{array}$ \\
\hline $\begin{array}{l}599 \\
600\end{array}$ & 1 & $\begin{array}{l}\text { REJECTED } \\
\text { REJECTED }\end{array}$ & & $\begin{array}{l}\text { EPICS } \\
\text { EPICS }\end{array}$ & $\begin{array}{l}\text { MOORE } \\
\text { MOORE } \\
\text { HINTZ }\end{array}$ & $\begin{array}{l}\text { C.F. } \\
\text { C.F. } \\
\text { N.M. }\end{array}$ & $\begin{array}{l}0.0 \\
0.0 \\
0.0\end{array}$ \\
\hline $\begin{array}{l}601 \\
602\end{array}$ & $\begin{array}{l}1 \\
1\end{array}$ & $\begin{array}{l}\text { APPROVED } \\
\text { APPROVED }\end{array}$ & & $\begin{array}{l}\text { EPICS } \\
\text { EPICS }\end{array}$ & $\begin{array}{l}\text { HINTZ } \\
\text { HARVEY } \\
\text { UEHNHARD }\end{array}$ & $\begin{array}{l}\text { N.M. } \\
\text { C.J. } \\
\text { D. }\end{array}$ & $\begin{array}{r}174.0 \\
120.0 \\
0.0\end{array}$ \\
\hline 603 & $\begin{array}{l}1 \\
2 \\
2\end{array}$ & $\begin{array}{l}\text { COMPLETE } \\
\text { APPROVED } \\
\text { APPROVED }\end{array}$ & & $\begin{array}{l}\text { AB } \\
\text { AB } \\
\text { P3 }\end{array}$ & TURKEVICH & A.L. & $\begin{array}{l}20.0 \\
54.0 \\
12.0\end{array}$ \\
\hline $\begin{array}{l}604 \\
605 \\
606 \\
607\end{array}$ & $\begin{array}{l}1 \\
1 \\
1 \\
1 \\
2\end{array}$ & $\begin{array}{l}\text { COMPLETE } \\
\text { APPROVED } \\
\text { COMPLETE } \\
\text { COMPLETE } \\
\text { APPROVED }\end{array}$ & BY ROSEN & $\begin{array}{l}\text { EPICS } \\
\text { EPICS } \\
\text { EPICS } \\
\text { LEP } \\
\text { LEP }\end{array}$ & $\begin{array}{l}\text { SETH } \\
\text { SETH } \\
\text { SETH } \\
\text { ALSTER } \\
\text { BAER } \\
\text { BOWHAN }\end{array}$ & $\begin{array}{l}\text { K.K. } \\
\text { K.K. } \\
\text { K.K. } \\
\text { J. } \\
\text { H.W. } \\
\text { J.D. }\end{array}$ & $\begin{array}{r}250.0 \\
100.0 \\
360.0 \\
360.0 \\
250.0 \\
0.0\end{array}$ \\
\hline 609 & 1 & REJECTED & & NEUTRINO-A & $\begin{array}{l}\text { KING } \\
\text { ANDERSON } \\
\text { BOUDRIE } \\
\text { KRUSE }\end{array}$ & $\begin{array}{l}\text { N.S.P. } \\
\text { R.E. } \\
\text { R.L. } \\
\text { H.W. }\end{array}$ & $\begin{array}{l}0.0 \\
0.0 \\
0.0 \\
0.0\end{array}$ \\
\hline 610 & 1 & DEFER & & AB -NUCCHEM & $\begin{array}{l}\text { HENNING } \\
\text { KUTSCHERA }\end{array}$ & $\begin{array}{l}\text { W. } \\
\mathbf{W} .\end{array}$ & $\begin{array}{l}0.0 \\
0.0\end{array}$ \\
\hline 611 & $\begin{array}{l}1 \\
1\end{array}$ & $\begin{array}{l}\text { APPROVED } \\
\text { APPROVED }\end{array}$ & & $\begin{array}{l}\text { P3 } \\
\text { LEP }\end{array}$ & HOGAN & J.J. & $\begin{array}{l}30.0 \\
12.0\end{array}$ \\
\hline $\begin{array}{l}612 \\
613\end{array}$ & $\begin{array}{l}1 \\
1\end{array}$ & $\begin{array}{l}\text { TOBE-HEARD } \\
\text { REJECTED }\end{array}$ & & $\begin{array}{l}\text { EPICS } \\
\text { HRS }\end{array}$ & $\begin{array}{l}\text { SETH } \\
\text { SAHA } \\
\text { SETH }\end{array}$ & $\begin{array}{l}\text { K.K. } \\
\text { A. } \\
\text { K.K. }\end{array}$ & $\begin{array}{l}0.0 \\
0.0 \\
0.0\end{array}$ \\
\hline $\begin{array}{l}614 \\
615\end{array}$ & 1 & APPROVED & & P3 & FUNSTEN & H. O. & $\begin{array}{r}210.0 \\
0.0 \\
0.0\end{array}$ \\
\hline 616 & $\begin{array}{l}1 \\
2\end{array}$ & $\begin{array}{l}\text { COMPLETE } \\
\text { TOBE - HEARD }\end{array}$ & & $\begin{array}{l}\text { HRS } \\
\text { HRS }\end{array}$ & $\begin{array}{l}\text { BLESZYNSKI } \\
\text { MCCLELLAND } \\
\text { HINTZ } \\
\text { MOSS }\end{array}$ & $\begin{array}{l}\text { M. } \\
\text { J.B. } \\
\text { N.M. } \\
\text { J.M. }\end{array}$ & $\begin{array}{r}225.0 \\
0.0 \\
0.0 \\
0.0\end{array}$ \\
\hline $\begin{array}{l}617 \\
618\end{array}$ & $\begin{array}{l}1 \\
1 \\
1\end{array}$ & $\begin{array}{l}\text { APPROVED } \\
\text { COMPLETE } \\
\text { REJECTED }\end{array}$ & & $\begin{array}{l}\text { P3 } \\
\text { EPICS } \\
\text { EPICS }\end{array}$ & $\begin{array}{l}\text { ZIOCK } \\
\text { MORRIS } \\
\text { MOORE }\end{array}$ & $\begin{array}{l}\text { K.o.H. } \\
\text { G.i. } \\
\text { C.F. }\end{array}$ & $\begin{array}{r}180.0 \\
140.0 \\
0.0 \\
0.0\end{array}$ \\
\hline 619 & 1 & COMPLETE & & EPICS & $\begin{array}{l}\text { MOORE } \\
\text { FORTUNE } \\
\text { MORRIS }\end{array}$ & $\begin{array}{l}\text { C.F. } \\
\text { H.T. } \\
\text { C.L. }\end{array}$ & $\begin{array}{r}120.0 \\
0.0 \\
0.0\end{array}$ \\
\hline $\begin{array}{l}620 \\
621\end{array}$ & $\begin{array}{l}1 \\
1\end{array}$ & $\begin{array}{l}\text { REJECTED } \\
\text { REJECTED }\end{array}$ & & $\begin{array}{l}\text { EPICS } \\
\text { EPICS }\end{array}$ & $\begin{array}{l}\text { MOORE } \\
\text { DEHNHARD } \\
\text { FORTUNE }\end{array}$ & $\begin{array}{l}\text { C.F. } \\
\text { D. } \\
\text { H.T. }\end{array}$ & $\begin{array}{l}0.0 \\
0.0 \\
0.0\end{array}$ \\
\hline 622 & 1 & COMPLETE & & EPICS & $\begin{array}{l}\text { HOLTKAMP } \\
\text { BAER }\end{array}$ & $\begin{array}{l}\text { D.B. } \\
\text { H.W. }\end{array}$ & $\begin{array}{r}120.0 \\
0.0\end{array}$ \\
\hline $\begin{array}{l}623 \\
624\end{array}$ & $\begin{array}{l}1 \\
1\end{array}$ & $\begin{array}{l}\text { APPROVED } \\
\text { INACTIVE }\end{array}$ & & $\begin{array}{l}\text { HRS } \\
\text { HRS }\end{array}$ & $\begin{array}{l}\text { GL.ASHAUSSE } \\
\text { GOODMAN }\end{array}$ & C.D. & $\begin{array}{r}66.0 \\
0.0\end{array}$ \\
\hline
\end{tabular}


STATUS OF PROPOSALS AS OF B2/01/11.

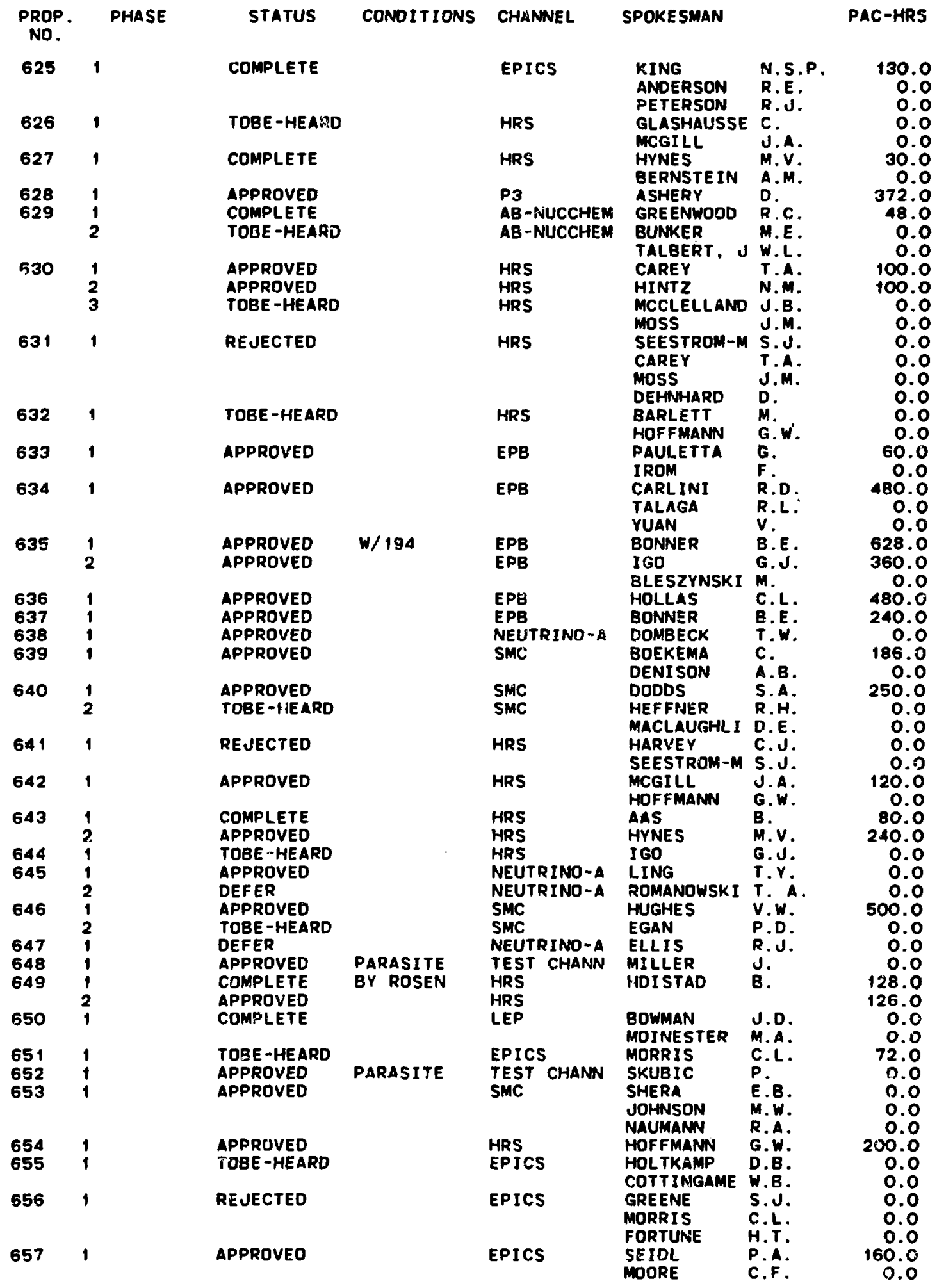


STATUS OF PROPOSALS AS OF $82 / 01 / 11$.

\begin{tabular}{|c|c|c|c|c|c|c|c|}
\hline $\begin{array}{l}\text { PROP. } \\
\text { NO }\end{array}$ & PHASE & STATUS & CONOITIONS & CHANNEL & SPOKE SMAN & & PAC-HRS \\
\hline 658 & 1 & APPROVED & & EPICS & $\begin{array}{l}\text { SEESTROM-M } \\
\text { CAREY } \\
\text { MOSS } \\
\text { DEHNHARD } \\
\text { BLAND } \\
\text { MOORE }\end{array}$ & $\begin{array}{l}\text { S.J. } \\
\text { T.A. } \\
\text { J.M. } \\
\text { D. } \\
\text { L.C. }\end{array}$ & $\begin{array}{r}120.0 \\
0.0 \\
0.0 \\
0.0 \\
150.0 \\
0.0\end{array}$ \\
\hline $\begin{array}{l}660 \\
661\end{array}$ & $\begin{array}{l}1 \\
1\end{array}$ & $\begin{array}{l}\text { TDBE - HEARD } \\
\text { APPROVED }\end{array}$ & & $\begin{array}{l}\text { HRS } \\
\text { EPICS }\end{array}$ & $\begin{array}{l}\text { GLASHAUSSE } \\
\text { MORRIS } \\
\text { BLAND }\end{array}$ & $\begin{array}{l}\text { C.F. } \\
\text { C. } \\
\text { C.L. } \\
\text { L.C. }\end{array}$ & $\begin{array}{r}0.0 \\
0.0 \\
200.0 \\
0.0\end{array}$ \\
\hline 662 & 1 & APPROVED & & EPICS & $\begin{array}{l}\text { KRAUSHAAR } \\
\text { PETERSON }\end{array}$ & $\begin{array}{l}\text { J.J. } \\
\text { R.J. }\end{array}$ & $\begin{array}{r}193.0 \\
0.0\end{array}$ \\
\hline 663 & 1 & APPROVED & & HRS & $\begin{array}{l}\text { IGO } \\
\text { BLESZYNSKI }\end{array}$ & $\begin{array}{l}\text { G.J. } \\
\text { M. }\end{array}$ & $\begin{array}{r}160.0 \\
0.0\end{array}$ \\
\hline 664 & 1 & APPROVEO & & $A B$ & $\begin{array}{l}\text { GLASS } \\
\text { STANEK }\end{array}$ & $\begin{array}{l}\text { G.C. } \\
\text { R. }\end{array}$ & $\begin{array}{r}288.0 \\
0.0\end{array}$ \\
\hline 665 & 1 & APPROVED & & $\mathbf{A B}$ & $\begin{array}{l}\text { BURLESON } \\
\text { WAGNER }\end{array}$ & $\begin{array}{l}\text { G.R. } \\
\text { R. }\end{array}$ & $\begin{array}{r}1200.0 \\
0.0\end{array}$ \\
\hline 666 & $i$ & APPROVED & PARASITIC & HRS & $\begin{array}{l}\text { GLASHAUSSE } \\
\text { WHI TTEN }\end{array}$ & C.A. & $\begin{array}{r}100.0 \\
0.0 \\
0.0\end{array}$ \\
\hline 667 & & & & & & & $\begin{array}{l}0.0 \\
0.0\end{array}$ \\
\hline 668 & & & & & & & $\begin{array}{l}0.0 \\
0.0\end{array}$ \\
\hline 669 & 1 & APPROVED & & HRS & $\begin{array}{l}\text { SHERA } \\
\text { WOHLFAHRT }\end{array}$ & $\begin{array}{l}\text { E.B. } \\
\text { H.D. }\end{array}$ & $\begin{array}{r}100.0 \\
0.0\end{array}$ \\
\hline 670 & 1 & APPROVED & & HRS & $\begin{array}{l}\text { MOSS } \\
\text { CAREY } \\
\text { ADAMS }\end{array}$ & $\begin{array}{l}\text { J.M. } \\
\text { T.A. } \\
\text { G.S. }\end{array}$ & $\begin{array}{r}116.0 \\
0.0 \\
0.0\end{array}$ \\
\hline 674 & 1 & TOBE - HEARD & & EPICS & $\begin{array}{l}\text { SAHA } \\
\text { SETH }\end{array}$ & A. & $\begin{array}{l}0.0 \\
0.0\end{array}$ \\
\hline 672 & 1 & APPROVED & & EPICS & $\begin{array}{l}\text { CAREY } \\
\text { MOSS }\end{array}$ & T.A. & $\begin{array}{r}160.0 \\
0.0\end{array}$ \\
\hline $\begin{array}{l}673 \\
674\end{array}$ & $\begin{array}{l}1 \\
1\end{array}$ & $\begin{array}{l}\text { APPROVED } \\
\text { DEFER }\end{array}$ & & $\begin{array}{l}\text { P3 } \\
\text { P3 }\end{array}$ & $\begin{array}{l}\text { HOLT } \\
\text { BURLESON } \\
\text { MORRIS }\end{array}$ & $\begin{array}{l}\text { P.J. } \\
\text { G.R. } \\
\text { C.L. }\end{array}$ & $\begin{array}{r}490.0 \\
0.0 \\
0.0\end{array}$ \\
\hline $\begin{array}{l}675 \\
676\end{array}$ & $\begin{array}{l}1 \\
1\end{array}$ & $\begin{array}{l}\text { APPROVED } \\
\text { APPROVED }\end{array}$ & & $\begin{array}{l}\text { LEP } \\
\text { LEP }\end{array}$ & $\begin{array}{l}\text { KUNSELMAN } \\
\text { CHANT } \\
\text { REDWINE } \\
\text { ROOS }\end{array}$ & $\begin{array}{l}\text { A.R. } \\
\text { N.S. } \\
\text { R.P. } \\
\text { P.G. }\end{array}$ & $\begin{array}{r}90.0 \\
288.0 \\
0.0 \\
0.0\end{array}$ \\
\hline 677 & 1 & APPROVED & & EPICS & $\begin{array}{l}\text { HOL TKAMP } \\
\text { FUNSTEN }\end{array}$ & $\begin{array}{l}\text { D. B. } \\
\text { H.O. }\end{array}$ & $\begin{array}{r}100.0 \\
0.0\end{array}$ \\
\hline 678 & 1 & APPROVED & & EPICS & $\begin{array}{l}\text { DEHNHARD } \\
\text { MORRIS }\end{array}$ & $\begin{array}{l}\text { D. } \\
\text { C.L. }\end{array}$ & $\begin{array}{r}200.0 \\
0.0\end{array}$ \\
\hline $\begin{array}{l}679 \\
680 \\
681 \\
682\end{array}$ & $\begin{array}{l}1 \\
1 \\
1 \\
1\end{array}$ & $\begin{array}{l}\text { APPROVED } \\
\text { REJECTED } \\
\text { APPROVED } \\
\text { APPROVED }\end{array}$ & & $\begin{array}{l}\text { AB - NOCCHEM } \\
\text { EPICS } \\
\text { EPICS } \\
\text { P3 }\end{array}$ & $\begin{array}{l}\text { CLARK } \\
\text { GREENE } \\
\text { GURLESON } \\
\text { IMAI } \\
\text { GREENE }\end{array}$ & $\begin{array}{l}\text { J.L. } \\
\text { S.J. } \\
\text { G.R. } \\
\text { K. } \\
\text { S.J. }\end{array}$ & $\begin{array}{r}42.0 \\
0.0 \\
290.0 \\
200.0 \\
0.0\end{array}$ \\
\hline 683 & 1 & APPROVED & & $A B$ & $\begin{array}{l}\text { DI TZLER } \\
\text { SI MMONS }\end{array}$ & $\begin{array}{l}\text { W.R. } \\
\text { J.E. }\end{array}$ & $\begin{array}{l}0.0 \\
0.0\end{array}$ \\
\hline 684 & 1 & REJECTED & & HRS & $\begin{array}{l}\text { KALLNE } \\
\text { HOISTAD }\end{array}$ & J. & $\begin{array}{r}180.0 \\
0.0\end{array}$ \\
\hline 685 & 1 & APPROVED & & HRS & $\begin{array}{l}\text { BLESZYNSKI } \\
\text { I GO }\end{array}$ & M.J. & $\begin{array}{r}240.0 \\
0.0\end{array}$ \\
\hline $\begin{array}{l}686 \\
687 \\
688\end{array}$ & $\begin{array}{l}1 \\
1 \\
1\end{array}$ & $\begin{array}{l}\text { APPROVED } \\
\text { TOBE - HEARD } \\
\text { APPROVED }\end{array}$ & & $\begin{array}{l}\text { HRS } \\
\text { HRS } \\
\text { LEP }\end{array}$ & $\begin{array}{l}\text { HINTZ } \\
\text { RAHBAR } \\
\text { LEITCH } \\
\text { COOPER }\end{array}$ & $\begin{array}{l}\text { N.M. } \\
\text { A. } \\
\text { M.J. } \\
\text { M.D. }\end{array}$ & $\begin{array}{r}150.0 \\
0.0 \\
230.0 \\
0.0\end{array}$ \\
\hline 689 & 1 & COMPLETE & & P3 & $\begin{array}{l}\text { NEFKENS } \\
\text { FITZGERALD }\end{array}$ & $\begin{array}{l}\text { B.M.K. } \\
\text { D.H. }\end{array}$ & $\begin{array}{r}320.0 \\
0.0\end{array}$ \\
\hline $\begin{array}{l}690 \\
691 \\
592 \\
693 \\
694 \\
695\end{array}$ & $\begin{array}{l}1 \\
1 \\
1 \\
1 \\
1 \\
1\end{array}$ & $\begin{array}{l}\text { APPROVED } \\
\text { APPROVED } \\
\text { APPROVED } \\
\text { RESUBMIT } \\
\text { DEFER } \\
\text { REJECTED }\end{array}$ & & $\begin{array}{l}\text { EPB } \\
\text { BSA-RAD } \\
\text { TIA } \\
\text { SMC } \\
\text { EPICS } \\
\text { SMC }\end{array}$ & $\begin{array}{l}\text { REEDY } \\
\text { REEDY } \\
\text { REEDY } \\
\text { REIDY } \\
\text { SETH } \\
\text { REIDY } \\
\text { HUTSON }\end{array}$ & $\begin{array}{l}\text { R.C. } \\
\text { R.C. } \\
\text { R.C. } \\
\text { J.J. } \\
\text { K.K. } \\
\text { J.J. } \\
\text { R.L. }\end{array}$ & $\begin{array}{l}0.0 \\
0.0 \\
0.0 \\
0.0 \\
0.0 \\
0.0 \\
0.0\end{array}$ \\
\hline 97 & 1 & $\begin{array}{l}\text { REJECTED } \\
\text { TOBE - HEARD }\end{array}$ & & $\begin{array}{l}\text { EPICS } \\
\text { SMC }\end{array}$ & $\begin{array}{l}\text { SETH } \\
\text { EUDICK }\end{array}$ & $\begin{array}{l}\text { K.K. } \\
\text { B. }\end{array}$ & $\begin{array}{l}0.0 \\
0.0\end{array}$ \\
\hline
\end{tabular}


STATUS OF PROPOSALS AS OF $82 / 01 / 11$.

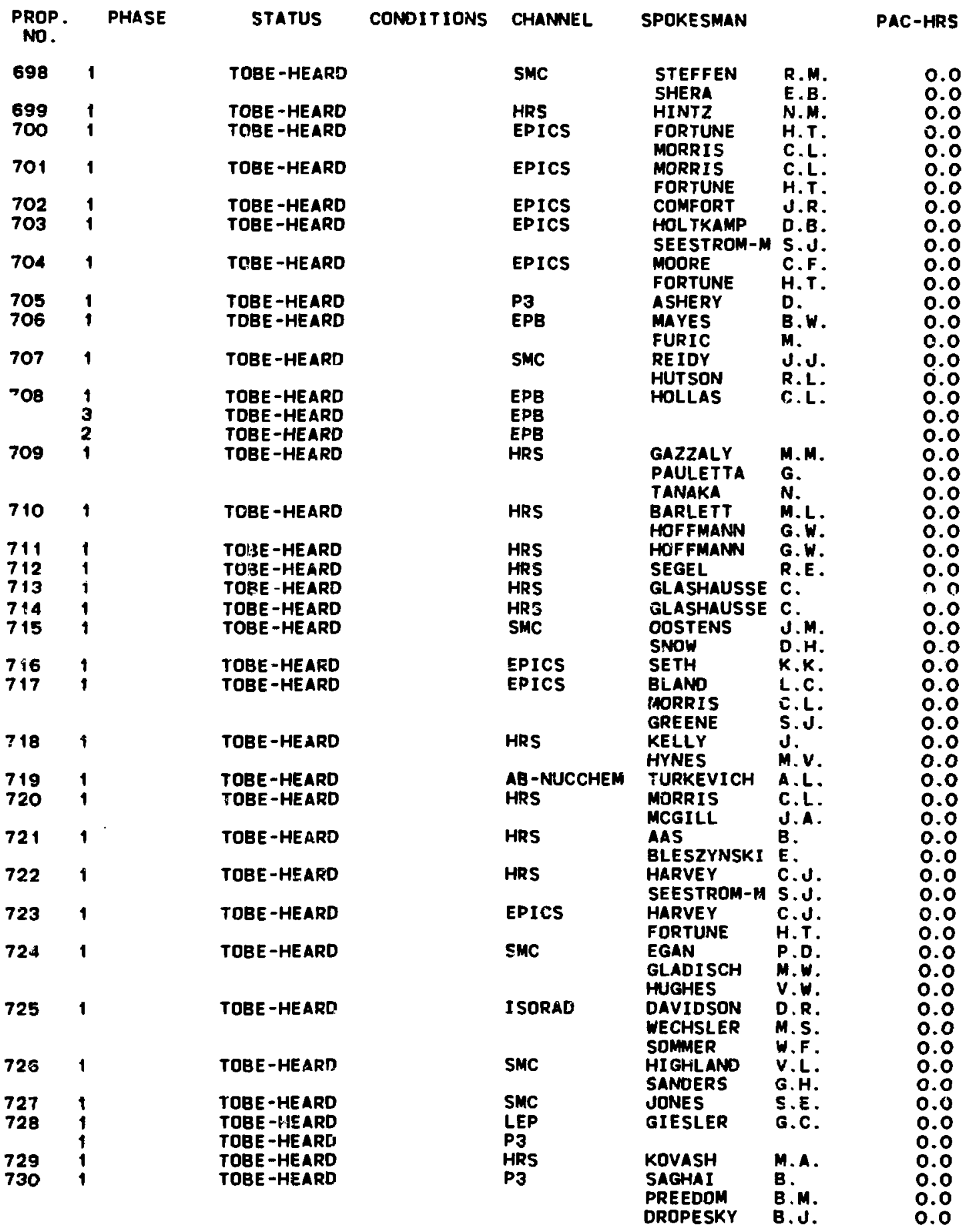




\title{
CONTENTS BY CHANNEL
}

\begin{abstract}
$\mathbf{A B}$
Exp. No.

Experiment Title

Page No.
\end{abstract}

55 Inverse Photodisintegration of the Deuteron Test of the Time-Reversal Invarience of Electromagnetic Interactions of Hadrons $\ldots \ldots \ldots \ldots \ldots \ldots \ldots \ldots \ldots \ldots \ldots, \ldots \ldots$

56 Study of Neutron Spectrum From Proton Bombardment of Deuterium in the

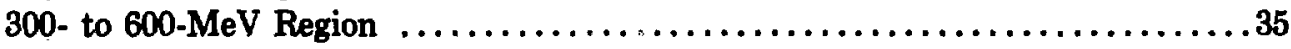

65 Neutron-Proton Polarization Measurements Using a Polarized Target:

Phase I. The n-p Polarization Observable $P(\theta) \ldots \ldots \ldots \ldots \ldots \ldots \ldots \ldots . \ldots 42$

66 Neutron Polarization Measurements with a Polarized Target:

Phase II. The n-p Spin Correlation Observable, $\mathrm{C}_{\mathrm{nn}}(\theta) \quad \ldots \ldots \ldots \ldots \ldots \ldots \ldots 42$

124 Measurement of the Neutron Energy Spectrum In $p+p \rightarrow n+\pi^{+} p \ldots \ldots \ldots \ldots 76$

125 Elastic Neutron-Proton Back-Angle Differential

Cross-Section Measurements $300-800 \mathrm{MeV} . \ldots \ldots \ldots \ldots \ldots \ldots \ldots \ldots \ldots \ldots . \ldots 76$

129 Pion Production in Neutron-Proton Collisions $\ldots \ldots \ldots \ldots \ldots \ldots \ldots \ldots \ldots \ldots \ldots 78$

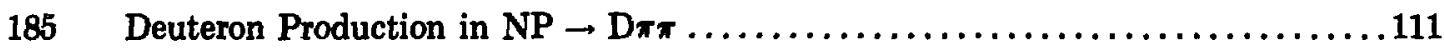

189 Search for Condensed Nuclear States and Study of High-q $q^{2}$ Low-

Nuclear Interactions $\ldots \ldots \ldots \ldots \ldots \ldots \ldots \ldots \ldots \ldots \ldots \ldots \ldots \ldots \ldots \ldots \ldots, \ldots \ldots \ldots$

193 Measurement of Small-Angle Neutron Elastic Scattering from Protons . . . . . . . 115

205 (n,p) Charge-Exchange and Neutron-Induced Quasi-Free Sicattering

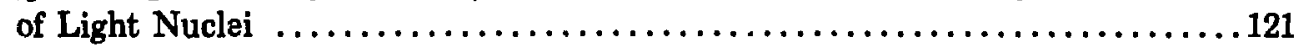

208 Measurement of $\sigma(\theta)$ for n-p Elastic Scattering At Forward Angles ...........123

255 Measurement of $\sigma(\theta)$ for n-p Elastic Scattering at $460 \mathrm{MeV} \ldots \ldots \ldots \ldots \ldots \ldots 148$

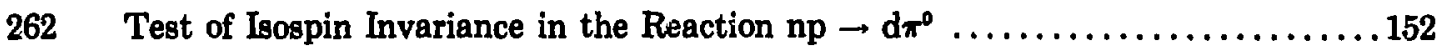


263 Measurement of the Energy and Angular Variation of the np Charge-Exchang:

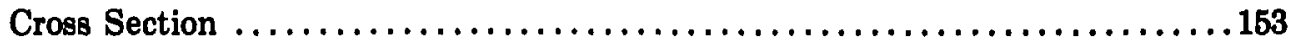

264 Measurement of the Energy Variation of the nD Elastic Differential Cross Section Near $180^{\circ}$

279 Measurement of Neutron-Neutron Differential Cross Section and a Test

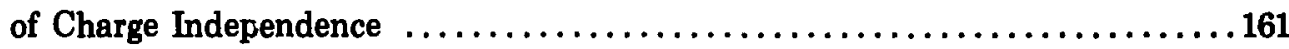

360 The Measurement of the Polarization Transfer Coefficients $D_{t}$ and $A_{t}^{\prime}$ at $800 \mathrm{MeV}$ for the Reactions $\mathrm{d}(\overrightarrow{\mathrm{p}}, \overrightarrow{\mathrm{n}}) 2 \mathrm{p},{ }^{\circ} \mathrm{Li}(\overrightarrow{\mathrm{p}}, \overrightarrow{\mathrm{n}})^{\circ} \mathrm{Be}$, and ${ }^{\circ} \mathrm{Be}(\overrightarrow{\mathrm{p}}, \overrightarrow{\mathrm{n}})^{\circ} \mathrm{B} \ldots \ldots \ldots . .205$

366 Nonresonant Pion Production in the Reaction $n p \rightarrow \pi^{-}$pp $\ldots \ldots \ldots \ldots \ldots \ldots \ldots 208$

387 Energy Dependence of the Forward Angle np Differential Cross Section .......219

402 A Measurement of the Polarization Transfer Coefficients $D_{t}\left(0^{\circ}\right)$ and $A_{\mathfrak{t}}\left(0^{\circ}\right)$

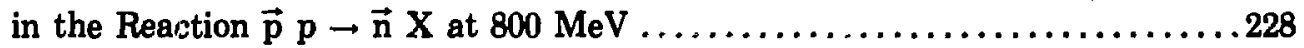

403 A Measurement of the Triple-Scattering Parameter $D_{t}$ for the Charge-Exchange

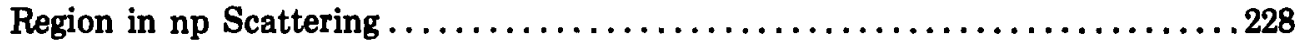

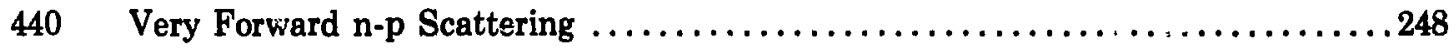

457 Measurement of the Quasi-Free pn and pp and Free pp Analyzing Powers,

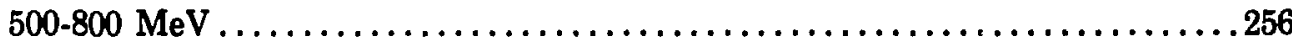

496 A Measurement of the Energy Dependence of Neutron Spectra at $0^{\circ}$ for the

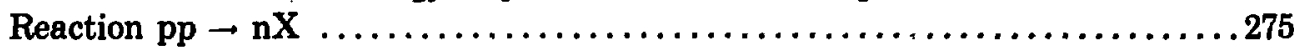

498 Measurements of Longitudinal Cross-Section Difference for Longitudinal Polarized Beam and Target, 1. $\Delta \sigma_{\mathrm{L}}(\mathrm{pp}), \quad$ 2. $\Delta \sigma_{\mathrm{L}}(\mathrm{pd}) \quad$ 3. $\Delta \sigma_{\mathrm{L}}(\mathrm{np}) \ldots \ldots \ldots .277$

504 Measurement of the Total Cross-Section Difference for Proton-Proton and Protsin-Neutron Scattering in Pure Transverse Initial Spin States in the $400-$ to $800-\mathrm{MeV}$ Region $\ldots \ldots \ldots \ldots \ldots \ldots \ldots \ldots .280$

505 Measurement of the Transverse Spin-Spin Asymmetry in the Reaction $\mathrm{pp} \rightarrow \mathrm{d} \pi^{+}$IN THE 500- to 800-MeV Region

528 Exploratory Measurement of $\Delta \sigma_{\mathrm{L}}$ in Free Neutron-Proton Scattering at $800 \mathrm{MeV}$ 292

664 The measurement of the Polarization Transfer Coefficients $A_{t}^{\prime}$ and $D_{t}$ at 500,650 and $800 \mathrm{MeV}$ for the Reaction $d(\vec{p}, \vec{n}) 2 p \ldots \ldots \ldots \ldots \ldots \ldots .364$

665 The Measurement of the Initial State Spin Correlation Parameters $\mathrm{C}_{\mathrm{LL}}$ and $\mathrm{C}_{\mathrm{SL}}$ in n-p.Elastic Scattering at 500, 650 and $800 \mathrm{MeV}$. 
683 Measurement of $\Delta \sigma_{\mathrm{L}}$ in Free Neutron Proton Scattering at 500,650 , and $800 \mathrm{MeV}$ 


\section{AB NUCLEAR CHEMISTRY}

Exp. No.

Experiment Title

Page No.

103 Spallation Yield Distributions from Pion Interactions with Complex Nuclei .... 64

104 Proposal for LAMPF Experiment: Studies of the

Proton- and Pion-Induced Fission of Medium-Mass Nuclides ...........65

105 Nuclear Spectroscopy Studies of Proton-Induced Spallation Products ........65

106 Proton-Induced Spallation Reactions Related to the Isotope-Production

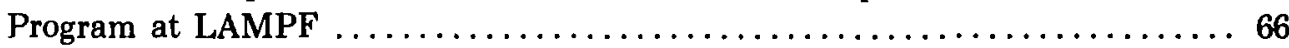

118 Fragment Emission from Pion linteractions with Complex Nuclei $\ldots \ldots \ldots \ldots \ldots 71$

119 Cross Sections of Simple Nuclear Reactions Induced by Pi-Mesons ......... 72

123 Nuclear Structure Effects in Pion-Induced Nuclear Reactions $\ldots \ldots \ldots \ldots \ldots \ldots 75$

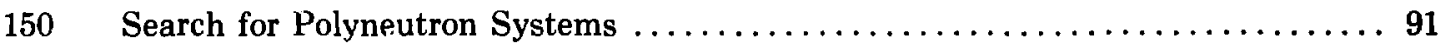

169 Request for Proton Irradiations at LAMPF for Project JUMper $\ldots \ldots \ldots \ldots \ldots 102$

243 Recoil Studies of Deep Spallation and Fragmentation Products from the Interaction of $800-\mathrm{MeV}$ Protons with Heavy Elements $\ldots \ldots \ldots \ldots \ldots \ldots \ldots 1$

282 Measurement of Cross Sections for Proton-Induced Formation of Spallation Products in Copper by Activation Analysis ................ 162

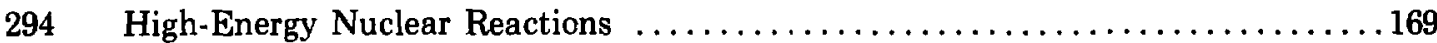

301 Impairment of Superconducting Characteristics by Proton Irradiation ......... 173

$383 \quad$ Nickel Irradiation with Protons and Neutrons $\ldots \ldots \ldots \ldots \ldots \ldots \ldots \ldots \ldots \ldots$

407 The Effect of Distribution Vibration on Void Growth in Metals

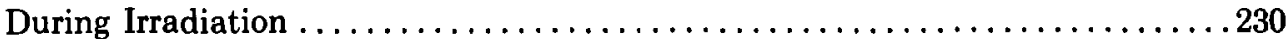

410 Radiation Effects in Amorphous Metals Due to $800-\mathrm{MeV}$ Protons ..........232

424 Preliminary Experiments for Double Charge Exchange and $\left(\mu^{-}, \mathrm{e}^{+}\right)$Searches $\ldots 239$

554 Irradiation of Technologically Importa it Metals

With $800-\mathrm{MeV}$ Protons Using the Is'stope Production

Facility at LAMPF 
555 Total Crosa-Section Measurements of the Single-Charge-Exchange

Reaction ${ }^{12} \mathrm{C}\left(\pi^{+}, \pi^{0}\right)^{12} \mathrm{~N}(\mathrm{~g} .8$.

557 Exposure, in a Parasitic Mode, of a $3 \mathrm{~cm} \times 3 \mathrm{~cm} \times 1 \mathrm{~cm}$ Stack of Solid Track Detectors to A $\pi^{-}$Beam

579 A Radiochemical Study of Neutron-Deficient

Products from $500 \mathrm{MeV}$ of ${ }^{280} \mathrm{U} \ldots \ldots \ldots \ldots \ldots \ldots \ldots \ldots \ldots \ldots \ldots \ldots . \ldots \ldots \ldots$

603 Search for Deltas in a Complex Nucleus by A

Radiochemical Technique $\ldots \ldots \ldots \ldots \ldots \ldots \ldots \ldots \ldots \ldots \ldots \ldots \ldots \ldots \ldots \ldots \ldots$

610 Use of LAMPF Beam Stop to Obtain ${ }^{\circ 0} \mathrm{~F} \ldots \ldots \ldots \ldots \ldots \ldots \ldots \ldots \ldots \ldots \ldots \ldots \ldots$

629 Feasibility of He-Jet Techniques for Studying Short-Lived

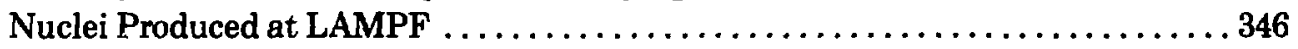

679 A Radiochemical Study of the ${ }^{200} \mathrm{Bi}\left(\mathrm{p}, \boldsymbol{r}^{0}\right)^{210} \mathrm{Po},{ }^{200} \mathrm{Bi}\left(\mathrm{p}, \pi^{-} \mathrm{xn}\right)^{210-x} \mathrm{At}$, and ${ }^{200} \mathrm{Bi}\left(\mathrm{p}, \mathrm{p} 2 \pi^{-} \mathrm{xn}\right)^{200}-\mathrm{x}$ at Pion Production Reactions at 500 t0 $800 \mathrm{MeV}$

690 Simulations of Cosmic-Ray-Produced Gamma Rays from Thick Targets .

691 Simulation of Cosmic-Ray Production of Nuclides by Spallation-Produced Neutrons . .......................... 379

692 Ge Detector Low-Level Radiation Damage Equilibration Experiment . . . . . . . . . 380

719 Production of Neutron Rich Radon Isotopes and

Determination of Their Cross Sections and

Half Lives by a Radiochemical Technique 


\section{BIOMED}

Exp. No.

Experiment Title

Page No.

19 Development of a Generation-II Image Intensifier-Vidicon Television System for Meson-Tissue Interaction Visualization $\ldots \ldots \ldots \ldots \ldots \ldots \ldots \ldots \ldots \ldots \ldots$

44 Radiobiology of Negative-Pi Mesons, A Preliminary Study . . . . . . . . . . 29

78 Proton Beam Monitor $\ldots \ldots \ldots \ldots \ldots \ldots \ldots \ldots \ldots \ldots \ldots \ldots \ldots \ldots \ldots \ldots$

83 Investigation of Multiwire Proportional Counters For Treatment Volume

Visualization.$\ldots \ldots \ldots \ldots \ldots \ldots \ldots \ldots \ldots \ldots \ldots \ldots \ldots \ldots \ldots \ldots \ldots \ldots \ldots \ldots \ldots$

84 Quality of Meson Radiation Fields $\ldots \ldots \ldots \ldots \ldots \ldots \ldots \ldots \ldots \ldots \ldots \ldots \ldots$

143 Study of the Radiobiological Properties of Negative Pions $\ldots \ldots \ldots \ldots \ldots \ldots \ldots$

151 Determination of Heavy Charged Particles From Stopped and Moving

Negative Pions in Water by Solid Dielectric Track Recorders ............ 91

167 Heavy Fragment Formation Following $\pi^{-}$Absorption in ${ }^{12} \mathrm{C} \ldots \ldots \ldots \ldots \ldots \ldots 1$

168 Formation of ${ }^{4} \mathrm{H}$ Following $\pi^{-}$Absorption in ${ }^{4} \mathrm{Li}$ and ${ }^{7} \mathrm{Li} \ldots \ldots \ldots \ldots \ldots \ldots$

171 Study of Negative-Pion Beams by Plastic Nuclear Track Detectors ..........103

187 Nuclear Gamma Rays Produced by Negative Pions Stopping in Carbon,

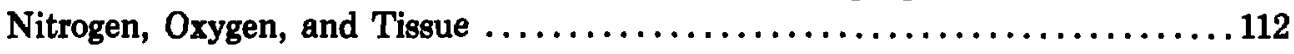

188 Negative-Pion Effects on Immunocompetent Cells $\ldots \ldots \ldots \ldots \ldots \ldots \ldots \ldots \ldots \ldots 112$

195 Nuclear Resonance Effect in Pionic Atoms $\ldots \ldots \ldots \ldots \ldots \ldots \ldots \ldots \ldots \ldots \ldots$

196 A Visualization Experiment with Charged Particles $\ldots \ldots \ldots \ldots \ldots \ldots \ldots \ldots \ldots 117$

198 Effects of Pions on DNA on Nondividing Cell Systems $\ldots \ldots \ldots \ldots \ldots \ldots \ldots \ldots$

207 Measurement of Neutron Spectrum and Intensity Resulting from $\pi^{-}$Capture in Water Phantom and Human Tissue .......................... 123

209 Pion Interactions in Nuclear Emulsions $\ldots \ldots \ldots \ldots \ldots \ldots \ldots \ldots \ldots \ldots \ldots \ldots$

212 Comparative Effectiveness of Negative Pions vs ${ }^{2 n} \mathrm{Cf}$ in a Tumor-Animal System 124

215 Visualization of Stopping Pion Distribution $\ldots \ldots \ldots \ldots \ldots \ldots \ldots \ldots \ldots \ldots \ldots$ 
218 Pion Dosimetry with Nuclear Emulsions and Alanine 127

235 Radiation Repair of Normal Mammalian Tissues 136

236 Biological Effects of Negative Pions

239 Study of ${ }^{11} \mathrm{C}$ and ${ }^{19} \mathrm{~N}$ Production by $\pi^{-}$Irradiation of

C, N, $\mathrm{O}$, and Tissue for Radiotherapy Monitoring...

242 Survival of Synchronized Cultured Human-Kidney T-1 Cells Exposed to

Stopping Pions and X Rays at Various Times after Mivosis .

244 Systems Development for Efficient Utilization of High-Purity Germanium

Mosaic Detectors for Tumor Localization ......................... 141

270 Therapy Beam Development - Biomedical Channel Tuning $\ldots \ldots \ldots \ldots \ldots \ldots 158$

271 Therapy Beam Development - Dosimetry $\ldots \ldots \ldots \ldots \ldots \ldots \ldots \ldots \ldots \ldots$

272 Therapy Beam Development- Microdosimetry $\ldots \ldots \ldots \ldots \ldots \ldots \ldots \ldots \ldots \ldots$

273 Therapy Beam Development - LET Measurements .................. 159

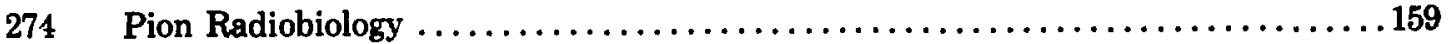

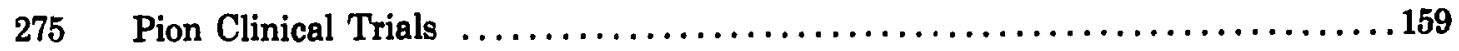

285 Migration of ${ }^{11} \mathrm{C}$ and ${ }^{12} \mathrm{~N}$ Radioactivity Produced in vivo by Negative Pions ..... 164

$300 \pi^{-}$Coulomb Capture and $\pi^{-}$Transfer in Tissue, Tissue-Equivalent Liquid,

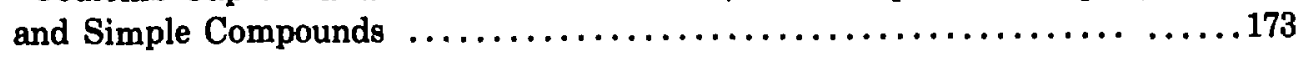

304 Study of the Auger Process in Pionic Atoms $\ldots \ldots \ldots \ldots \ldots \ldots \ldots \ldots \ldots \ldots$

372 Stopping Power of $\pi^{ \pm}$at Energies below $100 \mathrm{MeV} \ldots \ldots \ldots \ldots \ldots \ldots \ldots \ldots \ldots \ldots \ldots$

380 RBE and OER for Normal and Tumor Tissues $\ldots \ldots \ldots \ldots \ldots \ldots \ldots \ldots$

384 Biological Intercomparison of $\pi^{-}$Therapy Beams at TRIUMF and LAMPF Using Mouse Testes as a Biological Test System .................. 218 
45 Radiation-Damage Studies - High-Temperature Reactor Materials and

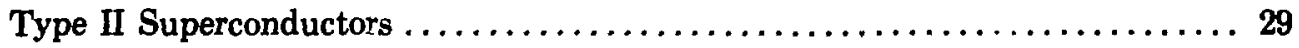

111 Search for New Neutron-Rich Nuclides Produced by Fast Neutrons $\ldots \ldots \ldots \ldots 68$

113 Radiation Damage and Helium Embrittlement in Eleveted-Temperature Reactor Structural Alloys $\ldots \ldots \ldots \ldots \ldots \ldots \ldots \ldots \ldots \ldots \ldots \ldots, 69$

147 Determination of the Energy Distribution of Neutrons from the LAMPF Beam Stop .......................................... 88

157 Microdistribution of Thorium in Geologic Samples .................... 95

161 The Microdistribution of Thorium in Meteorites $\ldots \ldots \ldots \ldots \ldots \ldots \ldots \ldots \ldots . \ldots 8$

174 Investigation of the Chemical Reactions of Atsmic "F as a Means for Direct Synthesis of ${ }^{10} \mathrm{~F}$-Labeled Compounds .............................105

237 Radiation-Damage Studies on Structural Materials for Advanced Reactors ..... 137

251 Neutron Irradiation of Copper Tensile Specimens $\ldots \ldots \ldots \ldots \ldots \ldots \ldots \ldots \ldots \ldots \ldots$

290 Measurement of the Neutron Spectrum from the Main Beam Stop at LAMPF with a Self-Contained Two-Parameter Spectrometer ..................167

326 Electrical Component Radiation-Effects Study $\ldots \ldots \ldots \ldots \ldots \ldots \ldots \ldots \ldots \ldots \ldots 7$

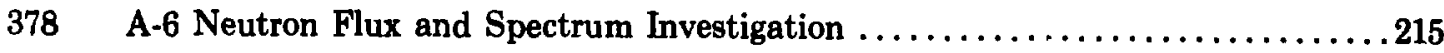

406 Neutron Flux Characterization at A-6 Radiation-Effeets Facility ...........230

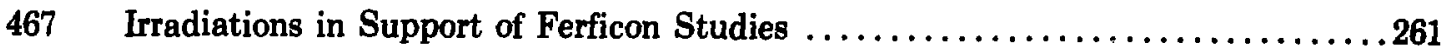

542 Feasibility Study: Using an Existing Neutron Beam Pipe at LAMPF Beam Stop for Crystal Diffraction Spectrometer Experiments

545 Fusion Materials Neutron Irradiations A Parasite Experiment

560 Study of Neutron-Irradiation-Induced Growth of

Metals at Radiation Effects Facility 


\section{EXTERNAL PROTON BEAM (EPB)}

Exp. No.

Experiment Title

Page No.

26 Neutron Time-of-Flight Experiment at Beam Stop ................. 16

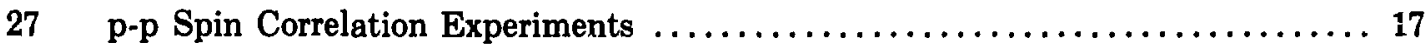

33 Search for Asymmetry in $\pi^{+}$Production by Proton-Proton Collision ........ 21

42 Breakup of Few-Nucleon Systems and Nuclei $\ldots \ldots \ldots \ldots \ldots \ldots \ldots \ldots \ldots \ldots$

52 Solitary Micropulses by Photodetachment of the $\mathrm{H}^{-}$Beam $\ldots \ldots \ldots \ldots \ldots . \ldots 33$

81 Study of Neutron-Proton and Proton-Proton Coincidence Spectra from

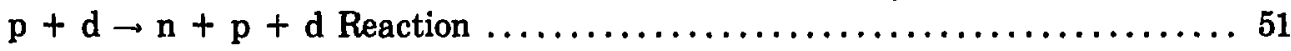

92 Search for Structures in $\pi-\pi$ Mass-Spectrum Near Threshold $\ldots \ldots \ldots \ldots \ldots \ldots 8$

124 Measurement of the Neutron Energy Spectrum in $p+p \rightarrow n+\pi^{+} p \ldots \ldots \ldots 76$

$128 \quad$ WNR Storage Ring Stripper Experiment $\ldots \ldots \ldots \ldots \ldots \ldots \ldots \ldots \ldots \ldots \ldots \ldots$

137 Search For Parity-Violating Contribution to Scattering of Hadrons ........ 83

153 Investigation of Nuclear Gamma Rays Resulting from In-Flight Pion and

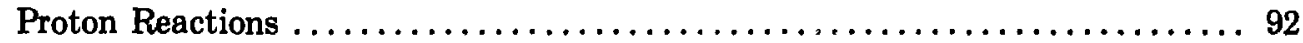

159 Charged-Particle Emission in Proton-Induced Reactions as a Feacibility Study in the Use of Intrinsic Germanium Detectors with the Primary LAMPF Beam . 96

160 Measurement of "D," "R," and "A" Parameters in p-p Eiastic Scettering ...... 97

176 P-Nucleus Total and Total Reaction Cross-Section Measurements .......... 106

186 Measurement of $\left(\mathrm{p}, \pi^{+}\right)$and $\left(\mathrm{p}, \pi^{-}\right)$Reaction Cross Sections on Complex Nuclei...111

192 Measurement of the Emittance Growth in $\mathrm{H}^{-}$Stripping $\ldots \ldots \ldots \ldots \ldots \ldots \ldots 115$

194 P-P, D, R, and A Measurements............................

197 Investigation Reaction $\mathrm{p}+\mathrm{d} \rightarrow{ }^{\mathrm{8}} \mathrm{He}+\pi^{0}$ at LAMPF Energies $\ldots \ldots \ldots \ldots \ldots \ldots$

200 Study of the Photodetachment Spectrum of $\mathrm{H}^{-}$in the Vicinity of $11 \mathrm{eV} \ldots \ldots . .119$

219 Double Pion Production in Proton-Proton Scattering $\ldots \ldots \ldots \ldots \ldots \ldots \ldots \ldots \ldots$ 
278 Study of Reaction Mechanisms Using Internal Conversion Techniques

279 Measurement of Neutron-Neutron Differentia: Cross Section and a Test of Charge Independence $\ldots \ldots \ldots \ldots \ldots \ldots \ldots \ldots \ldots \ldots \ldots \ldots \ldots \ldots \ldots$

289 Measurement of the Phase of the Forward Nucleon-Nucleon Spin-Independent

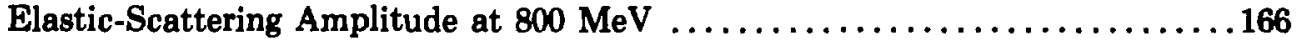

296 Measurement of Inclusive $\pi^{0}$ Production on Hydrogen Isotopes and Selected

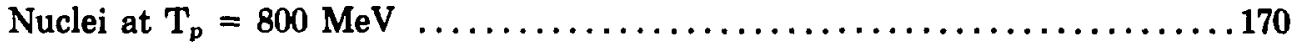

Stark-Effect Quenching of Resonances in the Photodisintegration of the $\mathrm{H}^{-}$Ion.. 185

339 Survey of Photodetachment Cross Section of $\mathrm{H}^{-}$from Threshold to $15 \mathrm{eV}$ and its Dependence upon Electric Field .......................... 194

$341 \quad$ Study of $\mathrm{pd} \rightarrow \mathrm{d} \cdot \pi^{+} \mathrm{n}$ Reaction Mechanisms $\ldots \ldots \ldots \ldots \ldots \ldots \ldots \ldots \ldots \ldots \ldots$

449 Survey of the Single and Double Photodetachment Cross Section of the $\mathrm{H}^{-}$Ion from 14 to $21.8 \mathrm{eV}$

468 Mechanisms of Luminescence Induced by Protons Incident of Ultraviolet Grade

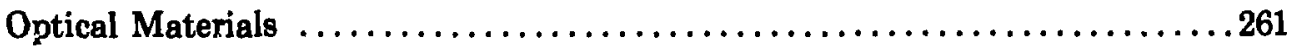

492 Polarimeter Calibrations and Search for Energy-Dependent Structure in pp Elastic Scattering via Cross Section, Analyzing Power, and Wolfenstein Parameter Measurements

498 Measurements of Longitudinal Cross-Section Difference for Longitudinal Polarized Beam and Target, 1. $\Delta \sigma_{\mathrm{L}}(\mathrm{pp}), \quad$ 2. $\Delta \sigma_{\mathrm{L}}(\mathrm{pd}), \quad$ 3. $\Delta \sigma_{\mathrm{L}}(\mathrm{np})$

512 Proton-Proton Elastic-Scattering Measurements of the $A_{s g}(\theta), A_{L L}(\theta)$, and $A_{a t}(\theta)$ Spin Correlation Parameters at 500, 650, and $800 \mathrm{MeV} \ldots \ldots \ldots \ldots \ldots . \ldots 283$

517 Polarized Beam and Target Experiments in the p-p System:

Phase I. $A_{y}$ and $A_{y y}$ for the $\mathrm{d} x^{+}$Channel and $A_{y y}$ for the Elastic Channel from 500 to $800 \mathrm{MeV}$ .285

518 Polarized Beam and Target Experiments in the p-p System:

Phase II. Measurements of $A_{x z}$ and $A_{x z}$ for the drat Channel and for the Elastic Channel from 500 to $800 \mathrm{MeV}$ .286 
526 Measurement of Analyzing Powers in $p d \rightarrow p d, p p \rightarrow d \pi$, and $p p \rightarrow p p$ Reactions

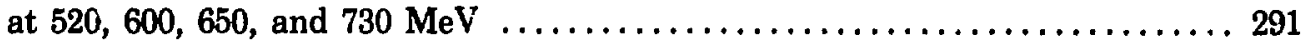

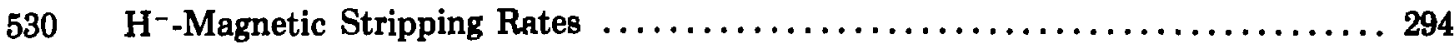

586 A Study of the Effects of the Very Strong Electric Fields on the Structure of the $\mathrm{H}^{-}$Ion

587. Fundamental Experiments with Relativistic Hydrogen

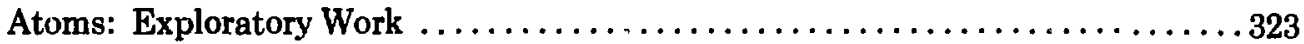

588 A Search for Long-Lived States of the $\mathrm{H}^{-}$Ion

$589 \quad$ Free-Forward np Elastic-Scattering Analyzing

Power Measurements at $800 \mathrm{MeV}$

590 Measurement of $D(\theta)$ in p-n and n-p Scattering at 800 ,

$650 \mathrm{MeV}$ and Other Energies with Associated

p-p Measurements

591 An Investigation of Inclusive One Pion Production

in Proton Nucleus Collisions

592 An Investigation of Two Pion Production and

Correlations in Proton Nucleus Collisions at $800 \mathrm{MeV}$

633 Measurement of p-p Scattering in the Coulomb Interference Region

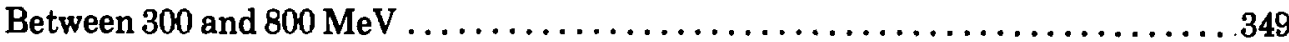

634 Measurment of Parity Violation in the p-Nucleon Total

Cross Sections at $800 \mathrm{MeV}$

635 Spin Measurements in pd Elastic Scattering

636 A Measurement of the Wolfenstein Polarization Parameters

$D_{L L}, D_{S L}, K_{L L}$, and $K_{s L}$ for p-p Elastic Scattering

637 A Measurement of the Vector Polarization of the Deuteron

in the Reaction $\mathrm{pp} \rightarrow \mathrm{D}_{\pi^{+}}$

706 Unpolarized p-p Differential Cross Sections at $90^{\circ}$ c.m.

708 A Measurement of the Depolarization, the Polarization, and the Polarization Rotation Parameters and the Analyzing Power for the Reaction $\vec{p} \mathbf{p} \rightarrow \overrightarrow{\mathrm{p}} \pi^{+} \mathbf{n}$ 
$9 \quad$ Elastic and Inelastic Pion Scattering from Calcium Isotopes $\ldots \ldots \ldots \ldots \ldots \ldots$

13 Study of $\pi^{+}$-Induced Double-Charge-Exchange Reactions $\ldots \ldots \ldots \ldots \ldots \ldots \ldots$

$14 \pi^{+}$and $\pi^{-}$Elastic and Inelastic Scattering from ${ }^{10} 0 \ldots \ldots \ldots \ldots \ldots \ldots$

17 Inelastic Pion Scattering from Light Nuclei ${ }^{\circ} \mathrm{Li},{ }^{10} \mathrm{~B}$, and ${ }^{10} \mathrm{~N} \ldots \ldots \ldots \ldots \ldots 11$

18 Survey of $\pi$ Scattering by Complex Nuclei $\ldots \ldots \ldots \ldots \ldots \ldots \ldots \ldots \ldots \ldots \ldots$

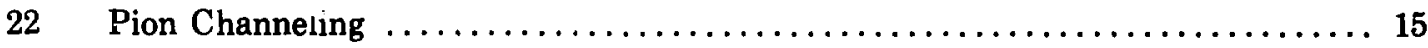

23 A Survey of Pion-Nucleus Elastic and Inelastic Scattering at $180 \mathrm{MeV} \ldots \ldots \ldots 15$

$39 \quad$ Search for $(\pi, p)$ Reactions with EPICS $\ldots \ldots \ldots \ldots \ldots \ldots \ldots \ldots \ldots \ldots \ldots$

41 Search for Muonium to Antimuonium Conversion $\ldots \ldots \ldots \ldots \ldots \ldots \ldots \ldots \ldots$

43 Elastic ard Inelastic Scattering of Pions From Nuclei in the Lead Region ....... 28

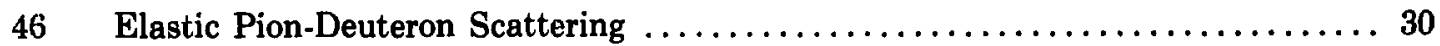

47 Elastic and Inelastic Pion Scattering from ${ }^{\circ y}, \ldots \ldots \ldots \ldots \ldots \ldots \ldots$

48 Elastic and Inelastic Pion Scattering from the Nickel Isotopes ........... 31

$61 \pi^{+}$and $\pi^{-}$Forward Elastic Scattering from Oxygen and Carbor $\ldots \ldots \ldots \ldots$

74 Study of Pion-Induced Double-Charge-Exchange Reactions on Low-Z Elements .. 47

$77 \pi^{+}$Elastic and Inelastic Scattering from Carbon, Magnesium, Strontium, and

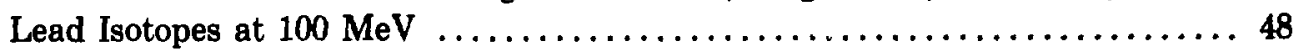

$87 \pi^{+}$and $\pi^{-}$Scattering from ${ }^{3} \mathrm{He}$ and ${ }^{4} \mathrm{He} \ldots \ldots \ldots \ldots \ldots \ldots \ldots \ldots \ldots \ldots \ldots \ldots \ldots \ldots \ldots$

89 Detailed Study of the Resonance Behavior of the Total Elastic Cross Section

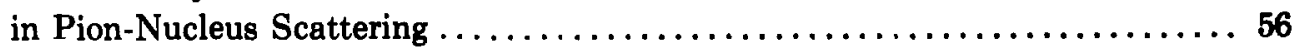

$130 \quad$ EPICS Tuneup Proposal: Pion Carbon Scattering $\ldots \ldots \ldots \ldots \ldots \ldots \ldots \ldots \ldots \ldots$

133 Preliminary Pion-Channeling Experiments $\ldots \ldots \ldots \ldots \ldots \ldots \ldots \ldots \ldots \ldots \ldots, 81$

$136 \quad$ Large-Angle Pion-Nucleus Scattering $\ldots \ldots \ldots \ldots \ldots \ldots \ldots \ldots \ldots \ldots \ldots$ 
$\pi^{+}$vs $\pi^{-}$Inelastic Excitation of Low Lying Collective States in

$\mathrm{N} \approx 28$ Nuclei

231 Selectivity in $\pi^{+}$vs $\pi^{-}$Inelastic Excitation of Odd-A Nuclei

232 Inelastic Pion Scattering by ${ }^{24} \mathrm{Mg}$ and ${ }^{26} \mathrm{Mg}$

245 Study of the $\left(\pi^{-}, n\right)$ and $(\pi, \pi p)$ Reactions in ${ }^{8,4} \mathrm{He}$ and Heavier Nuclei by Detecting Recoiling Tritons or Deuterons

246 Studies of $\pi^{+}$Scattering at $50 \mathrm{MeV}$ from Light Nuclei 143

252 Pion Charge Exchange and Inelastic Scattering on Lithium Nuclei by Observing the Gamma Decays ................................. 146

265 Study of Prompt Nuclear Deexcitation Gamma Rays from Pion Interactions

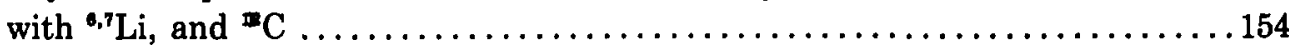

291 Comparison of the Quasi-Elastic Ratio $\sigma\left(\pi^{-}, \pi^{-} n\right) / \sigma\left(\pi^{+}, \pi^{+} n\right)$ to the Ratio $\sigma\left(\pi^{+}, \pi^{+} p\right) / \sigma\left(\pi^{-}, \pi^{-} p\right)$ in A Coincidence Experiment .................... 167

$310\left(\pi^{+}, \pi^{-}\right)$Double-Charge-Exchange Reactions Using Core 2n Targets ............179

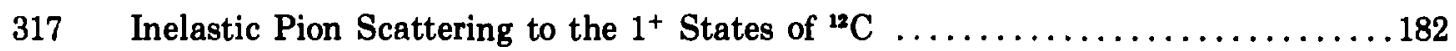

318 Excitation of Single-Particle States in Nuclei by Low-Energy Inelastic

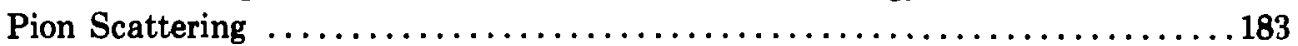

Pion and Muon Multiple Coulomb-Scattering Experiment

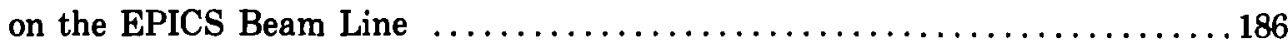

332 Masses of Extremely Neutron-Rich Nuclei by $\left(\pi^{-}, \pi^{+}\right)$Reactions .190

338 Mass Measurements of Exotic Neutron-Rich Nuclei Using the $\left(\pi^{-}, \pi^{+}\right)$Reaction . 193

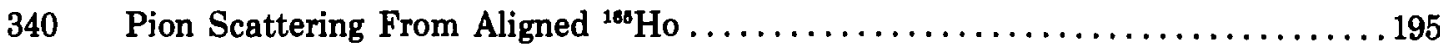

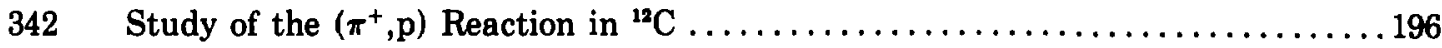

368 Inelastic Pion Scattering to the $19.2 \pm 0.3-\mathrm{MeV}$ State in ${ }^{12} \mathrm{C} \ldots \ldots \ldots \ldots \ldots . .209$ 
369 Inelastic Pion Scattering by ${ }^{17} \mathrm{O},{ }^{10} \mathrm{O}$, and ${ }^{10} \mathrm{~F} \ldots \ldots \ldots \ldots \ldots \ldots \ldots \ldots \ldots$

389 Inelastic Pion Scattering from Light Nuclei: ${ }^{10} \mathrm{~B},{ }^{11} \mathrm{~B},{ }^{14} \mathrm{~N}$, and ${ }^{14} \mathrm{~N} \ldots \ldots \ldots \ldots 220$

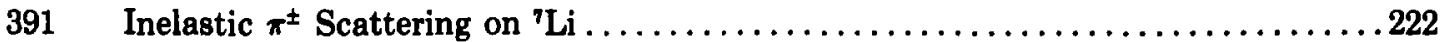

413 Mass Measurement of ${ }^{*} \mathrm{Ne}$ and "Ar by the $\left(\pi^{-}, \pi^{+}\right)$Reaction $\ldots \ldots \ldots \ldots \ldots .234$

419 Excitation of Single-Particle and Core-Coupled States in ${ }^{200} \mathrm{~Pb}$ and ${ }^{200} \mathrm{Bi} \ldots \ldots . .237$

423 Excitation of Giant Resonances by Inelastic Pion Scattering ...............239

426 Elastic and Inelastic Scattering of $162-\mathrm{MeV} \pi^{+}$and $\pi^{-}$from ${ }^{18} \mathrm{C} \ldots \ldots \ldots \ldots 240$

442 Study of the Inclusive Pion Double-Charge-Exchange Reaction ............248

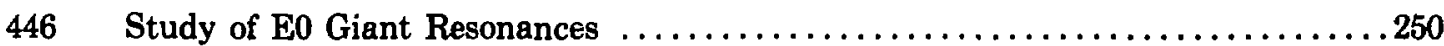

447 Measurement of Neutron and Proton Transition Matrix Elements in ${ }^{100} \mathrm{Ba}$

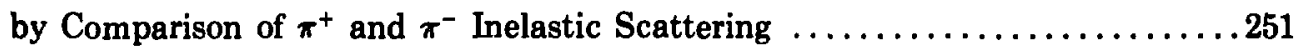

448 A Study of $\pi^{+}$Double-Charge-Exchange Scattering at Small Angles

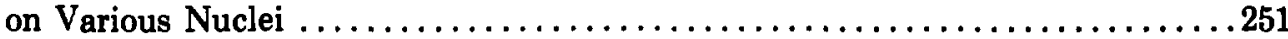

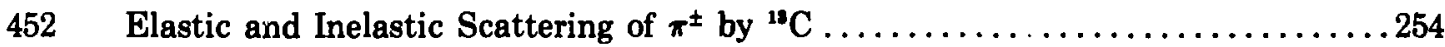

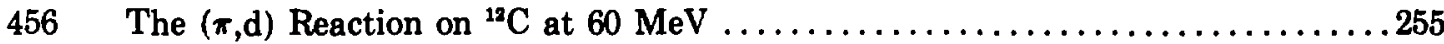

460 An Investigation of the Stability of ${ }^{\circ} \mathrm{H},{ }^{7} \mathrm{H}$, and ${ }^{\bullet} \mathrm{He}$ by $\left(\pi^{-}, \pi^{+}\right)$Reactions $\ldots \ldots 258$

463 Comparative Study of the $\left(\pi^{+}, \pi^{-}\right)$and $\left(\pi^{-}, \pi^{+}\right)$Reactions on ${ }^{12} \mathrm{C} \ldots \ldots \ldots \ldots 259$

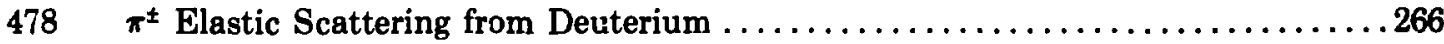

481 Excitation of High-Spin States in $\mathrm{T}_{\mathbf{z}}=0 \mathrm{~s}-\mathrm{d}$ Shell Nuclei by Pion

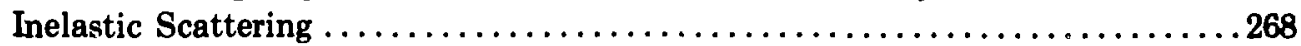

482 Excitation of High-Spin Particle-Hole States in $\mathrm{T} \neq 0$ Nuclei:

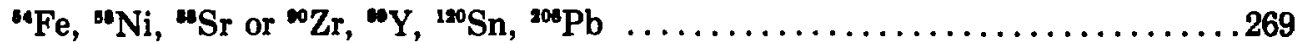

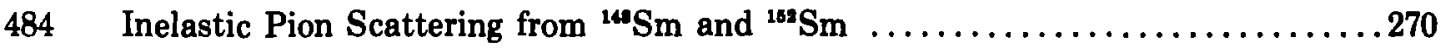

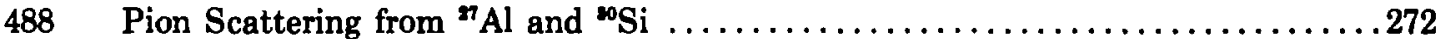

493 Pion Elastic Excitation of $4^{-}$States in ${ }^{10} \mathrm{O} \ldots \ldots \ldots \ldots \ldots \ldots \ldots \ldots \ldots \ldots \ldots \ldots \ldots$

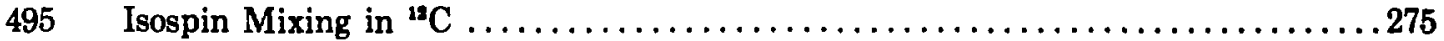

506 Inelastic Pion Scattering to the Unnatural Parity Levels in ${ }^{12} \mathrm{C}$ and ${ }^{\circ} \mathrm{Li} \ldots \ldots \ldots 281$ 
509 Survey of Inelastic Pion Scattering by Odd-A Nuclei 282

510 Energy Dependence of Elastic and Inelastic Scattering of $\pi^{ \pm}$by ${ }^{19} \mathrm{C}$ between 116 and $280 \mathrm{MeV}$

511 Pion Double Charge Exchange on Neutron-Rich Nuclei . .283

516 The $\left(\pi^{+}, \mathrm{p}\right)$ Reaction on ${ }^{16,18} \mathrm{O}$

522 Excitation of Giant Resonance States in ${ }^{\circ 0} \mathrm{Zr}$ and ${ }^{200} \mathrm{~Pb}$ with $150-\mathrm{MeV}$ Pions 289

A Siudy of the Relation Between the $(x, P)$ and $(p, d)$

Reaction in a Pion Exchange Model

539 Search for Pure Neutron/Proton Transitions in ${ }^{14} \mathrm{C}$

546 Investigation of the Spin Form Factor of Tritium and Helium-Three

548 An Investigation of the Isovector Character of the $\mathrm{2}_{2}^{+}$

State in ${ }^{20} \mathrm{Mg}$ by $\pi^{+}, \pi^{-}$Inelastic Scattering

549 A Study of the DCX Reaction Mechanism - The

${ }^{42} \mathrm{Ca}\left(\pi^{+}, \pi^{-}\right)^{42} \mathrm{Ti}$ Reacion

550 Excited State Spectra of the Exotic Nuclei ${ }^{18} \mathrm{C}$ and

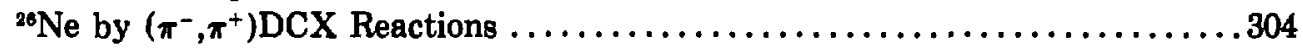

$551 \quad$ Masses of ${ }^{40} \mathrm{Ti}$ and ${ }^{80} \mathrm{Zn}$ by $\left(\pi^{-}, \pi^{+}\right)$Reaction ......................

558 Measurement of $\left(\pi^{+}, \pi^{-}\right)$Reactions on ${ }^{18,14} \mathrm{C}$ and ${ }^{26} \mathrm{Mg} \ldots \ldots \ldots \ldots \ldots \ldots \ldots \ldots$

565 Excitation of High-Spin Particle-Hole States in

${ }^{54} \mathrm{Fe}$ and ${ }^{56} \mathrm{Ni}$

568 Measurements of the Masses of $\mathrm{T}_{z}=-2$ Nuclei and of the

Systematics of $\left(\pi^{+}, \pi^{-}\right)$Cross Sections on $\mathrm{N}=\mathrm{Z}$ Nuclei

$\pi^{+} / \pi^{-}$Inelastic Scattering from ${ }^{10} \mathrm{~F}$

570 Investigation of the Structure of ${ }^{18} \mathrm{O}$ with Pion Inelastic Scattering

572 A-Dependence of the $\left(\pi^{+}, \pi^{-}\right)$Reaction and the Width of $A$

Double Isobaric Analog State in Heavy Nuclei 316

573 Pion Scattering From ${ }^{24} \mathrm{Mg}$ and ${ }^{20} \mathrm{Mg}$ 
577 Measurement of Angular Distributions for ${ }^{18} \mathrm{O}\left(\pi^{+}, \pi^{-}\right)^{10} \mathrm{Ne}$ 318

578 Pion Inelastic Scattering from ${ }^{20} \mathrm{Ne}$ 319

$581 \pi^{ \pm}$Elastic Scattering from Deuterium at $237 \mathrm{MeV}$ .320

582 Quadrupole Scattering of Pions by ${ }^{\circ} \mathrm{Be}$

584 Good-Resolution Study of ${ }^{18} \mathrm{O}\left(\pi, \pi^{\prime}\right)$

597 The Study of Broad Range Pion Inelastic Scattering Spectra

(With Emphasis on the Excitation of the Giant Monopole Resonance)

598 Inelastic Pion Scattering to the Unnatural Parity Levels in ${ }^{8} \mathrm{Li}$

599 Isospin Mixing Measurements Using the $\pi^{+}$vs $\pi^{-}$Inelastic

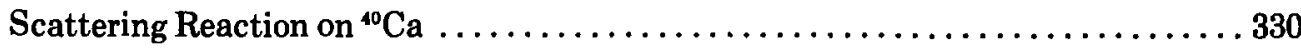

$600 \pi^{+}$vs $\pi^{-}$Inelastic Excitation of High-Spin, Unnatural

Parity States in ${ }^{208} \mathrm{~Pb}$

601 Determination of Isoscalar and Isovector Transition

Rates for Low-Lying Collective States in ${ }^{90} \mathrm{Zr}$ and ${ }^{208} \mathrm{~Pb}$ by $\pi^{+}$and $\pi^{-}$Inelastic Scattering

602 Neutron-Proton Components of Inelastic Transitions

in Pion Scattering on ${ }^{23} \mathrm{Na}$ and ${ }^{26} \mathrm{Mg}$

604 An Investigation of the Near-Stability of ${ }^{\circ} \mathrm{H}$

605 A Dibaryon Search at EPICS

606 Tests of the (N-Z) Dependence of Pion Double Charge Exchange 334

608 Inelastic Scattering of Pions to Giant Resonances 334

612 Mass of Beryllium-14 338

617 A Study of the (3/2,3/2) Resonance in Light Nuclei 340

618 Inelastic $\pi^{ \pm}$Scattering From the $\mathrm{N} \approx 28$ Isotones 340

619 Inelastic Pion Scattering to $0^{+}$and $2^{+}$States in ${ }^{40} \mathrm{Ca}$ and ${ }^{42} \mathrm{Ca}$ 340

620 The Nuclear Reaction $\pi^{+}$vs $\pi^{-}$Inelastic Scattering on ${ }^{40} \mathrm{Ca}$ 342

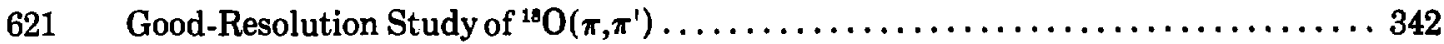

622 Investigation of the Strong Cancellation of Neutron/Proton Transition Amplitudes in ${ }^{14} \mathrm{C}$ 
651 Measurement of a Lower Limit for the Subthreshold Produciton

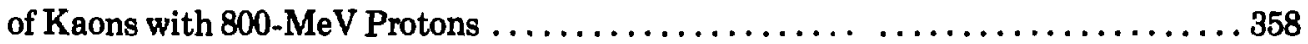

$655 \pi^{ \pm}$Inelastic Scattering From ${ }^{4} \mathrm{He}$ : An examination of Isospin-

Symmetry Breaking . . . . . . . . . . . . . . . . . . . . . . . . . . 360

656 Pion Double Charge Exchange on Self-Conjugate Nuclei $\ldots \ldots \ldots \ldots \ldots \ldots \ldots \ldots . \ldots 360$

657 Inelastic $\pi^{ \pm}$Scattering from the $\mathrm{N}=28$ Isotones $\ldots \ldots \ldots \ldots \ldots \ldots \ldots \ldots \ldots \ldots \ldots \ldots$

659 Spin-Flip Giant Resonance Excitation $\ldots \ldots \ldots \ldots \ldots \ldots \ldots \ldots \ldots \ldots \ldots \ldots$

661 Good Resolution Study of ${ }^{18} \mathrm{O}\left(\pi, \pi^{1}\right) \ldots \ldots \ldots \ldots \ldots \ldots \ldots \ldots \ldots \ldots \ldots \ldots \ldots \ldots \ldots \ldots$

662 Elastic and Inelastic $\pi^{-}$and $\pi^{+}$Scattering from ${ }^{32} \mathrm{~S},{ }^{31} \mathrm{P}$ and ${ }^{80} \mathrm{Zr},{ }^{89} \mathrm{Y} \ldots \ldots \ldots \ldots 3$

671 Experimental Investigations of Isovector Properties of Collective Transitions ...... 368

672 Study of Giant Resonances in ${ }^{90} \mathrm{Zr}$, ${ }^{110} \mathrm{Sn}$, and ${ }^{208} \mathrm{~Pb}$ with

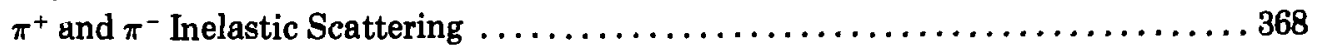

677 A Determination of $\Delta S=1$ Contributions in Inelastic Pion

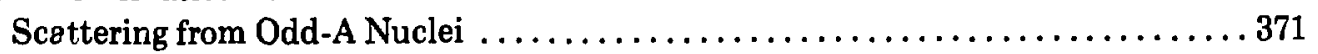

678 Study of the M1 Transition in ${ }^{48} \mathrm{Ca}$ by Inelastic Scattering

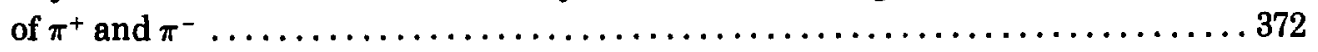

680 Angular Distributions for ${ }^{24,26} \mathrm{Mg}\left(\pi^{+}, \pi^{-}\right)^{24,26} \mathrm{Si} \ldots \ldots \ldots \ldots \ldots \ldots \ldots \ldots \ldots \ldots \ldots \ldots \ldots$

681 Measurements of Large-Angle Pion-Nucleus Scattering with EPICS . . . . . . . . . 374

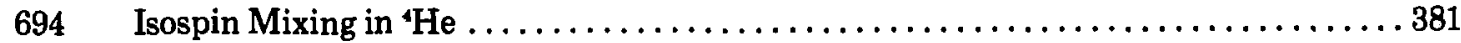

696 The Angular Distribution Anomaly in Pion Double Charge Exchange . . . . . . . . . . 382

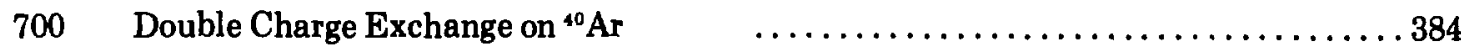

701 Pion Double Change Exchange on Self-Conjugate Nuclei . . . . . . . . . . . . 384

702 Nuclear Structure Effects in Pion Scattering From ${ }^{92-100}$ Mo . . . . . . . . . . 385

703 Study of M4 Strength in ${ }^{15} \mathrm{~N}$ by $\pi^{+}$and $\pi^{-}$Inelastic Scattering $\ldots \ldots \ldots \ldots \ldots$

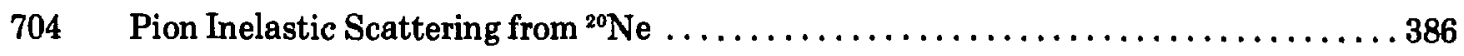

716 Pion Double Charge Exchange on Heavy Nuclei $\ldots \ldots \ldots \ldots \ldots \ldots \ldots \ldots \ldots \ldots 2$ 
723 Measurement of the Neutron and Proton Contributions to Excited States in ${ }^{30} \mathrm{~K}$ by $\pi^{+}$and $\pi^{-}$Inelastic Scattering 
4 Large-Angle Elastic Scattering of Protons from Helium and the Quasi-Elastic Knockout of Alpha Particles by $800-\mathrm{MeV}$ Protons ................ 2

5 Inelastic Scattering of $800-\mathrm{MeV}$ Protons from Nuclei to Study

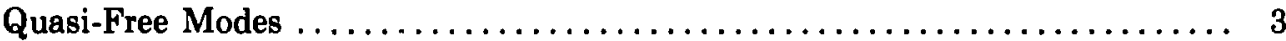

$6 \quad$ Study of $n-p$ and $p-p$ Correlations in Nuclei $\ldots \ldots \ldots \ldots \ldots \ldots \ldots \ldots \ldots \ldots$

10 Search for $(p, \pi)$ Reactions with HRS $\ldots \ldots \ldots \ldots \ldots \ldots \ldots \ldots \ldots \ldots \ldots$

15 Elastic Scattering and Total Cross-Section Measurements of Proton on

Hydrogen, Deuterium, and Helium $\ldots \ldots \ldots \ldots \ldots \ldots \ldots \ldots \ldots \ldots \ldots$

49 Elastic and Inelastic Proton Scattering from the Nickel Isotopes and from ${ }^{*} Y \ldots 31$

59 High-Resolution Study of the Boson Mass Region,

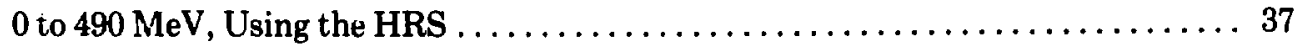

$73(\mathrm{p}, 2 \mathrm{p})$ Experiments Using Laminated Solid-State Detectors .............. 46

109 The Study of the Microscopic Structure of Collective Modes by

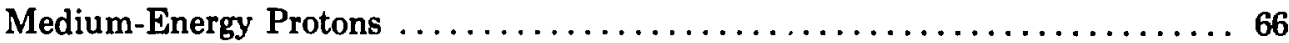

117 High-Resolution Study of the Neutron Pickup Reactions $\ldots \ldots \ldots \ldots \ldots \ldots \ldots \ldots 1$

138 Inelastic Proton Scattering and Excitation of States of Intermediate

Collectivity in Open-Shell Nuclei $\ldots \ldots \ldots \ldots \ldots \ldots \ldots \ldots \ldots \ldots \ldots \ldots \ldots . \ldots 3$

139 Preliminary Proton-Scattering Survey with HRS $\ldots \ldots \ldots \ldots \ldots \ldots \ldots \ldots \ldots . .84$

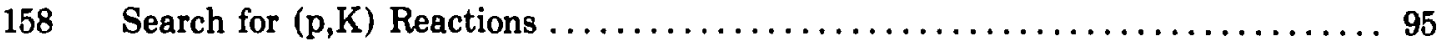

177 Quasi-Elastic Knockout of Alpha Particles by Medium-Energy Protons ........ 107

178 Proton-Scattering Survey on s-d Shell Nuclei $\ldots \ldots \ldots \ldots \ldots \ldots \ldots \ldots \ldots \ldots$

183 Proton-Scattering Survey on Heavy Deformed Nuclei . . . . . . . . . . . . . 110

202 The $(\mathrm{p}, \mathrm{t})$ Reaction on Spherical Nuclei $\ldots \ldots \ldots \ldots \ldots \ldots \ldots \ldots \ldots \ldots \ldots$

204 Excitation and Asymmetry Measurement of $T \approx 1$, High-Spin, Nonnormal-Parity "Particle-Hole" State by $(p, p$ ') Scattering in the

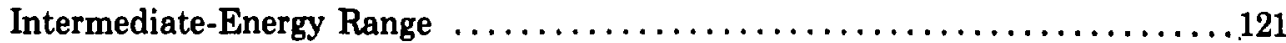




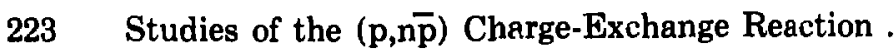
129

227 (p,n) Reaction Studies on Light Nuclei

233 Search for $\delta$ Configurations in Nuclei

249 The $\left(\mathrm{p}, \pi^{+}\right)$Reaction on ${ }^{4} \mathrm{He}$ with $800-\mathrm{MeV}$ Protons .

256 I. $p$-Nucleus Elastic Scattering at $q^{2}={ }^{8} B e, C$, and the Study of $p$-Nucleus Interactions in Co and $A u$ up to $\mathrm{m}^{*}=\mathrm{q}^{2} / 2 \nu \cong 20 \ldots \ldots \ldots \ldots \ldots \ldots \ldots \ldots$

257 II. Inclusive $\left(180^{\circ}\right)$ Production of Neutrons in High-q ${ }^{2}$-Nucleus Collisions

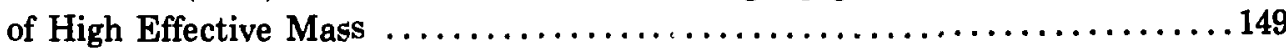

258 Study of Mechanisms for Ejection of $\Delta \mathrm{C}$ High-Momentum Particles from Nuclei by Study of the Coincidence Spectrum in $p+A \rightarrow(p, d, t)+(p, d, \hat{\imath})+X \ldots 149$

260 Determination of Neutron Density Distributions from Elastic Proton Scattering

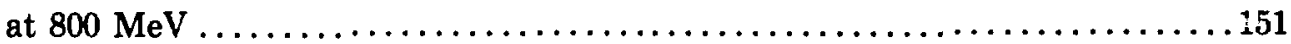

261 Intermediate Energy (p,d) Reaction Mechanism Studies 152

280 Measurement of Forward-Scattering Cross Section in p-p and p-d Elastic Scattering between $500-800 \mathrm{MeV}$

306 Forward-Angle Analyzing Power and Backward-Angle Differential Cross-Section Measurements of Collective-State Excitations by Intermediate-Energy Protons 175

307 Polarization in p- ${ }^{4} \mathrm{He}$ Elastic Scattering at $800 \mathrm{MeV} \ldots \ldots \ldots \ldots \ldots \ldots \ldots \ldots$

$311 \quad$ Elastic-Scattering Survey Using Polarized Protons $\ldots \ldots \ldots \ldots \ldots \ldots \ldots \ldots \ldots$

343 High-Spin States in Medium-Energy Proton Inelastic Scattering . . . . . . . . 196

345 Study of the Structure Function and the Connection between Elastic and Inelastic Cross Section at Large $t$ in the $p$ - ${ }^{4}$ He Interaction .............. 197

346 Study of High-Momentum Components in Nuclei Using a Polarized

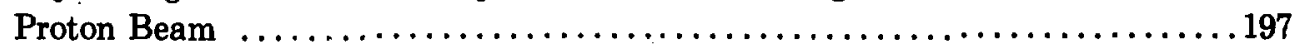

347 Search for "Orbit-Flip" States by Inelastic Proton Scattering .............. 198

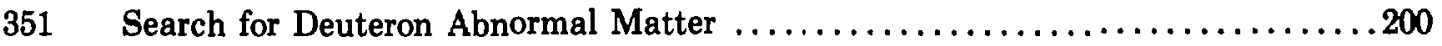

352 Determination of Neutron Mass Distributions from Proton Measurements $[P(t)$ and $d \sigma / d t]$ in Isotopes on the Calcium Region $\ldots \ldots \ldots \ldots \ldots \ldots \ldots . \ldots 201$

353 Proton Elastic and Inelastic Scattering at $\sim 600 \mathrm{MeV}$ .201 
355 Further Elastic-Scattering Cross Section and Analyzing Power Measurements

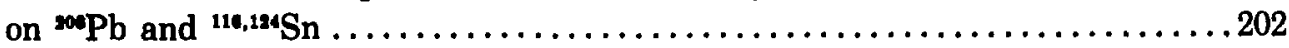

356 Analyzing Power and Cross-Section Measurements for Inelastic Proton

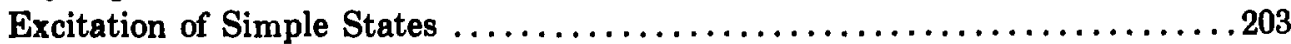

359 Asymmetry Nieasurements of the $\left(p, \pi^{+}\right)$Reaction on Light Targets at $T_{p}=800 \mathrm{MeV}$ and $T_{p}=650 \mathrm{MeV}$

361 Cross-Section and Asymmetry Measurements for the Reactions ${ }^{2} \mathrm{H}\left(\overrightarrow{\mathrm{p}}, \boldsymbol{\pi}^{+}\right)^{2} \mathrm{H}$

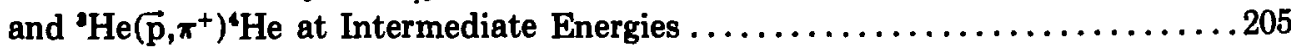

362 Study of Quasi-Free $(p, 2 p)$ Reactions at $800 \mathrm{MeV}$ with Use of Unpolarized

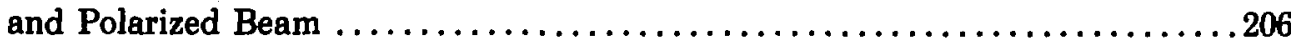

365 Comparison of Density Distributions of ${ }^{207} \mathrm{~Pb},{ }^{200} \mathrm{~Pb}$, and ${ }^{200} \mathrm{Bi}$ .207

367 Study of High-Spin States by the $\left(p,{ }^{\prime} \mathrm{He}\right)$ Reaction $\ldots \ldots \ldots \ldots \ldots \ldots \ldots \ldots$

376 Large-Angle Elastic Scattering on ${ }^{10} \mathrm{Ca}$ by Medium-Energy Protons ............ 214

385 Measurement of the $\vec{p}+n$ Analyzing Power, $A_{y}(\theta)$, from $\theta_{c . m .}, 10-70^{\circ} \ldots \ldots \ldots 218$

386 Total Reaction Cross Sections for $\mathbf{P}^{+}$Nuclei at $800 \mathrm{MeV} \ldots \ldots \ldots \ldots \ldots \ldots \ldots . \ldots 219$

392 A Measurement of the Triple-Scattering Parameters D, R, A, R', and A' for Proton-Proton and Proton-Neutron Scattering at $800 \mathrm{MeV} \ldots \ldots \ldots \ldots \ldots \ldots 223$

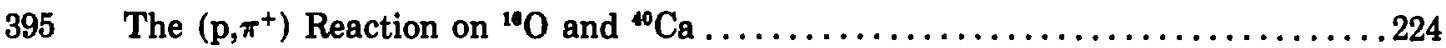

397 A Measurement of the Triple-Scattering Parameters $R, A, R^{\prime}$, and $A^{\prime}$ for

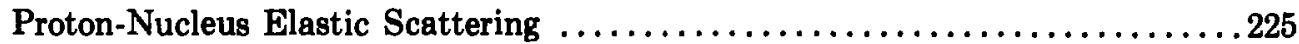

398 A Systematic Study of Isotopic (Isotonic) Dependence of the Neutron-Matter

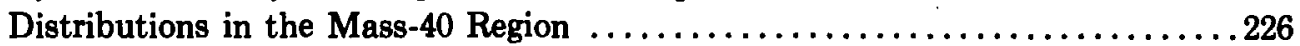

399 Excitation of Giant Multipole Resonances by $200-$ to $400-\mathrm{MeV}$ Protons ........226

405 The $\left(\mathrm{p}, \pi^{-}\right)$Reaction on ${ }^{19} \mathrm{C}$ and ${ }^{11} \mathrm{C}$

411 Measurement of Spin-Flip Probabilities in Proton Inelastic Scattering at $800 \mathrm{MeV}$ and Search for Collective Spin-Flip Modes, Preliminary Survey .... 233

$(p, p)$ and $\left(p, p^{\prime}\right)$ on Potassium and Titanium $\ldots \ldots \ldots \ldots \ldots \ldots \ldots \ldots \ldots \ldots$ 
431 Cross Section and Analyzing Power for Inelastic Proton Excitation of

Unnatural Parity States in ${ }^{\circ} \mathrm{Li},{ }^{12} \mathrm{C},{ }^{14} \mathrm{~N}$, and ${ }^{10} \mathrm{O}$

432 Cross Section for Excitation of Unnatural Parity States in ${ }^{12} \mathrm{C}$ at $\mathrm{E}_{\mathrm{p}}<800 \mathrm{MeV} .243$

433 Elastic-Scattering Differential Cross Sections and Analyzing Powers for $\overrightarrow{\mathrm{p}}+{ }^{40,40} \mathrm{Ca},{ }^{\infty} \mathrm{Zr}$, and ${ }^{200} \mathrm{~Pb}$ at $\sim 400 \mathrm{MeV}$

434 The $\left(\mathrm{p}, \pi^{+}\right)$Reactions on ${ }^{12} \mathrm{C},{ }^{10} \mathrm{O}$, and ${ }^{\circ 0} \mathrm{Ca}$ around $650 \mathrm{MeV}$

438 The (p,d) Reactions on ${ }^{12,18} \mathrm{C},{ }^{7} \mathrm{Li},{ }^{10} \mathrm{O},{ }^{26} \mathrm{Mg},{ }^{20} \mathrm{Si}$, and ${ }^{{ }^{\circ}} \mathrm{Cu}$ between 650 and $800 \mathrm{MeV}$

443 The Energy Dependence in the $(p, \pi)$ Reaction on ${ }^{12} \mathrm{C}$ 249

450 Preliminary Cross-Section Measurements for the (p,t) Reaction at $400 \mathrm{MeV} \ldots \ldots 253$

451 Inelastic Proton Scattering in the Range 300 to $500 \mathrm{MeV}$ 253

461 Elastic and Inelastic Scattering of $800-\mathrm{MeV}$ Protons from ${ }^{11} \mathrm{O}$ 258

462 Analyzing Power and Differential Cross Sections for the Reactions $p+\rightarrow d+\pi^{+}$and $p+d \rightarrow t+\pi^{+}$at $\sim 600$ and $400 \mathrm{MeV}$

471 Study of the ${ }^{\circ 0} \mathrm{Zr}$ and ${ }^{200} \mathrm{~Pb}(\mathrm{p}, \mathrm{d})$ Reactions at $\sim 500 \mathrm{MeV}$

472 Study of the (p,d) Reaction on ${ }^{\infty} \mathrm{Zr},{ }^{140} \mathrm{Ce}$, and ${ }^{200} \mathrm{~Pb}$ at $800 \mathrm{MeV}$ 264

473 Study of Giant Multipole Resonances with $800-\mathrm{MeV}$ Protons

474 A Measurement of Spin-Dependent Effects in $p+d$ Elastic and Inelastic Scattering .265

476 The Analyzing Power for $\vec{p}+{ }^{24,20} \mathrm{Mg}$ at 500 and $800 \mathrm{MeV}$ .266

477 Role of the $p+d \rightarrow d+\pi$ Interaction in Nucleon Transfer Reactions at

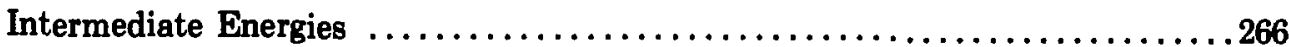

479 Measurement of R, A, R', and $A^{\prime}$ in Elastic and Inelastic Scattering of $800-\mathrm{MeV}$ Protons from Light Nuclei: Revised Version of "Q" Proposal ............. 267

485 The Energy Dependence in the $\left(p, \pi^{ \pm}\right)$Reactions .270 
Measurement of $\vec{p}-p$ and $\vec{p}-d$ Elastic Scattering in the Coulomb Interference

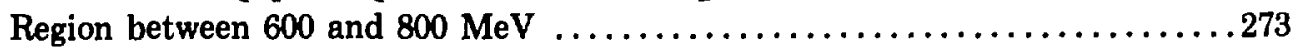

A Search for Energy-Dependent Structure in the Spin Dependence of

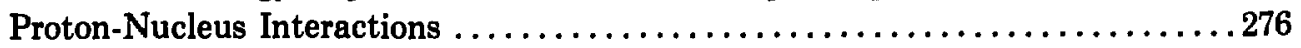

Measurement of Differential Elastic Cross Section and Polarization for p-Nucleus Scattering in the Coulomb Interference Region.....................279

502 Measurement of $\mathrm{C}_{11}$ in the Coulomb Interference Region ................279

$503 \quad$ Masses of ${ }^{41} \mathrm{Ti}$ and ${ }^{80} \mathrm{Zn}$ by $\left(\mathrm{p}, \pi^{-}\right)$Reaction

508 Dibaryon Resonances in Pion Production

519 Study of the Reaction $p(p o l)+d \rightarrow(p, \pi)+X$ to Measure the Analyzing Power and Structure Function for Backward Particles ....................286

520 Study of the Reaction $\mathrm{p}($ Polarized $)+\left({ }^{2} \mathrm{He},{ }^{4} \mathrm{He}\right) \rightarrow(\mathrm{p}, \mathrm{d}, \pi .)+.\mathrm{X}$ to Measure the Analyzing Power and Structure Functions for Backward Particles .........288

532 Measurements of Cross Sections and Analyzing Power in the $(p, 2 p)$ Reaction of Deuterium

533 The Asymmetry in the $(p, \pi)$ Reaction on ${ }^{\circ} \mathrm{Li}$ at $800 \mathrm{MeV}$

534 Measurement of $\bar{p}-p$ and $\bar{p}-d$ Elastic Scattering in the Coulomb Interference Region Between 500 and $800 \mathrm{MeV}$

535 A Study of the Relation Between the $(p, d)$ and $(\pi, p)$ Reaction in a Pion Exchange Model

538 Analyzing Power and Cross-Section Measurements of the

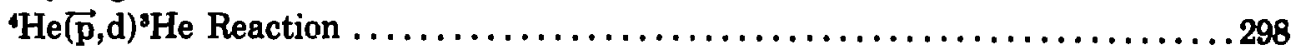

540 Elastic Scattering from Light Nuclei 299

556 A Proposal to Study the ( $\left.p, p^{\prime}\right)$ Process Leading to $\pi$-Atomic States 
566 Inelastic p-p an p-d Cross Sections at $800 \mathrm{MeV}-$

A Search for Narrow Excited States

574 Polarized Proton Scattering from ${ }^{\circ} \mathrm{Ar}$

575 Polarized Proton Scattering From $\mathrm{N}=28$ Nuclei

580 Cross Sections and Analyzing Powers for Elastic and

Inelastic Scattering of $515-\mathrm{MeV}$ Protons from ${ }^{19} \mathrm{C}$

583 Measurement of $\mathrm{C}_{\ell \ell}$ in the Coulomb Interference Region

585 Measurement of $\vec{p}-p)$ and $\vec{p}-d$ Elastic Scattering in the

Coulomb Interference Region Between 500 and $800 \mathrm{MeV}$

593 Measurement of the Spin Rotation and Depolarization

Parameters in the ${ }^{12} \mathrm{C}\left(\mathrm{p}, \mathrm{p}^{\prime}\right)$ Reaction to the

$1^{+} 12.72 \mathrm{MeV} \mathrm{T} \approx 0$

and to the $1^{+} 15.11 \mathrm{MeV} \mathrm{T}=1$ Levels

613 Study of Deeply Bound Hole States in the Tin Isotopes

Via the $(\overline{\mathrm{p}}, \mathrm{d})$ Reaction

616 Nuclear Information from the Spin Rotation and Depolarization

Parameters in the ${ }^{12} \mathrm{C}\left(\mathrm{p}, \mathrm{p}^{\prime}\right)$ Reaction to the $1^{+} 12.72 \mathrm{MeV} \mathrm{T} \approx 0$ and

to the $1^{+} 15.11 \mathrm{MeVT} \approx 1$ Levels

623 Measurement of Cross Section, Analyzing Power and Depolarization

Parameters in the ${ }^{28} \mathrm{Si}\left(\mathrm{p}, \mathrm{p}^{\prime}\right)^{28} \mathrm{Si}^{*}\left(6^{-} \mathrm{T} \approx 0\right.$ and $\left.\mathrm{T} \approx 1\right)$ Reaction at $400 \mathrm{MeV}$

624 An Attempt to Observe Directly the Coupling of Particle Hole

States to $\Delta$-Hole States

626 Measurement of the Depolarization Parameters $D_{n n}, D_{l_{n n}}$,

and $D_{\mathbf{u s}^{\prime}}$ in Proton-Nucleus Scattering at Very High

Excitation Energies

627 Measurement of the Relative Sign of Neutron and Proton

Transition Matrix Elements in $\left(p, p^{\prime}\right)$ R eactions $\ldots \ldots \ldots \ldots \ldots \ldots \ldots \ldots \ldots \ldots$

630 A Study of Proton Inelastic Scattering at Zero Degrees

and a Search for Giant Monopole and Giant Magnetic

Dipole Excitations

631 Study of the Spin-Flip Probabilaity for Elastic and Inelastic

Scattering from Odd-Mass Nuclei 
632 Can Proton Density Differences be Extracted from Medium

Energy p-Nucleus Elastic Scattering Data?

641 Measurement of Cross Section and Analyzing Powers for Elastic and Inelastic Scattering of 400 to 500 Protons from ${ }^{14} \mathrm{C} \ldots \ldots \ldots \ldots \ldots \ldots 3 . \ldots \ldots \ldots$

642 Reactive Content of the Optical Potential-Phase II

643 Structure of States in the Oxygen Isotopes via Measurements

of the Spin Depolarization and

Spin Rotation Observables

644 Tests of the Polarization-Analyzing Power Equality

in Elastic Scattering of Intermediate Energy Protons from Nuclei

649 Asymmetry Measurements of the (p, $\pi^{ \pm}$Reactions on ${ }^{8} \mathrm{Li}$ and ${ }^{\circ} \mathrm{Be}$ at $650 \mathrm{MeV}$

654 Measurement of the Spin-Rotation Parameters $Q$ for $800 \mathrm{MeV} \mathrm{p}+{ }^{16} \mathrm{O}$,

${ }^{40} \mathrm{Ca}$ and ${ }^{208} \mathrm{~Pb}$ Elastic Scattering

658 Study of the Spin-Flip Probability for Elastic and Inelastic Scattering from Odd-Mass Nuclei . . . . . . . . . . . . . . . . . . . . . . . . . . . 361

660 Measurement of Polarization Parameters for M1 Transitions in the ${ }^{80} \mathrm{Zr}\left(\mathrm{p}, \mathrm{p}^{\prime}\right)^{90} \mathrm{Zr}^{*}$ and ${ }^{116} \mathrm{Sn}\left(\mathrm{p}, \mathrm{p}^{\prime}\right)^{110} \mathrm{Sn}^{*}$ Reactions at $500 \mathrm{MeV} \ldots \ldots \ldots \ldots \ldots . \ldots 363$

663

Elastic Scattering of Polarized Protons from ${ }^{3} \mathrm{H}$ and ${ }^{3} \mathrm{He}$ at Intermediate Energies

666

The ${ }^{12} \mathrm{C}\left(\mathrm{p}, \mathrm{p}^{\prime} \pi\right)^{12} \mathrm{C}^{*}$ Reaction and the Search for Coherent

Isobar-Hole Resonances

669 Investigation of the $\mathrm{N}=28$ Neutron Shell Closure by Elastic

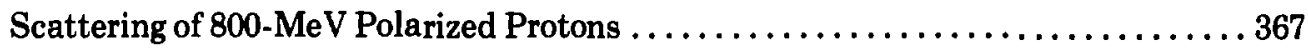

670 Continuation of Giant Resonance Studies at HRS

684 Polarization Effects in the Deuteron Production by Proton-

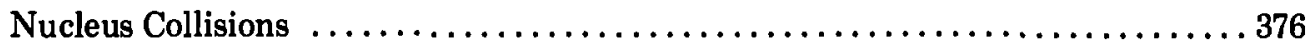

685 Spin Correlation in the Reaction $\vec{p}(\overrightarrow{\mathrm{d}}, \mathrm{d}) \mathrm{p} \overrightarrow{\mathrm{p}}$ at $500 \mathrm{MeV}$

686 Determination of Neutron Transition Densities in ${ }^{10} \mathrm{O}$ and ${ }^{208} \mathrm{~Pb}$ by Inelastic Scattering of $\sim 400 \mathrm{MeV}$ Protons 
687 Measurement of the Spin Rotation Parameters in ${ }^{200} \mathrm{~Pb}$ and in ${ }^{10} \mathrm{Ca}$ at $400 \mathrm{MeV}$

699 Measurements of Spin Flip and Depolarization Parameters for ${ }^{88} \mathrm{Ni}\left(\mathrm{p}, \mathrm{p}^{\prime}\right)^{\mathrm{ss}} \mathrm{Ni}^{*}\left(6^{+}, \mathrm{T}=0\right)-\mathrm{A}$ Test of the Spin-Orbit Force in Nuclei at $500 \mathrm{MeV}$.

709 Measurements of $A_{n n}, A_{a n}$, and $A_{\text {sl }}$ in the Coulomb Interference Region at 650 and $800 \mathrm{MeV}$

710 A Measurement of the Triple Scattering Parameters $\mathrm{D}, \mathrm{R}, \mathrm{A}, \mathrm{R}^{\prime}$, and $\mathrm{A}^{\prime}$ for Quasi-Elastic Scattering at $800 \mathrm{MeV}$

711 Reactive Content of the Optical Potential at $500 \mathrm{MeV}$

712 Inelastic Proton Scattering on ${ }^{48} \mathrm{Ca}$ and ${ }^{50} \mathrm{Ti}$ :

An Attempt to Identify Mesonic Effects as the Cause of M1 Quenching .

713 M1's, Deltas, and Medium Effects in Cross Sections for ${ }^{84} \mathrm{Sn}\left(\mathrm{p}, \mathrm{p}^{\prime}\right)^{80} \mathrm{Sr}^{*}$ at $400 \mathrm{MeV}$

714 A Search for the Giant Isovector Monopole Resonance in Inelastic Proton Scattering at Zero Degrees

718 Energy Dependence of the Two-Nucleon Effective Interaction

720 Recoilless Delta Production in the Reaction ${ }^{13} \mathrm{C}(\mathrm{p}, \mathrm{d}){ }^{12} \mathrm{C} \Delta$ 395

721 Measurement of the Proton Polarization Observables in the ${ }^{7} \mathrm{Li}\left(\overrightarrow{\mathrm{p}}, \overrightarrow{\mathrm{p}}^{\prime}\right)^{7} \mathbf{L i}$ and the Test of the Reaction Theory at Intermediate Energies

722 Measurement of Cross Sections and Analyzing Powers

For Elastic and Inelastic Scattering of 400- to 500-MeV Protons From ${ }^{14} \mathrm{C}$

729 Radiative Capture of Polarized Protons by Deuterons at 500 to $800 \mathrm{MeV}$ 
184 Production of "Sr

210 Isotope Production Facility Irradiation Vanadium, Molybdenum, and Lanthanum Targets

211 Neutron Irradiation of Copper Single Crystals 124

253 Neutron Irradiation of Metal Samples for Use in Position Annihilation Studies of Defects

267 Preparation of Radioisotopes for Medicine and the Physical Sciences Using LAMPF Isotope Production Facility .156

383 Nickel Irradiation with Protons and Neutrons 217

554 Irradiation of Technologically Important Metals with $800-\mathrm{MeV}$ Protons Using the Isotope Production Facility at LAMPF

725 The Effect of Rare Earth Additions on Radiation Damage in Alloy HT-9 (Ferritic/Martensitic Alloy Steel) 397 


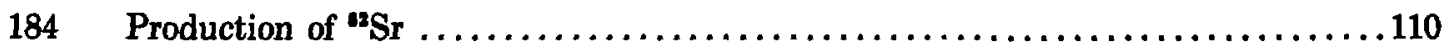




\section{LOW-ENERGY PION (LEP)}

1 Rare Decay Modes of the Neutral Pion

2 Total Pion Cross Sections $\ldots \ldots \ldots \ldots \ldots \ldots \ldots \ldots \ldots \ldots \ldots \ldots \ldots \ldots \ldots \ldots$

8 Precision Measurement of Soft X Rays from Muonic and Pionic Atoms ....... 5

25 Pion Double-Charge-Exchange Reactions $\ldots \ldots \ldots \ldots \ldots \ldots \ldots \ldots \ldots \ldots \ldots$

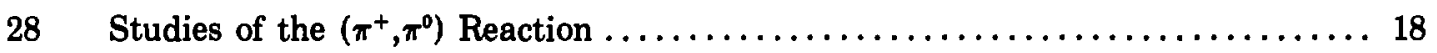

29 Elastic Scattering of $\pi^{+}$and $\pi^{-}$at $10-30 \mathrm{MeV} \ldots \ldots \ldots \ldots \ldots \ldots \ldots \ldots$

35 Cluster Effects in Nuclear Pion Capture $\ldots \ldots \ldots \ldots \ldots \ldots \ldots \ldots \ldots \ldots \ldots \ldots$

$50 \quad$ Radiative Pion Capture in Light Nuclei $\ldots \ldots \ldots \ldots \ldots \ldots \ldots \ldots \ldots \ldots \ldots \ldots$

54 Elastic Scattering of Mesons in the Energy Range $20-60 \mathrm{MeV} \ldots \ldots \ldots \ldots \ldots 34$

67 Development of Pion Beam-Monitoring Techniques $\ldots \ldots \ldots \ldots \ldots \ldots \ldots \ldots \ldots 43$

78 Proton Beam Monitor $\ldots \ldots \ldots \ldots \ldots \ldots \ldots \ldots \ldots \ldots \ldots \ldots \ldots \ldots \ldots$

79 Calibration of the Pion Beam Transport Systems and a Pion Beam Monitor .... 49

96 Scattering of $20-40 \mathrm{MeV} \pi^{ \pm}$by Hydrogen and Deuterium $\ldots \ldots \ldots \ldots \ldots \ldots$

102 Excitation Functions and Angular Distribution Recoil Studies of Simple

Pion-Induced Nuclear Reactions $\ldots \ldots \ldots \ldots \ldots \ldots \ldots \ldots \ldots \ldots \ldots \ldots \ldots$

121 Interaction of Stopped Negative Pions with Complex Nuclei $\ldots \ldots \ldots \ldots \ldots$

122 Pionic-Atom X Rays and Nuclear Distributions $\ldots \ldots \ldots \ldots \ldots \ldots \ldots \ldots \ldots . \ldots$

131 A Study of the $\pi^{+}+\mathrm{d} \rightarrow \mathrm{p}+\mathrm{p}$ Reaction at Pion Energies $10-60 \mathrm{MeV} \ldots \ldots . .79$

140 Study of the $\left(\pi^{ \pm}, \mathrm{d}\right)$ Reaction with an Intrinsic Germanium Detector $\ldots \ldots \ldots . .85$

144 Search for the C-Violating Decay $\pi^{0}+3 \gamma \ldots \ldots \ldots \ldots \ldots \ldots \ldots \ldots \ldots$

162 Studies of the $\left(\pi^{+}, \pi^{0}\right)$ Reaction on Light Elements $\ldots \ldots \ldots \ldots \ldots \ldots \ldots \ldots$

164 Pion Total Cross-Section Measurements with an Oriented ${ }^{165} \mathrm{Ho}$ Target ....... 100

170 Study of the Reaction ${ }^{10} \mathrm{C}\left(\pi^{+}, \pi^{0}\right)^{10} \mathrm{~N}$ (Ground State) $\ldots \ldots \ldots \ldots \ldots \ldots \ldots \ldots$ 
180 Elastic and Inelastic $\pi^{+}-$Nucleus Scattering at 25,50 , and $75 \mathrm{MeV}$ .109

181 Measurements of the $\pi^{-} p \rightarrow \pi^{0} n$ Angular Distribution at Low Energies and Calibration of the $\pi^{0}$ Spectrometer

182 Short-Lived Radioactivities from Pion Bombardment 110

190 A Precision Measurement of the $\pi^{-}-\pi \pi^{0}$ Mass Difference ...............114

$191 \pi^{+}$-Nucleus Inelastic Scattering to Giant Resonances $\ldots \ldots \ldots \ldots \ldots \ldots \ldots \ldots 114$

209 Pion Interactions in Nuclear Emulsions $\ldots \ldots \ldots \ldots \ldots \ldots \ldots \ldots \ldots \ldots \ldots \ldots \ldots \ldots$

234 A Study of the Inelastic Pion-Scattering Reaction at Pion Energies $10-100 \mathrm{MeV}$

247 Distributions of Products from Interactions of Stopped $\pi^{-}$with Several

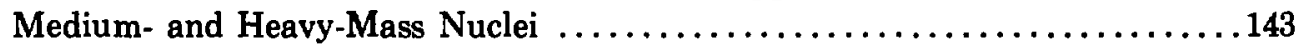

284 Measurement of the ${ }^{8} \mathrm{He}\left(\pi^{-}, \pi^{0}\right)^{2} \mathrm{H}$ Angular Distribution .164

293 Study of the Dominant Reaction Modes for Pions Interacting with

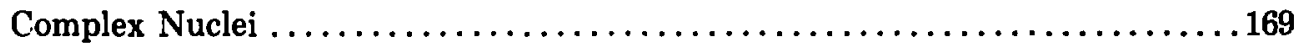

295 Study of the Pion-Deuteron Single-Charge-Exchange Reaction $D\left(\pi^{-}, \pi^{0}\right) 2 n \ldots 170$

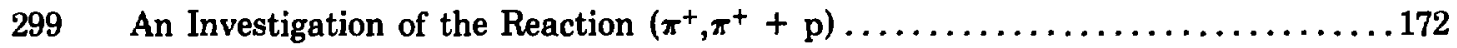

303 A Survey of Pion Single-Charge-Exchange Scattering Using Back-Angle Gamma Spectroscopy ............................. 174

315 High-Resolution Study of $\left(\pi^{+}, 2 \mathrm{p}\right)$ Reaction $\ldots \ldots \ldots \ldots \ldots \ldots \ldots \ldots \ldots \ldots \ldots$

$316 \pi^{-}$-Nucleus Elastic Scattering between 20 and $50 \mathrm{MeV} \ldots \ldots \ldots \ldots \ldots \ldots \ldots$

318 Excitation of Single-Particle States in Nuclei by Low-Energy Inelastic

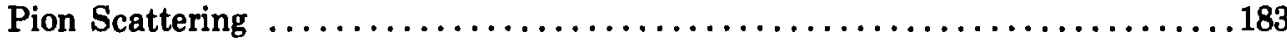

320 A Comparison of $\left(\pi^{+}, \mathbf{x n}\right)$ and $\left(\pi^{-}, \mathbf{x n}\right)$ Reactions .184

322 Systematic Study of Pion-Nucleus Inelastic Scattering at Energies below $100 \mathrm{MeV}$

324 Precision Measurement of Ratios of Certain Light Element Pion Excitation Functions . . . . . . . . . . . . . . . . . . . . . . . . . . . . . . . 186

$333 \pi^{ \pm}$-Nuclear Elastic Scattering at Energies between 50 to $100 \mathrm{MeV}$

348 Study of Giant Resonances with Radiative Pion Capture on Medium-Z Nuclei at LEP 
Sub-Coulomb $\pi^{+}$Elastic Scattering and $\left(\pi^{+}, \mathrm{p}\right)$ Reactions ${ }^{204} \mathrm{~Pb}$ at

$\mathrm{E}_{\pi}=7-12 \mathrm{MeV}$

372 Stopping Power of $\pi^{ \pm}$at Energies below $100 \mathrm{MeV}$

388 Low-Energy Pion Elastic Scattering from the Proton and Deuteron at $180^{\circ}$

393 Angular Distribution Measurements of the Pion Single-Charge-Exchange

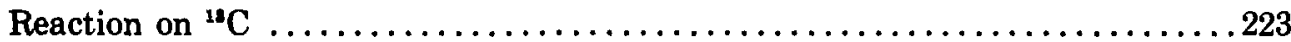

401 Study of the Isobaric Analog Charge-Exchange Reaction ${ }^{15} \mathrm{~N}\left(\pi^{+}, \pi^{0}\right)^{16} \mathrm{O}$

412 Search for Analog State Transitions in $\left(\pi^{+}, \pi^{0}\right)$ Reactions on ${ }^{7} \mathrm{Li},{ }^{27} \mathrm{Al},{ }^{90} \mathrm{Zr},{ }^{120} \mathrm{Sn}$, and ${ }^{200} \mathrm{~Pb}$ and for Collective Isovector States in the $\left(\pi^{-}, \pi^{\circ}\right)$ Reaction on ${ }^{\circ 0} \mathrm{Zr} \ldots 233$

415 Two-Nucleon-Out Products from Stopped $\pi^{-}$Interactions .235

441 The ${ }^{12} \mathrm{C}\left(\mathrm{p}, \mathrm{K}^{+}\right){ }_{\Lambda}^{18} \mathrm{C}$ Reaction at $800 \mathrm{MeV}$ 248

Radiochemical Study of Pion Single Charge Exchange .259

483 Measurement of the Angular Dependence of Tensor Polarization in the ${ }^{2} \mathrm{H}\left(\pi^{+}, \pi^{+}\right)^{2} \overrightarrow{\mathrm{H}}$ Reaction

523 Study of the ${ }^{14} \mathrm{C}\left(\pi^{+}, \pi^{0}\right)^{14} \mathrm{~N}$ Reaction

524 Study of the Isovector Terms in $\pi$-Nucleus Interactions with $\left(\pi^{+}, \pi^{0}\right)$ Reactions on ${ }^{10,42,44,48} \mathrm{Ca}$ and ${ }^{112,118,124} \mathrm{Sn}$.

525 Excitation of Isovector Transitions with Pion Single Charge Exchange on ${ }^{12} \mathrm{C} \ldots . .291$

527 Study of the ${ }^{10} \mathrm{~B}\left(\pi^{-}, \pi^{0}\right)^{10} \mathrm{Be}$ Reaction

536 Efficiency Measurements for the $\pi^{+}$Identification

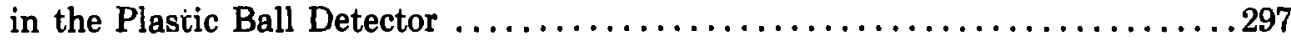

541 A Search for Nuclear Critical Opalescence Using the

Reaction ${ }^{40} \mathrm{Ca}\left(\pi^{+}, 2 \gamma\right)$

$544 \quad$ Search for a Fast Fission Process .301

553 Study of Target Thickness Effects in the Cross-Section

Measurement of the Pion Single-Charge-Exchange Reaction ${ }^{19} \mathrm{C}\left(\pi^{+}, \pi^{0}\right){ }^{18} \mathrm{~N}$ (g.s) from 50 to $350 \mathrm{MeV}$ .305

$561 \pi^{ \pm}-$Nuclear Elastic Scattering at Energies Between 30 and $80 \mathrm{MeV}$ 309 
576 Study of the $\left(\pi^{+}, 2 \mathrm{p}\right)$ and $\left(\pi^{ \pm}, \mathrm{pn}\right)$ Reactions on the Isotopic Pairs ${ }^{10} \mathrm{O}-{ }^{18} \mathrm{O}$ and ${ }^{10} \mathrm{Ca}-{ }^{10} \mathrm{Ca}$

596 An Experimental Test of Genralized Wheeler-Feynmann

Absorber Theory by Direct Observacion of

Muon-Neutrino Recoil

607 Study of Isovector Giant Resonances With Pion

Charge Exchange

611 Excitation Functions of the Four Reactions ${ }^{130} \mathrm{Te}\left(\pi^{ \pm}, \pi^{ \pm} \mathrm{N}\right)$

650 A Search for Neutrino Mixing via Nonexponential $\pi \rightarrow \mu \nu$ Decay 358

675 Nuclear Distributions from the Study of the 2P States of Pionic Atoms

676 Study of Pion Absorption on ${ }^{88} \mathrm{Ni}$ at $\mathrm{T}_{\pi}=160 \mathrm{MeV}$ 371

688 Study of the Mass and Energy Dependence of Low-Energy Pion

Single Charge Exchange

728 Study of Pion Charge-Exchange Mechanisms by Means of Activation Techniques 
Exp. No.

179 Differential Production Cross Sections of Multiply-Charged

Fragments in Proton- and Pion-Induced Spellation

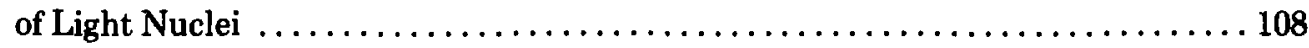


24 Search for Pulsed Extraterrestrial Neutrino Sources $\ldots \ldots \ldots \ldots \ldots \ldots \ldots \ldots \ldots$

31 A Neutrino Experiment to Test Muon Conservation $\ldots \ldots \ldots \ldots \ldots \ldots \ldots \ldots 20$

38 Neutrino Physics Program: Elastic-Scattering Test of Multiplicative Law, Inverse $\beta$ Decay $\ldots \ldots \ldots \ldots \ldots \ldots \ldots \ldots \ldots \ldots \ldots \ldots \ldots \ldots \ldots \ldots, 24$

53 Observation of the Electron Neutrino at LAMPF $\ldots \ldots \ldots \ldots \ldots \ldots \ldots \ldots \ldots$

148 Neutrino-Electron Elastic Scattering at LAMPF (A Feasibility Study) ........ 89

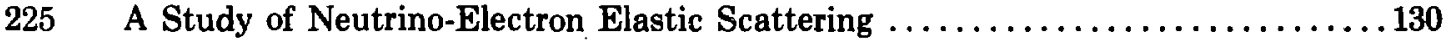

254 Feasibility Study for the Measurement of the Inelastic Neutrino-Scattering

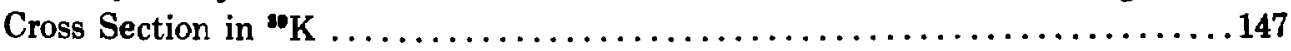

559 Search for Neutrino Oscillations and Violations of Lepton

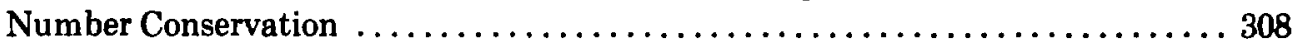

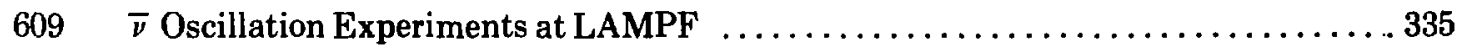

$638 \quad$ A Search for Oscillations Using Muon-Neutrinos ................... 351

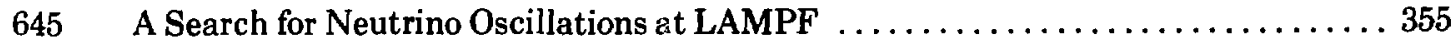

647 A Neutron Oscillation Experiment at LAMPF $\ldots \ldots \ldots \ldots \ldots \ldots \ldots \ldots \ldots \ldots \ldots \ldots \ldots$ 
32 Precision Measurement of the Processes $\pi^{ \pm} \rightarrow \pi^{0}+\mathrm{e}^{ \pm}+\nu \ldots \ldots \ldots \ldots \ldots \ldots 21$

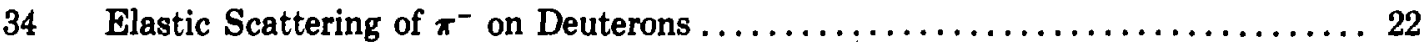

36 Radiative Pion Scattering from Hydrogen $\ldots \ldots \ldots \ldots \ldots \ldots \ldots \ldots \ldots \ldots \ldots$

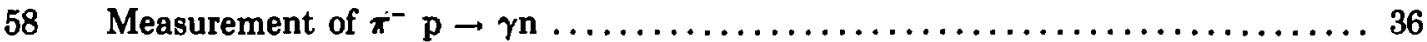

62 Studies of Gamma-Ray Spectra from Reactions Induced by Pions and Protons at LAMPF ..................................... 40

67 Development of Pion Beam-Monitoring Techniques $\ldots \ldots \ldots \ldots \ldots \ldots \ldots \ldots \ldots$

68 Precise Measurement of the Muon $g-2$ Value $\ldots \ldots \ldots \ldots \ldots \ldots \ldots \ldots \ldots$

79 Calibration of the Pion Beam Transport Systems and a Pion Beam Monitor ... 49

80 Forward Elastic Scattering of $\pi^{+}$and $\pi^{-12} \mathrm{C},{ }^{13} \mathrm{C},{ }^{10} \mathrm{O},{ }^{10} \mathrm{Ca}$, and ${ }^{200} \mathrm{~Pb} \ldots \ldots \ldots 1$

82 Investigation of Pion-Induced Reactions on Light Elements with Three Particles

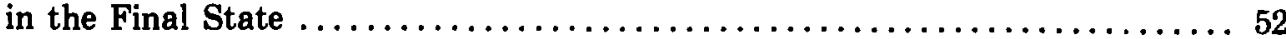

90 A Test of the Reversal Invariance in Single-Pion Photoproduction through a Study of Reciprocity in the Reactions $\boldsymbol{\pi}^{-3} \mathrm{He} \leftrightharpoons \gamma \mathrm{T}$ and $\boldsymbol{\pi}^{+} \mathrm{T} \leftrightharpoons{ }^{2} \mathrm{He} \gamma \ldots \ldots \ldots \ldots . \ldots 7$

91 Proton Polarization in Radiative $\pi$-Proton Scattering at $300 \mathrm{MeV} \ldots \ldots \ldots \ldots . \ldots 7$

93 Mechanism of $(\pi, \pi N)$ Reactions on Complex Nuclei $\ldots \ldots \ldots \ldots \ldots \ldots \ldots \ldots$

99 Measurement of the Cross Section for $\pi^{-}+p \rightarrow \pi^{-}+\pi^{+}+n$ with a Magnetic Spectrometer $\ldots \ldots \ldots \ldots \ldots \ldots \ldots \ldots \ldots \ldots \ldots \ldots \ldots \ldots \ldots \ldots$

102 Excitation Functions and Angular Distribution Recoil Studies of Simple Pion-Induced Nuclear Reactions . . . . . . . . . . . . . . . . . 64

103 Spallation Yield Distribuitions from Pion Interactions with Complex Nuclei . ... 64

104 Proposal for LAMPF Experiment: Studies of the Proton- and Pion-Induced Fission of Medium-Mass Nuclides $\ldots \ldots \ldots \ldots \ldots \ldots \ldots \ldots \ldots \ldots \ldots \ldots \ldots$

110 Below-Threshold Kaon Production Rates with the Pion Beam ........... 67

118 Fragment Emission from Pion Interactions with Complex Nuclei $\ldots \ldots \ldots \ldots \ldots 71$ 
119 Cross Sections of Simple Nuclear Reactions Indıced by Pi-Mesons

120 Measurement of the Polarization Asymmetry and the Differential Cross Section of Pion-Nucleon Charge Exchange from 160 to $500 \mathrm{MeV} \ldots \ldots \ldots \ldots \ldots \ldots 73$

121 Interaction of Stopped Negative Pions with Complex Nuclei $\ldots \ldots \ldots \ldots \ldots \ldots 73$

123 Nuclear Structure Effects in Pion-Induced Nuclear Reactions . . . . . . . . 75

132 Measurements of "P," "R," and "A" Parameters in $\pi^{ \pm}-p$ Elastic Scattering ...... 80

144 Search for the C-Violating Decay $\pi^{0}+3 \gamma \ldots \ldots \ldots \ldots \ldots \ldots \ldots \ldots \ldots \ldots$

153 Investigation of Nuclear Gamma Rays Resulting from In-Flight Pion and

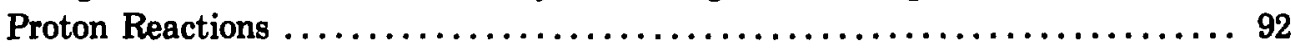

154 Elastic Scattering of $\pi^{+}$and $\pi^{-}$from the Helium Isotopes $\ldots \ldots \ldots \ldots \ldots \ldots$

195 Nuclear Resonance Effect in Pionic Atoms $\ldots \ldots \ldots \ldots \ldots \ldots \ldots \ldots \ldots \ldots \ldots$

201 The $\pi^{+} \mathrm{d} \rightarrow 2 \mathrm{p}$ Reaction at $100-500 \mathrm{MeV} \ldots \ldots \ldots \ldots \ldots \ldots \ldots \ldots \ldots \ldots \ldots$

214 Pionic X-Ray Absolute Yields as a Function of $\mathrm{Z} \ldots \ldots \ldots \ldots \ldots \ldots \ldots \ldots$

221 Precision Measurement of the Decay Rate for the Dalitz Decay Mode of the

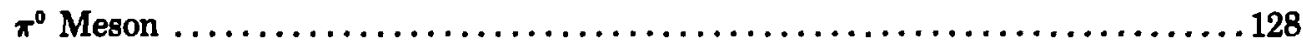

222 Measurement of the Decay Rate for $\pi^{0} \rightarrow e^{+} e^{-} \ldots \ldots \ldots \ldots \ldots \ldots \ldots \ldots \ldots \ldots$

247 Distributions of Products from Interactions of Stopped $\pi^{-}$with Several Medium-

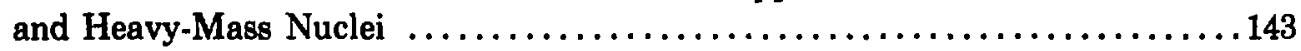

248 Study of the $(\pi, \pi N),(\pi \Delta),\left(\pi, B_{\Delta}\right)$, and $(\pi, N)$ Reactions in ${ }^{2,4} \mathrm{He}$ and 'Li by Measuring Recoil Spectra .................................. 44

283 Charged-Particle Emission Following $\mu$ - Capture $\ldots \ldots \ldots \ldots \ldots \ldots \ldots \ldots \ldots$

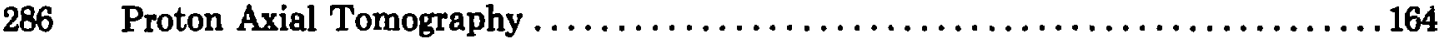

287 Studies of Gamma Angular-Ray Spectra and Pion-Gamma Angular Correlations

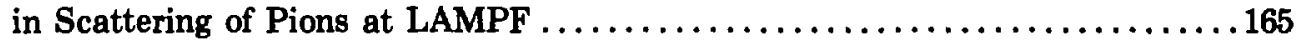

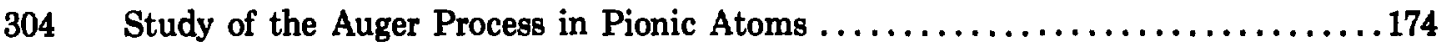

$309 \pi^{+}$and $\pi^{-}$Double-Charge-Exchange Disintegration of ${ }^{10} \mathrm{O},{ }^{\circ 0} \mathrm{Ca}$, and ${ }^{20} \mathrm{~Pb} \ldots \ldots 177$

319 Determining the Mechanism for Multinucleon and Cluster Removal in 200-MeV

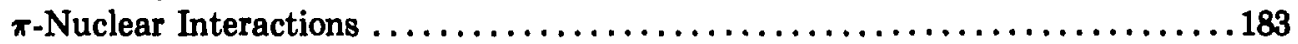

320 A Comparison of $\left(\pi^{+}, \mathrm{xn}\right)$ and $\left(\pi^{-}, \mathrm{xn}\right)$ Reactions $\ldots \ldots \ldots \ldots \ldots \ldots \ldots \ldots \ldots$ 
337 Measurement of the Cross Section for $\pi^{-} \mathrm{p} \rightarrow \pi^{-} \pi^{+} \mathrm{n}$ at 200 and $229 \mathrm{MeV} \ldots \ldots 192$

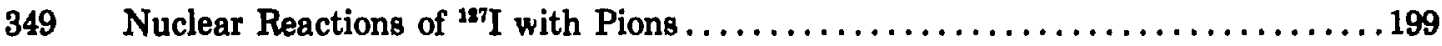

358 Elastic Scattering of Pions from Deuterium $\ldots \ldots \ldots \ldots \ldots \ldots \ldots \ldots \ldots \ldots \ldots$

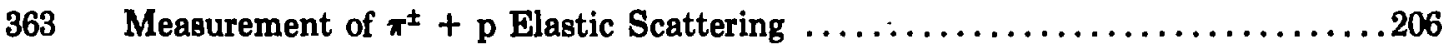

373 A Comparison of Residual Nuclei Yields from $\pi^{-}$Absorption in ${ }^{112} \mathrm{Cd}$

(Ground State) and ${ }^{112} \mathrm{Cd}$ (First Excited State) $\ldots \ldots \ldots \ldots \ldots \ldots \ldots \ldots \ldots \ldots$

379 Development of a Muon Polarimeter Using a Stroboscopic Technique .......215

390 A Study of Inclusive Inelastic Pion Scattering Near the $\Delta(3 / 2,3 / 2)$

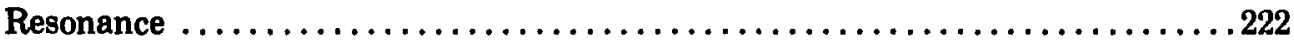

394 Application of Proton-Computed Tomography $\ldots \ldots \ldots \ldots \ldots \ldots \ldots \ldots \ldots \ldots \ldots \ldots$

396 Comparison of Measured Pionic-Atom Cascade Intensities with Theoretical Intensities Obtained Using Parameters from Muonic-Atom Studies . . . . . . . 224

404 A Kinematically Complete Study of the ( $\left.\pi, \pi^{\prime} p\right)$ Reaction on ${ }^{10} \mathrm{O}$ above the Resonance by Detecting Pions and Protons in Coincidence ............ 229

$409 \quad$ A Study of Pion-Induced Cluster Removal $\ldots \ldots \ldots \ldots \ldots \ldots \ldots \ldots \ldots \ldots \ldots \ldots$

416 Study of Fast Pion-Induced Fission of Uranium $\ldots \ldots \ldots \ldots \ldots \ldots \ldots \ldots \ldots \ldots$

418 Particle $\gamma$-Ray Coincidence Studies from $\pi$-Nuclear Reactions $\ldots \ldots \ldots \ldots \ldots 236$

420 Development of a High-Resolution Liquid-Argon Charged-Particle Detector of Medium-Energy Particles . . . . . . . . . . . . . . . . . . . . . . 238

429 An Investigation of the Anomalous Proton Emission Rate Following $\pi^{-}$Capture

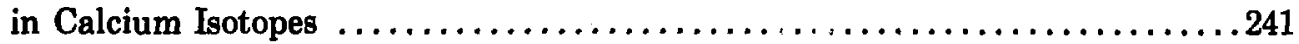

437 Study of Double-Radiative Pion Absorption $\ldots \ldots \ldots \ldots \ldots \ldots \ldots \ldots \ldots \ldots \ldots$

439 Particle-Gamma-Ray Coincidence Studies from $\pi$-Nuclear Reactions .........246

453 Survey of Relative Branching Ratios for Radiative Pion Capture on a Series of

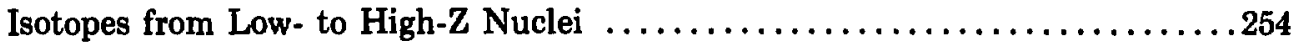

455 High-Precision Study of the $\mu^{+}$Decay Spectrum $\ldots \ldots \ldots \ldots \ldots \ldots \ldots \ldots \ldots \ldots$

458 The Excitation Function for the Single-Charge-Exchange Reaction

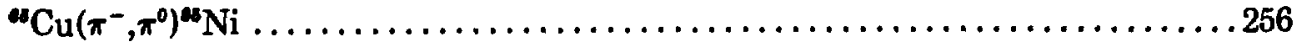


Nuclear Configuration of Individual Core-Coupled States in ${ }^{200} \mathrm{Bi}$ from Inelastic $\pi^{ \pm}$Scattering

Study of the ${ }^{11} \operatorname{Zr}\left(\pi^{+}, \pi^{0} \tilde{\mathrm{p}}\right)^{\infty 0} \mathrm{Z}$ Charge-Exchange Reaction

480 Discrete States from Pion Double Charge Exchange on Heavy Nuclei 268

487 Measurement of the Nuclear Resonance Effect in Some Pionic Atoms .271

500 Fission Fragment Distributions in Fast Pion-Induced Fission of ${ }^{200} \mathrm{U}$..........279

$513 \pi^{ \pm}$Quasi-Free Scattering from the Helium Isotopes $\ldots \ldots \ldots \ldots \ldots \ldots \ldots \ldots \ldots 284$

515 Measurement of the $t \mu \mathrm{d}$ and $t \mu \mathrm{t}$ Molecular Formation Rates $\ldots \ldots \ldots \ldots \ldots \ldots \ldots 285$

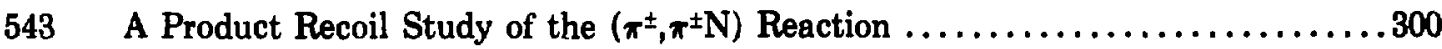

553 Study of Target Thickness Effects in the Cross-Section

Measurement of the Pion Single-Charge-Exchange Reaction

${ }^{13} \mathrm{C}\left(\pi^{+}, \pi^{0}\right)^{13} \mathrm{~N}(\mathrm{~g}) .8$. ) from 50 to $350 \mathrm{MeV}$

562 Study of the Pion Absorption Mechanism Through the

$\mathrm{A}(\pi, \mathrm{p}) \mathrm{X}$ Reaction at $\mathrm{T}_{\pi}=500 \mathrm{MeV}$

564 Study of Small Angle ${ }^{4} \mathrm{He}\left(\pi^{-}, \pi^{+}\right)$Reaction

$595 \quad$ An On-Line $\gamma$-Ray Study of Pion-Induced Single Nucleon

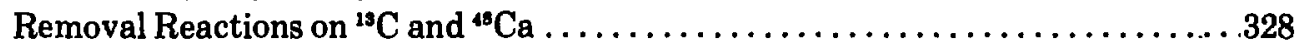

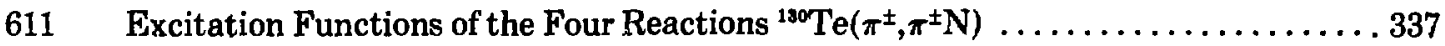

614 Studies of Scalar and Vector Parts of the $\pi-\mathrm{N}$ Interaction

by Measuring Nuclear De:excitation Gamma Ray Correlation

Following Inelastic Pion Scattering $\ldots \ldots \ldots \ldots \ldots \ldots \ldots \ldots \ldots \ldots \ldots \ldots \ldots, \ldots \ldots \ldots$

617 A Study of the $(3 / 2,3 / 2)$ Resonance in Light Nuclei $\ldots \ldots \ldots \ldots \ldots \ldots \ldots \ldots \ldots . \ldots \ldots$

628 Study of the $(\pi, \pi \mathrm{p})$ Reaction and Quasifree Scattering in ${ }^{4} \mathrm{He} \ldots \ldots \ldots \ldots \ldots, \ldots, \ldots$

673 Measurement of the Angular Dependence of Tensor Polarization in the ${ }^{2} \mathrm{H}\left(\pi^{+}, \pi^{+}\right)^{2} \mathrm{H}$ Reaction at $\mathrm{T}_{\pi}=180$ and $256 \mathrm{MeV}$

674 Measurements of Pion-Nucleus Elastic and Double-Change-

Exchange Scattering at Energies above $300 \mathrm{MeV}$ 
682 Search for Dibaryon Resonances in the Reaction $\pi \mathrm{D} \rightarrow \mathrm{p} \pi \mathrm{n}$ at $\mathrm{P}_{\mathrm{L}}^{\pi}=200$ to $600 \mathrm{MeV} / \mathrm{c}$

689 A. Neutron Counter Calibration Using Tagged Neutrons from the Reaction $--d \rightarrow n n$

B. Feasibility Study: Measurements of the Differential Cross

Section for $--d \rightarrow$ nn to Test

Charge Symmetry and Isospin Invariance 378

705 Study of Pion Absorption in ${ }^{3} \mathrm{He}$ on and Above the $(3,3)$ Resonance 386

728 Study of Pion Charge-Exchange Mechanisms by Means of Activation Techniques .................................... 398

730 Pion Production in Pion-Nucleon and Pion-Nucleus Interactions .400 
$302800-\mathrm{MeV}$ Proton Irradiation of an Aluminum Sample $\ldots \ldots \ldots \ldots \ldots \ldots \ldots \ldots \ldots \ldots$

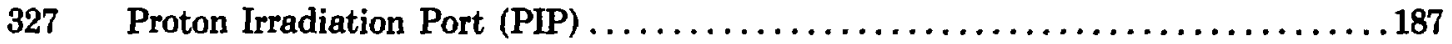

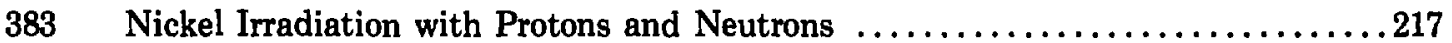

$302800-\mathrm{MeV}$ Proton Irradiation of an Aluminum Sample $\ldots \ldots \ldots \ldots \ldots \ldots \ldots \ldots \ldots$ 
3 Proposal for the Study of Muon Capture $\gamma$ Rays at the Stopped Muon Channel of LAMPF $\ldots \ldots \ldots \ldots \ldots \ldots \ldots \ldots \ldots \ldots \ldots \ldots \ldots \ldots, 2$

$7 \quad$ Nuclear Structure Physics Using Stopped Muons $\ldots \ldots \ldots \ldots \ldots \ldots \ldots \ldots \ldots, 4$

11 High-Resolution Studies of Muonic X Rays and Prompt Nuclear Gamma Rays.. 6

12 Muonic X Rays and Nuclear Charge Distributions $\ldots \ldots \ldots \ldots \ldots \ldots \ldots \ldots, 7$

16 Determination of the Mass of the Muon Neutrino $\ldots \ldots \ldots \ldots \ldots \ldots \ldots \ldots \ldots$

$37 \quad$ Ultrahigh-Precision Measurements of Muonium Ground-State Energy Levels: Hyperfine Structure Interval and Muon Magnetic Moment ............. 23

51 Techniques for Materials Identification and Analysis $\ldots \ldots \ldots \ldots \ldots \ldots \ldots, \ldots, \ldots \ldots$

60 Chemical Effects in the Capture of Negative Mesons in Matter .............. 38

69 Precision Measurements of Muonic X Rays in Low-Z Atoms: Vacuum Polarization and Nuclear Sizes ................................. 44

76 Search for Muonium-Antimuonium Transition ....................... 48

85 Gamma-Neutrino Correlation after Negative-Muon Capture $\ldots \ldots \ldots \ldots \ldots \ldots \ldots$

97 Muon Capture in Gaseous Hydrogen and Deuterium - Measurement of Singlet and Triplet Rates in Hydrogen $\ldots \ldots \ldots \ldots \ldots \ldots \ldots \ldots \ldots \ldots \ldots, 61$

100 Tissue Chemical Analysis with Mu-Mesic X Rays.$\ldots \ldots \ldots \ldots \ldots \ldots \ldots \ldots \ldots 63$

101 Feasibility Studies: Measurements of Muonic X Rays and Nuclear Gamma Rays with Crystal Diffraction Spectrometers at LAMPF .................. 63

115 Radiochemical Study of Stopped Negative-Muon-Induced Fission $\ldots \ldots \ldots \ldots \ldots 70$

122 Pionic-Atom X Rays and Nuclear Distributions $\ldots \ldots \ldots \ldots \ldots \ldots \ldots \ldots \ldots \ldots . \ldots \ldots$

142 Negative-Muon-Induced Fission in the Actinide Elements $\ldots \ldots \ldots \ldots \ldots \ldots 6$

149 Test of Lepton Nonconservation and Assignment Schemes in

1. $\mu^{-}+(\mathrm{Z}, \mathrm{A}) \rightarrow(\mathrm{Z}-2, \mathrm{~A})+\mathrm{e}^{+}$and $2 . \mu^{-}+(\mathrm{Z}, \mathrm{A}) \rightarrow(\mathrm{Z}, \mathrm{A})+\mathrm{e}^{-} \ldots \ldots \ldots . . .89$

152 High-Precision Muonic X-Ray Measurements Using Intrinsic Germanium

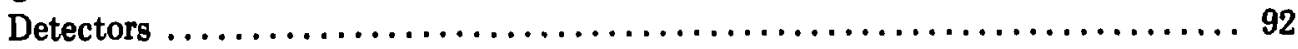


155 High-Precision Measurements of Pionic Mass with Crystal Diffraction

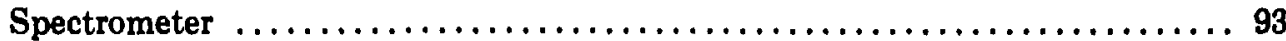

163 Investigation of Changes in Charge Distributions for Nuclei Near $Z=28$ by Electron Scattering and Muonic X Rays $\ldots \ldots \ldots \ldots \ldots \ldots \ldots \ldots \ldots \ldots . . .69$

165 Muonium Formation in Helium and Other Rare Gases ................... 100

166 Muonic X Rays and Nuclear Charge Distributions Electric Quadrupole

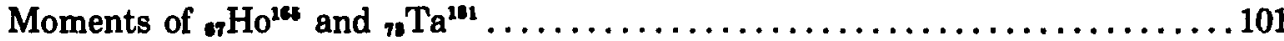

172 A Proposal to Measure the Helicity of $\mu$ Decay Electrons $\ldots \ldots \ldots \ldots \ldots \ldots \ldots \ldots$

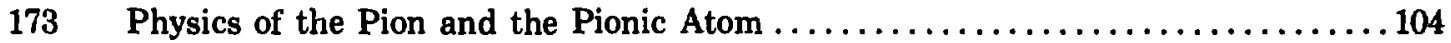

175 Search for the Formation of Muonic Helium $\left(\alpha \mu^{-} \mathrm{e}\right) \ldots \ldots \ldots \ldots \ldots \ldots \ldots \ldots . \ldots \ldots$

206 Search for the 2S Metastable State of Muonic Hydrogen $\ldots \ldots \ldots \ldots \ldots \ldots \ldots \ldots 122$

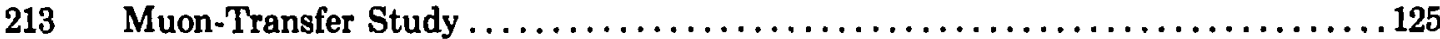

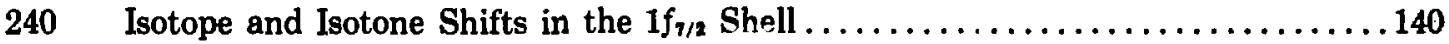

250 Investigation of the Use of Stopped Negative Muons for Materials Analysis ....146

259 High-Resolution Relative Muonic X-Ray Intensity Measurements from Elemental Targets in the Range $Z=12-52 \ldots \ldots \ldots \ldots \ldots \ldots \ldots \ldots \ldots \ldots \ldots$

266 Trapping of Positive Muons at Defects in Metals ......................155

268 Measurement of the Ground-State Hyperfine Structure Interval of the

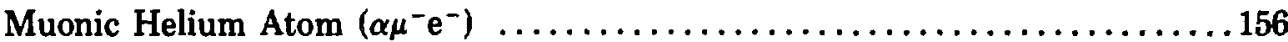

276 Perturbed Circular Polarization of Muonic X Rays $\ldots \ldots \ldots \ldots \ldots \ldots \ldots \ldots \ldots \ldots$

277 Muonic X-Ray Analysis of Core Samples from Oil-Bearing Formations ........160

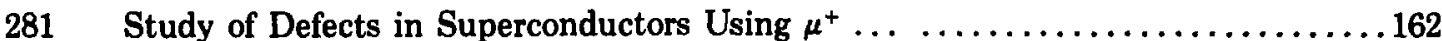

283 Charged-Particle Emission Following $\mu^{-}$Capture $\ldots \ldots \ldots \ldots \ldots \ldots \ldots \ldots \ldots \ldots \ldots \ldots \ldots \ldots$

288 Studies of $\mu^{-}$Capture Probabilities for Solid-State Solutions $\ldots \ldots \ldots \ldots \ldots \ldots \ldots$

292 Neutron Emission from Muon-Induced Reactions on Actinide Elements ........168

297 A Bicentennial Proposal to Study the Behavicr of Positive Muons in Solids .....171

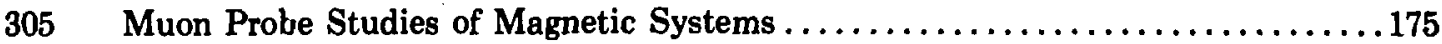

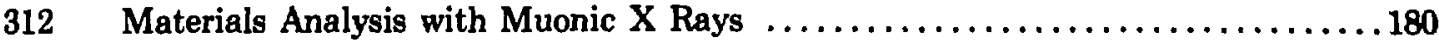


314 Measurement of Temperature Dependence for the Meson-Molecular-Fusion Rate

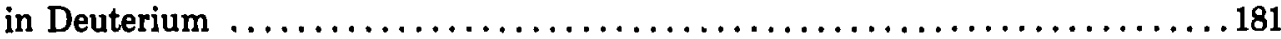

Measurement of the Decay Rate and Parity-Violating Asymmetry for $\mu^{+} \rightarrow \mathrm{E}^{+} \gamma \cdot 188$

Sensitive Search for $\mu^{-} \rightarrow$ E Conversion

Nuclear Charge Parameters of ${ }^{41} \mathrm{Ca}$ and the Stable Cadmium and

Tellurium Isotopes

335 Monopole and Quadrupole Charge Distributions in the Samarium and Gadolinium Isotopes

344 Higher Precision Measurement of Muon Magnetic Moment and of Muonium

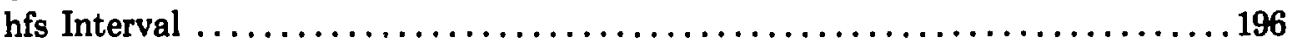

357 Muonic X-Ray Spectra of Gases: I. Density and Admixture Effects .203

364 Search for the Excited 2S State of Muonium 207

377 Investigation of the Effect of Grain Size in Muon Capture in Inhomogeneous

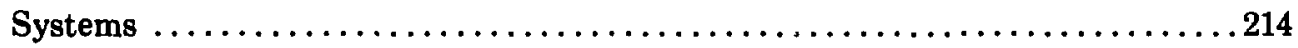

382 A $\mu$ SR Investigation of the Effects of Impurities on the Trapping and Diffusion of $\mu^{+}$Particles in BCC Metals .............................. 216

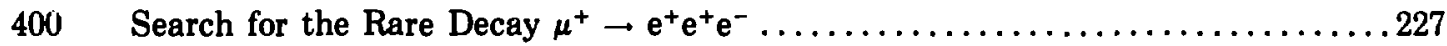

408 Macroscopic Diffusion Studies in Metals .231

414 Bone Calcium Assay with Muonic X Rays: Signal/Noise and Reproducibility

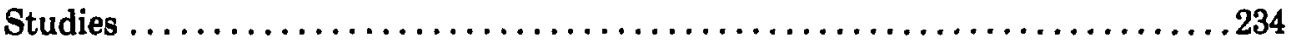

417 Study of the Nuclear Auger Process in Heavy Muonic Atoms . . . . . . . . . 236

421 Sensitive Search for $\mu^{-} \rightarrow$ e Conversion $\ldots \ldots \ldots \ldots \ldots \ldots \ldots \ldots \ldots \ldots \ldots \ldots \ldots \ldots \ldots$

422 High Precision Measurements of Pionic Mass and Pionic X-ray Energies with a Bent Crystal Spectrometer .....................239 
427 Magnetic Resonance Studies of $\mu^{+}$-Electron Defect Complexes in Nonmetals . ...240

430 A Search for the Effect of Phase Transitions in Atomic Muon Capture .......242

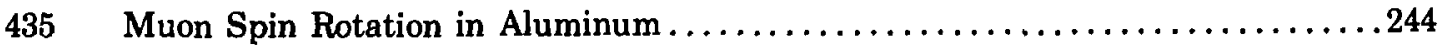

436 Negative Muon Spin Rotation and Relaxation in Magnetic Materials ......... 245

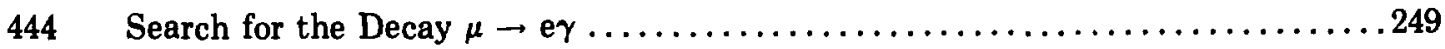

445 Search for the Lepton Flavor Violating Decay $\mu^{+} \rightarrow \mathrm{e}^{+} \gamma \gamma \ldots \ldots \ldots \ldots \ldots \ldots \ldots$

454 Measurement of the Eta Parameter in Muon Decay ..................254

464 Radiative Muon Capture in Gaseous ${ }^{s} \mathrm{He} \ldots \ldots \ldots \ldots \ldots \ldots \ldots \ldots \ldots \ldots$

491 Experimental Determination of the Strong Interaction Shift in the $2 \mathrm{p}-1 \mathrm{~s}$ Transition of Pionic Deuterium and Hydrogen Atoms $\ldots \ldots \ldots \ldots \ldots \ldots \ldots . \ldots 273$

494 Nuclear Charge Parameters of the Stable Ru and Pd Isotopes............274

499 Muon Longitudinal and Transverse Relaxation Studies in Spin-Glass Systems .. 277

$514 \quad$ A $\mu$ SR Study of Muonium-Substituted Free Radicals . . . . . . . . . . 284

529 Part I. Measurement of the Residual Muon Polarization in 'He Muonic Atom

(A Feasibility Test for Part II), and Part II. Angular Correlations in the Capture of Polarized Muons in Gaseous ${ }^{2} \mathrm{He} . \ldots \ldots \ldots \ldots \ldots \ldots . \ldots . \ldots 292$

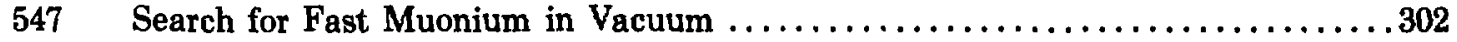

552 Ultrahigh Precision Measurements on Muonium ................... 304

571 Muon Spin Rotation Studies of Dilute Magnetic Alloys . . . . . . . . . . . . 315

594 Precision Determination of the Relative Muonic Coulomb

Capture Ratios in Oxides of Different Valences . . . . . . . . . . . . . . . 327

639 Muon Spin Rotation Study of Muon Bonding and Motion in Selected Magnetic Oxides . . . . . . . . . . . . . . . . . . . . . . 352

640 Transverse and Longitudinal Field $\mu$ SR Measurements in Selected Ternary Metallic Compounds $\ldots \ldots \ldots \ldots \ldots \ldots \ldots \ldots \ldots \ldots \ldots \ldots \ldots$

646 Hyperfine Structure of Muonic Helium-3 and Muonic Helium-4 Atoms 
653 Muonic X-ray Study of ${ }^{241} \mathrm{Am}$ and ${ }^{243} \mathrm{Am}$ .359

693 Investigation of the Two-Photon Decay Rate from the $\left(\mu^{4} \mathrm{He}\right)_{2 \mathrm{~s}}^{+}$

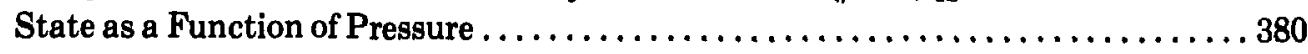

695 Study of Transfer Effects in Muon Capture in Gas Targets . . . . . . . . . . . . 381

697 Nuclear Excitation Following Muon Caputre on

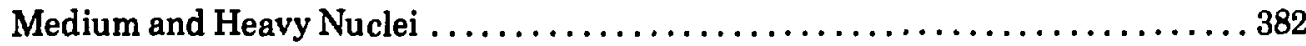

698 Ground-State Quadrupole Moments of Deformed Nuclei . . . . . . . . . . . . 383

707 Study of Transfer Effects in Muon Capture in gas Targets . . . . . . . . . . . . 387

715 Analysis of Chemical Composition of Archeological

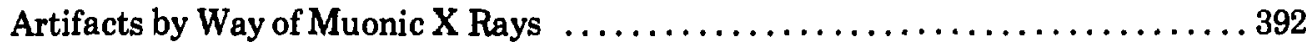

724 Measurement of the Lamb Shift in Muonium $\ldots \ldots \ldots \ldots \ldots \ldots \ldots \ldots \ldots \ldots$

726 Search for the C-Noninvariant Decay $\pi^{0} \rightarrow 3 \gamma \ldots \ldots \ldots \ldots \ldots \ldots \ldots \ldots \ldots$

727 Measurement of the Efficiency of Muon Catalysis in Deuterium-Tritium Mixtures at High Densities . . . . . . . . . . . . . . 398 
Exp. No.

Page No.

105 Nuclear Spectroscopy Studies of Proton-Induced Spallation Products ........65

118 Fragment Emission from Pion Interactions with Complex Nuclei $\ldots \ldots \ldots \ldots \ldots 7$

$269800-\mathrm{MeV}$ Proton Irradiation of Metal Samples $\ldots \ldots \ldots \ldots \ldots \ldots \ldots \ldots \ldots \ldots$

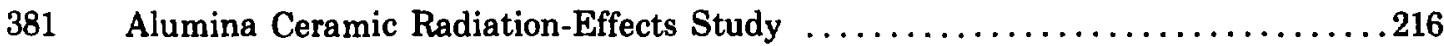


Exp. No.

86 Counter Experiments in the Thin Target Area $\ldots \ldots \ldots \ldots \ldots \ldots \ldots \ldots \ldots$

308 An attempt to Make Direct Atomic Mass Measurements in the Thin Target Area $\ldots \ldots \ldots \ldots \ldots \ldots \ldots \ldots \ldots \ldots \ldots \ldots \ldots \ldots \ldots$ 
stopped $\pi^{-}$and $\mathrm{K}^{-}$work is observable with in-flight reactions. Rather than survey a large number of targets, we propose to concentrate on three neighboring nuclei and to use three bombarding energies. The variation in target will show binding energy and pairing effects, while the variation in bombarding energy will indicate the role of the 3-3 resonance in the production process. We further propose to look at the gamma-ray spectrum produced in proton bombardment to ascertain whether the pion plays a special role in these reactions.

Exp. 154

\section{ELASTIC SCATTERING OF $\pi^{+}$AND $\pi^{-}$FROM THE HELIUM ISOTOPES}

\section{University of Virginia}

R. C. Minehart and J. S. McCarthy, Spokesmen

D. Day, J. Davis, J. Källne, R. Whitney, K. O. H. Ziock

We plan to measure elastic scattering for both $\pi^{+}$and $\pi^{-}$on the helium isotopes in the $\mathrm{P}^{4}$ channnel. The energy range will be from 250 to $500 \mathrm{MeV}$ and will cover scattering angles of $\sim 20$ to $160^{\circ}$ for ${ }^{~} \mathrm{He}$ and $\sim 45$ to $160^{\circ}$ for ${ }^{2} \mathrm{He}$. We also plan on measuring the inclusive quasi-free scattering on these isotopes, $\left(\pi, \pi^{\prime}\right)$. The complete kinematic region will be covered for three energies and four scattering angles for both ${ }^{\circ} \mathrm{He}$ and ' $\mathrm{He}$.

Beam requirements are $500-\mathrm{mA}$ primary proton beam, 30D40 magnet plus a new support stand, and cryogenic support for helium gas and liquid targets.

Exp. 155

\section{HIGH-PRECISION MEASUREMENTS OF PIONIC MASS WITH CRYSTAL DIFFRACTION SPECTROMETER}

\section{Yale University}

D. C. Lu, Spokesman

L. A. Schaller (University of Frieberg), V. W. Hughes, R. D. Ehrlich

\section{Lawrence Berheley Laboratory}

K. M. Crowe

Columbia University

C. S. Wu, M. Y. Chen

California Institute of Technology

P. Vogel, R. J. Powers, F. Boehm

The pion mass $m_{\pi}$ will be determined to an accuracy of about 15 parts per million, which will represent an improvement by a factor of 4 over our current krowledge. Measurements will be made with a crystal diffraction spectrometer of pionic $x$ rays in low- $Z$ atoms, in particular, of the 4f-3d transitions in $\pi-{ }^{11} \mathrm{Na}, \pi-{ }^{12} \mathrm{Mg}, \pi-11 \mathrm{Al}$, and $\pi-{ }^{14} \mathrm{Si}$. The high-energy resolution (about $10 \mathrm{eV}$ at $30 \mathrm{keV}$ ) and the inherent stability of a crystal diffraction spectrometer make such a highprecision measurement possible with a high-intensity pion beam. For relatively low- $Z$ atoms, theoretical uncertainties, such as orbital electron screening and nuclear-structure effects, are sufficiently small so that $m_{\pi}$ can be determined from the measured pionic $x$-ray energies to the desired accuracy. 


\section{SURVEY OF QUASI-ELASTIC PION SCATTERING}

Orezon State Univeraity

L. W. Swenson, Spokesman

T. C. Sharma, S. A. Richert, D. M. Stupin

Florida State Univeraity

H. S. Plendl

Univeraity of Oregon

P. Varghese, D. K. McDaniels

Florida AdM Univeraity

M. Greenfield

Univeraity of Virginia

S. E. Sobottka

\section{LASL}

H. A. Thiessen

A single-counter quasi-elastic-scattering survey is proposed for the EPICS beam line. Scattered pions will be detected from $\left(\pi, \pi^{\prime}\right),\left(\pi, \pi^{\prime} \mathrm{N}\right),\left(\pi, \pi^{\prime} \mathrm{d}\right)$, and $\left(\pi, \pi^{\prime} \alpha\right)$ reactions for incident pion momenta of $415 \mathrm{MeV} / \mathrm{c}\left(\mathrm{T}_{\pi}=300 \mathrm{MeV}\right)$ and $160 \mathrm{MeV} / \mathrm{c}\left(\mathrm{T}_{\pi}=75 \mathrm{MeV}\right)$. Where kinematically allowed, the p's, d's, and $\alpha$ 's will also be detected from these reactions (but not in coincidence with the pions).

The anomalous $\pi^{+}: \pi^{-}$ratio for $\left(\pi, \pi^{\prime} n\right)$ reactions, the pion wavefunction in nuclear matter, effects due to a neutron halo, and $\left(\pi, \pi^{\prime} d\right)$ and $\left(\pi, \pi^{\prime} \alpha\right)$ reactions will be studied. Giant resonances and strongly excited states from $\left(\pi, \pi^{\prime}\right)$ reactions will be noted.

This proposal is preliminary to experiments in which two particles will be detected in coincidence with two detectors at EPICS.

Exp. 157

\section{MICRODISTRIBUTION OF THORIUM IN GEOLOGIC SAMPLES}

\section{Argonne National Laboratory}

M. G. Seitz, Spokesman

The purpose of the experiment is to map the microscopic distribution of thorium in geologic samples. This is to be done by inducing fission of thorium and uranium with high-energy neutrons. 'The resulting fission fragments produce radiation-damage tracks in a solid detector such as quartz, and are made visible by chemical etching. The detector then serves as a map of the fissionable material in the sample. Using an auxiliary experiment in which the uranium is mapped by thermal neutron bombardment, the contribution of tracks from uranium can be subtracted from the map p:oduced by high-energy neutrons to give the distribution of thorium in the samples. The technique will be used in two studies of geologic importance - one concerning the thorium distribution in ultramafic rocks, the other concerning the partitioning of thorium and uranium in meteorites. 
We propose to measure the excitation function for the reaction ${ }^{\infty} \mathrm{Cu}\left(\pi^{-}, \pi^{\circ}\right)^{\omega} \mathrm{Ni}$ over the region of the $(3,3)$ resonance by an activation technique. The formation of $\mathrm{Ni}$ implies a low-momentum transfer process, since otherwise enough nuclear excitation would be caused by the final-state neutron to result in nuclear evaporation. Distorted-wave calculations of this reaction predict a minimum in the cross section near resonance, because of the strong absorption of the pion waves. Observation of such an effect would confirm these calculations; however, if that effect is not found, it would cast doubt on the usual models for pion-nucleus reactions.

Exp. 459

\section{CROSS-SECTION MEASUREMENTS OF MHE ${ }^{24} \mathrm{~N}\left(\boldsymbol{\pi}^{+}, \boldsymbol{\pi}^{0}\right)^{14} \mathrm{O}$ (ground state) REACTION}

\section{LASL}

D. J. Vieira, Spokesman

G. W. Butler, C. J. Orth, R. S. Rundberg

We propose to measure the nonanalog single-charge-exchange (SCE) reaction ${ }^{14} \mathrm{~N}\left(\pi^{+}, \pi^{0}\right)^{14} \mathrm{O}$ (g.s.) at six different incident energies between 100 and $350 \mathrm{MeV}$ using the full pion intensity available in the $P^{*}$ area. In repeated short irradiations of boron-nitride targets, the yield of ${ }^{14} \mathrm{O}$ will be measured via $\beta^{+}$-delayed gamma counting, while the total pion flux will be integrated using "Al monitor foils. Since the ground state is the only particle-bound state of ${ }^{14} \mathrm{O}$, these measurements provide a good determination of the nonanalog SCE reaction cross section to an isolated final state. Comparison of these data to a variety of theoretical models, namely, optical model, fixed scatterer model, Glauber model, and isobar doorway model, will contribute to a better understanding of SCE reactions. 


\section{BY $\left(\pi^{-}, \pi^{+}\right)$REACTIONS}

\section{Northwestern Univeraity}

K. K. Seth, Spokesman

\section{LASL}

S. G. Iversen, M. O. Kaletka, H. Nann

H. A. Thiessen

It is proposed to study the possible stability of the exotic nuclei ${ }^{\circ} \mathrm{H}$, ${ }^{7} \mathrm{H}$, and ${ }^{\circ} \mathrm{He}$ by the pion double-charge-exchange reaction $\left(\pi^{-}, \pi^{+}\right)$on targets of ${ }^{\circ} \mathrm{Li},{ }^{7} \mathrm{Li}$, and ${ }^{\circ} \mathrm{Be}$ at $\mathrm{T}(\pi)=164 \mathrm{MeV}$. It is expected that mass determinations can be made with an accuracy of $\pm 200 \mathrm{keV}$ if significant enhancements over phase space are observed.

Exp. 461

ELASTIC AND INELASTIC SCATTERING OF 800-MeV PROTONS FROM "O

Northweotern University

S. G. Iversen and K. K. Seth, Spokesmen

M. O. Kaletka, H. Nann

In a recent ${ }^{10} \mathrm{O}\left(\pi^{ \pm}, \pi^{ \pm 1}\right)^{10} \mathrm{O}^{*}$ experiment done at EPICS two very interesting results emerged:

a) the proton and neutron radii of ${ }^{110}$ are nearly equal $\left(\Delta r_{n p}=0.03 \pm 0.03\right)$, and

b) the $B(E 2)$ for the $2_{1}^{+}$state has a substantial isovector component [i.e., $B(E 2)_{\text {neut. }}$ is substantially larger than $\mathrm{B}(\mathrm{E} 2)_{\text {prot. }}$. On the other hand, the opposite is true, although to a smaller extent, for $B(E 3)$ to the $3 i$ state.

It is proposed to study elastic and inelastic scattering of $800-\mathrm{MeV}$ polarized protons to provide a more reliable measure of the results in (a) and to see to what extent result (b) can be verified.

Exp. 462

ANALYZING POWER AND DIFFERENTIAL CROSS SECTIONS FOK THE REACTIONS $p+p \rightarrow d+\pi^{+}$AND $p+d \rightarrow t+\pi^{+}$AT $\sim 600 \mathrm{MeV}$ AND $400 \mathrm{MeV}$

\section{Northwestern University}

K. K. Seth and H. Nann, Spokesmen

S. G. Iversen, M. O. Kaletka, H. Nann

\section{LASL}

R. L. Burman

It is proposed to study the $\left(\overrightarrow{\mathrm{p}}, \boldsymbol{\pi}^{+}\right)$reaction on hydrogen and deuterium at energies in the vicinity of 400 and $600 \mathrm{MeV}$. In an earlier experiment at $800 \mathrm{MeV}$ it was found that analyzing powers for hydiogen and deuterium are completely dissimilar. This is in complete contrast to threshold $\left(E_{p} \approx 200 \mathrm{MeV}\right.$ ) results obtained at TRIUMF in which the elementary $p+p \rightarrow d+\pi^{+}$ vertex was found to dominate for a wide choice of targets. It is necessary to study the reactions at 400 and $600 \mathrm{MeV}$ in order to find how this basic change between 200 - and $800-\mathrm{MeV}$ behaviors comes about, and what its proper explanation is. 


\section{A MEASUREMENT OF SPIN DEPENDENT EFFECTS IN P + D ELASTIC AND INELASTIC SCATTERING}

\section{LASL}

W. D. Cornelius, Spokesman

J. F. Amann, G. W. Hoffmann, H. A. Thiessen, R. L. York

We propose to measure the five "triple scattering" parameters in the scattering of polarized protons from deuterium. We intend to examine both elastic and inelastic scattering to the final state interaction region. The discovery of spin dependent resonances in the LAMPF energy region makes the examination of spin-dependent effects in this energy range especially timely. The inelastic scattering reaction is sensitive only to the spin-dependent parts of the nucleon-nucleon force because $\Delta S=1$ is required by angular momentum selection rules. These measurements are intended to complement recent work in connection with Exp. 360 where $D$ was measured in the charge analogue reaction. Unexpectedly $D$ was very small $(0.01 \pm 0.01)$. This value is inconsistent with lower energy results and theoretical expectations. Measurements performed at HRS would have an advantage over the neutron measurements because of better energy resolution and the high efficiency of the HRS focal plane polarimeter. The HRS is also unique in that two components of the outgoing proton spin may be measured simultaneously. If this experiment is scheduled immediately following Exp. 392, no additional set-up time is required and the polarimeter calibrations will have been done. In a run of $130 \mathrm{~h}$, we expect a statistical precision of \pm 0.02 and an absolute accuracy of \pm 0.05 over the angular region to be examined.

Exp. 475 (Revised August 1981)

\section{SCATTERING OF 0.8 GeV PROTONS FROM ${ }^{20} \mathrm{Ne}$ AND ${ }^{22} \mathrm{Ne}$}

\section{University of South Carolina}

G. S. Blanpied, Spokesman

B. G. Ritchie

University of Texas, Austin

G. W. Hoffmann, M. L. Barlett, J. A. McGill

\section{Michigan State University}

B. H. Wildenthal

The originally proposed experiment was to use the HRS to measure angular distributions and analyzing powers for $800-\mathrm{MeV}$ protons scattered from gas targets of ${ }^{20} \mathrm{Ne}$ and ${ }^{22} \mathrm{Ne}$. Only the ${ }^{20} \mathrm{Ne}$ part of the experiment was approved and has been completed. Preliminary analysis of the ${ }^{20} \mathrm{Ne}$ data, along with concurrent work on the isotopic pair ${ }^{24} \mathrm{Mg}$ and ${ }^{26} \mathrm{Mg}$, has prompted this request for additional time for ${ }^{22} \mathrm{Ne}$. We are requesting 96 hours of beam (either polarized or unpolarized). 
THE ANALYZING POWER FOR $\overrightarrow{\underline{\mathbf{n}}}+{ }^{20,20} \mathrm{Mg}$ AT 500 AND $800 \mathrm{MeV}$

Now Moxico State Univeraity

G. S. Blanpied, Spokesman

G. R. Burleson

Univeraity of Minnesota

N. M. Hintz

University of Toxas, Austin

M. Barlett, J. McGill

LASL

G. W. Hoffmann

Rutgers Univeroity

C. Glashausser

The experiment consists of using the HRS to measure the elastic and inelastic analyzing powers for 500 - and $800-\mathrm{MeV} \overrightarrow{\mathrm{p}}+{ }^{2, \omega} \mathrm{Mg}$. Particular emphasis will be placed upon studies of the ground state rotational band $\left(0_{1}^{+}, 2_{1}^{+}, 4_{1}^{+}, 6_{1}^{+}\right)$and the gamma band $\left(2+, 3_{2}^{+}, 4_{3}^{+}\right)$in these nuclei. Data will be taken in such a way as to maximize the statistics for unnatural parity $3 \frac{1}{2}$ state. We are requesting $100 \mathrm{~h}$ for measurements with $800-\mathrm{MeV}$ polarized protons and $100 \mathrm{~h}$ with $500-\mathrm{MeV}$ polarized protons.

Exp. 477

ROLE OF THE $p+p-d+\pi$ INTERACTION IN NUCLEON TRANSFER REACTIONS AT INTERMEDIATE ENERGIES

\author{
Univereity of Callfornia, Los Angeles \\ G. J. Igo, Spokesman \\ G. S. Adams, M. Bleszyneski, J. B. McClelland, G. Pauletta, C. A. Whitten, Jr.
}

The HRS will be used to measure the differential cross section ( $d \sigma / d \Omega)$ for neutron transfer via the $(p, d)$ reaction on ${ }^{1} \mathrm{Li},{ }^{12} \mathrm{C},{ }^{10} \mathrm{O},{ }^{10,48,4} \mathrm{Ca}$, and ${ }^{80} \mathrm{Zr}$. At four fixed values of $\mathrm{q}$, the momentum transfer, $\mathrm{d} \sigma / \mathrm{d} \Omega$ will be measured in approximately $100-\mathrm{MeV}$ (smaller steps of $50 \mathrm{MeV}$ would be very welcome) bombarding energy steps between 0.4 and $0.8 \mathrm{GeV}$. The values of $q^{2}$ chosen are 0.1 , $0.5,0.8$, and $1.2(\mathrm{GeV} / \mathrm{c})^{2}$. Selected states in these targets will be focused on in which the $\mathrm{pp} \rightarrow \mathrm{d} \pi$ amplitudes may play a predominant role.

Exp. 478

\title{
$\boldsymbol{\pi}^{ \pm}$ELASTIC SCATTERING FROM DEUTERIUM
}

\section{Univeraity of Colorado}

T. G. Masterson, Spokesman

J. J. Kraushaar, D. A. Lind, R. J. Peterson, R. A. Ristinen

\section{LASL}

R. L. Boudrie 
these measurements represent total cross-section determinations to an isolated final state enabling straightforward comparison of these data to theory. Such comparison should elicit a better understanding of the isovector component of single-charge-exchange reactions. Furthermore, comparisons of these measurements to integrated angular distributions of ${ }^{12} \mathrm{C}$ inelastic pion scattering leading to the analog state of ${ }^{12} \mathrm{~N}$ (g.s.), which resides at $15.11 \mathrm{MeV}$ in ${ }^{12} \mathrm{C}$, provide an important test of isospin symmetry.

Exp. 556

\section{A PROposal to study the (p,p') PRocess leading TO $\pi$-ATOMIC STATES}

\section{Masachusetts Institute of Technology}

W. Bertozzi, Spokesman

M. Hynes, J. Kelly, S. Kowalski, W. Pugh, R. P. Redwine, W. Sapp, C. P. Sargent, and

W. Turchinetz

LASL

G. W. Hoffmann

We propose to investigate the inelastic scattering of a proton from a nucleus wherein a pion in a bound mesonic orbit is created.

Exp. 557

EXPOSURE, IN A PARASITIC MODE, OF A $3 \mathrm{~cm} \times 3 \mathrm{~cm} \times 1 \mathrm{~cm}$ STACK OF SOLID TRACK DETECTORS TO A $\pi$ - BEAM

Washington University

Ramanath Cowsik, Spokesman

No summary available.

Exp. 558

MEASUREMENT OF $\left(\pi^{+}, \pi^{-}\right)$REACTIONS ON ${ }^{13,14} \mathrm{C}$ AND ${ }^{26} \mathrm{Mg}$

Case Western Reserve Univereity

H. W. Baer, Spokesrian

\section{LASL}

J. D. Bowman, C. L. Morris, H. A. Thiessen

New Mexico State University

G. R. Burleson, Spokesman

S. J. Greene. B. Cottingame

University of Texas, Austin

W. J. Braithwaite, C. Harvey, C. F. Moore

University of Indiana

C. D. Goodman

University of Minnesota

D. B. Holtkamp 
We propose to measure $\left(\pi^{+}, \pi^{-}\right)$DIAS angular distributions at $T_{\pi}=164$ and $T_{\pi}=292 \mathrm{MeV}$ on ${ }^{10} \mathrm{C}$ and at $\mathrm{T}_{\pi}=164 \mathrm{MeV}$ on ${ }^{*} \mathrm{Mg}$. The " $\mathrm{C}$ data constitutes a part of the complete set of measurements of $\pi^{+}$and $\pi^{-}$elastic, $\left(\pi^{+}, \pi^{0}\right)$ IAS charge exchange, and $\left(\pi^{+}, \pi^{-}\right)$DIAS scattering on a single nucleus. The ${ }^{20} \mathrm{Mg}$ data will complete the systematics of $\left(\pi^{+}, \pi^{-}\right)$DIAS transitions on ${ }^{14} \mathrm{C}$, ${ }^{18} \mathrm{O}$, and ${ }^{20} \mathrm{Mg}$ at 164 and $292 \mathrm{MeV}$. We also propose to measure the non-DIAS ${ }^{13} \mathrm{C}\left(\pi^{+}, \pi^{-}\right)^{13} \mathrm{O}$ angular distribution at $T_{\pi}=292 \mathrm{MeV}$. This will provide first data at the higher energy for an odd A nucleus, and it will constitute an important part of the isotope chain systematics ${ }^{12,13,14} \mathrm{C}\left(\pi^{+}, \pi^{-}\right)$. We also propose to measure the $5^{\circ}$ excitation functions of ${ }^{13,14} \mathrm{C}$ at five additional energies between 100 and $300 \mathrm{MeV}$.

\section{Parameters:}

EPICS spectrometer with sweeping magnet installed.

$\mathrm{T}_{\pi}=164$ and $292 \mathrm{MeV}$ for angular distribution.

$T_{\pi}=100$ to $300 \mathrm{MeV}$ for $5^{\circ}$ excitation function.

$500 \mathrm{~h}$ of $\pi^{+}$beam.

Exp. 559 (Revised August 1981)

\section{SEARCH FOR NEUTRINO OSCILLATIONS AND VIOLATION OF LEPTON NUMBER CONSERVATION}

\section{Los Alamos National Laboratory}

Minh Duong-Van, Spokesman

J. C. Allred, A. A. Browman, R. L. Burman, D.R.F. Cochran, J. B. Donahue, A. J. Gjovig, M. V. Hynes, B. W. Noel

Rice University

G. C. Phillips, Spokesman

S. D. Baker, J. A. Buchanan, M. D. Corcoran, J. M. Clement, I. M. Duck, H. E. Miettinen, G. S. Mutchler, J. B. Roberts, E. A. Umland

University of Houston

A. D. Hancock, B. W. Mayes, L. S. Pinsky

University of California, Lo\& Angeles

B. Aas, J. B. Carroll, J. Geaga, G. J. Igo, A. Shor, C. A. Whitten, Jr.

New Mexico State University

S. J. Greene

Lawrence Berkeley National Iaboratory

T. A. Mulera, A. L. Sagle

We propose to search for the neutrino oscillation channel $\bar{\nu}_{\mu} \rightarrow \bar{\nu}_{\mathrm{e}}$ and for the additive lepton-

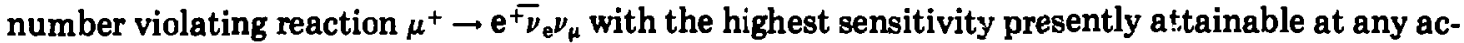
celerator. Using the LAMPF beam dump as a "clean" source of $\bar{\nu}_{\mu}\left(\bar{\nu}_{\mathrm{e}}\right.$ contamination is negligible) and a 6.1-ton detector consisting of liquid-scintillator modules and wire chambers, we expect to achieve an oscillation parameter sensitivity $\delta \mathrm{m}^{2}$ of $0.10 \mathrm{eV}^{2}$ for $\sin ^{2} 2 \theta=1$ and $0.21 \mathrm{eV}^{2}$ for $\sin ^{2} 2 \theta$ $=0.25$ at a $68 \%$ confidence level. We expect to be able to set an upper limit of $1.1 \%$ (68\% C.L.) on the branching ratio $\mu^{+} \rightarrow \mathrm{e}^{{ } \bar{\nu}_{\mathrm{e}} \nu_{\mu}} / \mu^{+} \rightarrow$ all.

We will search for the reaction $\bar{\nu}_{\mathbf{e}} \mathrm{p} \rightarrow \mathrm{e}^{+} \mathrm{n}$, where both final state particles are detected in fast $(20 \mathrm{~ns})$ coincidence. We hope to take advantage of this extra constraint to reduce the background and thus to attain a significant improvement in signal-to-noise. We believe the coincident direction will allow us to achieve the same sensitivity as that of a detector having three to four times 
the mass that detects only the positron. In case the backgrounds scale more rapidly with mass than we expect, the $e^{+} n$ coincident detection scheme may be the only one clean enough to permit observation of the $\bar{\nu}_{\mu} \rightarrow \bar{\nu}_{\mathrm{e}}$ oscillation.

The detector cost, estimated at $\$ 270000$, will be shared among the collaborating institutions. We propose to use tuff as the principal shielding with an additional 200 tons of steel shielding (at about $\$ 40000$ ). The required tunnel or filled hole will cost about an additional $\$ 70000$.

The neutrino detector will consist of modular liquid-scintillator detectors, organized into 12 walls, 10 modules high. Each wall is separated by a 10 -in. drift space to delay the neutron coincidence. In this drift space, multiwire chambers of coarse resolution will be located for chargedparticle tracking. The detector will be surrounded by a 6-in.-thick steel shield as well as an active scintillator veto. This whole structure will be located below grade.

We believe that because of both the low cost and the simplicity of design, the detector can be constructed within one year (August 1982) and that results will be available one year later (August 1983). This experiment utilizes the unique, presently available, feature of LAMPF for neutrino physics: a very high flux of $\bar{\nu}_{\mu}$ from the beam stop with energy below $\mu$-production threshold and a presumed minute flux of $\bar{\nu}_{\mathrm{e}}$. Our proposed design takes advantage of this uniqueness to attain very important physics goals in a timely fashion: to show definitively whether lepton-number conservation is violated and/or whether neutrinos have mass. A positive result from this experiment would be of comparable significance to observation of the decay of the proton.

Since the Los Alamos National Laboratory is planning a major expansion of effort in neutrino physics, we believe that development of sensitive and novel neutrino detector systems should be of considerable interest to the Laboratory. The detector system that we are building will be of maximal sensitivity because it uses the best available technology to detect both the $\mathrm{e}^{+}$and the neutron in the reaction $\bar{\nu}_{\mathrm{e}} \mathrm{p} \rightarrow \mathrm{e}^{+} \mathrm{n}$. The relatively large duty cycle at the LAMPF beam stop (compared to other accelerator facilities and what is expected for PSR) makes beam-stop experiments especially sensitive to cosmic-ray backgrounds. Our technique of time-delayed $\mathrm{e}^{+}$-neutron fast coincidence is expected substantially to improve the signal-to-noise ratio, and it therefore makes our method attractive. Thus we believe that the technical contribution of successful development of our detector provides a secondary, but important, contribution to the Los Alamos efforts in neutrino science.

This proposed expriment will search for lepton number violation and/or $\bar{\nu}_{\mu} \rightarrow \bar{\nu}_{e}$ oscillations as follows:

in a timely fashion

-at low cost

- with an advancemnt of neutrino technology

-with maximal sensitivity. 


\section{B}


Exp. 610

\section{USE OF LAMPF BEAM STOP TO OBTAIN ${ }^{\circ} \mathrm{Fe}$}

Argonne National Laboratory

W. Henning and W. Kutschera, Spokesmen

No Summary Available

Exp. 611

\section{EXCITATION FUNCTIONS OF THE FOUR REACTIONS ${ }^{100} \mathrm{Te}\left(\pi^{ \pm}, \pi^{ \pm} \mathbf{N}\right)$}

McGill University

\section{LASL}

J. J. Hogan, Spokesman

K. E. Thomas, K. W. Thomas

Istituto Nazionale di Fisica Nucleare, Milan

E. W. Gadioli

It is hoped that this experiment will be the first in a series, the ultimate goul of which is to extend pre-equilibrium model calculations to reactions of fast pions on heavy, complex nuclei. In this experiment, the initial interaction of energetic pions with the nucleons of a moderatley heavy nucleus will be studied.

It is proposed that four reactions of a single target nucleus be studied, systematically, as a function of pion energy. Specifically these four possibilities of single nucleon removal, the $\left(\pi^{+}, \pi^{+} n\right)$, $\left(\pi^{+}, \pi^{+} p\right),\left(\pi^{-}, \pi^{-} n\right)$ and $\left(\pi^{-}, \pi^{-} p\right)$. The target nucleus is ${ }^{130} \mathrm{Te}$, the products ${ }^{120} \mathrm{Te}$ and ${ }^{12} \mathrm{Sb}$. The pion energies would be expected to vary from $F_{\pi}$ of 50 to $300 \mathrm{MeV}$. While the experiments will be designed specifically to measure the excitation functions for these reactions under optimum conditions, it is apparent that as much of the spallation yield pattern as possible will also be determined.

We propose to radiochemically isolate these products from a mixed target of tellurium and aluminum (as a beam monitor) which is being fabricated in the Department of Metallurgical Engineering of McGill University.

There are two principal advantages to the particular target-reaction system chosen. First, ${ }^{120} \mathrm{Te}$ appears to be the only reasonably abundant naturally occuring isotope for which these four reactions may be studied. This avoids the uncertainties always present in the comparison of reactions carried out on different targets. Second, the relatively short half lives of the principal products, roughly one and four hours, allow a very systematic study to be carried out with a relatively modest requirement of beam time.

The principal experimenters, Hogan, Thomas, and Williams, will always be present at LASL when experiments are performed.

The theoretician, Gadioli, has been interested in pre-equilibrium simulations of pion induced reactions for some time; however, his previous work has been entirely with stopped pions. He intends to use the data of these experiments to provide the framework for an extension of the Exciton model to fast pion reactions. Our collaboration, which has extended over the last decade, has seen the extension of the model for proton induced reactions to account for alpha particle clustering, fissionability, and the calculation of spallation yields of as many as forty reaction products simultaneously down to the microbarn level. Recently, we have successfully explored alpha particle and light heavy ion induced reactions and it is felt that similar successes in pion induced reactions are possible. 
Exp. 612

\section{MASS OF BERYLLIUM-14}

Northwestern Univeraity

K. K. Seth, Spokesman

D. Barlow, S. G. Iverson, M. O. Kaletka, D. Kielczewska, A. Saha, D. Smith

Indiana University

LASL

H. Nann, Spokesman

H. W. Baer

It is proposed to measure the mass of the exotic nucleus ${ }^{14} \mathrm{Be}(\mathrm{Z}=4, \mathrm{~N}=10)$ by means of the reaction ${ }^{14} \mathrm{C}\left(\pi^{-}, \pi^{+}\right)^{14} \mathrm{Be}$. This mass is of fundamental importance in our study of nuclei farthest away from the valley of stability. It is conjectured that that excited $0_{2}^{+}$state will also be seen in the spectrum and that its energy and strength will shed special light on the coexistence of spherical and highly deformed $0^{+}$states.

Exp. 613

\section{STUDY OF DEEPLY BOUND HOLE STATES IN THE TIN ISOTOPES VIA THE ( $\overline{\mathbf{p}}$, d) REACTION}

\section{Northwestern University}

A. Saha and K. K. Seth, Spokesmen

D. Barlow, S. G. Iversen, M. O. Kaletka, D. Kielczewska, D. Smith

Single neutron pick-up reactions, like $(p, d)$, have been used in recent years to study the deeply bourd hole states in nuclei. Most previous studies have been done at incident energies of $90 \mathrm{MeV}$ or less. It would be of great interest to see what charactristics these states exhibit at higher incident energies where momentum matching would preferentially excite the high spin states. In this experiment, we therefore propose to do the ( $\overrightarrow{\mathrm{p}}, \mathrm{d})$ reaction at $400 \mathrm{MeV}$ on the $\mathrm{Sn}$ isotopes. Excitation to the low-lying valence states will also be investigated. These results are also of importance for this study, since they give a measure for the reliability of any reaction mechanism to describe the data.

Exp. 614

STUDIES OF SCALAR AND VECTOR PARTS OF THE $\pi-N$ INTERACTION BY MEASURING NUCLEAR DEEXCITATION GAMMA RAY CORRELATION FOLLOWING INELASTIC PION SCATTERING

\section{College of William and Mary \\ H. O. Funsten, Spokesman}

Utah State University

E. N. Hatch, V. G. Lind, R. E. McAdams, O. H. Ottenson

George Mason University

B. J. Lieb

Florida State University

H. S. Plendl 
Virginia State College

C. E. Stronach

\section{LASL}

D. J. Vieira

This experiment is a study of the role of the relative scalar to vector strengths of the $\pi-\mathrm{N}$ scattering amplitudes in producing polarized residual nuclei in inelastic pion-nucleus scattering. The polarization is to be obtained by measuring the correlation between the scattered pion and the nuclear deexcitation gamma ray. Five directional scintillation telescopes will be used for $\pi^{\prime}$ detection using $\mathrm{dF} / \mathrm{dx}$ identification of the pions; four $\mathrm{Ge}(\mathrm{Li})$ detectors will be used for $\gamma$-ray detection.

Exp. 615

Experiment 615 was entered in error.

Exp. 616

NUCLEAR INFORMATION FROM THE SPIN ROTATION AND DEPOLARIZATION PARAMETERS IN THE ${ }^{12} \mathrm{C}\left(\mathrm{p}, \mathrm{p}^{\prime}\right)$ REACTION TO THE $1^{+} 12.72 \mathrm{MeV} \mathrm{T}=0$ AND TO THE $1^{+} 15.11 \mathrm{MeV} \mathrm{T}=1$ LEVELS

University of California, Los Angeles

M. Bleszvnski, Spokesman

B. Aas, E. Bleszynski, G. L. Igo, G. Pauletta, C. A. Whitten, Jr.

$\boldsymbol{L A S L}$

J. B. MeClelland and J. Moss, Spokesmen

T. Carey, S. J. Seestrom-Morris

University of Minnesota

N. M. Hintz, Spokesman

Rutgers University

C. Glashausser

Measurements of the final state proton polarizations resulting from the inelastic scattering of polarized proton beans to the $1^{+} 12.72 \mathrm{MeV} \mathrm{T}=0$ and $1^{+} 15.11 \mathrm{MeV} \mathrm{T}=1{ }^{12} \mathrm{C}$ levels will be used to study the reaction mechanism for the excitation of these levels. Since these levels have unnatural parity $\left(1^{+}\right)$and two isospin values $T=0$ and $T=1$, they are particularly good states to use in studying the isoscalar and isovector character of the spin-dependent $\mathrm{N}-\mathrm{N}$ amplitudes. This experimental proposal presents a systematic approach where measurements of three triple scattering parameters taken together with previous measurements on the unpolarized scattering cross sections and asymmetries $A_{y}$ will allow a determination of the product of a specific spin dependent amplitude (absolute value) and a nuclear form factor. Comparison of the magnitudes of various spin dependent amplitudes are thus possible. In this systematic approach the axial longitudinal as well as the transverse nuclear transition form factor may be studied separately. Only one of these formfactors, the transverse one, can be extracted from (e,e') measurements, whereas the $\left(p, p^{\prime}\right)$ reaction will also provide us with information on the axial longitudinal form factor. 
Exp. 617

A STUDY OF THE (3/2, 3/2) RESONANCE IN LIGHT NUCLEI

University of Virginia

K. O. H. Ziock. Spokesri:in

J. S. McCarthy, R. C. Minehart, Y. Tzeng

LASL

C. L. Morris

No Summary Available

Exp. 618

\section{INELASTIC $\pi^{ \pm}$SCATTERING FROM THE $\mathbf{N} \approx 28$ ISOTONES}

\section{LASL}

C. L. Morris, Spokesman

R. L. Boudrie

University of Texas, Austin

C. Fred Moore, Spokesman

P. A. Seidl

University of S. Carolina

G. S. Blanpied

Wave function calculations are often tested by comparing Eigen energies and electromagnetic decay rates that are predicted with experimental measurements. However, often more stringent tests can be made using information gained from detailed measurements of the transition densities from inelastic scattering. Indeed, electron inelastic scattering has proven very useful in this respect. In the present experiment we hope to provide complementary data about the neutron transition densities which can be used to test wave function models.

We will measure inelastic scattering of $\pi^{ \pm}$to collective states in the neutron magic $\mathrm{N}=28$ isotones: ${ }^{48} \mathrm{Ca},{ }^{50} \mathrm{Ti},{ }^{51} \mathrm{~V},{ }^{52} \mathrm{Cr}$, and ${ }^{54} \mathrm{Fe}$. For most of these isotones, form factors and consequently transition densities, are well known from inelastic electron scattering at momentum transfers from 0.5 to $1.7 \mathrm{~h} \mathrm{fm}^{-1}$. As a consequence we can compare $\pi^{+}$scattering (scattering mainly from protons) with DWIA calculations using these well known proton transition densities, and we can determine the transition densities for the neutron components in the wave function from the $\pi^{-}$ inelastic scattering.

Exp. 619

INELASTIC PION SCATTERING TO $0^{+}$AND $2^{+}$STATES IN ${ }^{\circ \circ} \mathrm{Ca}$ and ${ }^{\circ 2} \mathrm{Ca}$

University of Texas

C. F. Moore, Spokesman

C. J. Harvey, P. A. Seidl

University of Pennsylvania

H. T. Fortune, Spokesman

G. Gunn, J. Sweet, L. Bland 


\section{LASL}

C. L. Morris, Spokesman

S. J. Seestrom-Morris

We intend to measure ${ }^{40} \mathrm{Ca}\left(\pi^{ \pm}, \pi^{ \pm^{\prime}}\right){ }^{40} \mathrm{Ca} *$ and ${ }^{42} \mathrm{Ca}\left(\pi^{ \pm}, \pi^{ \pm 1}\right)^{42} \mathrm{Ca}^{*}$ at angles between $15^{\circ}$ and $50^{\circ}$, and at three energies, 120,180 , and $300 \mathrm{MeV}$. 


\section{THE NUCLEAR REACTION $\pi^{+}$v $\pi^{-}$INELASTIC SCATTERING ON ${ }^{+0} \mathrm{Ca}$}

Univeraity of Texas

C. F. Moore, Spokesman

C. J. Harvey, P. A. Seidl

LASL

C. L. Morris, Spokesman

S. J. Seestrom-Morris

U. S. Air Force Academy

R. Joseph

Pion-nucleon elastic scattering on the $(3,3)$ resonance favors $\pi^{+}+p$ and $\pi^{-}+n$ over $\pi^{-}+p$ and $\pi^{+}+n$ by a factor of $9: 1$. Thus, from a shell model point-of-view, one might reasonably hope that a comparison of $\pi^{+}$inelastic scattering with $\pi^{-}$inelastic scattering on complex nuclei would permit an extraction of the proton contribution from the neutron contribution in the description of nuclear excited states.

In doubly closed shell nuclei, there are two types of excitations of interest:

1. Natural Parity, collective in character, where the proton-neutron configurations are well correlated, but the proton and neutron configurations are not the same in nuclei with $\mathbf{N}$ not equal to $\mathrm{Z}$.

2. Unnatural Parity, one single particle-hole in character, where one should see close to a 9:1 ratio in $\pi^{+}$vs $\pi^{-}$cross section. Measurement of these will provide sensitivity to even small configuration mixing.

In a comparison of inelastic scattering yields, we expect to see $\pi^{+}$preferentic.lly exciting singleparticle-hole proton states and $\pi^{-}$preferentially exciting single-particle-hole neutron states. The observation of states of pure proton or neutron configuration (bad isospin), even in self-ronjugate nuclei, has been one of the most striking finds at EPICS.

We propose to measure inelastic scattering of positive and negative pions from ${ }^{40} \mathrm{Ca}$ at incident pion energies of 120,155 , and $180 \mathrm{MeV}$. This study will concentrate on particle-hole states resulting from a stretched $\left(\mathbf{1 d}_{5 / 2}\right.$ hole, $1 \mathrm{f}_{7 / 2}$ particle) configuration. The identification of such states will be based on the selectivity of pion inelastic scattering a low energy for exciting unnatural parity states. Noveral previously obtained spectra of pion inelastic scattering on ${ }^{40} \mathrm{Ca}$ show evidence for a broad state at $14.5 \mathrm{MeV}$ which is a possible condidate for the $6^{-}$state.

Specifically, we intend to measure ${ }^{10} \mathrm{Ca}\left(\pi^{ \pm}, \pi^{ \pm 1}\right)^{40} \mathrm{Ca}^{*}$ at momentum transfers of 181,251 , and $310 \mathrm{MeV} / \mathrm{c}$ corresponding to angles of 50,70 , and $90^{\circ}$ at $120 \mathrm{MeV}$, and at three energies 120,155 , and $180 \mathrm{MeV}$.

Exp. 621

\section{GOOD-RESOLUTION STUDY OF ${ }^{18} \mathrm{O}\left(\pi, \pi{ }^{\prime}\right)$}

\section{University of Minnesota}

D. Dehnhard, Spokesman

D. B. Holtkamp

University of Pennsylvania

H. T. Fortune, Spokesman

\section{LASL}

S. J. Seestrom-Morris, C. L. Morris, J. F. Amann 
We propose to measure inelastic cross sections at $\sim 160 \mathrm{MeV}$ for $\pi^{ \pm}$inelastic scattering from 100 with about $100-\mathrm{keV}$ resolution, in order to resolve states not previously separable, and thereby to enable meaningful comparison between theory and experiment.

Exp. 622

\title{
INVESTIGATION OF THE STRONG CANCELLATIONS OF NEUTRON/PROTON TRAN:TTION AMPLITUDES IN ${ }^{14} \mathrm{C}$
}

\author{
University of Minnesota \\ D. B. Holtkamp, Spokesman \\ D. Dehnhard \\ LASL \\ H. W. Baer, Spokesman \\ S. J. Seestrom-Morris, C. L. Morris \\ New Mexico State University \\ S. J. Greene \\ University of Texas \\ C. J. Harvey
}

We are requesting time on EPICS in order to measure excitation functions at two values of constant momentum transfer for $\pi^{ \pm}$excitations of ${ }^{14} \mathrm{C}$. Two states at 11.67 and $17.23 \mathrm{MeV}$ appear to be high-spin states (probably $\mathrm{J}^{\pi}=4^{-}$) with $\pi^{+} / \pi^{-}$cross section ratios of $0.06 \pm 0.03$ and $12.83 \pm$ 4.41 , respectively. By measuring an excitation function at large $\mathrm{q}$, we can determine whether these states are of natural or unnatural parity. In addition, the $2_{2}^{+}$state at $8.32 \mathrm{MeV}$ exhibits a $\pi^{+} / \pi^{-}$cross section ratio of $33_{-18}^{+\infty}$, and it would be very interesting to see if this ratio is energy dependent. This ratio exceeds the free $\pi-\mathrm{N}$ ratio of $9: 1$ and probably results from strong cancellations of neutron and proton transition amplitudes in $\pi^{-}$scattering. We also request time to measure inelastic angular distributions at $292 \mathrm{MeV}$, an energy off the $(3,3)$ resonance, to study form factor differences in the $2^{+}$(and proposed $4^{-}$) states. In order to complement the approved SCX and DCX experiments on ${ }^{14} \mathrm{C}$, we will obtain angular distributions of elastic scattering at $292 \mathrm{MeV}$.

The total time requested for this experiment is 380 hours.

Exp. 623

\section{MEASUREMENT OF CROSS SECTION, ANALYZING POWER AND DEPOLARIZATION PARAMETERS IN THE ${ }^{28} \mathrm{Si}\left(p, p^{\prime}\right)^{28} \mathrm{Si}^{*}\left(6^{-} \mathrm{T}=0\right.$ AND $\left.\mathrm{T}=1\right)$ REACTION AT $400 \mathrm{MeV}$}

Rutgers University

C. Glashausser, Spokesman

K. Jones, S. Nanda

University of Minnesota

N. Hintz, M. Gazzaly

The observables $d \sigma / d \Omega, A_{y}, D_{n n^{\prime}}, D_{s s^{\prime}}$, and $D_{\ell s^{\prime}}$ will be measured at $400 \mathrm{MeV}$ for the reaction ${ }^{28} \mathrm{Si}\left(\mathrm{p}, \mathrm{p}^{\prime}\right)^{28} \mathrm{Si}$ to the stretched $6^{-}$states at $11.58 \mathrm{MeV}(\mathrm{T}=0)$ and $14.35 \mathrm{MeV}(\mathrm{T}=1)$. The first two parameters will be measured over the range 10 to $28^{\circ}$ (LAB) in $3^{\circ}$ steps. The spin transfer 
parameters will be measured at three angles each; three orthogonal polarization states of the incident beam are required. The primary aim is a consistent determination of the effective tensor interaction, particularly fcr isovector transfer, in the region of momentum transfer where it is largest. This requires that the other components of the interaction also be determined. The theoretical analysis will be carried out via the distorted wave impulse approximation. Form factors from electron scattering and nucleon-nucleon amplitudes from the recent Franey and Love analysis will be used in the first comparison with the data.

Exp. 624

\section{AN ATTEMPT TO OBSERVE DIRECTLY THE COUPLING OF PARTICLE-HOLE STATES TO $\triangle$-HOLE STATES}

\section{Indiana University}

C. D. Goodman, Spokesman

University of Texas

LASL

C. A. Goulding

B. E. Bonner, M. D. Cooper, N.S.P. King

We propose to use the (p,n) reaction at 800 and $500 \mathrm{MeV}$ to search for direct evidence of coupling of Gamow-Teller strength as nucleon particle-hole states to $\Delta$-hole states. Studies with the $(p, n)$ reaction at $200 \mathrm{MeV}$ show a systematic GT strength deficit of the order of $50 \%$. It has been suggested that $\Delta$-hole coupling shifts the missing strength to excitations of the order of $300 \mathrm{MeV}$. We propose to excite the high excitation component directly and to attempt to associate the high excitations with missing GT strength by comparing spectra for targets with and without normal GT strength. Neutron energy spectra are to be measured by time of flight.

Exp. 625

\section{INELASTIC SCATTERING OF PIONS TO GIANT RESONANCES}

\section{LASL}

N.S.P. King, Spokesman

H. W. Baer, R. L. Boudrie, C. L. Morris

University of North Carolina

R. E. Anderson, Spokesman.

University of Colorado

R. J. Peterson, Spokesman

J. J. Kraushaar, R. A. Ristinen, R. S. Raymond

\section{Oak Ridge National Laboratory}

F. E. Bertrand

This proposal is an extension of Exp. 522 which was a feasibility study to determine whether pions would strongly populate known giant resonances and if so, what problems would be encountered in using EPICS for continued study.

Results from Exp. 522 showed clear evidence for population of the LEOR and isoscaler GQR in both $\pi^{-}$and $\pi^{+}$scattering from ${ }^{118} \mathrm{Sn}$ at $130 \mathrm{MeV}$. Weak evidence (poor statistics) was also found for the recently observed $\mathrm{HEOR}$ at $23 \mathrm{MeV}$ with an angular dependence similar to the LEOR. 
Following this experiment, a somprehensive study of the properties of pionic giant resonance excitation was proposed (Exp. 608). This included exploring their energy dependence, $\pi^{-} / \pi^{+}$differences for an isotopic sequence of targets, confirmation of the HEOR and new isovector resonances, and the mass dependence of giant multipole strength. The present proposal is more modest in its goals. We wish to: 1) obtain improved statistics at some angles where data from Exp. 522 exists, 2) obtain good statistics at a few more angles to confirm observed $\pi^{-} / \pi^{+}$differences on ${ }^{118} \mathrm{Sn}$ at $130 \mathrm{MeV}$, 3) while carrying out parts 1 and 2, confirm our observation of the HEOR and explore $\pi^{-} / \pi^{+}$differences near $\sim 23-\mathrm{MeV}$ excitation energy, 4) measure the sirength of the GQR at a few angles in ${ }^{10} \mathrm{Ca}$ to provide data on an $\mathrm{N}=\mathrm{Z}$ nucleus where one expects no $\pi^{-} / \pi^{+}$ differences which might arise from $\mathrm{T}_{0}>0$.

Exp. 626

MEASUREMENT OF THE DEPOLARIZATION PARAMETERS $\mathrm{D}_{\mathrm{nn}}$, $\mathrm{D}_{\text {lss', }}$

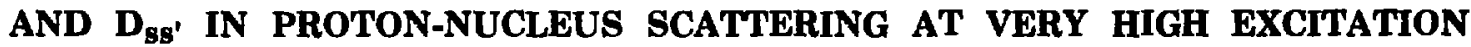
ENERGIES

\section{Rutgers University}

C. Glashausser, Spokesman

K. Jones, S. Nanda

University of Texas, Austin

J. McGill, Spokesman

M. Barlett, G. W. Hoffmann

The depolarization parameters $\mathrm{D}_{\mathrm{nn}}, \mathrm{D}_{\ell s^{\prime}}$, and $\mathrm{D}_{\mathrm{ss}}$ ' will be measured for proton scattering from ${ }^{1} \mathrm{H},{ }^{12} \mathrm{C}$, and ${ }^{208} \mathrm{~Pb}$ in the excitation region corresponding to quasi-elastic scattering and quasi-free delta production. The beam energy will be about $800 \mathrm{MeV}$; the scattering angles will range from 5 to $30^{\circ}$ in $5^{\circ}$ steps. The excitation region will be scanned in about 10 coarse steps corresponding to intervals of about $100 \mathrm{MeV} / \mathrm{c}$ in outgoing particle momentum. This will be the first examination of the magnetic properties of nuclei at high-excitation energies where magnetic resonances have recently been suggested. It will provide detailed data for comparison with the recent calculations of Alexander, Wallace, and co-workers which incorporate isobar production into the intermediate energy scattering formalism on an equal footing with elastic nucleon-nucleon scattering. Double spin-flip terms in the strongly spin-dependent nucleon-nucleon isobar production amplitudes will be determined for the first time. Finally, the data may provide evidence for the production of giant isobar resonances.

Exp. 627

MEASUREMENT OF THE RELATIVE SIGN OF NEUTRON AND PROTON TRANSITION MATRIX ELEMENTS IN (p,p') REACTIONS

LASL

M. V. Hynes, Spokesman

M. J. Leitch

Massachusetts Institute of Technology

A. M. Bernstein, Spokesman

R. Miskimen

Univeraity of South Carolina

G. S. Blanpied 
We propose to use the High Resolution Spectrometer (HRS) facility to study $2^{+}$states in selected s-d shell nuclei via inelastic proton scattering. In particular, we propose to measure the relative sign of neutron and proton matrix elements for the first two $2^{+}$states $\left(2_{1}^{+}\right.$and $\left.2_{2}^{+}\right)$in ${ }^{\circ} \mathrm{Si}$ and ${ }^{\mathrm{S}} \mathrm{S}$. Recent shell model calculations by Brown and Wildenthal indicate that neutron and. proton contributions to the cross sections for the $2{ }_{1}^{+}$states in these nuclei have the same relative sign, while in the $2{ }_{2}^{+}$state in ${ }^{30} \mathrm{Si}$ they have the opposite sign. Independent evidence from the BE2 values for these transitions in the mirror nuclei provide a measure of the magnitudes of the separate neutron and proton matrix elements but do not measure their relative sign. Proton scattering studies of these levels provide a unique opportunity to measure this relative sign, thus putting to a strict test our shell model understanding of their structure.

Exp. 628

STUDY OF THE ( $\pi, \pi p)$ REACTION AND QUASIFREE SCATTERING IN 'He

Arganne National Laboratory

D. Ashery, Spokesman

D. F. Geesaman, R. J. Holt, H. E. Jackson, J. P. Schiffer, (also Univ. of Chicago), J. R. Specht, K. E. Stephenson, B. Zeidman

LASL

P. A. M. Gram, Spokesman

University of Oregion

J. Faucett

College of William \& Mary

H. O. Funsten, D. Joyce

Univergity of Texas, Austin

C. A. Goulding (also LASL)

Florida State University

J. Norton, H. S. Plendl

Northwestern University

R. E. Segel

Oregon State University

L. W. Swenson

A measurement of inelastic pion scattering observed in coincidence with a recoil proton is planned with $160,220,350 \mathrm{MeV} \pi^{+}$on a target of ${ }^{~} \mathrm{He}$ as a function of angle. The experiment will be performed at the $\mathrm{P}^{3}$ channel. Scattered pions will be detected in the LAS spectrometer and protons in a large solid angle counter array previously used in Exp. 404. Earlier measurements of inclusive pion scattering in ' $\mathrm{He}$ (Exp. 390) suggest that inelastic scattering at large angles is dominated by quasifree scattering. Data resulting from the coincidence observation of pion and recoil proton should provide a clear indication of the validity of the impulse approximation in describing the scattering and the importance of contributions from higher order processes.

Exp. 629

\section{FEASIBILITY OF He-JET TECHNIQUES FOR STUDYING SHORT-LIVED NUCLEI PRODUCED AT LAMPF}

Idaho National Engineering Lab

R. C. Greenwood, Spokesman

R. A. Anderl, R. J. Gehrke, V. J. Novick, C. W. Reich 


\section{LASL}

M. E. Bunker and W. L. Talbert, Jr., Spokesmen

W. Faubel, B. J. Dropesky, G. C. Giesler, J. W. Starner

\section{University of Oklahoma}

R. F. Petry

We propose to explore the feasibility of studying shortlived radionuclides far from stability, produced at LAMPF via high-energy proton-induced reactions on various nuclei, including fission of heavy nuclei. The methodology would involve $\mathrm{H}$--jet transport of the reaction products to an isotope separator. The experiments described in the present proposal are concerned with preliminary on-line tests of a possible He-jet system.

The principal objectives of these experiments will be: 1) to determine optimal design and operational parameters for maximizing transport efficiencies for fission and spallation products, particularly those which cannot be isolated at other facilities employing isotope sefarators (for example, isotopes of the elements Mo, Tc, and various rare earths), and 2) to use the results of these studies to evaluate the viability of placing a He-jet target chamber in Line A thead of the primary beam dump (Station $\mathrm{A}$ ) and connecting it via a capillary transport line to an isotope separator located in the new staging area.

The experiments will be carried out in LAMPF Area B. The target chamber will be located in the Nuclear Chemistry Cave, and the rest of the apparatus will be located in the corridor between Area $B$ and C. Radioactive samples collected by means of the He-jet apparatus will be studied on-line or in the counting laboratory of CNC-11/LAMPF. The development and testing of the described system will be a joint effort of LASL and EG\&G Idaho participants. 
Exp. 630

\section{A STUDY OF PROTON INELASTIC SCATTERING AT ZERO DEGREES AND A SEARCH FOR GIANT MONOPOLE AND GIANT MAGNETIC DIPOLE EXCITA- TIONS}

LASL

J. B. McClelland and J. M. Moss, Spokesmen

T. A. Carey, W. D. Cornelius, S. J. Seestrom-Morris

Univeraity of Minnesota

N. M. Hintz, Spokesman

I. Cook, M. A. Franey, M. Gazzaly

The purpose of the experiment is to develop techniques for measuring inelastic cross sections at $\theta=0^{\circ}$. This angle is of special interest since cross sections for $\mathrm{L}=0$ orbital angular momentum transfer peak at $0^{\circ}$ while cross sections for $L>0$ either vanish or are very small there. Thus, $\mathrm{E}(0)(\Delta \mathrm{S}=0)$ and $\mathrm{M}(1)(\Delta \mathrm{S}=1)$ modes should dominate the spectrum. Location of the GMDR in heavy nuclei $(A>60)$ continues to be one of the major unsolved problems of nuclear structure. Many interesting problems involving the structure of the GMR also remain to be solved.

Techniques that will be employed include careful tuning of Lines $\mathrm{X}$ and $\mathrm{C}$ using only the Line$\mathrm{X}$ strippers to define the beam. Active collimators will be employed to eliminate beam halo and slit-edge and pole-face scattering within the HRS. Special $0^{\circ}$ focal plane chambers will be employed to record inelastic spectra.

Exp. 631

STUDY OF THE SPIN-FLIP PROBABILITY FOR ELASTIC AND INELASTIC SCATTERING FROM ODD-MASS NUCLEI

\section{LASL}

S. J. Seestrom-Morris, T. A. Carey, J. M. Moss, Spokesmen

W. D. Cornelius, J. B. McClelland

University of Minnesota

D. Dehnhard, Spokesman

We propose to use the HRS focal plane polarimeter to measure the spin-flip probability in elastic scattering from ${ }^{7} \mathrm{Li}$ and ${ }^{51} \mathrm{~V}$ and in inelastic scattering to three states in ${ }^{15} \mathrm{C} ; 1 / 2^{+}(3.09$ $\mathrm{MeV}), 1 / 2^{-}(8.86 \mathrm{MeV})$, and $9 / 2^{+}(9.5 \mathrm{MeV})$. The sensitivity of the spin-flip probability to the spin transferred to the nucleus will be used to investigate the relative importance of $\Delta S=0$ and $\Delta \mathbf{S}=1$ amplitudes in whe transitions to these states. The elastic scattering measurements are aimed at identifying contributions due to nonzero angular momentum transfer in the elastic scattering.

Exp. 632

CAN PROTON DENSITY DIFFERENCES BE EXTRACTED FROM MEDIUM ENERGY p-NUCLEUS ELASTIC SCATTERING DATA?

University of Texas, Austin

M. Barlett and G. W. Hoffmann, Spokesmen

R. Ferguson, J. Marshall, J. McGill, E. C. Milner, L. Ray, C. Sorenson 


\section{Massachusetts Institute of Technology}

W. Bertozzi, S. Kowalski

Using the HRS and an $800-\mathrm{MeV}$ polarized beam, we will determine accurate cross section and analyzing power ratios (as a function of scattering angle) for elastic scattering from the isotone pairs: ${ }^{39} \mathrm{~K}-{ }^{10} \mathrm{Ca},{ }^{58} \mathrm{Fe}-{ }^{58} \mathrm{Ni}$, and ${ }^{80} \mathrm{Zr}-{ }^{02} \mathrm{Mo}$.

Using mode]-independent techniques and the KMT formalism, we will analyze the experimental ratios to obtain empirical matter density differences. According to Hartree-Fock theory, these differences are expected to be due mainly to differences in the proton distributions. Since the charge density differences are already known from electron scattering experiments, a comparison of our results with the electron scattering results will provide a test of our ability to make meaningful statements about matter density differences in general.

The HRS will be moved in increments of $1.5^{\circ}$ to span the laboratory angular range 3.5 to $29.0^{\circ}$. The MBD cut will be utilized as necessary to guarantee sufficient statistical accuracy $(₹ 1 \%)$ of the binned $\left(\approx 0.2^{\circ}\right)$ elastic angular distribution data for reasonably short running times $(\approx 1-\mathrm{h}$ total per nucleus per HRS angle setting for the larger angles). A total time of $150 \mathrm{~h}$ is requested.

Exp. 633

\section{MEASUREMENT OF p-p SCATTERING IN THE COULOMB INTERFERENCE REGION BETWEEN 300 AND $800 \mathrm{MeV}$}

\section{University of California, Los Angeles}

F. Irom and G. Pauletta, Spokesmen

B. Aas, S. M. Haji-saeid, G. Igo, C. A. Whitten

\section{University of Minnesota}

M. Gazzaly

LASL

J. B. McClelland

We will measure the differential cross section and analyzing power for $p$-p scattering at energies ranging between 300 and $700 \mathrm{MeV}$, and at angles ranging between 0 and $10^{\circ}$ in the laboratory system.

This measurement will be performed in Line B, using the EPB channel. The experimental method for the N-N small angle has been established in the course of Exp. 289. In this method the forward angle elastic scattering cross section and analyzing power are obtained from measurements in a gas cell of the energy spectra for the recoil target particles.

A number of measurements between 300 and $800 \mathrm{MeV}$ would be quite interesting. There are some available data between 300 to $800 \mathrm{MeV}$ but the data is sparse and most have large errors. An exception is the data of Aebischer, et al. These authors have measured $A_{y} \theta$ and $d \sigma / d t$ at energies ranging between 300 to $600 \mathrm{MeV}$ with better than average accuracy. However, there is a pronounced discrepancy between their values for $\rho$ (ratio between real to imaginary part of the spin independent nuclear term) and those of the Arndt phase shift prediction and FDR calculations (Fig. 1). We feel that it is important to resolve this discrepancy. The measurements we propose will span the energy region covered by the data of Aebischer and overlap with other presently approved measurements at LAMPF. 
Exp. 634

\section{MEASUREMENT OF PARITY VIOLATION IN THE p-NUCLEON TOTAL CROSS SECTIONS AT $800 \mathrm{MeV}$}

\section{LASL}

R. Carlini and R. L. Talaga, Spokesmen

J. D. Bowman, R. E. Mischke, D. E. Nagle

\section{University of Illinois}

V. Yuan, Spokesman

H. Frauenfelder, R. Harper

No Summary Available

Exp. 635

\section{SPIN MEASUREMENTS IN pd ELASTIC SCATTERING}

\section{LASL}

B. E. Bonner, Spokesman

W. D. Cornelius, J. B. McClelland, M. W. McNaughton

University of California, Los Angeles

G. J. Igo and M. Bleszynski, Spokesmen

B. Aas, E. Bleszynski, G. Pauletta, M. Hajisaeid, F. Irom, A. Rahbar

University of Texas, Austin

C. L. Hollas, R. D. Ransome, P. J. Riley

As part of the program for determining the spin dependent NN amplitudes at LAMPF energies, we are proposing to measure the spin rotation and depolarization parameters in the $\vec{p} d \rightarrow \vec{p} d$ reaction. In the context of a Glauber calculation, these measurements will yield new information on the double spin-flip parts of the $\mathrm{T}=0 \mathrm{NN}$ interaction. A rigorous check on our ability to extract this information will be obtained by measurements made at $0.5 \mathrm{GeV}$ where these amplitudes are known.

One of the merits of this proposal is that for the angular range that can be covered in EPB, measurements will not be undertaken at HRS where scheduling conflicts caused by spin directions other than $\mathrm{N}$-type arise. Unfortunately, the very small angles cannot be covered at EPB; hence, the HRS measurements will concentrate on these angles.

Exp. 636

A MEASUREMENT OF THE WOLFENSTEIN POLARIZATION PARAMETERS

$$
D_{\mathrm{LL}}, \mathrm{D}_{\mathrm{sL}}, \mathrm{K}_{\mathrm{LL}}, \text { AND } \mathrm{K}_{\mathrm{SL}} \text { FOR p-p ELASTIC SCATTERING }
$$

\section{University of Texas, Austin}

C. L. Hollas, Spokesman

R. D. Ransome, P. J. Riley

LASL

B. E. Bonner, W. D. Cornelius, E. W. Hoffman, M. W. McNaughton, O. B. van Dyck, R.

L. York

Argonne National Laboratory

K. Imai, K. Toshioka 


\section{Rice University}

J. B. Roberts. S. E. Turpin

The objective of the proposed experiment is to measure the proton-proton elastic scattering Wolfenstein observables $D_{\mathrm{LL}}, \mathrm{D}_{\mathrm{sI}}, K_{\mathrm{LL} . \mathrm{l}}$, and $K_{\mathrm{SI}}$ at 650 and $800 \mathrm{MeV}$ incident proton energies over a range of center-of-mass angles 30 to $90^{\circ}$ for the depolarization parameters and 40 to $90^{\circ}$ for the transfer parameters. The EPB beam line polarization precession system will be used to provide the polarization direction of the incident beam either longitudinally or sideways. The longitudinal polarization component of the scattered particle will be precessed $90^{\circ}$ to sideways by a dipole magnet. This resulting sideways component will be analyzed by the recoil proton polarimeter JANUS.

Exp. 637

\section{A MEASUREMENT OF THE VECTOR POLARIZATION OF THE DEUTERON IN THE REACTION $p p \rightarrow d \boldsymbol{\pi}^{+}$}

\section{LASL}

B. E. Bonner, Spokesman

W. D. Cornelius, E. W. Hoffman, O. B. van Dyck, M. W. McNaughton, J. B. Roberts (Rice/LASL.)

University of Texas, Austin

C. L. Hollas, R. D. Ransome, P. J. Riley

Rice University

S. Turpin

TRIUMF

J. A. Niskanen

We propose new measurements for the $\mathrm{pp} \rightarrow \mathrm{d} \pi^{+}$reaction. They consist of the vector polarization and vector polarization transfer for the deuteron using an unpolarized and polarized proton beam. The unpolarized proton beam is obtained simply by averaging over the initial states of the polarized beam. These parameters, when expressed in terms of the reaction amplitudes, probe a completely new combination of these amplitudes and therefore will test predictions of the various models of the reaction at a new level.

Exp. 638

\section{A SEARCH FOR OSCILLATIONS USING MUON-NEUTRINOS}

\section{University of Maryland}

T. W. Dombeck, Spokesman

LASL

T. J. Bowles, R. L. Burman, J. S. Frank, C. M. Hoffman, H. S. Matis

We propose to search for evidence of muon-neutrinos oscillating into electron-neutrinos using muon-neutrinos from pion decays in flight at LAMPF. The experiment will also be sensitive to the disappearance of muon-neutrino flux as a function of distance from the source due to other oscillation modes. The modular detector we propose for this experiment consists of alternating layers of liquid scintillator and proportional drift chambers with a fiducial mass of 50 tons. After 
100 days of running time, we will be able to set an upper limit of $\Delta \mathrm{m}^{2}<0.025 \mathrm{eV}^{2}$ for the muonelectron neutrino mass squared difference and $\Delta \mathrm{m}^{2}<0.20 \mathrm{eV}^{2}$ in the muon-neutrino disappearance experiment with fine sensitivity to mixing parameters well below the Cabibbo angle. We discuss the requirements that this experiment places on a new neutrino beam proposed for LAMPF.

Exp. 639

\section{MUON SPIN ROTATION STUDY OF MUON BONDING AND MOTION IN SELECTED MAGNETIC OXIDES}

\section{LASL}

C. Boekema, Spokesman

R. H. Heffner, R. L. Hutson, M. Leon, C. E. Olsen, M. E. Schillaci

University of Wyoming

A. B. Denison, Spokesman

Technical Univeroity of Eindhoven, The Netherlands

V.A.M. Brabers

AERE, Harwell (UK)

A. M. Stoneham

The technique of muon spin rotation $(\mu \mathrm{SR})$ will be used to probe the local magnetic fields in the interstitial regions of a set of magnetic oxides. One goal of this work is to understand the interaction of the muon with its atomic environment. Implied in this goal is an understanding of the muon motion at higher temperatures and the chemical bonding at lower temperatures. The manner in which the muon affects its own chemical environment is to be understood. The magnetic oxides chosen, which possess known magnetic behavior, are particularly helpful hosts in this endeavor. Our study will begin with temperature- and field-dependent measurements on ilmenite $\left(\mathrm{FeTiO}_{3}\right)$, erbium orthoferrite $\left(\mathrm{ErFeO}_{3}\right)$, and magnetite $\left(\mathrm{Fe}_{3} \mathrm{O}_{4}\right)$. We feel reliable measurements can be made in 30 shifts. 
Exp. 640

TRANSVERSE AND LONGITUDINAL FIELD HSR MEASUREMENTS IN SELECTED TERNARY METALLIC COMPOUNDS

\section{Rice Univeraity}

LASL

S. A. Dodds, Spokesman

R. H. Heffner, Spokesman

C. Boekema, R. L. Hutson, M. Leon, M. E. Schillaci, J. L. Smith

University of Califomia, Riverside

D. E. MacLaughlin, Spokesman

The proposed work will use muon spin rotation $(\mu \mathrm{SR})$ to examine the properties of some ternary metallic compounds which exhibit both superconductivity and magnetic order. The advantages of the $\mu \mathrm{SR}$ technique for studying these systems are: (1) the ability to measure depolarization in zero and low fields, (2) the ability to measure short relaxation times (compared to NMR) and the capability of measuring both $T_{1}$ and $T_{2}$. The first samples to be measured will be $\mathrm{Lu}_{1-x} \mathrm{Ho}_{\mathbf{2}} \mathrm{Rh}_{4} \mathrm{~B}_{4}$, for $x=0,1$ and $\sim 0.7$. LuRh, $B_{4}$ has a superconducting transition at $T_{c}=11.5 \mathrm{~K}$, whereas HoRh, $B_{4}$ has a ferromagnetic transition at $T_{M} \approx 6.8 \mathrm{~K}$. The mixed system $(\mathrm{x} \simeq 0.7)$ has a superconducting transition at $T_{c 1} \simeq 7.4 \mathrm{~K}$ and a ferromagnetic transition at $T_{c 2} \simeq 4.2 \mathrm{~K}$. We will examine these systems using finite (transverse and longitudinal) and zero-field $\mu$ SR to measure internal field inhomogeneities and rare-earth ion fluctuation rat $s$ throughout the temperature range $T \leq T_{\mathrm{cl}}+$ 20. We will specifically address important questions such as: 1) Does the onset of superconductivity affect the spin dynamics in the paramagnetic state and thus modify the magnetic ordering? and (2) To what extent does the onset of ferromagnetic order immediately suppress superconductivity (i.e., is there a spin-fluctuation regime in the superconducting state)? The $\mu \mathrm{SR}$ measurements will be compared to "B NMR and neutron scattering experiments on the same samples as is feasible. We request $250 \mathrm{~h}$ for these studies.

Exp. 641

\section{MEASUREMENT OF CROSS SECTION AND ANALYZING POWERS FOR ELASTIC AND INELASTIC SCATTERING OF 400 TO 500 PROTONS FROM ${ }^{14} \mathrm{C}$}

\section{University of Texas}

C. J. Harvey, Spokesman

C. A. Goudling, P. A. Seidl

LASL

S. J. Seestrom-Morris, Spokesman

C. L. Morris

\section{University of Minnesota}

D. Dehnhard, D. B. Holtkamp

U. S. Air Force Academy

R. J. Joseph

We propose to measure cross sections and analyzing powers for elastic and inelastic scattering of $500-\mathrm{MeV}$ polarized protons from ${ }^{14} \mathrm{C}$ for excitation energies up to $25 \mathrm{MeV}$. The nucleon-nucleon interaction is well known at this energy and the impulse approximation is probably still valid. The spin-dependent terms in the nucleon-nucleon interaction are more pronounced in this energy region, abetting the observation of two interesting spin-flip transitions: tie two $4^{-}$states at 11.7 
and $17.3 \mathrm{MeV}$ which have been seen in pion inelastic scattering. Data will be taken from $6^{\circ}$ out to $36^{\circ}$ in $2^{\circ}$ steps. Among other states, we will measure angular distributions for the aforementioned $4^{-}$states and the low-lying $2^{+}$states which appear to share the p-shell strength and are expected to have significant spin-flip components also. We plan to measure a cross section for the lowlying $0^{-}$state at $6.9 \mathrm{MeV}$ in ${ }^{14} \mathrm{C}$ which is separated by $100 \mathrm{keV}$ from the nearest excited state and should be well resolved.

Exp. 642

REACTIVE CONTENT OF THE OPTICAL POTENTIAL - PHASE II

University of Texas, Austin

G. W. Hoffmann, T. McGill, Spokesmen

M. Barlett, R. Ferguson, J. Marshall, E. C. Milner, L. Ray, C. Sorenson Rutgere Univeroity

C. Glashausser, K. Jones, S. Nanda

University of Maryland

E. F. Redish, S. J. Wallace

No Summary Available

Exp. 643

STRUCTURE OF STATES IN THE OXYGEN ISOTOPES VIA MEASUREMEISTS OF THE

SPIN DEPOLARIZATION AND SPIN ROTATION OBSERVABLES

University of California, Los Angeles

B. Aas. Spokesman

E. Bleszynski, M. Bleszynski, M. Hajisaeid, G. J. Igo, F. Irom, G. Pauletta LASL

M. V. Hynes, Spokesman

Lawrence Livermore Laboratory

B. Berman

University of Virginia

B. Norum

Massachusetts Institute of Technology

W. Bertozzi, J. Kelly, B. Murdock

We propose to measure elastic observables for the oxygen isotopes; for ${ }^{10} \mathrm{O}$ we also propose to measure observables for the low-lying isoscalar excitations. We will measure: 1) with a precision of $1.5 \%$ and 0.015 , the differential cross section $\mathrm{d} v / \mathrm{d} \Omega$ and analyzing power $A P$, respectively, for ${ }^{17} \mathrm{O}$ and ${ }^{18} \mathrm{O}$ from $2-30^{\circ}$ lab, and 2) the spin rotation observables $\mathrm{R}, \mathrm{A}, \mathrm{R}, \mathrm{A}^{\prime}$ for ${ }^{10} \mathrm{O}$, ${ }^{17} \mathrm{O}$, and ${ }^{10} \mathrm{O}$ and $\mathrm{D}$ for ${ }^{17} \mathrm{O}$ from $5-25^{\circ}$ with statistical accuracy of 0.015 at the smal'er angles and absolute uncertainty of $\leq 0.04$. The deduced observables

$$
\mathrm{D} \sigma / \mathrm{d} \Omega, \operatorname{AP}(=\mathrm{P}), \mathrm{Q} \text {, and } \frac{\left|\mathrm{F}^{2}\right|-\left|\mathrm{G}^{2}\right|}{\left|\mathrm{F}^{2}\right|+\left|\mathrm{G}^{q}\right|}
$$


will be analyzed using multiple scattering theory to deduce isotopic neutron mass distributions (INMD) for the oxygen isotopes. We anticipate that the INMD will be considerably better defined than was possible before because of the inclusion of spin rotation observables in the analysis. In the case of the low-lying isoscalar excitations in ${ }^{10} \mathrm{O}$, we will deduce the Coulombic density. A subsequent phase of our plan of investigation of the oxygen isotopes is also briefly outlined.

Exp. 644

\title{
TESTS OF THE POLARIZATION-ANALYZING POWER EQUALITY IN ELASTIC SCATTERING OF INTERMEDIATE ENERGY PROTONS FROM NUCLEI
}

\author{
University of California \\ G. J. igo, Spokesman \\ B. Aas, E. Bleszynski, M. Bleszynski, M. Hajisaeid, F. Irom, G. Pauletta, R. Rahbar
}

We propose the following measurements to test for time reversal invariance in elastic scattering: $\mathrm{D}$ (depolarization parameter) in $\mathrm{p}+{ }^{2} \mathrm{H}$ elastic scattering near $\mathrm{t}=-0.4(\mathrm{GeV} / \mathrm{c})^{2}, \mathrm{D}$ in $\mathrm{p}+$ ${ }^{209} \mathrm{Bi}$ and $\mathrm{p}+{ }^{40} \mathrm{Ti}$ elastic scattering for $0.2 \leq-\mathrm{t} \leq 0.6(\mathrm{GeV} / \mathrm{c})^{2}, \mathrm{~A}$ (asymmetry) and $\mathrm{P}$ (polariza-

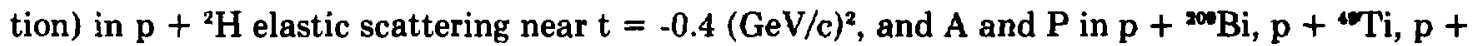
${ }^{200} \mathrm{~Pb}$ and $\mathrm{p}+{ }^{48} \mathrm{Ca}$ at a $\mathrm{t}$ value where $\mathrm{I}-\mathrm{D}$ is maximal for the first two. We propose to make these investigations at a bombarding energy of $\leq 400 \mathrm{MeV}$ and at $800 \mathrm{MeV}$. Our objective is to measure $P$ - A in p-d elastic scattering with experimental uncertainty of the order of 0.03 . In p-200 Bi and p${ }^{39} \mathrm{Ti}$, we anticipate uncertainties below 0.03 .

Exp. 645

\section{A SEARCH FOR NEUTRINO OSCILLATIONS AT LAMPF}

\section{Ohio State University}

T. Y. Ling and T. A. Romanowski, Spokesmen

Argonize National Laboratory

L. G. Hyman, B. Musgrave

Louisiana State University

R. Imlay, W. J. Metcalf

California Institute of Technology

R. B. McKeown

We propose a program at LAMPF to search with highest sensitivity for neutrino oscillations in three different channels $\nu_{\mathrm{e}} \rightarrow \nu_{\mathrm{e}}, \bar{\nu}_{\mu} \rightarrow \bar{\nu}_{\mathrm{e}}$ and $\nu_{\mu} \rightarrow \nu_{\mu}$ and wish to achieve our objective in the stages as follows.

I. Construction of neutrino detector and a shielding culvert at the existing beam Line-A. In this phase we will search for $\nu_{\mathrm{e}}$ disappearance and the process $\bar{\nu}_{\mu} \rightarrow \bar{\nu}_{\mathrm{e}}$. This experiment can be performed at LAMPF with high sensitivity unmatchable elsewhere. In order to suppress the background we plan to investigate the detection of neutrons in the reaction $\vec{\nu}_{a}+\mathbf{p} \rightarrow \mathrm{e}^{+}+\mathbf{n}$ as suggested by the PAC. LAMPF at this time is the only existing source of intense $\nu_{*}$ and $\vec{\nu}_{\mu}$ beams with some unique characteristics as compared to the neutrino beams at reactors or other accelerators which make our program competitive and complementary to other experiments on this important suhject. The early construction of the culvert should not interfere with the present 
neutrino oxperiments E-225 and E-609. It will also allow another series of timely experiments to take data soon and run concurrently, thus, enhancing the utilization of the LAMPF proton beam.

II. At the time of completion oi tise experiments E-225 and E-609, about two years from now we propose to vearrange present beam stop to accommodate an in-flight $\nu_{\mu}$ beam. This would become the most intense source in existence of low-energy $\nu_{\mu}$ which would enable us to pursue search for $\nu_{\mu}$ disappearance with high sensitivity and excellent background rejection. Such a facility will use all of the available proton flux at LAMPF with least impact on the scheduling of the accelerator. The construction of such a facility is technically feasible and will be cost effective as compared to other possible alternatives.

III. The Neutrino Detector - The proposed neutrino detector with capabilities for tracking particle velocity, range and ionization measurements, as well as the active cosmic ray shield will enable us to sharply identify the required neutrino events. The detector does not require development of any novel techniques and its construction is relatively straight forward and it is modular.

IV. Future Neutrino Program at the Proton Storage Ping (PSR) - The use of the microstructure of the PSR will virtually eliminate the cosmic ray background in a neutrino experiment performed there. We suggest severil neutrino experiments for which PSR neutrino beams and our detector wuuld be particularly suitable. Our detector could be readily installed at a PSR neutrino facility.

V. We feel that the proposed program for the search of neutrino oscillations is timely and an important physics which we are prepared to pursue with total commitment. Our time and cost estimates for building the neutrino detector shows that it could be possible to start equipment testing and assembly of the experiment in about 12 months from the approval of the experiment. As the detector modules are built we plan to progressively assemble the modules at LAMPF, thus reducing the installation time. Preliminary data taking with a partially completed detector should commence in the fall of 1982 . We will interact with the LAMPF staff in construction of a new neutrino facility in Beam $A$ and could provide some of the required engineering expertise from our home institutions.

Exp. 646

\section{HYPEIRFINE STRUCTURE OF MUONIC HELIUM-3 AND MUONIC HELIUM-4 ATOMS}

Yale

V. W. Hughes and P. O. Egan, Spokesmen

We propose two measurements on hyperfine structure intervals of muonic helium atoms:

Part 1. The first rneasurement of $\Delta \nu$ for the ${ }^{3} \mathrm{He}^{-} \mathrm{e}^{-}$atom with an expected accuracy of $50 \mathrm{ppm}$ or better.

Part II. Additional measurements using different transitions for the ${ }^{4} \mathrm{He}^{-} \mathrm{e}^{-}$atom to determine $\Delta \mu$ to about $5 \mathrm{ppm}$ and $\mu_{\mu-} / \mu_{\mathrm{p}}$ to about $30 \mathrm{ppm}$. These measurements test the theory of atomic hyperfine structure to high accuracy and also provide the most precise direct measurement of the ratio of the negative muon to proton magnetic moments. 
Exp. 647

\title{
A NEUTRON OSCILLATION EXPERHMENT AT LAMPF
}

\section{LASL}

R. J. Ellis, Spokesman

J. D. Moses, A. Taylor

It is proposed to search for neutron oscillations at the $135^{\circ}$ neutron port at the LAMPF beam stop. A novel detector is proposed which is simple to construct and moderate in cost. It has a detection efficiency of $47 \%$. The charged cosmic-ray background rate is of order $10^{-8}$ per day. The main source of backgrounds is from neutral cosmic rays. With reasonable amounts of shielding this amounts to five $10^{-2}$ counts per day. It is possible to put a limit of $10^{\circ} \mathrm{s}$ on the neutron mixing time $\tau$, in 100 days running.

LAMPF is a unique facility to do this experiment because it is the most intense pulsed neutron source in the world. The experiment has been designed to exploit the pulsed structure of the beam to reduce backgrounds.

No civil engineering is required. No structures to be moved. No modifications to the machine are required. No change in the mode of operation of the machine are requested.

The limit on $\tau$ could be extended to $10^{7} \mathrm{~s}$ in a second phase of the experiment if a cold moderator is added.

Exp. 648

\section{TEST OF EQUIPMENT FOR THE MEASUREMENT OF THE $\boldsymbol{\Sigma}^{-}$ FOR THE MAGNETIC MOMENT AT BNL}

\author{
Boston University \\ J. Miller, Spokesman
}

This experiment will use the Test Channel in a parasitic mode.

Exp. 649

\section{ASYMMETRY MEASUREMENTS OF THE (p, $\left.\pi^{ \pm}\right)$REACTIONS ON ${ }^{\circ} \mathrm{Li}$ and ${ }^{\circ B e}$ AT $650 \mathrm{MeV}$}

\author{
University of Texas, Austin \\ B. Hoistad, Spokesman \\ M. Barlett, G. W. Hoffmann \\ Massachusetts Institute of Technology \\ G. S. Adams \\ University of Minnesota \\ M. M. Gazzaly
}

We propose to use the HRS spectrometer facility to study the asymmetry in positive and negative pion production from the $(p, \pi)$ reaction on nuclei, induced by polarized protons of about $650 \mathrm{MeV}$. New $\left(p, \pi^{ \pm}\right)$data indicate that the analyzing power is sensitive to the incident proton energy, the nuclear structure involved, as well as the charge state of the pion. It is therefore likely that such measurements should give important information about the reaction process. This is also suggested by current theories of the $(p, \pi)$ reaction. 
Exp. 650

\title{
A SEARCH FOR NEUTRINO MIXING VIA NONEXPONENTIAL $\pi \rightarrow \mu v$ DECAY
}

Los Alamos National Laboratory

J. D. Bowman, Spokesman

Tel Aviv University/Los Alamos Nationai Laboratory

M. A. Moinester

We propose to search for neutrino mixing via measurements of a modulation of the exponential time dependence of the appearance probability of muons in the decay $\pi \rightarrow \mu \nu$. The muon appearance probability at a point $x$ and a time $t$ from a pion stopped at $x=0, t=0$ is given by:

$$
|A(x, t)|^{2}=\frac{1}{\tau} e^{-t / \tau}\left[1+\sin 2 \delta \cos 2 \pi\left(\frac{t}{T}-\frac{x}{\lambda}\right)\right] .
$$

For neutrino mass splittings of the order of hundreds of $(\mathrm{ev})^{2}$, $\mathrm{T}$ and $\lambda$ liave laboratory sizes. Furthermore, the fraction of oscillation is first-order in sin $2 \delta$, allowing previously nonaccessible regions of $(\delta$, mass) space to be studied.

Exp. 651

\section{MEASUREMENT OF A LOWER LIMIT FOR THE SUBTHRESHOLD PRODUCTION OF}

KAONS WITH 800-MeV PROTONS

\author{
Los Alamos National Laboratory \\ C. L. Morris, Spokesman \\ J. F. Amann, R. L. Boudrie, T. A. Carey, N. J. DiGiacomo, J. B. McClelland, J. M. \\ Moss, S. J. Seestrom-Morris \\ University of Texas, Austin
}

B. Hoistad

We intend to use the EPICS channel and spectrometer to look for delayed muons arising from stopped kaon decays in the A-1 production target, and consequently to place limits on the $\mathrm{p}+{ }^{12} \mathrm{C}$ subthreshold kaon production cross section. This measurement should provide a useful bound for current models of this rare process and will be useful in designing future experiments to investigate hypernuclear levels and reaction mechanisms for subthreshold kaon production. In a preliminary run we were able to show the feasibility of the experiment, and we established an upper limit of $10 \mathrm{pb} / \mathrm{sr}$ for the angle averaged $\mathrm{d} \sigma / \mathrm{d} \omega$ for kaon production (see progress report attached to proposal). Data from this preliminary run shows that this upper limit can be improved by at least a factor of 10 . Consequently we are requesting additional running time.

Exp. 652

TEST OF PROTOTYPE SEMICONDUCTOR DETECTORS

\author{
University of Oklahoma \\ P. Skubic \\ G. Kalbfleisch
}

Fermi National Laboratory

M. Johnson, C. Nelson 


\section{Ohio State University}

J. Kalen, S. Kuramata, N. W. Reay, K. Reibal, R. Sidwell, N. R. Stanton

No summary available.

Exp. 653

\section{MUONIC X-RAY STUDY OF ${ }^{241}$ Am AND ${ }^{243}$ Am}

\section{Los Alamos National Laboratory}

E. B. Shera and M. W. Johnson, Spokesmen

M. V. Hoehn, M. W. Johnson, H. D. Wohlfahrt

Princeton University

R. A. Naumann, Spokesman

Oak Ridge National Laboratory

C. E. Bemis, Jr.

We propose to measure the energy levels of muonic ${ }^{241} \mathrm{Am}$ and ${ }^{243} \mathrm{Am}$ with a high-precision $\mathrm{Ge}(\mathrm{Li})$ spectrometer system. The primary objectives of this work are to measure nuclear charge distribution parameters for these nuclides, which will be the heaviest ever studied with muonicatom techniques, and in particular to determine the shift in mean-square radius $\delta\left(r^{2}\right)_{243-241}$ between the isotopes. The latter quantity is of great importance in its implications for an optical isomer-shift study of the ${ }^{240} \mathrm{Am}$ fission isomer. The experiments will be done at the SMC with the $\mathrm{P}^{3}$ apparatus used on the previous proposals 334 and 495 .

Exp. 654

\section{MEASUREMENT OF THE SPIN-ROTATION PARAMETER Q FOR $800 \mathrm{MIeV} p+{ }^{10} \mathrm{O}$,} ${ }^{40} \mathrm{Ca}$ AND ${ }^{209} \mathrm{~Pb}$ ELASTIC SCATTERING

\section{University of Texas, Austin}

G. W. Hoffmann, Spokesman

M. Barlett, R. Fergerson, J. Marshall, J. McGill, E. C. Milner, L. Ray

\section{Lo8 Alamos National Laboratory}

J. F. Amann, J. B. McClelland

University of California, Los Angeles

G. J. Igo

Using the HRS and an $800-\mathrm{MeV} \mathrm{L}$ - and S-type polarized beam, we will measure the spinrotation parameter, $\mathrm{Q}$, for $\mathrm{p}+{ }^{10} \mathrm{O},{ }^{10} \mathrm{Ca}$ and ${ }^{208} \mathrm{~Pb}$ over the laboratory angular range 2 to $15.5^{\circ}$ $\left({ }^{10} \mathrm{Ca}\right.$ and $\left.{ }^{208} \mathrm{~Pb}\right)\left[2\right.$ to $\left.23^{\circ}\left({ }^{18} \mathrm{O}\right)\right]$. These data will be used to test medium energy scattering theories which employ medium corrections to the impulse approximation. 
Exp. 655

\title{
$\pi \pm$ INELASTIC SCATTERING FROM 'He: AN EXAMINATION OF ISOSPIN- SYMMETRY BREAKNG
}

\author{
University of Minnesota \\ D. B. Holtkamp, Spokesman \\ D. Dehnhard \\ New Mexico State University \\ W. B. Cottingame, Spokesman \\ G. R. Burleson, S. J. Greene \\ Florida State University \\ D. Halderson \\ Los Alamos National Laboratory \\ M. V. Hynes \\ University of Colorado \\ E. R. Siciliano
}

For the last 15 years, the comparison between photo-proton and photo-neutron disintegration of 'He has provided startling evidence of large isospin mixing in the $A=4$ iystem. Recently, Calarco and Berman have concluded from an exhaustive, global data compa: un that the isospin mixing needed to explain the data is far in excess of that attributed to the Coulomb force, which is small for the $Z=2$ nucleus.

We propose to use $\pi^{+} / \pi^{-}$comparison in inelastic scattering from ${ }^{4} \mathrm{He}$ to test the hypothesis that there is large isospin mixing in this nucleus. Such comparisons have proved to be a very sensitive and accurate measure of isospin mixing in ${ }^{12} \mathrm{C}$ and ${ }^{18} \mathrm{O}$.

As a simultaneous goal, we also would search for evidence of $\Delta$-hole admixtures in low-lying excited states, as has been recently proposed by Bohr and Mottelson.

The total time requested for this experiment is 336 hours.

Exp. 656

\section{PION DOUBLE CHARGE EXCHANGE ON SELF-CONJUGATE NUCLEI}

New Mexico State University

S. J. Greene, Spokesman

G. R. Burleson, W. B. Cottingame

Los Alamos National Laboratory

C. L. Morris, Spokesman

University of Minnesota

D. B. Holtkamp

University of Pennsylvania

H. T. Fortune, Spokesman

L. Bland, M. Carchidi

University of Texas

C. F. Moore

We propose to measure $\mathrm{DCX}$ excitation functions from the $\mathrm{T}=0$ nuclei ${ }^{28} \mathrm{Si}$ and ${ }^{40} \mathrm{Ca}$, at EPICS. We have several uses for the data, complementary to previous data. The ${ }^{28} \mathrm{Si}$ data will be used in conjuriction with our previous ${ }^{26} \mathrm{Mg}$ data to extend our two-amplitude analysis of DCX. Similarly, the ${ }^{40} \mathrm{Ca}$ data will be used with previous ${ }^{42} \mathrm{Ca}$ data. 
Of all $\pi$-nuclear reactions, unly nonanalog DCX resembles strongly the $(3,3)$ resonance energy dependence. This may indicate that the reaction proceeds simply through $\Delta$ formation in the intermediate state, or that the final states involve a $\Delta$-hole component in their wave functions.

Exp. 657

\title{
INELASTIC $\pi^{ \pm}$SCATTERING FROM THE $\mathbf{N}=28$ ISOTONES
}

\section{University of Texas, Austin}

P. A. Seidl and C. F. Moore, Spokesmen

\section{Los Alamos}

C. L. Morris

University of S. Carolina

G. S. Blanpied

Wave function calculations are often tested by comparing Eigen energies and electromagnetic decay rates that are predicted with experimental measurements. However, often more stringent tests can be made using information gained from detailed measurements of the transition densities from inelastic scattering. Indeed, electron inelastic scattering has proven very useful in this respect. In the present experiment we hope to provide complementary data about the neutron transition densities that can be used to test wave function models.

We will measure inelastic scattering of $\pi^{ \pm}$to collective states in the neutron magic $N=28$ isotones: ${ }^{80} \mathrm{Ca},{ }^{80} \mathrm{Ti},{ }^{11} \mathrm{~V},{ }^{82} \mathrm{Cr}$, and ${ }^{\circ 4} \mathrm{Fe}$. For most of these isotones, form factors and consequently transition densities, are well known from inelastic electron scattering at momentum transfers from 0.5 to $1.7 \mathrm{~h} \mathrm{fm}^{-1}$. As a consequence we can compare $\pi^{+}$scattering (scattering mainly from protons) with DWIA calculations using these well known proton transition densities, and we can determine the transition densities for the neutron components in the wave function from the $\pi^{-}$ inelastic scattering.

Exp، 658

\section{STUDY OF THE SPIN-FLIP PROBABILITY FOR ELASTIC AND INELASTIC SCATTERING FROM ODD-MASS NUCLEI}

\author{
Los Alamos National Laboratory \\ S. J. Seestrom-Morris, T. A. Carey, J. M. Moss, Spokespersons \\ W. D. Cornelius, J. B. McClelland \\ University of Minnesota \\ D. Dehnhard, Spokesman
}

We propose to use the HRS focal plane polarimeter to measure the spin-flip probability in elastic scattering from ${ }^{7} \mathrm{Li}$ and ${ }^{61} \mathrm{~V}$ and in inelastic scattering to three states in ${ }^{19} \mathrm{C} ; 1 / 2^{+}(309$ $\mathrm{MeV}), 1 / 2^{-}(8.86 \mathrm{MeV})$, and $9 / 2^{+}(9.5 \mathrm{MeV})$. The sensitivity of the sp:n-flip probability to the spin transferred to the nucleus will be used to investigate the relative importance of $\Delta S=0$ End $\Delta \mathbf{S}=1$ amplitudes in the transitions to these states. The elastic scattering measurements are aimed at identifying contributions due to nonzero angular momentum transfer in the elastic scattering. 
Exp. 659

\section{SPIN-FLIP GIANT RESONANCE EXCITATION}

\section{University of Pennaylvania}

L. C. Bland, Spokesman

H. T. Fortune, M. Carchidi

\section{University of Texas}

C. F. Moore, Spokesman

P. A. Seidl, R. Kiziah, S. Elston, G. Nelson, C. J. Harvey

\section{Los Alamos National Laboratory}

S. J. Seestrom-Morris, C. L. Morris

New Mexico State University

S. J. Greene

In inelastic pion scattering from ${ }^{12} \mathrm{C}$ and ${ }^{12} \mathrm{O}$, one of the strongest peaks in the spectra corresponds to a level or group of levels at $25.5 \mathrm{MeV}(\Gamma=5 \mathrm{MeV})$ in ${ }^{12} \mathrm{C}$, and at $\approx 22 \mathrm{MeV}(\Gamma=2 \mathrm{MeV})$ in ${ }^{18} \mathrm{O}$. Cross section angular distributions in both ${ }^{12} \mathrm{C}$ and ${ }^{18} \mathrm{O}$, as well as an excitation function measured at $q=165 \mathrm{MeV} / \mathrm{c}$ in ${ }^{16} \mathrm{O}$, suggest a spin-flip mechanism and a spin assignment of $1^{-}$or $2^{-}$for this complex of states. A comparison with DWIA calculations, using simple particle-hole form factors, indicates this state must contain a large fraction of the $T=0, J^{\pi}=1^{-}, \Delta L=1, \Delta S$ $=1$ (isoscalar dipole spin flip) strength in both nuclei. In order to establish this state as a new giant resonance, we propose to search for it in the nuclei ${ }^{4} \mathrm{He},{ }^{10} \mathrm{Ca},{ }^{90} \mathrm{Zr}$. In order to establish its $\Delta S=1$ character in these nuclei as well as in ${ }^{12} \mathrm{C}$, we also wish to measure excitation functions. 
Exp. 660

\title{
MEASUREMENT OF POLARIZATION PARAMETERS FOR M1 TRANSITIONS IN THE ${ }^{90} \mathrm{Zr}\left(\mathbf{p}, \mathbf{p}^{\prime}\right)^{90} \mathrm{Zr}^{*}$ AND ${ }^{118} \mathrm{Sn}\left(\mathbf{p}, \mathbf{p}^{\prime}\right)^{118} \mathrm{Sn}^{*}$ REACTIONS AT $500 \mathrm{MeV}$
}

\author{
Rutgers \\ C. Glashausser, Spokesman \\ J. McGill, K. Jones, S. Nanda \\ Michigan State University \\ G. Crawley \\ Los Alamos National Laboratory
}

J. B. McClelland, J. M. Moss

The observables $A y, D_{n n}, D_{s s^{\prime}}$, and $D_{\ell s^{\prime}}$ will be measured at $500 \mathrm{MeV}$ for the reaction ${ }^{80} \mathrm{Zr}\left(\mathrm{p}, \mathrm{p}^{\prime}\right)^{90} \mathrm{Zr}{ }^{*}$ and ${ }^{116} \mathrm{Sn}\left(\mathrm{p}, \mathrm{p}^{\prime}\right)^{116} \mathrm{Sn}^{*}$ at small angles. A recent experiment carried out at Orsay at $200 \mathrm{MeV}$ has tentatively jdentified strong $\mathrm{M} 1$ strength in the ${ }^{00} \mathrm{Zr}\left(\mathrm{p}, \mathrm{p}^{\prime}\right)^{00} \mathrm{Zr}$ reaction at an excitation energy of about $8.9 \mathrm{MeV}$. We will attempt to confirm this identification by measuring the spin-flip probabilities for this resonance. We will also look for evidence of a similar resonance in ${ }^{116} \mathrm{Sn}$ where results from the previous experiment are not conclusive. In addition, the measurements should yield information about the isospin transfer.

Exp. 661

\section{GOOD RESOLUTION STUEY OF ${ }^{18} \mathrm{O}\left(\pi, \pi^{\prime}\right)$}

\section{Los Alamos National Laboratory}

C. L. Morris, Spokesman

J. F. Amann, R. L. Boudrie, S. J. Seestrom-Morris

University of Pennsylvania

L. C. Bland, Spokesman

R. Gilman, H. T. Fortune

\section{University of Minnesota}

D. Dehnhard, D. B. Holtkamp

We propose to measure cross sections at $\sim 160 \mathrm{MeV}$ for $\pi^{ \pm}$inelastic scattering from ${ }^{18} \mathrm{O}$ with about $130-\mathrm{keV}$ resolution, in order to resolve states not previously separable, and thereby to enable meaningful comparison between theory and experiment. We will also attempt to locate the high-lying $4^{-}$stretched states arising from $1 p_{9 / 2} \rightarrow 1 d_{5 / 2}$ and $1 d_{5 / 2} \rightarrow 1 f_{7 / 2}$ excitations, respectively. We will search for population of $T=2$ final states which should be excited, but which have not previously been cbserved in pion inelastic scattering on a $T=1$ target. The new cooled gas target system will remove the problem of hydrogen contamination and hence make accessible the region of high excitation.

Exp. 662

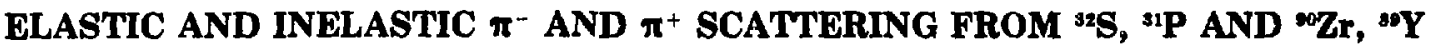 \\ University of Colorado \\ J. J. Kraushaar and R. J. Peterson, Spokesmen \\ T. G. Masterson, R. A. Ristinen, M. A. Rumore, E. R. Siciliano, J. L. Ullman}




\title{
Los Alamos National Laboratory
}

R. L. Boudrie

It is proposed that the EPICS system be used to measure the $\pi^{-}$and $\pi^{+}$elastic and inelastic cross section on two pairs of targets: ${ }^{32} \mathrm{~S},{ }^{31} \mathrm{P}$ and ${ }^{\circ 0} \mathrm{Zr}$, ${ }^{30} \mathrm{Y}$ at $140 \mathrm{MeV}$. Using good $\pi^{ \pm}$elastic data on ${ }^{32} \mathrm{~S}$ and ${ }^{00} \mathrm{Zr}$ and the proton distributions as determined by electron scattering, optical model calculations will be used to help determine the neutron distributions for these two nuclei as well as the odd members of the pairs, where a proton has been removed.

The low-lying states of ${ }^{3 !} \mathrm{P}$ and ${ }^{80} \mathrm{Y}$ excited by $\pi^{ \pm}$will be examined in terms of the proton hole coupling with the excitations of the ${ }^{32} \mathrm{~S}$ and ${ }^{80} \mathrm{Zr}$ cores. In the case of ${ }^{89} \mathrm{Y}$ and ${ }^{90} \mathrm{Zr}$, the inelastic cross sections will also be compared to microscopic distorted wave calculations.

Exp. 663

\section{ELA. AT INTERMEDIATE ENERGIES}

\author{
Univr sity of California, Los Angeles \\ G. J. Igo and $M$. Bleszynski, Spokesmen \\ B. Aas, A. Rahbar, G. Pauletta, A.T.M. Wang, C. A. Whitten \\ University of Minnesota \\ M. Gazzaly \\ Los Alamos National Laboratory
}

J. B. McClelland, M. V. Hynes

The objective of this experiment is to measure the neutron densities of ${ }^{3} \mathrm{H}$ and ${ }^{3} \mathrm{HE}$. A second objective is to extract information about the double spin flip components of $\mathrm{N}-\mathrm{N}$ amplitudes at small momentum transfers, which are especially important to know in connection with protonnucleus elastic and inelastic scattering analysis on intermediate and heavy nuclei. The spin rotation and depolarizatinn parameters will be measured out to $25^{\circ}$. The differential cross section and asymmetry will be measured out to momentum transfers of approximately $1.1 \mathrm{GeV} / \mathrm{c}$. From the experience with the measurement of $\mathrm{Q}$ during the last cycle on ${ }^{\circ 0} \mathrm{Ca}$ and ${ }^{200} \mathrm{~Pb}$, we have the capability to make realistic evaluations of the time required to complete a measurement on two targets at one bombarding energy. Furthermore, we will present to the PAC at the meeting some examples of what kind of statistical and systematic uncertainties we can anticipate. We will compare these with predictions of the observables calculated using multiple scattering treory. In this way we can illustrate our sensitivity to the parameters of the neutron $:$ insities and the doubie spin-flip parts of the N-N amplitude.

Exp. 664

THE MEÁSUREMENT OF THE POLARIZATION TRANSFER COEFFICIENTS $A_{t}^{\prime}$ AND $D_{t}$ AT 500, 650 AND $800 \mathrm{MeV}$ FOR THE REACTION d( $\left.\vec{p}, \vec{n}\right) 2 p$

Texas A\&M University

G. Glass, Spokesman

T. S. Bhatia, J. C. Hiebert, R. A. Kenefick, L. C. Northcliffe

Argonne National Laboratory

$R$. Stanek, Spokesman

W. R. Ditzler, D. Hill, K. Imai, H. Spinka, K. Toshioka, R. Wagner, A. Yokosawa 


\section{Los Alamos National Laboratory}

J. J. Jarmer, J. E. Simmons

New Mexico State University

G. R. Burleson, W. B. Cottingame, S. J. Greene

A series of neutron-proton scattering experiments utilizing a polarized neutron beam is being proposed by a collaboration of physicists from Argonne National Laboratory, Los Alamos National Laboratory, New Mexico State University, and Texas A\&M University. The polarized neutron beam is to be produced via the reaction $d(\vec{p}, \vec{n}) 2 p$ at $0^{\circ}$. Initial experiments seek to measure $\Delta \sigma_{\mathrm{L}}(\mathrm{np}), \mathrm{C}_{\mathrm{LL}}(\mathrm{np})$, and $\mathrm{C}_{\mathrm{SL}}(\mathrm{np})$ at 500,650 , and $800-\mathrm{MeV}$ kinetic energies. Knowledge of the proton-to-neutron polarization transfer is required so that the neutron beam polarization may be inferred from polarization measurements of the primary $\mathrm{H}^{-}$beam. One also wants to choose the spin direction for the proton beam that gives rise to the largest neutron polarization at $0^{\circ}$. Hence, we propose here to measure the spin transfer coefficienis $A_{i}^{\prime}\left(0^{\circ}\right)$ and $D_{t}\left(0^{\circ}\right)$ for the $\mathrm{d}(\overrightarrow{\mathrm{p}}, \overrightarrow{\mathrm{n}}) 2 \mathrm{p}$ reaction.

Both $A_{t}^{\prime}\left(0^{\circ}\right)$ and $D_{t}\left(0^{\circ}\right)$ have been previously measured at LAMPF at $800 \mathrm{MeV}(\mathrm{E}-360)$. In order to verify the results and check our experimental technique we would like to remeasure at least one, and preferably both, of the parameters at $800 \mathrm{MeV}$ Both $A_{i}$ and $D_{t}$ must be measured at 500 and $650 \mathrm{MeV}$ since no $0^{\circ}$ production data exists here.

Exp. 665

THE MEASUREMENT OF THE INITIAI STATE SPIN CORRELATION PARAMETERS $C_{L L}$ AND $C_{S L}$ IN n-p ELASTIC SCATTERING AT 500, 650 AND $800 \mathrm{MeV}$

\section{New Mexico State University}

G. R. Burleson, Spokesman

W. B. Cottingame, S. J. Greene

Argonne National Laboratory

R. Wagner, Spokesman

R. Ditzler, D. Hill, K. Imai, H. Spinka, R. Stanek, K. Toshioka, A. Yokosawa

Los Alamos National Laboratory

R. Damjanovich, J. J. Jarmer, J. E. Simmons

Texas A\&M University

T. S. Bahtia, G. Glass, J. C. Hiebert, R. A. Kenefick, L. C. Northcliffe

As part of a program to determine the isospin zero nucleon-nucleon phase shifts at 500,650 , and $300 \mathrm{MeV}$, we propose to measure the elastic scattering initial state spin correlation parameters $\mathrm{C}_{\mathrm{LI}}(\mathrm{np})$ and $\mathrm{C}_{\mathrm{SL}}(\mathrm{np})$ at these three energies. By using a large solid angle spectrometer to detect and momentum analyze the recoil proton we will collect in a single setup enough data to provide greater than 10 points for each parameter, at each energy, over the c-m angular range of 80 to $135^{\circ}$. The experimental setup will be identical for the two parameters since only precession of the neutron spin direction by $90^{\circ}$ is required to change from one parameter to the other. The experiment may be performed in line $\mathrm{B}$ using the $0^{\circ}$ unchopped neutron beam or combined with the measurement of $\Delta \sigma_{L}(\mathrm{np})$ being proposed by the same collaboration. 
Exp. 666

\title{
THE ${ }^{12} \mathbf{C}\left(p, p^{\prime} \pi\right)^{12} \mathbf{C}^{*}$ REACTION AND THE SEARCH FOR COHERENT ISOBAR-HOLE RESONANCES
}

\author{
Rutgers Univeraity \\ C. Glashausser, Spokesman \\ K. Jones, J. McGill, S. Nanda \\ University of California, Los Angeles \\ C. A. Whitten, Spokesman \\ Los Alamos National Laboratory \\ J. B. McClelland, H. A. Thiessen
}

The ${ }^{12} \mathrm{C}\left(\mathrm{p}, \mathrm{p}^{\prime} \pi\right)^{12} \mathrm{C}^{*}$ reaction will be studied at $800 \mathrm{MeV}$ for small $\mathrm{p}^{\prime}$ angles $\left(5,10\right.$ and $\left.15^{\circ}\right)$ and a fixed large pion angle $\left(\sim 170^{\circ}\right)$. The HRS magnet field will be set to observe scattered protons corresponding to excitation energies between 200 and $300 \mathrm{MeV}$ in ${ }^{12} \mathrm{C}$, the so-called "delta" region. The aim of the experiment is to determine whether collective delta-hole nuclear resonances are excited. To distinguish between such resonances and ordinary quasi-free delta production, the pion counter will be sensitive only to pions of energy greater than about $70 \mathrm{MeV}$. Pions from the decay of quasi-free deltas will have energies smaller than $70 \mathrm{MeV}$, because of the large forward momentum of the deltas, whereas pions from the decay of a nuclear delta resonance should have energies corresponding to delta decay at rest.

Exp. 667

This experiment was entered in error.

Exp. 668

This experiment was entered in error.

Exp. 669

\section{INVESTIGATION :OF THE $\mathbf{N}=28$ NEUTRON SHELL CLOSURE BY ELASTIC SCATTERING OF $800 \mathrm{MeV}$ POLARIZED PROTONS}

\section{Los Alamos National Laboratory}

E. B. Shera and H. I. Wohlfahrt, Spokesmen

M. V. Hoehn, M. W. Johnson

University of California, Los Angeles

B. Aas, G. J. Igo, G. Pauletta, C. A. Whitten, Jr.

University of Texas, Austin

L. Ray

We propose to use the High Resolution Spectrometer (HRS) facility to measure the elastic scattering of $0.8-\mathrm{GeV}$ polarized protons from the chromium isotopes, ${ }^{50,52,54} \mathrm{Cr}$ in order to investigate the neutron shell closure at $\mathrm{N}=28$. The proton radius and distribution differences for the $\mathrm{Cr}$ isotopes are already known precisely from combined model-independent analyses of elastic electron scattering and muonic atom data. 
In the simplest shell model configuration the neutron distribution of the ground state of the $\mathrm{Cr}$ isotopes consists of two neutron holes in the $1 f_{7 / 2}$ shell $\left({ }^{50} \mathrm{Cr}\right)$, a closed $1 f_{7 / 2}$ shell $\left({ }^{52} \mathrm{Cr}\right)$ and two neutrons in the $2 \mathrm{p}_{\mathrm{s} / 2}$ shell $\left({ }^{54} \mathrm{Cr}\right)$. Elastic electron scattering and muonic $\mathrm{x}$-ray measurements for the $\mathrm{Z}=28$ proton shell closure indicate that such simple configuration assignments for the protons are consistent with the deduced charge distribution differences of the ground states.

The existing charge distribution data for the $\mathrm{Cr}$ isotopes will enable us to extract reliable neutron radius and neutron distribution differences from the proton scattering data. A detailed comparison of the distribution of both neutrons and protons with the predictions of calculations will therefore be possible. 
Exp. 670

\title{
CONTINUATION OF GIANT RESONANCE STUDIES AT HRS
}

\author{
Los Alamos National Laboratory \\ J. M. Moss and T. A. Carey, Spokesmen \\ N. J. DiGiacomo, S. J. Seestrom-Morris, J. B. McClelland \\ Massachusetts Inotitute of Technology \\ G. S. Adams, Spokesman \\ Texas AdM University \\ U. Garg \\ University of Minuesota \\ M. Gazzaly
}

We will continue to study the isoscalar giant resonances at the HRS. The time requested will be used to continue the survey of the newly discovered high-energy octupole giant resonance in light nuclei $\left({ }^{10} \mathrm{O},{ }^{28} \mathrm{Si}\right.$, and $\left.{ }^{10} \mathrm{Ca}\right)$. We will also search for a possible isoscular giant dipole resonance, believed to have been seen in ${ }^{200} \mathrm{~Pb}$ with $172 \mathrm{MeV}$ alphas. Additionally, a detailed study will be made of the giant quadrupole-monopole resonance region in ${ }^{\circ 0} \mathrm{Ca}$ in order to search for $\ell=0$ strength and determine the distribution of $\ell=2$ strength. Finally, our studies of the continuum underlying the giant resonance region will continue with the aid of polarized beam.

Exp. 671

\section{EXPERIMENTAL INVESTIGATIONS OF ISOVECTOR PROPERTIES OF COLLECTIVE TRANSITIONS}

\author{
Northwestern University \\ A. Saha, K. K. Seth, Spokesmen \\ D. Barlow, M. O. Kaletkz, D. Kielczewska, O. Scholten, D. Snith
}

We propose to measure cross-sections for $\pi^{+}$and $\pi^{--}$inelastic scattering to the low-lying collective states in the Pd isotopes. Van Isacker and Puddu have recentily constructed a proton-neutron IBA model Hamiltonian, the parameters of which have been determined to give an excellent description of the properties of $\mathrm{Pd}$ and $\mathrm{Ru}$ isotopes. Using the wavefunction for the Pd isotopes, one finds that the ratio of the $\pi^{-}$to $\pi^{+}$strengths, for the first excited $2^{+}$state, is predicted to increase from 2:1 to 3:1 as one goes from ${ }^{104} \mathrm{Pd}$ to ${ }^{110} \mathrm{Pd}$. These ratios are approximately twice as large as those predicted from the hydrodynamic model. This indicates a rather large isovector component in the IBA wavefunction for the first $2^{+}$state, which if verified experimentally, would be an important and crucial test of the new microscopic IBA model.

Exp. 672

$$
\begin{aligned}
& \text { STUDY OF GIANT RESONANCES IN }{ }^{90} \mathrm{Zr},{ }^{110} \mathrm{Sn} \text {, AND }{ }^{208} \mathrm{~Pb} \text { WITH } \\
& \pi^{+} \text {AND } \pi^{-} \text {INELASTC SCATTERING }
\end{aligned}
$$

\author{
Los Alamos National Laboratory \\ T. A. Carey, J. M. Moss, S. J. Seestrom-Morris, Spokespersons \\ C. L. Morris \\ Maseachusetts Inotitute of Techrology \\ G. S. Adams
}




\title{
University of Minnesota
}

D. Dehnhard

We plan to measure cross sections for the excitation of giant resonances near $22 \mathrm{MeV}$ in ${ }^{200} \mathrm{~Pb}$ with $162 \mathrm{MeV} \pi^{+}$and $\pi^{-}$. Angular distributions for $\pi^{+}$will be measured in $3^{\circ}$ steps from 15 to $45^{\circ}$ in order to determine the multipolarity of the resonances excited. Three additional points will be measured with $\pi^{-}$to determine a ratio of $\sigma\left(\pi^{+}\right) / \sigma\left(\pi^{-}\right)$for studying the isospin composition of these transitions. We also plan to measure cross sections for $\pi^{+}$and $\pi^{-}$scattering from the wellknown LEOR and low-lying $3^{-}$state(s) in ${ }^{90} \mathrm{Zr}$ and ${ }^{116} \mathrm{Sn}$. Their comparison will enable us to measure the effects of the $\left.N=50\left({ }^{80} \mathrm{Zr}\right)\right)$ and $\mathrm{Z}=50\left({ }^{110} \mathrm{Sn}\right)$ shell closures on the neutron and proton contributions to the $1 \hbar \omega$ octupole strength distribution.

Exp. 673

\section{MEASUREMENT OF THE ANGULAR DEPENDENCE OF TENSOR POLARIZATION IN THE ${ }^{2} \mathbf{H}\left(\pi^{+}, \pi^{+}\right)^{2} \overrightarrow{\mathbf{H}}$ \\ REACTION AT $\mathrm{T}_{\pi}=180$ AND $256 \mathrm{MeV}$}

\author{
Argonne National Laboratory \\ R. J. Holt, Spokesman \\ D. F. Geesaman, J. R. Specht, K. E. Stephenson, B. Zeidman \\ Los Alamos National Laboratory \\ J. S. Frank, M. J. Leitch, J. D. Moses \\ University of Illinois \\ R. M. Laszewski \\ Indiana University \\ E. J. Stephenson
}

We propose to measure the angular and energy dependence of the tensor polarization $t_{20}$ in $\pi-d$ elastic scattering in the angular range $\theta_{\mathrm{cm}}=90$ to $145^{\circ}$ and at $\mathrm{T}_{\pi+}=180$ and $256 \mathrm{MeV}$. In Experiment 388 , we demonstrated the feasibility of observing tensor polarization in $\pi$-d elastic scattering by measuring $t_{20}$ at $180^{\circ}$. In addition, in Experiment 483 we measured the angular distribution of $t_{20}$ at $T_{z^{\prime}+}=142 \mathrm{MeV}$ for angles $\theta_{\pi}=98,122$, and $145^{\circ}$.

The purpose of studying the polarization in this reaction is to provide more information on the $\pi$-nucleus reaction which is most amenable to theoretical solution. Moreover, the tensor polarization is balieved to be sensitive to the effects of true pion absorption. This sensitivity to absorption is not reflected in the differential cross section for $\pi$-d elastic scattering. The measurement at $T_{\pi}$ $=256 \mathrm{MeV}$ should be particularly interesting since the vector polarization data show rapid oscillations in the angular distribution. At present there is a controversy over whether these oscillations are produced by the presence of a dibaryon resonance or an absorption effect. Hopefully, the proposed tensor polarization measurements would resolve this issue.

The experiment should be performed at the $\mathrm{P}^{3}$ area, where a $\pi^{+}$beam would be directed onto a liquid deuterium target. A quadrupole doublet would be used to focus the recoil deuterons from the ${ }^{2} \mathrm{H}(\pi, \pi)^{2} \overrightarrow{\mathrm{H}}$ reaction onto the polarimeter. An additional quadrupole doublet would be used to focus the elastically scattered pions into an array of scintillators. 
Exp. 674

\title{
MEASUREMENTS OF PION-NUCLEUS ELASTIC AND DOUBLE CHARGE EXCHANGE SCATTERING AT ENERGIES ABOVE $300 \mathrm{MeV}$
}

\author{
New Mexico State University \\ G. R. Burleson, Spokesman \\ S. J. Greene, W. B. Cottingame \\ Los Alamos National Laboratory \\ C. L. Morris, Spokesman \\ University of Pennsylvania \\ H. T. Fortune, L. Bland \\ University of Texas, Austin \\ C. F. Moore \\ Argonne National Laboratory \\ B. Zeidman \\ University of Minnesota \\ D. B. Holtkamp
}

Nearly all high-quality measurements of pion-nucleus elastic, inelastic and double-chargeexchange (DCX) scattering have been made at energies below $300 \mathrm{MeV}$, largely because of the presence of the $(3,3)$ resonance in the 100 - to $300-\mathrm{MeV}$ energy region, as well as the limitations of the existing instrumentation. As a result, much has been learned about the pion-nucleus interaction at these energies. For elastic scattering, theoretical models that have been used have been tailored somewhat to the features of this energy region, dominated by the $(3,3)$ resonance, and they have given good fits to the data. With data at higher energy, near the next higher resonance, which is different in character from the $(3,3)$ resonance, the validity of these models can be tested further. For $\left(\pi^{+}, \pi^{-}\right)$DCX scattering, the systematics of the reaction have shown an apparent simplicity in angular distributions, excitation functions, and variation with A. Since these features are not yet adequately understood, we believe that studies of this process over the region of the next higher resonance should help improve our understanding of it.

To begin such studi s, we propose to make measurements on both of these processes at energies above $300 \mathrm{MeV}$, using the same experimental setup. For DCX scattering, we propose to measure $\left(\pi^{+}, \pi^{-}\right)$excitation functions at $5^{\circ}$ for a $\mathrm{T}=1$ nucleus $\left({ }^{14} \mathrm{C}\right.$ or $\left.{ }^{18} \mathrm{O}\right)$ and a $\mathrm{T}=0$ nucleus $\left({ }^{12} \mathrm{C}\right.$ or $\left.{ }^{16} \mathrm{O}\right)$ for pion energies between 300 and $550 \mathrm{MeV}$. For elastic scattering, we propose to measure angular distributions for $\pi^{ \pm}$scattering on ${ }^{14} \mathrm{C}$ at $500 \mathrm{MeV}$, near the peak of the next higher resonance. Both of these measurements would involve the use of the large angle spectrometer in $\mathrm{P}^{3}$.

Exp. 675

\section{NUCLEAR DISTRIBUTIONS FROM THE STUDY OF THE 2P STATES OF PIONIC ATOMS}

University of Wyoming

A. R. Kunselman, Spokesman

Los Alamos National Laboratory

M. V. Hoehn, E. B. Shera, H. D. Wohlfahrt

California Institufe of Technology

R. J. Powers 
The experiment involves measurement of the $3 \mathrm{~d}-2 \mathrm{p} x$-ray transitions of pionic atoms for the isotopes ${ }^{54,56,67,58} \mathrm{Fe}$ and ${ }^{58,60,82} \mathrm{Ni}$. The measurements will allow determination of the strong interaction shifts and line broadenings for the $2 \mathrm{P}$ states in these nuclei. The new results will be combined with previous measurements and the known proton distributions of these isotopes to extract information concerning neutron distributions. The study will also improve our knowledge of the optical model potential for the pion-nuclear interaction. Five days of beam time are requested to perform the measurements.

Exp. 676

\section{STUDY OF PION ABSORPTION ON ${ }^{58}$ Ni AT $T_{\pi}=160 \mathrm{MeV}$}

\section{University of Maryland}

N. S. Chant \& P. G. Roos, Spokesmen

H. Breuer, C. C. Chang, H. D. Holmgren, A. Mignerey

Massachusetts Institute of Technology

R. P. Redwine, Spokesman

W. Burger

University of South Carolina

G. S. Blanpied, B. M. Preedom, B. G. Ritchie

Particle-particle correlations for $\pi^{+}+{ }^{58} \mathrm{Ni}$ at $\mathrm{T}_{\pi}=160 \mathrm{MeV}$ will be measured with 10 detector telescopes, in order to examine in detail the pion absorption process. The detector telescopes will provide a missing mass resolution of better than $5 \mathrm{MeV}$ and a proton energy dynamic range from 9 $\mathrm{MeV}$ to the maximum energy. Furthermore, two telescopes will be capable of detecting charged particles down to energies as low as the evaporation peak. Although the system will measure the correlation at 45 coplanar angle pairs, primary emphasis has been placed on the examination of symmetry about the direction of the second proton emitted in the capture on an n-p pair, and symmetries about the beam direction. Additionally, coincidences of higher order (3-fold, etc.) will be measured simultaneously to provide information on the charged particle multiplicity in the absorption process. In order to examine the absorption process in detail a sufficiently long running time is requested to obtain well-defined energy spectra for all emitted hadrons with $\mathrm{Z} \leq 2$ to be compared to $\mathrm{p}+{ }^{58} \mathrm{Ni}$ inclusive spectra.

Exp. 677

\section{A DETERMINATION OF $\Delta S=1$ CONTRIBUTIONS IN INELASTIC PION SCATTERING FROM ODD-A NUCLEI}

\section{University of Minnesota}

D. B. Holtkamp, Spokesman

D. Dehnhard

College of William \& Mary

H. O. Funsten, Spokesman

D. Joyce

New Mexico State University

W. B. Cottingame, S. J. Greene, G. R. Burleson

Los Alamos National Laboratory

S. J. Seestrom-Morris, C. L. Morris, H. A. Thiessen 
In inelastic transitions both values of spin transfer to the target $(\Delta S=0,1)$ are often allowed. There is great theoretical interest in determining the relative magnitude of the $\Delta \mathbf{S}=\mathbf{0}$ and $\Delta \mathbf{S}=$ 1 contributions to natural parity transitions. However, determinations of spin-flip probabilities are difficult.

The measurements of excitation functions of pion inelastic scattering at constant momentum transfer between 100 and $200 \mathrm{MeV}$ offers a new method of separating $\Delta S=1$ contributions from the (often) larger $\Delta S=0$ cross sections.

Using the wavefunctions of Brown, Chung, and Wildenthal, we select four good candidates for such a study in ${ }^{27} \mathrm{Al}\left(1 / 2^{+}, 0.842 \mathrm{MeV}\right),{ }^{85} \mathrm{Cl}\left(1 / 2^{+}, 1.22 \mathrm{MeV}\right),{ }^{37} \mathrm{Cl}\left(1 / 2^{+}, 1.73 \mathrm{MeV}\right)$, and ${ }^{30} \mathrm{~K}\left(1 / 2^{+}\right.$, $2.53 \mathrm{MeV})$. We propose to measure $\pi^{ \pm}$excitation functions for these nuclei at energies between 100 and $206 \mathrm{MeV}$.

Exp. 678

\section{STUDY OF THE M1 TRANSITION IN ${ }^{88} \mathrm{Ca}$ BY INELASTIC SCATTERING OF $\pi^{+}$AND $\pi^{-}$}

\section{University of Minnesota}

D. Dehnhard, Spokesman

D. B. Holtkamp

Los Alanos National Laboratory

C. L. Morris, Spokesman

S. J. Seestrom-Morris, R. L. Boudrie, H. A. Thiessen

We propose a measurement of differential cross sections for $\pi^{+}$and $\pi^{-}$inelastic scattering from ${ }^{48} \mathrm{Ca}$ at $\mathrm{T}_{\pi}=116,148$, and $180 \mathrm{MeV}$. Special emphasis will be placed on a study of the neutronprcton composition of the quenched M1 transition to a $1^{+}$state at $10.23 \mathrm{MeV}$. This transition has recently been cbserved in $\left(e, e^{\prime}\right)$ and its analog transition was seen in $(p, n)$. It may play a crucial role in studies of the relation of the quenching of magnetic transitions and the role of $\Delta(1232)$ degreees of freedom in nuclei.

Exp. 679

\section{A RADIOCHEMICAL STUDY OF THE ${ }^{200} \mathrm{Bi}\left(\mathrm{p}, \pi^{0}\right)^{210} \mathrm{Po},{ }^{200} \mathrm{Bi}\left(\mathrm{p}, \pi^{-\mathrm{xn}}\right)^{210-\mathrm{x}} \mathrm{At}$, AND ${ }^{200} \mathrm{Bi}\left(\mathrm{p}, \mathrm{p} 2 \pi^{-} \mathrm{xn}\right){ }^{209}-\mathrm{x}$ At PION PRODUCTION REACTIONS} AT 500 TO $800 \mathrm{MeV}$

Los Alamos National Laboratory

J. L. Clark, Spokesman

Simon Fraser University \& TRIUMF

J. M. D'Auria

Carnegie-Mellon University

P. J. Karol

Indiana University \& IUCF

T. E. Ward

Recent activation studies of the ${ }^{209} \mathrm{Bi}\left(\mathrm{p}, \pi^{0}\right)^{210} \mathrm{Po}$ reacton, done by an IUCF-TRIUMF collaboration, at proton energies of 62 to $480 \mathrm{MeV}$ suggest that pion production processes have significant cross sections at energies well below the free nucieon pion production threshold at $\mathrm{E}_{\mathrm{p}} \simeq 300 \mathrm{MeV}$. Similar observations have been made in preliminary studies of the ${ }^{200} \mathrm{Bi}\left(\mathrm{p}, \pi^{-} \mathrm{xn}\right)^{210-x}$ At reaction 
at BNL, IUCF, and TRIUMF. We propose to utilize radiochemical techniques to extend the ${ }^{200} \mathrm{Bi}\left(\mathrm{p}, \pi^{0}\right)^{210} \mathrm{Po}$ cross section measurements to LAMPF proton energies. Such techniques will be specifically designed to facilitate the evaluation of and correction for the large number of secondary reactions which typically plague such inclusive cross section measurements. Since some of the proton energies to be utilized in these experiments will exceed the threshold for multiple pion production $\left(E_{p} \simeq 600\right.$ ), a survey of the ${ }^{209} \mathrm{Bi}\left(\mathrm{p}, \mathrm{p} 2 \pi^{-} \times n\right){ }^{209-x}$ At reaction will also be attempted. Such measurements will serve to complement ${ }^{209} \mathrm{Bi}\left(\mathrm{p}, \pi^{-} \mathrm{xn}\right)^{210-x} \mathrm{At}$ studies recently proposed at TRIUMF and the IUCF. 
Exp. 680

\section{ANGULAR DISTRIBUTIONS FOR ${ }^{24,26} \mathbf{M g}\left(\pi^{+}, \pi^{-}\right){ }^{24,26} \mathrm{Si}$}

New Mexico State University

S. J. Greene, Spokesman

G. R. Burleson, W. B. Cottingame

Los Alamos National Laboratory

C. L. Morris

University of Minnesota

D. B. Holtkamp

University of Pennsylvania

H. T. Fortune, L. Bland M. Carchidi

University of Texas, Austin

C. F. Moore

We propose a direct continuation of the $\left(\pi^{+}, \pi^{-}\right)$experiments initiated in Experiments 310/448. Double-charge-exchange (DCX) research should now look to see if various assumptions and ensuing ideas are verifiable. These experiments with ${ }^{24,28} \mathbf{M g}$ targets will complement previous research, and seek to determine 1) whether anomalous minima are characteristics of below resonance DCX angular distributions from $T=1$ targets, 2) whether a newly developed phenomenological picture of $\mathrm{DCX}$ is applicable to more than one case, and 3) additional evidence for and/or systematics of a second-order optical potential for $\pi$-nucleus interactions.

The experiment utilizes the EPICS facility with the small-angle DCX apparatus we have previously developed, the installation of which appears fairly routine.

Exp. 681

\section{MEASUREMENTS OF LARGE-AIVGLE PION-NUCLEUS SCATTERING WITH EPICS}

\section{New Mexico State University}

G. R. Burleson, Spokesman

W. B. Cottingame, S. J. Greene

University of Minnesota

D. Dehnhard, D. B. Holtkamp

Los Alamos National Laboratory

H. A. Thiessen, R. L. Boudrie

We propose to set up a modification of the EPICS system that would extend its range in angle from its present maximum of $\sim 125$ to $180^{\circ}$. There is good evidence that effects will be seen in this angular region that are not accounted for by current theories, which, nevertheless, fit the existing data very well over the present "normal" angular regions. Because of this, we desire to make it possible to extend measurements with EPICS, for both elastic and inelastic scattering as well as for situations corresponding to large pion energy loss, into the backward region, to explore the general character of interactions there, as well as to study the specific behavior of certain reactions. Our proposed modification involves inserting a circular magnet in the region of the present pivot point of the spectrometer, in a manner similar to what was done to allow for small-angle double-charge-exchange (DCX) scattering measurements. We also propose to check out and debug the system and make an initial set of measurements of backward elastic and inelastic scattering which we feel should reveal some of the general characteristics of cross sections in this region. These proposed measurements would check the only published data (for $A>4$ ) in this 
angular region, study some of the systematics of backward scattering for $\mathrm{N}=\mathrm{Z}$ nuclei as a function of energy and A (over a limited range), investigate Coulomb effects, and study the effect of different neutron and proton distributions in a single nucleus, as seen in backward scattering. As with the DCX setup, this would become a general facility that could be used again for further measurements, as interest warrants.

Exp. 682

SEARCH FOR DIBARYON RESONANCES IN THE REACTION $\boldsymbol{\pi D} \rightarrow$ p $\pi \mathrm{n}$ AT $\mathbf{P}_{\mathbf{L}}^{\pi}=200$ to $600 \mathrm{MeV} / \mathrm{c}$

Argonne National Laboratory

K. Imai, Spokesman

H. Spinka, R. Stanek, K. Toshioka, R. Wagner, A. Yokosawa

New Mexico State University

S. J. Greene, Spokesman

G. R. Burleson, W. B. Cottingame

Recent experiments have provided evidence for the existence of dibaryon resonances. Most of this has centered about the two lowest mass resonances, the ${ }^{\prime} \mathrm{D}_{2}$ at $2.17 \mathrm{GeV} / \mathrm{c}$ and the ${ }^{3} \mathrm{~F}_{3}$ at 2.22 $\mathrm{GeV} / \mathrm{c}$. Most efforts have involved the pp and $\gamma \mathrm{D}$ elastic channels, however, the inelasticity of these resonances is believed to be large. Recently, a narrow anomaly was observed in the $\gamma \mathrm{D} \rightarrow$ $p \pi^{-} \mathbf{p}$ channel, though it has an unresolved ambiguity in the $\mathrm{T}=0,1$ isospin assignment. This indicates the importance of measuring the $\mathrm{NN} \pi$ channels.

We propose a kinematically complete set of measurements for the $\pi \mathrm{D} \rightarrow \mathrm{p} \pi \mathrm{n}(\mathrm{T}=1)$ reaction channel. We will look for excess yield, versus invariant mass (compared to current theory), concentrating on the three lowest resonances, ${ }^{1} \mathrm{D}_{2},{ }^{3} \mathrm{~F}_{3}$, and the possible ${ }^{2} \mathrm{G}_{4}$ at $2.42 \mathrm{GeV} / \mathrm{c}$. Otserving the ${ }^{1} \mathrm{G}_{4}$ ir: the $\mathrm{N}-\mathrm{N}$ channels is not possible at LAMPF energies. In particular, the same momentum range as in the $\gamma \mathrm{D}$ experiment will be studied extensively with fine momentum steps (12 $\mathrm{MeV} / \mathrm{c}$ ) to eliminate possible ambiguity in the isospin assignment, as occurs in the $\gamma \mathrm{D}$ channel.

We will utilize the $\mathrm{P}^{3}$ beam line with the LAS pion spectrometer and a recoil proton arm. The pion and proton will be detected in coincidence. This apparatus will allow us to investigate the $\mathrm{N} \Delta$ decay channel, as well as measuring the quasi-free scattering channel.

Exp. 683

\section{MEASUREMENT OF $\triangle \sigma_{L}$ IN FREE NEUTRON PROTON SCATTERING AT 500, 650, AND $800 \mathrm{MeV}$}

Argonne National Laboratory

W. R. Ditzler, Spokesman

D. Hill, K. Imai, H. Spinka, R. Stanek, K. Toshioka, R. Wa'ner, A. Yokosawa

Los Alamos National Laboratory

J. E. Simmons, Spokesman

J. J. Jarmer

New Mexico State University

G. R. Burleson, W. B. Cottingame, S. J. Greene

Texas A\&M University

T. S. Bhatia, G. C. Glass, J. C. Hiebert, R. A. Kenefick, L. C. Northcliffe 
The measurement of the total cross section difference for longitudinaily parallel and antiparsllel initial spin states in free neutron-proton scattering $\left[\Delta \sigma_{\mathrm{L}}(\mathrm{np})\right]$ at 500,650 , and $800 \mathrm{MeV}$ kinetic energies is proposed. This will be the first measurement of this quantity at intermediate energies with a neutron beam and will check the quasi-free measurement made at the Argonne ZGS with a polarized proton beam and a deuterated poiarized target. The experiment proposes to produce the neutron beam by collisions of the 40-ns-chopped, polarized proton beam in a liquid deuterium target. This will give the neutron beam a microstructure that will allow time-of-flight identification of neutron energy. The possibility of performing the experiment with an unchopped beam of 5-ns microstructure is also discussed.

Exp. 684

\section{POLARIZATION EFFECTS IN THE DEUTERON PRODUCTION BY PROTON- NUCLEUS COLLISIONS}

University of Virginia

J. Källne, Spokesman

J. S. McCarthy, R. R. Whitney

University of Texas, Austin

B. Höistad, Spokesman

M. Barlett, G. W. Hoffmann

We propose to measure the deuteron spectra from the nuclear $A(\vec{p}, d)$ reactions with $H R S$ for forward angles. The regions of interest are those where the quasi-free processes $p d_{A} \rightarrow d p$ and $P P_{A}$ $\rightarrow \mathrm{d} \pi$ dominate the inclusive $A(p, d)$ spectrum and are an identifiable part thereof. The purpose of the experiment is to study the origin of polarization effects in nucleon-nucleus interactions utilizing reactions for which the dynamics of the interactions are limited to one or two of the target nucleons.

Exp. 685

\section{SPIN CORRELATIONS IN THE REACTION $\vec{p}(\vec{d}, d) \overrightarrow{\mathbf{p}}$ AT $500 \mathrm{MieV}$}

\section{University of California, Los Angeles}

G. J. Igo and M. Bleszynski, Spokesmen

B. Aas, E. Bleszynski, J. Geaga, M. Hajisaeid, F. Irom, G. Pauletta, A. Azizi, A.T.M.

Wang, J. Wagner, G. Weston, A. Rahbar

\section{University of Minnesota}

M. M. Gazzaly

We propose to measure spin correlations in the reaction $\vec{p}(\mathbf{d}, d) \vec{p}$ with the vector polarized deuterium target at $500 \mathrm{MeV}$ in the angular range $2-30^{\circ}$ in the deuteron laboratory system using the newly developed proton polarimeter at HRS. Such measurements will provide new selective information on the $\mathrm{p}-\mathrm{d}$ collision matrix at intermediate energy. We shall be able to extract quantities sensitive to the spin components of the N-N amplitude, in particular those depending on the double spin-flip terms and the relative phases between the central, spin orbit and double spin-flip amplitudes. Our experiment will also provide a useful test of the multiple scattering theory at $500 \mathrm{MeV}$ where the recent $\mathrm{Q}$ experiment in $\mathrm{p}-{ }^{40} \mathrm{Ca}$ has revealed an interesting disagreement between the data and the thcory based on the NN input taken from the recent phase shift analysis. 
Exp. 686

\title{
DETERMINATION OF NEUTRON TRANSITION DENSITIES IN ${ }^{16} O$ AND ${ }^{208} \mathrm{~Pb}$ BY INELASTIC SCATTERING OF $\sim 400 \mathrm{MeV}$ PROTONS
}

\author{
University of Minnesota \\ N. M. Hintz, Spokesman \\ D. Cook, M. M. Gazzaly \\ University of Texas, Austin \\ M. Barlett, G. W. Hoffmann \\ University of Indiana \\ A. Bacher \\ Los Alamos National Laboratory \\ J. B. McClelland
}

We propose to measure cross sections for proton inelastic scattering at $\mathrm{HRS}$ for ${ }^{10} \mathrm{O}$ and ${ }^{208} \mathrm{~Pb}$ at some energy between 300 and $500 \mathrm{Me}^{\top}$, which we believe to be the optimum range for the quantitative determination of inelastic transition densities. The main purpose of the experiment is to obtain neutron transition densities, by comparison of $\left(p, p^{\prime}\right)$ with $\left(e, e^{\prime}\right)$, for a number of states in both nuclei, with special interest in the $11_{1}^{-}, 2_{1}^{-}$states of ${ }^{10} \mathrm{O}$ and the high spin $(\sim 1 \mathrm{p}-1 \mathrm{~h})$ "stretched" states in ${ }^{208} \mathrm{~Pb}\left(\mathrm{I}=10^{+}, 12^{+}, 12^{-}, 14^{-}\right)$. A secondary objective is to study the projectile energy dependence of the density dependent $c^{*}$ rrections to the free $\mathrm{N}-\mathrm{N}$ force in nuclear matter $\left({ }^{16} \mathrm{O}\right)$.

Exp. 687

\section{MEASUREMENT OF THE SPIN ROTATION PARAMETERS IN ${ }^{208} \mathrm{~Pb}$ AND IN ${ }^{40} \mathrm{Ca}$ AT $400 \mathrm{MeV}$}

\section{University of California, Los Angeles}

B. Aas, Spokesman

E. Bleszynski, M. Bleszynski, S. M. Hajisaeid, G. J. Igo, F. Irom, G. Pauletta, A. Rahbai, and A.T.M. Wang

We propose to measure the spin-rotation parameters $A, R, A^{\prime}$ and $R^{\prime}$ in elastic scattering with $400-\mathrm{MeV}$ polarized protons off ${ }^{208} \mathrm{~Pb}$ and ${ }^{40} \mathrm{Ca}$.

The measurement is to be performed with the focal plane polarimeter at HRS in the laboratory range of $4-16^{\circ}$ for ${ }^{208} \mathrm{~Pb}$ (i.e., momentum transfer $55-260 \mathrm{MeV} / \mathrm{c}$ in the CM-system) and of $6-25^{\circ}$ for ${ }^{10} \mathrm{Ca}$ (i.e., $10-390 \mathrm{MeV} / \mathrm{c}$ in $\mathrm{CM}$ ). The deduced observables $\mathrm{P}, \mathrm{Q}$, and $\mathrm{S}$ will be obtained with an accuracy of $\leq 0.03$ over the whole angular range.

Together with data on $d \sigma / d \Omega$ an $A_{y}$ obtained at TRIUMF, $Q$ and $S$ will be analyzed using multiple scattering theories. The comparison of these measurements on ${ }^{208} \mathrm{~Pb}$ and ${ }^{40} \mathrm{Ca}$ with the same measurements at $500 \mathrm{MeV}$ is important from a theoretical point of view, because the multiple scattering theories fail to describe the data taken at $500 \mathrm{MeV}$. At $400 \mathrm{MeV}$, one is below threshold for meson production in the measurement of the NN phaseshifts, used as input to the multiple scattering theories, whereas at $500 \mathrm{MeV}$ one is not. 
Exp. 688

\title{
STUDY OF THE MASS AND ENERGY DEPENDENCE OF LOW-ENERGY PION SINGLE CHARGE EXCHANGE
}

\author{
Los Alamos National Laboratory \\ M. J. Leitch and M. D. Cooper, Spokesmen \\ H. W. Baer, R. D. Bolton, J. D. Bowman, F. H. Cverna, M. V. Hynes, N. S. P. King \\ Tel-Aviv University \\ J. Alster, A. Erell, M. A. Moinester \\ TRIUMF \\ E. W. Blackmore
}

A recent measurement of the reaction ${ }^{16} \mathrm{~N}\left(\pi^{+}, \pi^{0}\right)$ at $50 \mathrm{MeV}$ shows an angular distribution which is strongly backward peaiked. This is qualitatively similar to the free nucleon chargeexchange angular distribuion, which is also strongly beckward-peaked at $50 \mathrm{MeV}$. This suggests that the nucleus is extremely uransparent. Standard theoretical calculations require large secondorder terms for even a rough qualitative resemblance to the data. The aim of this experiment is to investigate the A-dependence and the energy-dependence of this behavior. To do this we propose to measure the angular distributions for pion single charge exchange on ${ }^{40} \mathrm{Ca}$ and ${ }^{30} \mathrm{~K}$ at 50 and 80 $\mathrm{MeV}$.

Exp. 689
A. NEUTRON COUNTER CALIBRATION USING TAGGED NEUTRONS FROM THE REACTION - - d $\rightarrow$ nn
B. FEASIBILITY STUDY: MEASUREMENTS OF THE DIFFERENTIAL CROSS SECTION FOR
$--d \rightarrow$ nn TO TEST CHARGE SYMMETRY AND ISOSPIN INVARIANCE

\author{
University of California, Los Angeles \\ B.M.K. Nefkens and D. H. Fitzgerald, Spokesmen \\ W. J. Briscoe, J. Holt, A. Eichon, A. Mokhtari \\ Abilene Christian University \\ M. E. Sadler
}

We propose to measure the detection efficiency of the UCLA neutron counters, used earlier in Exp. 58/120 [d $\sigma\left(\pi^{-} p \rightarrow \gamma n\right)$ and $\left.\mathrm{d} \sigma\left(\pi^{-} p \rightarrow \pi^{\circ} \mathrm{n}\right)\right]$. The expected precision of the measurement is 3 to $5 \%$ for neutrons with energies between 80 and $300 \mathrm{MeV}$. The calibration technique involves the use of a spstially well-defined, tagged neutron beam produced in the reaction $\pi^{-} \mathbf{d} \rightarrow \mathrm{nn}$.

The second part of the proposed experiment is a measurement of the differential cross section for $\pi^{-} \mathrm{d} \rightarrow \mathrm{nn}$ at four angles for $\mathrm{T}_{\pi}=120-250 \mathrm{MeV}$. This measurement yields a test of charge symmetry by comparison to $\mathrm{pp} \rightarrow \mathrm{d} \pi^{+}$and a test of isospin invariance by comparison to $\mathrm{np} \rightarrow \pi^{0} \mathrm{~d}$. 
Exp. 690

\section{SIMULATIONS OF COSMIC-RAY-RRODUCED GAMMA RAYS FROM THICK TARGETS}

\section{Los Alamos National Laboratory}

R. C. Reedy, Spokesman

University of California, San Diego

J. R. Arnold, P. Englert

Jet Propulsion Laboratory

A. E. Metzger, J. Yellin

Lawrence Berkeley National Laboratory

R. Pehl

This experiment will study the gamma rays emitted from the front surfaces of various thick targets bombarded by $800-\mathrm{MeV}$ protons. The experiment will simulate the bombardment of a planet's surface by cosmic-ray particles. The results will help to plan for and to analyze data from future space missions that will determine the chemical compositions of the surfaces of the moon, planets, comets, or asteroids by measuring the cosmic-ray-produced gamma-rays that escape into space. LAMPF's external proton beam will simulate the energetic particles in the galactic cosmic rays. A target, which is sufficiently thick and wide, containing almost all primary and secondary particles, will simulate a planetary surface.

Different materials (iron, aluminum, calcium carbonate, magnesium, and granite) will be placed in a large steel sleeve. Two high-resolution germanium detectors will measure the gamma rays emitted from the thick target in the energy ranges of 50 to $600 \mathrm{keV}$ and 0.6 to $12 \mathrm{MeV}$. Monitor foils will be placed at various positions inside each thick target. Polyethylene slabs will be inserted into these thick targets to study the effects of hydrogen on the fluxes of secondary neutrons inside the target and on the relative intensities of various emitted gamma-ray lines. Separate, high-proton flux runs will be made with foils that have lunar or meteoritic compositions and the depth-versus-activity profiles of cosmic-ray-produced radionuclides measured in extraterrestrial samples will be compared with profiles measured for the same radionuclides in the thick target.

Exp. 691

\section{SIMULATION OF COSMIC-RAY PRODUCTION OF NUCLIDES BY SPALLATION-PRODUCED NEUTRONS}

Los Alamse National Laboratory

R. C. Reedy, Spokesman

J. S. Gilmore

University of California, San Diego

J. R. Arnold, P. Englert

Jet Propulsion Laboratory

J. Yellin

Cosmic-ray-p; oduced nuclides measured in lunar samples and meteorites are used to study the history of these objects and also of the cosmic radiation. Most nuclides made by cosmic rays are made by secondary neutrons. The cascade of secondary neutrons produced in extraterrestrial objects by cosmic rays is similar to that made at the LAMPF main beam stop. Determination of both absolute and relative cross sections for the production of nuclides by spallation neutrons 
would help in interpreting the concentrations of these nuclides measured in extraterrestrial objects.

The irradiations would be performed in the rabbit line or stringers near the main LAMPF beam stop. The targets would be the elements from which the more interesting cosmic-ray produced nuclides are produced. The nuclides to be studied include ${ }^{10} \mathrm{Be},{ }^{22} \mathrm{Na},{ }^{26} \mathrm{Al},{ }^{36} \mathrm{Cl},{ }^{85} \mathrm{Mn}$, ${ }^{44} \mathrm{Mn}$, and most stable noble-gas nuclides (especially $\mathrm{Ne}$ and $\mathrm{Xe}$ ). Packages of foils will be used to determine the fluxes of neutrons and the neutron energy spectra.

Exp. 692

\section{Ge DETECTOR LOW-LEVEL RADIATION DAMAGE EQUILIBRATION EXPERIMENT}

\section{Los Alamos National Laboratory}

R. C. Reedy, Spokesman

Jet Propulsion Laboratory

A. E. Metzger, J. Yellin

Lawrence Berkeley Laboratory

R. H. Pehl

Radiation damage produced in high-resolution Ge detectors in space by cosmic-ray or radiation-belt particles can seriously degrade their performance. In an experiment using high fluxes ( $\sim 10^{4}$ protons $/ \mathrm{cm} \mathrm{s}$ ) of protons, the threshold for radiation damage in high-purity Ge detectors was for a proton fluence of about $10^{8}$ protons $/ \mathrm{cm}^{2}$. This proton-induced damage was removed partially by annealing at room temperatue and was readily removed by thermal annealing at $130^{\circ} \mathrm{C}$. We would like to see whether maintaining a Ge detector at room temperature or a slightly warmer temperature is a low flux of protons for a long period of time would cause a low equilibrium level of radiation damage. The proposed experiment would involve several long irradiations of high-purity Ge detectors with a low flux of energetic protons. The irradiations would occur at the end of the beam pipes in the Thin Target Area. Some absorbers will be used in the beam pipe to remote low-energy particles produced in the thin target The flux and energy spectrum of particles at the detector position will be determined. During the long irradiation of a detector, several simple paddles will be used to monitor the proton flux. The resolution of the detector will be measured several times a month and compared with its pre-irradiation resolution.

Exp. 693

\section{INVESTIGATION OF THE TWO-PHOTON DECAY RATE FROM THE $\left(\mu^{4} \mathrm{He}\right){ }_{2 \mathrm{~S}}$ STATE AS A FUNCTION OF PRESSURE}

\section{University of Mississippi}

J. J. Reidy, Spokesman

\section{Los Alamos National Laboratory}

R. L. Hutson, J. D. Knight, M. Leon, M. E. Schillaci

Negative muons at SMC (Cave A) will be stopped in helium gas targets of 1, 5, 10 and 20 atm. The photons from the two-photon decay of the $\left(\mu^{4} \mathrm{He}\right){ }_{25}^{4}$ state will be detected in delayed coincidence with the stopped muon. From this data we shall extract the lifetime of the state as a function of pressure. In addition, the fraction of stopped muons, which ultimately reach this state, shall be determined. These measurements will provide further information about this system, 
which may give additional irsights into the apparent lack of signific ant quenching of this state. Presently there are about three orders of magnitude discrepancy between the experimental and theoretical lifetime values for this state. Jim Cohen, T-12, Los Alamos, is currently doing some calculations on this system. In addition, we shall also attempt to determine, for the first time, the angular distribution between tha two photons. This would serve as a further check that the photons we are observing are indeed coming from two photon decay.

Exp. 694

\section{ISOSPI:; MIXING IN 'He}

Northwestern University

K. K. Seth, Spokesman

D. Barlow, M. O. Kaletka, D. Kielczewska, A. Saha, D. Smith, J. Stuart

Yale University

F.W.K. Firk, J. Kruk

The photoneutron and photoproton cross sections for ${ }^{4} \mathrm{He}$ differ by almost a factor of two in the region of the giant dipole resonance. If this observation is correct, it implies large isospin mixing. It is claimed that the required mixing is so large that it cannot be explained in Coulomb terms alone; one may need to invoke charge dependent nuclear forces.

It is proposed to measure $\pi^{+}$and $\pi^{-}$inelastic scattering cross sections at $T(\pi)=180 \mathrm{MeV}$ to independently verify the reported isospin mixing. The claimed mixing should lead to a ratio $\sigma\left(\pi^{-}\right) / \sigma\left(\pi^{+}\right) \simeq 3$, and permit an accurate analysis of the energy variation of isospin mixing in the entire excitation region $20-50 \mathrm{MeV}$.

Exp. 695

\section{STUDY OF TRANSFER EFFECTS IN MUON CAPTURE IN GAS TARGETS}

\section{University of Mississippi} J. J. Reidy, Spokesman

Los Alamos National Laboratory

R. L. Hutson, Spokesman

J. D. Knight, M. Leon, M. E. Schillaci

Negative muons at SMC will be stopped in a 20 atm ${ }^{1} \mathrm{H}_{2}$ target containing dilute concentrations of other gases. The transfer of muons captured by the hydrogen to the dilute component will be studied by measuring the characteristic muonic Lyman x-ray intensities from these dilute components. In some cases, the electrons from the muon decaying in the $1 \mathrm{~S}$ muonic state of the dilute atoin will also be detected. Studies are proposed on $\mathrm{H}_{2}+\mathrm{N}_{2}, \mathrm{H}_{2}+\mathrm{O}_{2}, \mathrm{H}_{2}+\mathrm{Ne}$ and $\mathrm{D}_{2}+\mathrm{O}_{2}$ in order to test predictions of two different theories - due to Gershtein and Hoff et al. - for transfer from $\mu \mathrm{p}$ and $\mu \mathrm{d}$ to low $-\mathrm{Z}$ atoms. In addition, $\mathrm{H}_{2}+\mathrm{NO}$ and $\mathrm{D}_{2}+\mathrm{NO}$ will be studied in order to compare the transfer rates in binary gases. This may allow more defiritive constraints to be placed on the magnitude of the effects due to electron shielding. Furthermore, delayed $\mathbf{x}$-ray spectra from these low-Z elements will be acquired in order to get a better understanding of the $Z$ dependence effect and mesoatom transfer effect on characteristic muonic x-ray spectra. Studies are proposed on the $\mathrm{H}_{2}+\mathrm{Kr}$ system for the same reason. Finally, we propose to study the $\mathrm{H}_{2}+\mathrm{Ar}$ case in an attempt to resolve a reported discrepancy in the transfer rate at 26 atm and an unexplained relatively long-lived $x$-ray component in the Ar muonic Lyman series. 
Exp. 696

\title{
THE ANGULAR DISTRIBUTION ANOMALY IN PION DOUBLE CHARGE EXCHANGE
}

\section{Northwestern University}

K. K. Seth, Spokesman

D. Barlow, M. O. Kaletka, D. Kielczewska, A. Saha, D. Smith, J. Stuart

One of the most dramatic discrepancies between experimental data and conventional doublecharge-exchange (DCX) theories is in the location of the deep minimum observed in the angular distribution of the analog DCX transition in the reaction ${ }^{18} \mathrm{O}\left(\pi^{+}, \pi^{-}\right)^{18} \mathrm{Ne}$ at $162 \mathrm{MeV}$. It is pointed out that this discrepancy has been observed only in this one case so far, and it is not at all clear whether it represents a general feature of analog DCX transitions or whether it is a peculiarity of this one transition. It is proposed to settle this question by measuring differential cross sections for the g.s. analog transition in the reaction ${ }^{20} \mathrm{Mg}\left(\pi^{+}, \pi^{-}\right)^{26} \mathrm{Si}$ at $180 \mathrm{MeV}$. It is shown that if the displacement of the minimum turns out to be a general feature, its explanation most lilrely lies in the isotensor $\rho^{2}(r)$ term in the pion-nucleus optical potential.

Exp. 697

\section{NUCLEAP EXCITATION FOLLOWING MUON CAPTURE ON MEDIUM AND HEAVY NUCLEI}

\author{
New York University \\ B. Budick, Spokesman \\ R. Anigstein
}

Recent experimental and theoretical work has shown that muon capture on complex nuclei may leave the nucleus with as much as $80 \mathrm{MeV}$ of excitation energy. This high-energy tail in the nuclear energy distribution (the average energy is $15-20 \mathrm{MeV}$ ) is required to explain the observed rate of proton emission, and to account for the presence of nucleons with energies in excess of 30 $\mathrm{MeV}$. Within the last year, neutron multiplicities of six or more have been observed to accompany muon capture on bismuth and lead. Events of this type occur for nuclear excitations of $50 \mathrm{MeV}$ or greater.

The puzzle presented by these findings has evoked three very different theoretical responses. In a recent Physical Review Letter it was suggested that two processes with high thresholds, high multiplicity neutron emission and preactinide fission, could serve to investigate the high-energy tail of the nuclear response function. Predicted rates for these processes are strongly model dependent.

In the proposal we describe how we would extend our previous work on muon capture gamma rays and make a systematic study of high multiplicity neutron emission. As a second component of our proposed program we discuss how an earlier experiment on actinide fission by muons and pions would be modified to investigate preactinide fission.

Results for zero neutron emission following muon capture in heavy nuclei have been somewhat confusing. Evidence from delayed gamma-ray studies in support of the scanty radiochemical findings has appeared only in recent work of our own. The experimental results are generally lower than the theoretical predictions. The proposed program, involving six medium-to-heavy nuclei, should clarify this situation. 
Exp. 698

\section{GROUND-STATE QUADRUPOLE MOMENTS OF DEFORMED NUCLEI}

Purdue University

R. M. Steffen, Spokesman

Y. Tanaka

Los. Alamos National Laboratory

E. B. Shera, Spokesman

M. V. Hoehn, M. W. Johnson, H. D. Wohlfahrt

Freie Universität, Berlin, West, Germany

E. Matthias

It is proposed to determine the ground-state quadrupole moments of ${ }^{151,158} \mathrm{Eu},{ }^{160} \mathrm{~Tb},{ }^{167} \mathrm{Er}$, ${ }^{177,179} \mathrm{Hf}$ and ${ }^{191.183} \mathrm{Ir}$ with a precision of about $1 \%$. The quadrupole moments will be measured by observing the hyperfine splittings of muonic $\mathbf{M}$ - and $\mathbf{N}$. lines. The new data, of interest to nuclear structure theory, will also provide badly needed calibration points for the measurement of quadrupole moments of very rare or radioactive isotopes of these elements thrnugh Laser spectroscopy and atomic beam experiments.

Exp. 699

MEASUREMENTS OF SPIN FLIP AND DEPOLARIZATION PARAMETERS FOR ${ }^{58} \mathrm{Ni}\left(p, p^{\prime}\right)^{58} \mathrm{Ni}^{*}\left(6^{+}, \mathrm{T}=0\right)-$ A TEST OF THE SPIN-ORBIT FORCE IN NUCLEI AT $500 \mathrm{MeV}$

\section{University of Minnesota}

N. M. Hintz, Spokesman

D. Cook, M. A. Franey, M. M. Gazzaly

Los Alamos National Laboratory

J. B. McClelland

Rutgers University

C. Glashausser, K. Jones

We propose to measure the spin flip and rotation parameters $S_{\ell \ell^{\prime}}, S_{s s^{\prime}}, D_{\ell s^{\prime}}$, and $D_{\boldsymbol{l}}$, (as well as $\mathrm{A}_{\mathrm{y}}$ ) at $500 \mathrm{MeV}$ for ${ }^{58} \mathrm{Ni}\left(\mathrm{p}, \mathrm{p}^{\prime}\right)$ to the $6^{+} \mathrm{T}=0(5.13 \mathrm{MeV})$ state, at three lab angles. The state is a nearly pure $(94 \%) 1 \mathrm{p}-1 \mathrm{~h},\left(\mathrm{f}_{7 / 2}^{-1}, \mathrm{f}_{5 / 2}\right)$ configuration and so uncertainties in the nuclear wave function are minimal. The purpose of the experiment is to determine the strength of the spin-orbit part of the $N-N$-matrix $\left(t_{L s}\right)$ in nuclear matter. Current calculations using the free (Love-Franey) $t$-matrix in the DWIA are in agreement with experiment at $800 \mathrm{MeV}$ (where the central force, $t_{o}$, dominates) but in disagreement at 500 and $333 \mathrm{MeV}$ (where the spin-orbit force, $t_{\mathrm{LB}}$ dominates). 
Exp. 700

\section{DOUBLE CHARGE EXCHANGE ON ${ }^{\circ 0} \mathrm{Ar}$}

\section{University of Pennsylvania}

H. T. Fortune, Spokesman

L. C. Bland, R. Gilman

Los Alamos National Laboratory

C. L. Morris, Spokesman

S. J. Seestrom-Morris

University of Texas, Austin

C. F. Moore, C. J. Harvey

New Mexico State University

S. J. Greene, G. R. Burleson, W. B. Cottingame

\section{University of Minnesota}

D. B. Holtkamp

For pion energies near the $\Delta_{3 s}$ resonance, all theories of pion-induced double charge exchange (DCX) fail to explain env of the observed features of the data, other than a rapid decrease in cross section with target mass number, which is predicted and observed. On $\mathrm{T}=1$ targets of ${ }^{19} \mathrm{O}$ and ${ }^{20} \mathrm{Mg}$, the forward-angle excitation function has a minimum near $180 \mathrm{MeV}$ whereas theoretical calculations are roughly monotonic. $\mathrm{On}{ }^{18} \mathrm{O}$, calculations predict a minimum in the angular distribution at an angle of $34^{\circ}$, while the observed minimum is at $21^{\circ}$. Finally, all theories fail to account for the large cross sections observed for $T=0$ targets. Thus, calculations fail in predicting energy, angular, and isospin dependence of the DCX cross sections.

A two-amplitude model has been used to describe the ${ }^{18} \mathrm{O}$ amplitude as the sum of a doubleanalog DCX amplitude and one arising from DCX on the ${ }^{10} \mathrm{O}$ core. That model uses the experimental ${ }^{16} \mathrm{O}$ cross section as input, rather than attempting to calculate it. It is possible to understand the energy and angular dependence of the ${ }^{18} \mathrm{O} \mathrm{DCX}$ data within this simple model. And it is a challenge to theorists to arrive at a mechanism that will account for the DCX data on $T=0$ targets.

A severe test of the two-amplitude model would be to measure the dov'ble-analog and nondouble-analog (i.e., $\Delta \mathrm{T}=0$ and 2, respectively) cross sections in the sar nucleu: The lightest possible case involves an ${ }^{40} \mathrm{Ar}$ target, from which $\left(\pi^{+}, \pi^{-}\right)$goes to ${ }^{40} \mathrm{Ca}$. The $\Delta \mathrm{T}=2$ process will populate the ${ }^{40} \mathrm{Ca}(\mathrm{g} . \mathrm{s}$.$) , whereas the \Delta \mathrm{T}=0$ amplitude leads to the analog $0^{+} \mathrm{T}=2$ state at $11.98 \mathrm{MeV}$.

For this experiment, we propose to use a liquid argon target with an effective areal density of about $2 \mathrm{gm} / \mathrm{cm}^{2}$. We want to measure an angular distribution at $164 \mathrm{MeV}$ and single-angle (5 $5^{\circ}$ cross sections at two additional energies -110 and $210 \mathrm{MeV}$. Our run-time estimates are based on one data point we have for DCX on ${ }^{40} \mathrm{Ca}$ at $164 \mathrm{MeV}$ and $5^{\circ}$.

Exp. 701

\section{PION DOUBIE CHARGE EXCHANGE ON SELF-CONJUGATE NUCLEI}

\section{Los Alamos National Laboratory}

C. L. Morris, Spokesman

University of Pennsylvania

H. T. Fortune, Spokesman

L. C. Bland, R. Gilman 
New Mexico State Univursity

S. J. Greene

University of Texas, Austin

C. F. Moore

No summary available.

Exp. 702

NUCLEAR STRUCTURE EFFECTS IN PION SCATTERING FROM ${ }^{22-100 M 0}$

\author{
Arizona State University \\ J. R. Comfort, Spokesman \\ University of Colorado \\ J. J. Kraushaar, R. J. Peterson, T. G. Masterson, R. A. Ristinen, M. A. Rumore, E. R. \\ Siciliano \\ Los Alamos National Laboratory \\ C. L. Morris, R. L. Boudrie \\ Rutgers University \\ J. McGill
}

It is proposed to measure the differential cross sections for $\pi^{+}$and $\pi^{-}$elastic scattering and inelastic scattering to the low-lying collective states of the even isotopes ${ }^{22-100} \mathrm{Mo}$. The objective is to search for the explicit influence of nuclear structure as evidenced by residual shell effects on the scattering process. As the neutron number increases from $N=50$ to $N=58$, the valence neutrons fill out the $\mathrm{g}_{9 / 2}, \mathrm{~d}_{5 / 2}$, and $\mathrm{s}_{1 / 2}$ orbits. Meanwhile, the $\left(\mathrm{g}_{8 / 2}\right)^{2}$ proton configuration of the molybdenum isotopes remains relatively unaffected. Since $\pi^{-}$interacts primarily with valence neutrons and $\pi^{+}$interacts primarily with valence protons, plots of the elastic cross sections against the neutron asymmetry $\epsilon=(N-Z) / A$ should have a smooth behavior for $\pi^{+}$scattering and should show shell effects for $\pi^{-}$scattering. The data will be analyzed in terms of a recent model that incorporates a full treatment of isospin effects. They should also be useful for interpretations of neutron distributions in medium-mass nuclei.

Exp. 703

\title{
STUDY OF M4 STRENírTH IN ${ }^{15} \mathrm{~N}$ BY $\pi^{+}$AND $\pi^{-}$INELASTIC SCATTERING
}

University of Minnesota

D. B. Holtkamp, Spokesman

D. Dehnhard

Los Alamos National Laboratory

S. Seestrom-Morris, Spokesman

C. L. Morris, J. M. Moss

University of Texas, Austin

C. J. Harvey, C. F. Moore

New Mexico State University

S. J. Greene

We propose to use $\pi^{+}$and $\pi^{-}$inelastic scattering to identify $\mathrm{M} 4$ transitions in ${ }^{13} \mathrm{~N}$ and to determine the neutron/proton character of these transitions. Angular distributions will be measured at 
$164 \mathrm{MeV}$ to determine the multipolarity of the observed transitions. Cross sections will also be measured at $120 \mathrm{MeV}$ to confirm that the candidates for M4 transitions have the energy dependence expected for a $\Delta S=1$ transition. These data will be compared with existing data on M4 transitions in the p-shell to determine the systematics of the M4 strength within the p-shell. We will also obtain data on the low-lying states in ${ }^{15} \mathrm{~N}$ for comparison with microscopic DWIA calculations.

Exp. 704

\section{PION INELASTIC SCATTERING FROM ${ }^{20} \mathrm{Ne}$}

\section{University of Texas}

C. F. Moore, Spokesman

Univergity of Pennsylvania

H. T. Fortune, Spokesman

L. C. Bland, R. Gilman

University of Minnesota

D. Dehnhard, D. B. Holtkamp

Los Alamos National Laboratory

C. L. Morris, S. J. Seestrona-Morris

University of South Carolina

G. S. Blanpied

We propose to measure inelastic $\pi^{+}$and $\pi^{-}$scattering on ${ }^{20} \mathrm{Ne}$ at one incident energy of $164 \mathrm{MeV}$, using a cooled gas target containing enriched ${ }^{20} \mathrm{Ne}$ gas. The experiment will test the Brown-Fortune conjecture and should provide valuable information about the nature of the $\left(\pi, \pi^{\prime}\right)$ reaction mechanism, in a nucleus whose structure is reliably known.

Exp. 705

\section{STUDY OF PION ABSORPTION IN ${ }^{3} \mathrm{He}$ ON AND ABOVE THE (3,3) RESONANCE}

Tel Aviv University, Israel

D. Ashery, Spokesman

Argonne National Laboratory

D. F. Geesaman, R. J. Holt, H. E. Jackson, J. P. Schiffer, J. R. Specht, K. E. Stephenson, B. Zeidman

University of Virginia

R. Minehart, R. R. Whitney, G. Das

Kent State University

R. Madey, B. D. Anderson, J. Watson

Proton-proton angular correlation from the ${ }^{3} \mathrm{He}\left(\pi^{+}, 2 \mathrm{p}\right) \mathrm{p}$ reaction will be studied to determine the two-body ("quasi-deuteron") and three-body absorption cross sections. For each detection angle of one proton, the coincident proton will be detected over a large solid angle, and the measurement will be done for 4-5 detection angles. Proton-neutron angular correlation from the ${ }^{3} \mathrm{He}\left(\pi^{-}, \mathrm{pn}\right) \mathrm{n}$ reaction will be studied to determine the two-body absorption on the ${ }^{2} \mathrm{~S}_{0} \mathrm{~T}=1$ proton pair. This measurement is complemeritary to the absorption studies on the $\left({ }^{3} S_{1} T=0\right)$ deuteron and bears upon the nucleon-nucleon interaction, role of the $\Delta$ in the absorption process 
and pion absorption in nuclei. The measurements will be done in the $\mathrm{P}^{\mathrm{s}}$ area utilizing the LAS spectrometer and four 40 -in. by 10 -in. by 4 -in. plastic scintillators. The measurements will be done at 165-, 245-, and $315-\mathrm{MeV}$ bombarding energies. Auxiliary measurements of the ${ }^{3} \mathrm{He}\left(\pi^{+}, \pi^{+} \mathrm{p}\right)$ and ${ }^{3} \mathrm{He}\left(\pi^{-}, \pi^{-} n\right)$ will be done at one energy and one pion scattering angle in order to compare the relative momentum of a proton with respect to the $p-n$ pair and of $e$ neutron with respect to the p-p pair in ${ }^{3} \mathrm{He}$. This is relevant for the absorption measurement where the momentum of the absorbing pair with respect to the third nucleon determines the width of the two nucleon angular correlation.

Exp. 706

UNPOLARIZED p-p DIFFERENTIAL CROSS SECTIONS AT $90^{\circ} \mathrm{cm}$.

University of Houston

B. W. Mayes, Spokesman

A. D. Hancock, E. V. Hungerford, L. S. Pinsky, K. K. Sekharan

University of Zagreb, Yugoslavia

M. Furic, Spokesman

Rice University

J. M. Clement, M. D. Corcoran, G. S. Mutchler, G. P. Pepin, G. C. Phillips, J. B. Roberts, S. E. Turpin

Fecent theoretical speculation on the existence of dibaryon resonances has still not ruled out the possibility that much of what is seen as unusual behavior in p-p collisions at momenta between 1 and $3 \mathrm{GeV} / \mathrm{c}$ is an interference effect. In order to be definite about resonances or interference effects one needs to separate spin singlet and spin triplet behavior in p-p systems. This experiment proposes to measure $\mathrm{d} \sigma / \mathrm{dt}$ at $90^{\circ} \mathrm{cm}$. in more finely spaced energy steps than currently existing data have been measured in order to unravel spin dependence. Since the behavior of this quantity is drastically different for non-smooth behavior in the singlet and triplet parts of interaction, this should be of help in isolating whether the unusual behavior is in the singlet or triplet part. The energies were chosen to span the region where the most interesting deviations from smooth behavior occur.

Exp. 707

\section{STUDY OF TRANSFER EFFECTS IN MUON CAPTURE IN GAS TARGETS}

\section{University of Mississippi}

J. J. Reidy, Spokesman

Los Alamos National Laboratory

R. L. Hutson, Spokesman

J. D. Knight, M. Leon, M. E. Schillaci

Princeton University

R. A. Naumann, J. Zumbrow

Negative muons at SMC will be stopped in a 20 atm ${ }^{1} \mathrm{H}_{2}$ target containing dilute concentrations of other gases. The transfer of muons captured by the hydrogen to the dilute component will be studied by measuring the characteristic muonic Lyman $x$-ray intensities from these dilute components. In some cases, the electrons from the muon decaying in the 1S muonic state of the dilute atom will also be detected. Studies are proposed on $\mathrm{H}_{2}+\mathrm{N}_{2}, \mathrm{H}_{2}+\mathrm{O}_{2}, \mathrm{H}_{2}+\mathrm{Ne}$ and $\mathrm{D}_{2}+\mathrm{O}_{2}$ 
ir: order to test predictions of two different theories - due to Gershtein and Hoff et al. - for tzansfer from $\mu \mathrm{p}$ and $\mu \mathrm{d}$ to low-Z atoms. In addition, $\mathrm{H}_{\mathrm{a}}+\mathrm{NO}$ and $\mathrm{D}_{2}+\mathrm{NO}$ will be studied in order to compare the transfer rates in binary gases. This may allow more definitive constraints to be placed on the magnitude of the effects due to electron shielding. Furthermore, delayed $x$-ray spectra from these low-Z elements will be acquired in order to get a better understanding of the $Z$ dependence effect and mesoatom transfer effect on characteristic muonic $x$-ray spectra. Studies are proposed on the $\mathrm{H}_{2}+\mathrm{Kr}$ system for the same reason. Finally, we propose to study the $\mathrm{H}_{2}+\mathrm{Ar}$ case in an attempt to resolve a reported discrepancy in the transfer rate at 26 atm and an unexplained relatively long-lived $\mathrm{x}$-ray component in the Ar muonic Lyman series.

Exp. 708

\title{
A MEASUREMENT OF THE DEPOLARIzATION, THE POLARIZATION AND THE POLARIZATION ROTATION PARAMETERS AND THE ANALYZING POWER TOR THE REACTION $\overrightarrow{\mathbf{p}} \mathbf{p} \rightarrow \overrightarrow{\mathbf{p}} \boldsymbol{\pi}^{+} \mathbf{n}$
}

University of Texas, Austin

C. L. Hollas, Spokesman

D. C. Cremans, P. J. Riley

Los Alamos National Laboratory

B. E. Bonner, O. van Dyck, E. W. Hoffman, M. W. McNaughton

Rutgers University

J. A. McGill

The objective of the proposed experiment is to measure the depolarization parameter $D_{N N}$, the polarization parameter $P$, and the analyzing power $A$, and the polarization rotation parameters $D_{S s}, D_{S L}, D_{L S}$, and $D_{L L}$ as a function of the scattered proton momentum for the pion production reaction $\overrightarrow{\mathrm{p} p} \rightarrow \overrightarrow{\mathrm{p}} \pi^{+} \mathrm{n}$ at 800 and $650 \mathrm{MeV}$ for detection of the final proton and $\pi^{+}$at several angle pairs. The scattered proton will be momentum analyzed in a magnetic spectrometer, then will have its polarization determined with the recoil proton polarimeter JANUS. The associated $\pi^{+}$ will be detected on the opposite side of the beam using wire chambers and scintillators. The results will place severe tests upon models of single pion production.

Exp. 709

\section{MEASUREMENTS OF $A_{\mathrm{NN}}, A_{\mathrm{sS}}$ and $A_{\mathrm{SL}}$ IN THE COULOMB INTERFERENCE REGION AT 650 AND $800 \mathrm{MeV}$}

\author{
University of Minnesota \\ M. Gazzaly, Spokesman \\ University of California, Los Angeles \\ G. Pauletta, Spokesman \\ B. Aas, G. J. Igo, C. A. Whitten
}

Los Alamos National Laboratory

N. Tanaka, Spokesman

J. Amann, J. J. Jarmer, J. B. McClelland, O. B. van Dyck

Argonne National Laboratory

K. Imai, H. Spinka 
We will measure $A_{S g}, A_{N N}$, end $A_{S L}$ at angles ranging between $1.5^{\circ}$ and $20^{\circ}$ (lab) for two beam momenta at 1.28 and $1.46 \mathrm{GeV} / \mathrm{c}$. The measurements will be performed in Line $\mathrm{C}$ using the HRS spectrometer, and polarized targets. It is ideal to perform this type of experiment using the HRS spectrometer because, good momentum resolution is essential to discriminate against proton scattering off the heavier target components $\left({ }^{3} \mathrm{He},{ }^{12} \mathrm{C}\right.$, and $\left.{ }^{10} \mathrm{O}\right)$ down to small angles, and good beam handling conditions in Line $\mathrm{C}$ are necessary to ensure a stable, small-phase space beam. 
Exp. 710

\title{
A MEASUREMENT OF THE TRIPLE SCATTERING PARAMETERS $D, R, A, R$, AND A' FOR QUASI-ELASTIC SCATTERING AT $800 \mathrm{MeV}$
}

\author{
University of Texas, Austin \\ M. L. Barlett, G. W. Hoffmann, Spokesmen \\ R. Fergerson, J. Marshall, E. C. Milner, L. Ray \\ Los Alamos National Laboratory \\ J. F. Amann, J. B. McClelland \\ Rutgers University \\ J. McGill
}

Using the HRS and 800-MeV polarized beams (n-type, 1-type, and s-type), we will measure the triple-scattering-parameters, $D, R, A, R$, and $A^{\prime}$ for inclusive ( $\left.p, p^{\prime}\right)$ scattering from ${ }^{2} \mathrm{H}$ and ${ }^{12} \mathrm{C}$ or ${ }^{\circ} \mathrm{Ca}$ in the small momentum transfer quasielastic region. The angular range $5^{\circ}$ to $15^{\circ}$ will be covered and the anticipated statistical error on the triple-scattering parameters will be approximately \pm 0.01 (absolute).

The motivation for the experiment is to observe nuclear medium modifications to the spindependent quasielastic observables. These data will be coupled with the cross section and analyzing power data obtained by Exps. 470 and 642, and the entire data set will be used to obtain medium modified amplitudes for microscopic analyses of the $800-\mathrm{MeV} \mathrm{p}^{+}$-nucleus elastic and inelastic scattering data obtained at HRS over the years.

Exp. 711

REACTIVE CONTENT OF THE OPTICAL POTENTIAL AT $500 \mathrm{MeV}$

University of Texas, Austin

G. W. Hoffmann, Spokesman

M. Barlett, R. Fergerson, J. Marshall, E. C. Milner, L. Ray

Los Alamos National Laboratory

J. F. Amann, J. B. McClelland

Rutgers University

J. McGill

Using the HRS and a 500-. $\mathrm{eV}$ polarized beam (n-type), we will measure the inclusive $\left(\overrightarrow{\mathrm{p}}, \mathrm{p}^{\prime}\right)$ analyzing powers for targets $\mathrm{LH}_{2}, \mathrm{LD}_{2}$, and ${ }^{12} \mathrm{C}$ (or ${ }^{40} \mathrm{Ca}$ ) for quasielastic scattering over the laboratory angular range between $4^{\circ}$ and $20^{\circ}$.

The motivation for this experiment is, in part, the same as that for Exps. 470/642: to investigate whether quasifree mechanisms account for the bulk of the reaction cross section at this energy. Additionally, nuclear medium modifications to quasielastic scattering will be investigated and we anticipate that these data can be used to directly obtain the medium-modified nucleon-nucleon amplitudes that are required for the microscopic KMT analyses of the $500-\mathrm{MeV}$ elastic-scattering data. 
Exp. 712

\title{
INELASTIC PROTON SCATTERING ON ${ }^{80} \mathrm{Ca}$ AND ${ }^{\circ} \mathrm{Ti}:$ AN ATTEMPT TO IDENTIFY MESONIC EFFECTS AS THE CAUSE OF M1 QUENCHING
}

\author{
Northwestern University \\ R. E. Segel, Spokesman \\ S. L. Levenson \\ Arizona State University \\ J. R. Comfort \\ Technical University, Munich, W. Germany \\ P. Kienle \\ Los Alamos National Laboratory \\ J. M. Moss \\ Arsonne National Laboratory \\ K. E. Rehm, B. Zeidman
}

A study of polarized-proton scattering to states in ${ }^{88} \mathrm{Ca}$ and ${ }^{50} \mathrm{Ti}$ is proposed, with particular emphasis on scattering to $1^{+}$states. The HRS spectrometer is to be used with an incident proton energy below $500 \mathrm{MeV}$. Angular distributions will be taken and compared to DWIA calculations. The comparison will give insight into possible mesonic effects such as virtual $\Delta(1232)$-hole excitations on inelastic proton scattering populating unnatural parity states. Data on high-spin states will also be obtained.

Exp. 713

\section{M1's, DELTAS, AND MEDIUM EFFECTS IN CROSS SECTIONS FOR ${ }^{88} \mathrm{Sr}\left(\mathrm{p}, \mathrm{p}^{\prime}\right){ }^{88} \mathrm{Sr} * \mathrm{AT} 400 \mathrm{MeV}$}

\author{
Rutgers University \\ C. Glashausser, Spokesman \\ K. Jones, J. McGill, S. Nanda \\ Free University, Amsterdam \\ H. P. Blok \\ University of New Hampshire \\ J. Heisenberg \\ University of Georgia \\ F. T. Baker, A. Scott
}

Cross sections for the $\left(p, p^{\prime}\right)$ reaction to states in ${ }^{83} \mathrm{Sr}$ will be measured with the HRS at $400 \mathrm{MeV}$ over the angular range corresponding to $0.25-2.3 \mathrm{fm}^{-1}$ momentum transfer. The primary states of interest are the first two $2^{+}$states, the $1^{+}$state at $3.49 \mathrm{MeV}$, and the giant $\mathrm{M} 1$ resonance. All except the giant $M 1$ have been thoroughly examined recently in electron scattering. The lowlying $1^{+}$state is a pure proton transition; the shape of the $\left(e, e^{\prime}\right)$ angular distribution seems to require the participation of the delta resonance in the transition. The transition densities $\rho_{\mathrm{tr}}$ for the two $2^{+}$states can be explained as orthogonal combinations of two single-particle transitions. The differences between these $\rho_{\mathrm{tr}}$, and the fact that one peaks in the nuclear interior, provide a good testing ground for the recently proposed density-dependence in the effective NN interaction at LAMPF energies. 
Exp. 714

\section{A SEARCH FOR THE GIANT ISOVECTOR MONOPOLE RESONANCE IN INELASTIC PROTON SCATTERING AT 2ERO DEGREES \\ Rutgers University \\ C. Glashausser, Spokesman \\ K. Jones, J. McGill, S. Nanda}

Los Alamos National Laboratory

J. M. Moss, J. B. McClelland, J. D. Bowman

Methods for obtaining zero-degree inelastic spectra relatively free of nonphysical background have recently been developed at HRS. They now permit a search for the elusive giant isovector monopole resonance which is supposed to be responsible for most Coulomb mixing effects in nuclei. The expected excitation energy, about $30 \mathrm{MeV}$, requires a beam energy of about $650-800$ $\mathrm{MeV}$. Three targets, ${ }^{40} \mathrm{Ca},{ }^{80} \mathrm{Zr}$, and ${ }^{120} \mathrm{Sn}$, and 100 hours are requested for this search.

Exp. 715

\section{ANALYSIS OF CHEMICAL COMPOSITION OF ARCHEOLOGICAL ARTIFACTS BY WAY OF MUONIC X RAYS}

\section{Oklahoma University}

J. M. Oostens, Spokesman

H. Fischbeck

Museum of New Mexico's Laboratory of Anthropology, Santa Fe

D. H. Snow, Spokesman

University of New Mexico

L. Cordell

It is proposed to use the unique nondestructive character of muonic $x$-ray analysis to investigate two types of archeological objects: majolica earthenware and turquoise.

The very samples we intend to use have already been investigated by other scientific methods (including $x$-ray fluorescence, neutron activation and flame absorption). Muonic $\mathbf{x}$-ray analysis, which emphasizes the low-Z elements, will nicely complement the information already obtained by these other methods.

Exp. 716

\section{PION DOUBLE CHARGE EXCHANGE ON HEAVY NUCLEI}

\section{Northwestern University}

K. K. Seth, Spokesman

D. Barlow, B. Carragher, D. Kielczewska, A. Saha, J. Stuart, M. O. Kaletka

It is proposed to measure analog transitions for the pion double-charge-exchange reaction $\left(\pi^{+}, \pi^{-}\right)$on ${ }^{52} \mathrm{Cr},{ }^{00} \mathrm{Zr}$, and ${ }^{138} \mathrm{Ba}$. It is suggested that measurement of forward-angle cross sections on these nuclei will shed new light on the physics behind the anomalous cross sections just measured for the ${ }^{48} \mathrm{Ca}\left(\pi^{+}, \pi^{-}\right)^{48} \mathrm{Ti}(17.4 \mathrm{MeV})$ enalog transition. It is proposed that isotensor contributions to DUX are most likely responsible for the observed behavior of the cross sections. 
Exp. 717

\section{PION SCATTERING TO COLLECTIVE STATES IN Se ISOTOPES}

University of Pennsylvania

L. C. Bland, Spokesman

R. Gilman, H. T. Fortune

Los Alamos National Laboratory

C. L. Morris, Spokesman

S. J. Seectrom-Morris

New Mexico State University

S. J. Greene, Spokesman

University of Texas, Austin

C. F. Moore, C. J. Harvey

University of South Caralina

B. G. Ritchie

The pion has proven to be a very useful probe in determining isospin admixtures in particlehole states in light nuclei. The techniques for determining the different contributions of neutrons and protons to transition densities are well established from such studies. There exist other such uses, though, for these techniques. One of these uses is the determination of the proton and/or neutron contributions to collective transition densities as a function of neutron number in a region of known collectivity. From this information one can deduce the effect of additional valence neutrons on the nuclear collective motion.

The difficulty with such an endeavor is that generally a chain of isotopes displaying collective motion can only be found with $\mathrm{A}>100$. This means that the available resolution of the EPICS system ( 150-200 keV) is not adequate to extract yields for any excited states, except perhaps for the first. There does exist a region of known collective behavior near $N=40$. In particular, a number of theoretical and experimental studies of selenium isotopes have shown that this region has collective characteristics. Fig. 1 compares the low-lying spectra of six isotopes of selenium. It is clear that the spectra are characteristic of a vibrator or coupled rotor-vibrator. Table I shows the electromagnetic transition data available for these isotopes. The size of the $B(E 2)$ strengths indicates the collectivity of the excited states. Also, the fact that the second $2^{+}$state in these isotopes preferentially decays to the first $2^{+}$state indicates that the collective behavior, to first or$\mathrm{der}$, is that of a vibrator. As the neutron number approaches the closed $1 \mathrm{~g}_{\mathrm{g} / 2}$ shell value $(\mathrm{N}=50)$ there is a definite transition away from this collective behavior.

Experimentally, selenium isotopes display sufficient separations of the one- and two-phonon levels so as to enable the extraction of yields for all of these states. There also exist four even-even isotopes of selenium available for use as targets.

Exp. 718

\section{ENERGY DEPENDENCE OF THE TWO-NUCLEON EFFECTIVE INTERACTION}

\section{Massachusetts Institute of Technology}

J. Kelly, Spokesman

W. Bertozzi, T. Buti, M. Finn, C. Hyde, B. Murdock, B. Pugh, P. Ulner

Los Alamos Scientific Laboratory

M. V. Hynes, Spokesman

J. B. McClelland 


\section{Indiana University}

A. Bacher, G. Emery, C. Foster, W. Jones, D. Miller

University of California, Los Angeles

B. Aas, G. J. Igo, A. Rahbar

Lawrence Livermore Laboratory

B. Berman

We propose to study the energy dependence of the two-nucleon effective interaction between 200 and $500 \mathrm{MeV}$ by measuring cross sections and analyzing powers at HRS for proton scattering to states of ${ }^{18} \mathrm{O}$ below about $20-\mathrm{MeV}$ excitation. We have previously found that the isoscalar spinindependent central component of the two-nucleon effective interaction between 100 and 200 $\mathrm{MeV}$ is strongly dependent on density and can be well described by nuclear matter effective interactions. The application to finite nuclei uses the local density approximation. These medium effects are expected to remain important in the $200-1,0500-\mathrm{MeV}$ regime. We propose to measure five energies (250, 300,350,400,450 MeV). The 300- and 400-MeV measurements constitute our first priority. Particular attention will be paid to those states, such as inelastic monopole and dipole states which are expected to be most sensitive to medium corrections.

Exp. 719

\section{PRODUCTION OF NEUTRON RICH RADON ISOTOPES AND DETERMINATION OF THEIR CROSS SECTIONS AND HALF LIVES BY A RADIOCHEMICAL TECHNIQUE}

\section{University of Chicago}

A. L. Turkevich, Spokesman

D. E. Wachel

\section{Lakehead University, Ontario, Canada}

J. Warren

The properties of neutron-rich isotopes of the heaviest elements are important in defining the nuclear-mass surface in this region and in predicting the detailed course of neutron-capture processes in stars and nuclear explosions. It is proposed to produce and determine the half-lives of ${ }^{227} \mathrm{Rn}$ and ${ }^{228} \mathrm{Rn}$ by $800-\mathrm{MeV}$ proton irradiations of thick targets $(\sim 360 \mathrm{~g})$ of $\mathrm{ThO}_{2}$. The expected cross sections are low $(0.1-10 \mathrm{nb})$. The half lives $(30-100 \mathrm{sec})$ of the radons will be established by charged-wire collection of daughter products.

A preliminary experiment is proposed that will use ${ }^{226} \mathrm{Rn}(360 \mathrm{sec})$ to establish the magnitudes of yields of such neutron rich species and to test the experimental technique. 
Exp. 720

RECOILLESS DELTA PRODUCTION IN THE REACTION ${ }^{13} \mathrm{C}(\mathrm{p}, \mathrm{d})^{12} \mathrm{C}_{\Delta}$

Los Alamos Scientific Laboratory

C. L. Morris, Spokesman

S. J. Seestrom-Morris

Rutgers University

J. A. McGill, Spokesman

C. Glashausser, S. K. Nanda, K. Jones

Universicy of Texas

G. W. Hoffmann, C. F. Moore

We propose to measure the recoilless production of the $\Delta_{9,9}$ resonance by scattering $800-\mathrm{MeV}$ protons from a ${ }^{13} \mathrm{C}$ target and detecting a $500-\mathrm{MeV}$ deuteron at a small angle $\left(3^{\circ}<\theta_{\text {lab }}<12^{\circ}\right)$. In order to reduce backgrounds from quasifree $p$ - $d$ scattering and other processes, we will detect the delta-decay products in a pair of coincidence counters placed in the scattering chamber. Two options for this second arm are large plastic scintillators or a superconducting solenoid spectrometer. We are requesting 60 hours of time for initial measurements at $800 \mathrm{MeV}$.

Exp. 721

MEASUREMENT OF THE PROTON POLARIZATION OBSERVABLES IN THE $\operatorname{Li}\left(\overrightarrow{\mathbf{p}}, \overrightarrow{\mathbf{p}}^{\prime}\right)^{7} \mathrm{Li}$ AND THE TEST OF THE REACTION THEORY AT INTERMEDIATE ENERGIES

\title{
University of California, lws Angeles
}

B. Aas, E. Bleszynski, Spokesmen

M. Bleszynski, G. J. Igo, G. Pauletta, A. Rahbar, C. A. Whitten

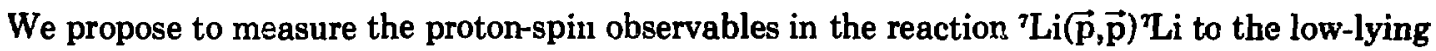
excited states. Our measurements will include: the differential cross sections, polarization, asymmetry and spin-rotation parameters at $500 \mathrm{MeV}$ in the angular range $10^{\circ}$ to $30^{\circ}$ with the statistical accuracy of $5 \%$ or better for the polarization and spin rotation parameters. The deduced observables will be used to test the information on the nuclear form factors which enter into the (p,p') transition amplitudes.

Exp. 722

MEASUREMENT OF CROSS SECTIONS AND ANALYZING POWERS FOR ELASTIC AND INELASTIC SCATTERING

OF 400- TO 500-MeV PROTONS FROM "C

\author{
University of Texas, Austin \\ C. J. Harvey, Spokesman \\ F. Seidl
}

Los Alamos Scientific Laboratory

S. Seestrom-Morris, Spokesman

C. L. Morris

University of Minnesota

D. Dehnhard, D. B. Holtkamp 
Kirtland Air Force Base

R. J. Joseph

Rutgere Univeraity

C. Glashausser, J. A. McGill

Tel Aviv University, Ierael

M. A. Moinester, J. Alster

EG\&G

C. A. Goulding

We propose to measure cross sections and analyzing powers for elastic and inelastic scattering of $500-\mathrm{MeV}$ polarized protons from ${ }^{14} \mathrm{C}$ for excitation energies up to $25 \mathrm{MeV}$. The nucleon-nucleon interaction is well known at this energy and the impulse approximation is probably still valid. The spin-dependent terms in the nucleon-nucleon interaction are more pronounced in this energy region, abetting the observation of two interesting spin-flip transitions: the two $4^{-}$states at 11.7 and $17.3 \mathrm{MeV}$ which have been seen in pion inelastic scattering. Data will be taken from $6^{\circ}$ out to $36^{\circ}$ in $2^{\circ}$ steps. Among other states, we will measure angular distributions for the aforementioned $4^{-}$states and the low-lying $2^{+}$states which appear to share the p-shell strength and are expected to have significant spin-flip components also. We plan to measure a cross section for the low-lying $0^{-}$state at $6.9 \mathrm{MeV}$ in ${ }^{14} \mathrm{C}$ which is separated by $100 \mathrm{keV}$ from the nearest excited state and should be well resolved.

Exp. 723

MEASUREMENT OF THE NEUTRON AND PROTON CONTRIBUTIONS TO EXCITED STATES IN ${ }^{30} \mathrm{~K}$ BY $\pi^{+}$AND $\pi^{-}$INELASTIC SCATTERING

University of Texas, Austin

C. J. Harvey, Spokesman

P. A. Seidl, C. F. Moore

University of Piennsylvania

H. T. Fortune, Spokesman

L. C. Bland, R. Gilman

University of Minnesota

D. B. Holtkamp

New Mexico State University

W. B. Cottingame, S. J. Greene

Special interest has been gentrated by hole nuclei in the p-shell due to the nuclear structure information derived from the large $\pi^{+} / \pi^{-}$asymmetries found in these nuclei. Since most $p$-shell nuclei have been studied at EPICS, it would now be interesting to study the s-d shell nuclei based on our p-shell experience. We propose to measure $\pi^{+}$and $\pi^{-}$inelastic cross sections to the protcn-hole nucleus ${ }^{30} \mathrm{~K}$ in $10^{\circ}$ steps from $20^{\circ}$ to $110^{\circ}$ at $140 \mathrm{MeV}$ and one point at a higher energy to separate natural and unnatural parity transitions. The first four levels of ${ }^{90} \mathrm{~K}$ are cleanly resolved and are expected to exhibit large $\pi^{+}$and $\pi^{-}$asymmetries. $A$ stretched $6^{-}$transition is also expected at $7.14 \mathrm{MeV}$. 
Exp. 724

\section{MEASUREMENT OF THE LAMB SHIFT IN MUONIUM}

\section{Yale University}

P. O. Egan, V. W. Hughes, Spukesmen

A. Badertscher, C. K. Gardner, M. Greene, D. C. Lu, F. G. Mariam, P. A. Souder University of Heidelberg, W. Germany

M. W. Gladisch, Spokesman

H. Orth, G. zu Putlitz

College of William \& Mary

M. Eckhause, J. Kane

We propose to measure the Lamb shift in the first excited state $(n=2)$ of muonium $\left(\mu^{+} e^{-}\right)$. We have observed ground (1S) state muonium in vacuum, produced when a low-energy $\mu^{+}$beam impinges on a thin foil target at LAMPF. Similarly, we expect $2 S$ muonium will be formed when an extremely low-energy $\mu^{+}$beam $(\sim 500 \mathrm{keV})$ traverses a foil target. Microwave transitions from $2 \mathrm{~S}_{1 / 2} \rightarrow 2 \mathrm{P}_{1 / 2}$ (Lamb shift) will quench the metastable $2 \mathrm{~S}$ state with emission of a $1221 \mathrm{~A}$ $(2 \mathrm{P} \rightarrow 1 \mathrm{~S})$ photon. By observing the UV photon rate as a function of nicrowave frequency we will measure the Lamb shift.

Exp. 725

\section{THE EFFECT OF RARE EARTH ADDITIONS ON RADIATION DAMAGE IN ALLOY HT-9 (FERRITIC/MARTENSITIC ALLOY STEEL)}

\section{Iowa State University}

D. R. Davidson, M. S. Wechsler, Spokesmen

\section{Los Alamos National Laboratory}

W. F. Sommer, Spokesman

R. D. Brown

The ferritic/martensitic alloy HT-9 is a candidate material for application in fusion reactors and as cladding and structural material for Liquid Metal Fast Breeder Reactors. This alloy has shown microstructural stability, swelling resistance and creep resistance under irradiation. On the other hand, it has also shown an increase in the ductile to brittle transition temperature.

The addition of up to $1 \%$ of a rare-earth element such as ytterium has, in a very limited number of investigations, been observed to further enhance the favorable alloy's properties and also to lower the ductile to brittle transition temperature. The purpose of this investigation is to perform a systematic study of the microstructural evolution of this alloy, with and without rare-earth additions, and to relate the microstructure to the observed changes in its mechanical properties. Information of both basic and practical importance will be realized.

A large part of this work is planned to constitute the thesis for Ph.D. in Nuclear Engineering by D. R. Davidson at the Iowa State University. 
Exp. 726

\section{SEARCH FOR THE C-NONINVARIANT DECAY $\pi^{0} \rightarrow 3 y$}

\section{Temple University}

V. L. Highland, Spokesman

L. B. Auerbach, W. K. McFarlane

\section{Los Alamos National Laboratory}

\section{G. H. Sanders, Spokesman}

L. S. Bayliss, R. D. Bolton, J. D. Bowman, R. D. Carlini, M. D. Cooper, J. S. Frank, T. A. Gordon, C. M. Hoffman, G. Hogan, W. W. Kinnison, R. J. Macek, H. S. Matis,

R. E. Mischke, D. E. Nagle, V. D. Sandberg, R. D. Werbeck, R. A. Williams

This experiment is a search for the decay $\pi^{0} \rightarrow 3 \gamma$, a strong/electromagnetic reaction that would violate charge-conjugation invariance. The experiment is designed to be sensitive to a branching ratio of about $1 \times 10^{-9}$, which would improve on the existing experimental information by two orders of magnitude. This improvement will be made possible by using the LAMPF Crystal Box as the detector for the three gamma rays.

Exp. 727

\section{MEASUREMENT OF THE EFFICIENCY OF MUON CATALYSIS IN DEUTERIUM-TRITIUM MIXTURES AT HIGH DENSITIES}

EG\&G Idaho, Inc.

S. E. Jones, Spokesman

A. J. Caffrey, J. B. Walter

We propose to measure the efficiency of the muon-catalyzed fusion reaction

$$
\mu^{-}+\mathrm{d}+\mathrm{t} \rightarrow \mu^{-}+{ }^{4} \mathrm{He}+\mathrm{n}+17.6 \mathrm{MeV}
$$

That is, we will determine the average number of reaction cycles a muon will catalyze, as a function of deuterium-tritium mixture density, temperature, and tritium concentration. We will, in addition, measure the probability of muon retention by the helium ion created during fusion along with other quantities affecting che efficiency of muon catalysis.

An understanding of muon catalysis gained by the proposed experiment will provide answers to recurring questions regarding the usefulness of muon-catalyzed fusion as a source of energy. Definitive answers require that the experiment be conducted at elevated mixture densities and tritium concentrations.

Exp. 728

\section{STUDY OF PION CHARGE-EXCHANGE MECHANISMS BY MEANS OF ACTIVATION TECHNIQUES}

\section{Los Alamos National Laboratory}

G. C. Giesler, Spokesman

B. J. Dropesky, L.-C. Liu, Y. Ohkubo, C. J. Orth 
We propose to determine by activation techniques the excitation functions for the following pion single-charge-exchange (SCE) reactions:
a) ${ }^{11} \mathrm{~B}\left(\pi^{+}, \pi^{0}\right)^{11} \mathrm{C}(20.4 \mathrm{~min})$
b) ${ }^{11} \mathrm{~B}\left(\pi^{-}, \pi^{0}\right)^{11} \mathrm{Be}(13.8 \mathrm{~s})$
c) ${ }^{23} \mathrm{Na}\left(\pi^{+}, \pi^{0}\right)^{23} \mathrm{Mg}(11.3 \mathrm{~s})$
d) ${ }^{23} \mathrm{Na}\left(\pi^{-}, \pi^{0}\right){ }^{23} \mathrm{Ne}(37.5 \mathrm{~s})$
e) ${ }^{44} \mathrm{Ca}\left(\pi^{+}, \pi^{0}\right)^{44} \mathrm{Sc}(3.9 \mathrm{~h})$
f) ${ }^{44} \mathrm{Ca}\left(\pi^{-}, \pi^{0}\right)^{44} \mathrm{~K}(22 \mathrm{~min})$

and explore the feasibility of studying the following double-charge-exchange reactions:

$$
\begin{aligned}
& \text { g) }{ }^{127} \mathrm{I}\left(\pi^{+}, \pi^{-}\right)^{127} \mathrm{Cs}(6.2 \mathrm{~h}) \\
& \text { h) }{ }^{127} \mathrm{I}\left(\pi^{-}, \pi^{+}\right)^{127} \mathrm{Sb}(91 \mathrm{~h})
\end{aligned}
$$

The cross sections of the SCE reactions will be measured at energies below, at, and above the $(3,3)$ resonance and the results for reaction $b\left(2\right.$ bound states in ${ }^{11} \mathrm{Be}$ ) will be compared with detailed calculations using appropriate wave functions, while those for reactions a, c, d, e, f, g, and $h$ (to many bound states in the the residual nucleus) will be compared with theoretical predictions by W. R. Gibbs employing his new Fermi gas model.

Exp. 729

\section{RADIATIVE CAPTURE OF POLARIZED PROTONS BY DEUTERONS AT 500 to $800 \mathrm{MeV}$}

\section{Massachusetts Institute of Technology}

M. A. Kovash, Spokesman

W. Bertozzi, T. Buti, J. M. Finn, F. W. Hersman, C. Hyde, J. Kelly, S. Kowalski, B. Murdock, B. Pugh

University of Texas, Austin

G. W. Hoffmann

\section{Los Alamos National Laboratory}

J. F. Amann

Precise measurements of the angular distributions of the cross section and analyzing power for the radiative capture reaction ${ }^{2} \mathrm{H}(\overrightarrow{\mathrm{p}}, \gamma)^{3} \mathrm{He}$ are proposed, over the range of incident proton energies from 500 to $800 \mathrm{MeV}$. The High Resolution Spectrometer is used to detect the recoil ${ }^{3} \mathrm{He}$, and a time coincidence with the radiated gamma ray is required to improve the event signal-to-noise ratio. High-energy gamma rays from $\pi^{0}$ production and the associated recoil ${ }^{3} \mathrm{He}$ are kinematically segregated from the radiative capture events. Results of these measurements will provide a strong test of the reaction mechanism for the intermediate energy capture process, and an accurate measure of time reversal invariance, when compared with the corresponding twobody photodisintegration data. 
Exp. 730

\title{
PION PRODUCTION IN PION-NUCLEON AND PION-NUCLEUS INTERACTIONS
}

\author{
CEN, Saclay, France \\ B. Saghai, Spokesman \\ G. Fournier, P. Vernin, C. Samour \\ University of S. Carolina \\ B. $M$. Preedom, Spokesman \\ Los Alamos National Laboratory \\ B. J. Dropesky, Spokesman \\ G. C. Giesler \\ University of Clermont-Ferrand, France \\ P. Bertin \\ Massachusetts Institute of Technology \\ R. P. Redwine
}

This proposal describes our intent to measure the $(\pi, 2 \pi)$ reaction on the proton and on nuclei by three different detection techniques. Because of the need to construct detection systems specific to $\pi^{0}$ and $\pi^{ \pm}$, we are requesting approval for beam time in two stages.

The first stage is for measurement of the cross sections (or set upper limits) by activation techniques of the reactions: ${ }^{31} \mathrm{P}\left(\pi^{+}, 2 \pi^{+}\right)^{31} \mathrm{Si}(2.67 \mathrm{~h}) ;{ }^{14} \mathrm{Ca}\left(\pi^{+}, 2 \pi^{+}\right)^{44} \mathrm{~K}(22 \mathrm{~min}) ;{ }^{81} \mathrm{~V}\left(\pi^{+}, 2 \pi^{+}\right)^{51} \mathrm{Ti}$ $(5.75 \mathrm{~min}) ;^{11} \mathrm{~B}\left(\pi^{-}, 2 \pi^{-}\right)^{11} \mathrm{C}(20.4 \mathrm{~min}) ;{ }^{18} \mathrm{O}\left(\pi^{-} 2 \pi^{-}\right)^{18} \mathrm{~F}(110 \mathrm{~min})$; and ${ }^{46} \mathrm{Sc}\left(\pi^{-}, 2 \pi^{-}\right)^{46} \mathrm{Ti}(3.08 \mathrm{~h})$. After making these measurements, we plan to present a progress report to the LAMPF PAC along with the detailed parameters of the $\pi^{0}$ and $\pi^{ \pm}$detection systems to demonstrate the feasibility of making the threshold measurements described in this proposal. These threshold measurements are the second stage of this proposal.

Exp. 731

Fission Probability of the Giant Quadrupole Resonance in Actinides

\section{Los Alamos National Laboratory}

A. I. Gauron and J. M. Moss, Spokesmen

H. C. Britt, T. A. Carey, Z. Fraenkel, J. B. McClelland, S. J. Seestrom-Morris, J. van der Plicht, J. B. Wilhelmy

Oak Ridge National Laboratory

F. Plasil

The object of this experiment is to determine the fissionability of the GQR. Previous experiments have produced contradictory results probably due to large background and random corrections, poor statistics or ambiguous methods of analysis. We intend to use the High Resolution Spectrometer to identify the $\mathrm{GQR}$ in the ${ }^{238} \mathrm{U}\left(\mathrm{p}, \mathrm{p}^{\prime}\right)$ reaction with $500-\mathrm{MeV}$ protons.

Parallel plate avalanche counters (PPAC) will be used to detect fission fragments in coincidence with the inelastically scattered protons; the fission probability is determined by the ratio of fission coincidences to proton singles. The PPAC are position-sensitive enabling the determination of the fission-fragment angular distribution. This can provide information on the degree of $\mathrm{K}$-mixing during the fission process. 